\title{
The Influence of Magma Supply and Eruptive Processes on Axial Morphology, Crustal Construction and Magma Chambers
}

by

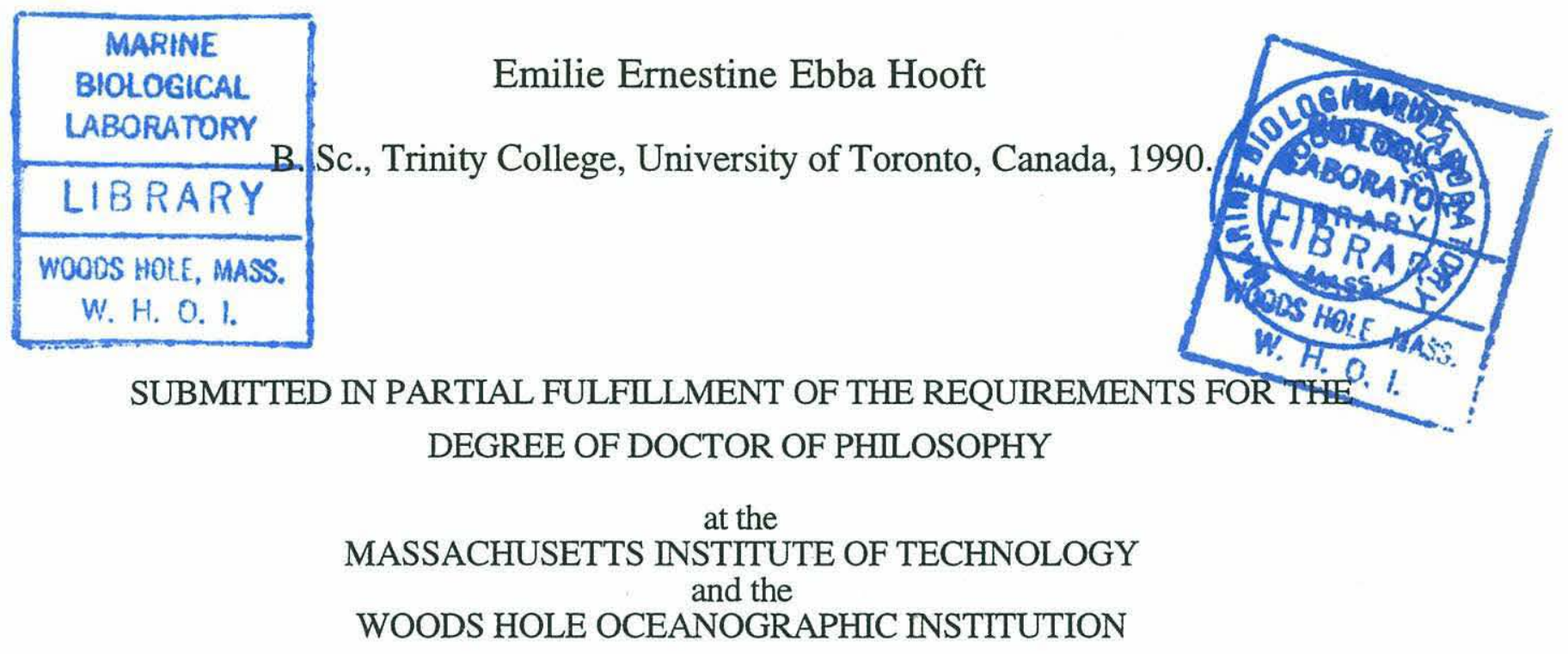

December, 1996

(C) Emilie E. E. Hooft, 1996. All rights reserved

The author hereby grants to MIT and WHOI permission to reproduce and distribute copies of this thesis document in whole or in part.

Signature of Author

$$
\begin{array}{r}
\text { Joint Program in Oceanography, Massachusetts Institute of Technology and } \\
\text { Woods Hole Oceanographic Institution, December } 1996
\end{array}
$$

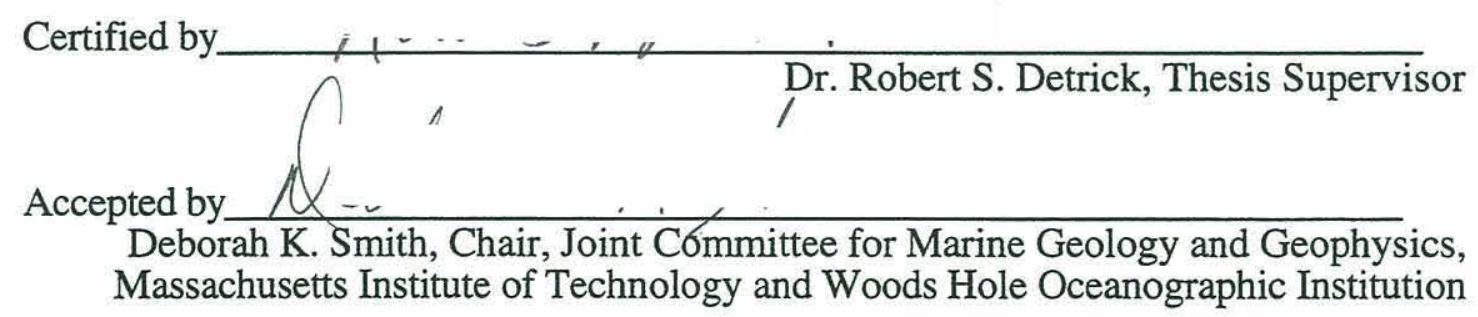




\section{TABLE OF Contents}

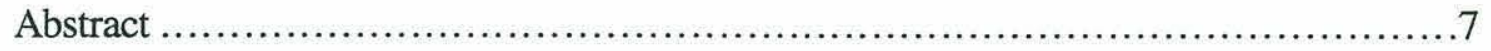

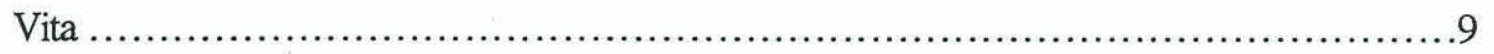

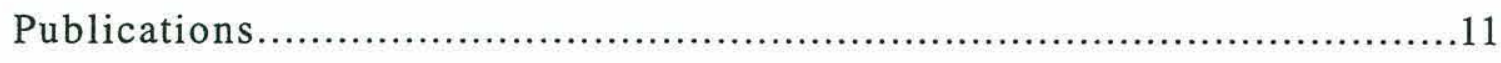

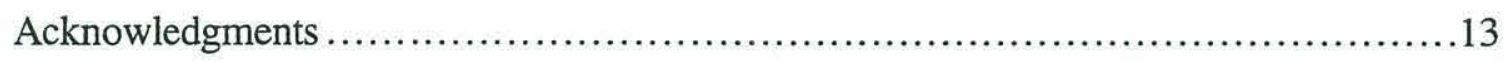

Chapter 1.

MAgma Chambers, CRUSTAl Construction, AND AXIAL Morphology............15

Evolution of Magma Chamber Models......................................17

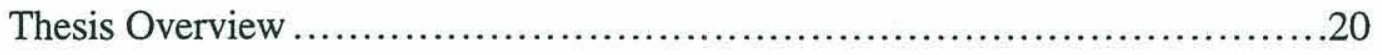

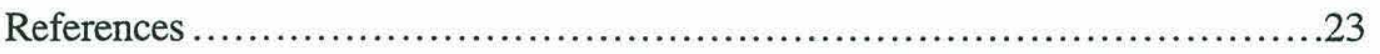

Chapter 2.

RELATIONSHIP BETWEEN AXIAL MORPHOLOGY, CRUSTAL THICKNESS, AND

MANTLE TEMPERATURE ALONG THE JUAN DE FUCA AND GORDA RIDGES...............29

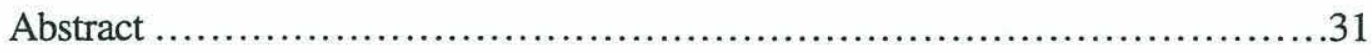

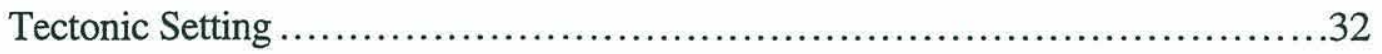

Free Air Gravity and Bathymetry ...........................................

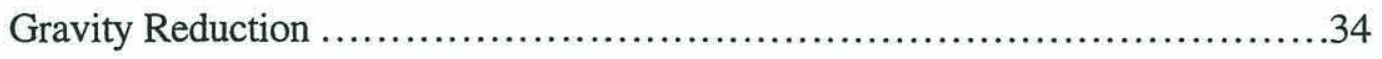

Modeling of Residual Mantle Bouguer Anomalies.......................................34

Model 1: Crustal Thickness Variations Only..................................36

Model 2: Crustal Thickness and Mantle Temperature Variations..........37

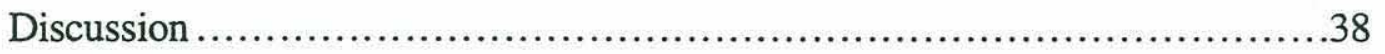

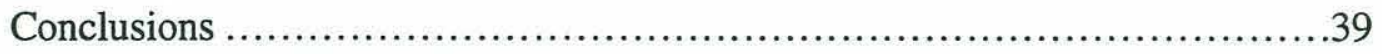

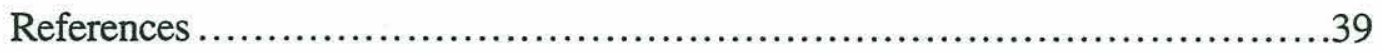




\section{Chapter 3.}

SEISMIC STRUCTURE AND INDICATORS OF MAGMA BUDGET ALONG THE

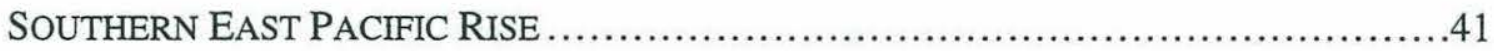

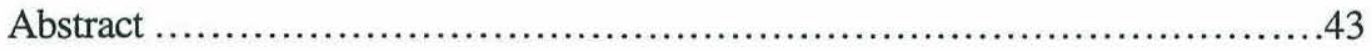

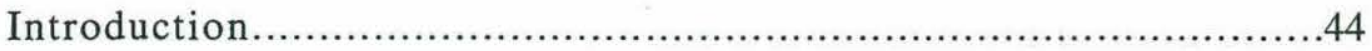

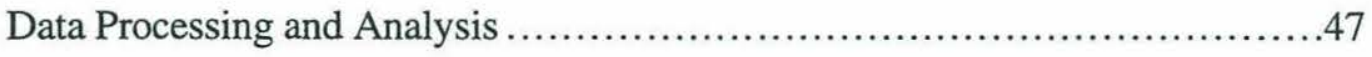

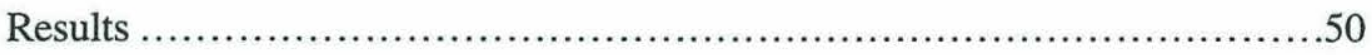

Variation in Seismic Structure along the SEPR .....................50

Correlations with Indicators of Magma Supply .....................54

Morphology and Gravity...................................5

Basalt Geochemistry ....................................55

Magma Sill Properties.....................................56

Extrusive layer (2A) thickness ...........................58

Hydrothermal Activity.....................................59

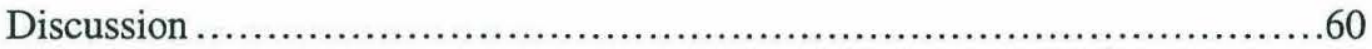

Thickness and Construction of the Extrusive Layer $\ldots \ldots \ldots \ldots \ldots \ldots \ldots \ldots 1$

Controls on the Depth of the Magma Sill ..........................62

Lack of Correlation of the Magma Sill Depth with Indicators of

Magma Supply..........................................63

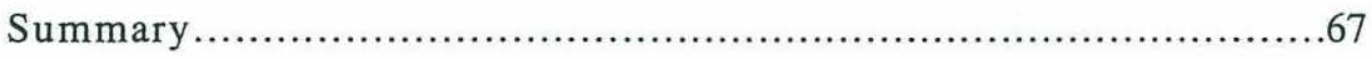

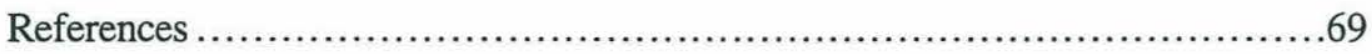

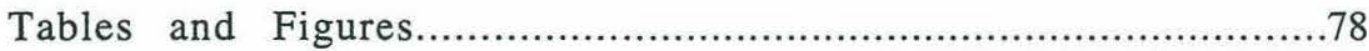


Chapter 4.

THE ROLE OF DENSITY IN THE ACCUMULATION OF BASALTIC MELTS AT MID-

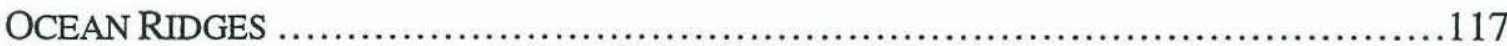

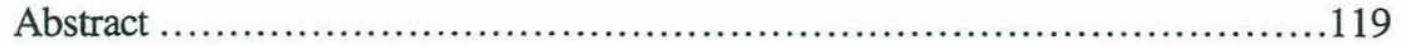

Introduction...............................................................

Estimation of melt and crustal densities ..................................119

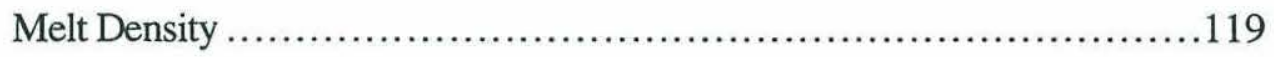

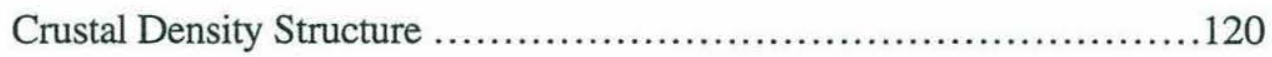

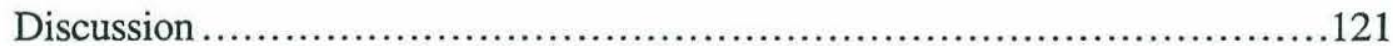

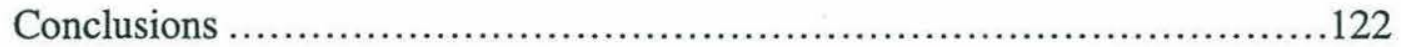

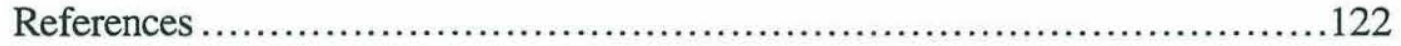

Chapter 5.

CONSTRAINING CRUSTAL EMPLACEMENT PROCESSES FROM THE VARIATION IN SEISMIC LAYER 2A THICKNESS AT THE EAST PACIFIC RISE.............................123

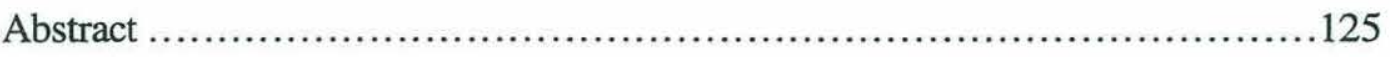

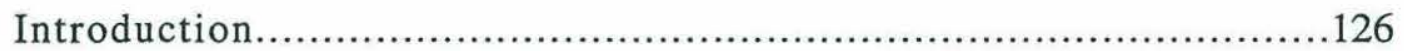

Observational Constraints on Upper Oceanic Crustal Structure at the EPR........126

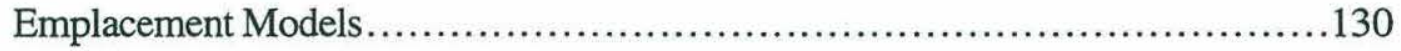

Unimodal Lava Emplacement Model ..............................130

Sensitivity of the Model .......................................133

Bimodal Lava Emplacement Model ...............................135

Implications of the Model ...........................................139

Velocity-depth profiles of the upper crust..................................139

Isochron dips and magnetic anomaly transition widths ................140

Age of Seafloor Lavas.................................................141

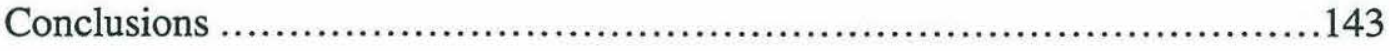




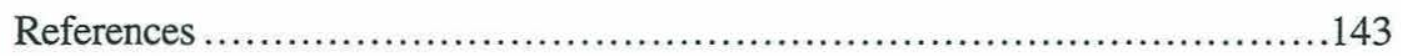

Chapter 6.

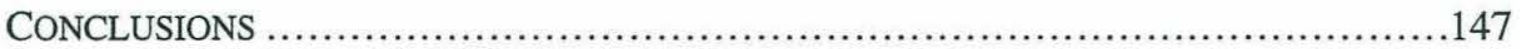

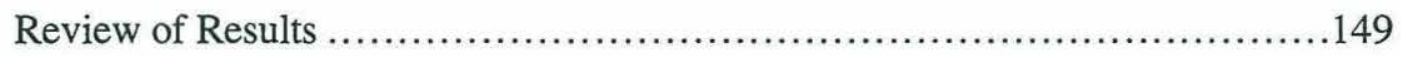

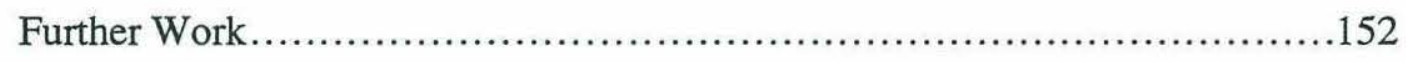

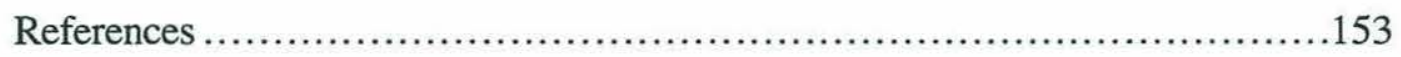




\title{
THE INFLUENCE OF MAGMA SUPPLY AND ERUPTIVE PROCESSES ON AXIAL MORPHOLOGY, CRUSTAL CONSTRUCTION AND MAGMA CHAMBERS
}

\author{
Emilie Ernestine Ebba Hooft
}

\author{
Submitted to the Department of Earth, Atmospheric, and Planetary Sciences \\ Massachusetts Institute of Technology \\ and \\ the Department of Geology and Geophysics, Woods Hole Oceanographic Institution, \\ December 1996 in partial fulfillment of the requirements for the degree of \\ Doctor of Philosophy
}

\begin{abstract}
Two-thirds of the surface of the Earth is created at mid-ocean ridges where magmas rise from the mantle and cool to form the oceanic crust. The objective of this Thesis is to examine the influence of magma supply and eruptive processes on axial morphology, crustal construction, and the properties of crustal magma chambers at intermediate and fast spreading ridges. Variations in magma supply on time scales of $\sim 100 \mathrm{Kyr}$ generate alongaxis changes in crustal thickness and temperature. Magma sill properties and hydrothermal activity are closely linked to spreading events which occur on much shorter time scales (ca. $10-100 \mathrm{yr}$ ) than the longer-term variations in magma supply reflected in along-axis changes in ridge morphology. The seismically constrained depths of ridge crest magma sills ( $>1-2$ $\mathrm{km})$ are considerably deeper than the level of neutral buoyancy $(100-400 \mathrm{~m})$. The apparent inverse relationship between magma sill depth and spreading rate suggests that a thermally controlled permeability boundary, such as the solidus horizon, controls the depth at which magma ponds beneath mid-ocean ridges. Recent thermo-mechanical models predict that, at intermediate spreading rates, rift valley and magma sill formation are sensitive to small changes in crustal thickness and mantle temperature. Analysis of gravity at an intermediate spreading ridge shows that small differences in crustal thickness $(300-700 \mathrm{~m})$ and mantle
\end{abstract}


temperature $\left(10-15^{\circ} \mathrm{C}\right)$ are indeed sufficient to produce major changes in lithospheric strength and axial morphology. A stochastic model for the emplacement of dikes and lava flows with a bimodal distribution of lava flows is required to satisfy geological and geophysical constraints on the construction of the extrusive section. Most dikes are intruded within a narrow zone at the ridge axis. Short flows build up approximately half the extrusive volume. Occasional flows that pond at a considerable distance off-axis build up the remainder of the extrusive section. This Thesis underlines the importance of eruption dynamics in the emplacement of the uppermost volcanic layer of the crust and of the crustal thermal structure in controlling local variations in magma sill depth and ridge morphology.

Thesis supervisor: Robert S. Detrick

Title:

Senior Scientist, Woods Hole Oceanographic Institution 


\section{VITA}

\section{Emilie E. E. Hooft}

Born 7th August, 1969, Utrecht, the Netherlands. Citizen of the Netherlands, permanent resident of Canada.

Languages: Dutch, English, French, German, modern Greek, Spanish.

\section{Education and Work Experience:}

12/96 Ph.D., Marine Geology and Geophysics, Joint Program in Oceanography Massachusetts Institute of Technology/Woods Hole Oceanographic Institution, Massachusetts, U.S.A.

9/95-12/95 Part-time Teaching Assistant for the graduate class, Marine Geology and Geophysics, MIT-WHOI Joint Program in Oceanography.

9/91-12/96 Graduate Research Assistant, Woods Hole Oceanographic Institution, Massachusetts, U.S.A.

9/90-6/91 Courses in art, archaeology, history and modern Greek at College Year in Athens, Greece.

6/90 B.Sc.; Specialized in Physics, Major in Astronomy, Minor in Mathematics from Trinity College, University of Toronto, Canada.

5/89-7/89 Research Assistant at the Pacific Geoscience Center, Canada, supervisor K. Rohr.

\section{$\underline{\text { Sea Experience }}$}

10-11/96 Seismic refraction and reflection study on the Mid-Atlantic Ridge aboard the R.V. Maurice Ewing.

3/96 Geophysical survey of the Galápagos spreading center aboard the B.I.O. Hespérides.

6/91-7/91 GLORIA and Hydrosweep cruise to the Juan Fernandez microplate, on board R.V. Maurice Ewing

6/89 NOBEL (ocean bottom explosives) and single channel seismics and gravity cruise to the Juan de Fuca ridge, on board R.V. J.P. Tully 


\section{Field Experience and Workshops}

1/96 Field trip and field work in the mantle and crustal sections of the Oman ophiolite with P. Kelemen and A. Nicolas.

6/95 RIDGE Theoretical Institute Short Course on Faulting and Magmatism at Mid-Ocean Ridges, Lake Tahoe, CA, USA.

4/95 Field trip to Maui and the Big Island, Hawaii with University of Hawaii class, lead by John Sinton and Scott Rowland.

9/94 RIDGE Workshop on RIdge SEgment Structure and Dynamics, Boston, Massachusetts, USA.

7/94 Field trip to Iceland in conjunction with attendance of the Conference on the Influence of the Icelandic Plume on the development of the NE Atlantic.

1/94 Death Valley, California, field trip to join the MIT field camp and study lowangle normal faults.

8/93 Bay of Islands Ophiolite, Newfoundland, Canada, Geodynamics field trip

$7 / 93$ InterRIDGE Symposium on MOR Segmentation and Workshop on MesoScale Processes, Durham, United Kingdom.

7/92 Josephine Ophiolite, Oregon, Geodynamics field trip.

1/92 RIDGE Theoretical Institute Short Course, Tuscon, Arizona, USA. 


\section{Publications}

\section{$\underline{\text { Papers }}$}

Hooft, E.E.E., R.S. Detrick, and G.M. Kent, Seismic Structure and Indicators of Magma Budget along the Southern East Pacific Rise, J. Geophys. Res., submitted, 1996a.

Canales, J.P., J.J. Dañobeitia, R.S. Detrick, E.E.E. Hooft, and D. Naar, Variations in Axial Morphology along the Galápagos Spreading Center and the Influence of the Galápagos Hotspot, in prep. for J. Geophys. Res., 1996.

Hooft, E.E.E., H. Schouten, and R.S. Detrick, Constraining Crustal Emplacement Processes from the Variation of Seismic Layer 2A Thickness at the East Pacific Rise, Earth Planet. Sci. Lett., 142, 289-309, 1996b.

Hooft, E.E.E., and R.S. Detrick, The Relationship between Axial Morphology, Crustal Thickness, and Mantle Temperatures along the Juan de Fuca and Gorda Ridges., $J$. Geophys. Res., 100, 22,499-22,508, 1995.

Hooft, E.E., M. Kleinrock, and C. Ruppel, Rifting of the Oceanic Crust at Endeavor Deep on the Juan Fernandez Microplate, Mar. Geophys. Res., 17, 251-273, 1995.

Hooft, E.E., and R.S. Detrick, The Role of Density in the Accumulation of Basaltic Melts at Mid-Ocean Ridges, Geophys. Res. Lett., 20, No. 6, pp. 423-426, 1993.

Larson, R.L., R. C. Searle, M. C. Kleinrock, H. Schouten, R. T. Bird, D. F. Naar, R. I. Rusby, E. E. Hooft, H. Lasthiotakis, Roller-Bearing Tectonic Evolution of the Juan Fernandez Microplate, Nature, 356, pp. 571-576, 1992.

$\underline{\text { Abstracts }}$

Hooft, E.E.E., R.S. Detrick, G.M. Kent, Seismic Structure and Indicators of Magma Budget along the Southern East Pacific Rise, EOS, Trans. Am. Geophys. Un., 46, 653, 1996.

Schouten, H. and E.E.E. Hooft, Structure of the Upper Oceanic Crust from Paleomagnetic Inclinations in Drill Cores, EOS, Trans. Am. Geophys. Un., 46, 157, 1996. 
Canales, J.P., D.R. Bartolome, J.J. Dañobeitia, R.S. Detrick, E.E.E. Hooft, and D. Naar, Variations in Axial Morphology along the Galápagos Spreading Center and the Influence of the Galápagos Hotspot, EOS, Trans. Am. Geophys. Un., 46, 728, 1996.

Hooft, E.E.E., R.S. Detrick, and H. Schouten, Constraining Crustal Emplacement Processes from the Variation in Layer 2A Thickness at the East Pacific Rise., ODPInterRidge-IAVCEI Workshop, May, 1996.

Schouten, H. and E.E.E. Hooft, Upper and Lower Pillow Lava Structure from Drill Cores in Oceanic Crust and Troodos Ophiolite, ODP-InterRidge-IAVCEI Workshop, May, 1996.

Hooft, E.E.E., R.S. Detrick, G.M. Kent, Magmatic Construction of the Super-Fast Spreading Southern East Pacific Rise, EGS, Spring, 1996.

Hooft, E.E.E., R.S. Detrick, and H. Schouten, Constraining Crustal Emplacement Processes from the Variation in Layer 2A Thickness at the East Pacific Rise., EOS, Trans. Am. Geophys. Un., 76, 595, 1995.

Hooft, E.E.E., R.S. Detrick, G.M. Kent, and H. Schouten, The Upper Crustal Structure along the Fast-Spreading Southern East Pacific Rise - Multichannel Seismic Data and some Simple Modeling, RIDGE Theoretical Institute, June 1995

Hooft, E.E.E., and R.S. Detrick, Variations in Crustal Thickness and Axial Morphology along the Juan de Fuca and Gorda Ridges., EOS, Trans. Am. Geophys. Un., 75, 640, 1994.

Hooft, E.E., M. Kleinrock, and C. Ruppel, Models of Microplate Rift Valleys: Endeavor Deep on the Juan Fernandez Microplate, EOS, Trans. Am. Geophys. Un., 74, $672,1993$.

Hooft, E.E., and R.S. Detrick, The Depth of the Level of Neutral Buoyancy at Mid-Ocean Ridges, EOS, Trans. Am. Geophys. Un., 74, No. 16, p. 291, 1993.

Hooft, E.E., and R.S. Detrick, The Role of Density in the Accumulation and Eruptability of Basaltic Melts at Mid-Ocean Ridges, EOS, Trans. Am. Geophys. Un., 73, No. 43, p. 495, 1992.

Hooft, E., and M. C. Kleinrock, Endeavor and Pito Deeps: Two Large Offset Rift Tips, EOS, Trans. Am. Geophys. Un., 72, No. 44, p. 509, 1991.

Hooft, E., and K. Rohr, A Comparison of Thermal Subsidence Curves for Young Pacific and Juan de Fuca Plates at the Endeavour Segment, EOS, Trans. Am. Geophys. Un., 70, No. 43, p.1383, 1989. 


\section{ACKNOWLEDGMENTS}

First of all I would like to thank those people who I have worked with and who have inspired me during my time in the Joint Program: This means in particular Bob Detrick who has guided me in my work and scientific interactions and has also been a good friend. Marty Kleinrock first welcomed me to WHOI. Hans Schouten acted as a surrogate Dutch uncle as well as a challenging counselor. All that I know about seismic processing I learnt from Graham Kent - I can think of no one more approachable and interested than he has been. I would also like to thank the other members of my thesis committee, Kathy Gillis, Jian Lin, Marcia McNutt, and Debbie Smith (the chair), all of whom have discussed my work and helped me in its development over the years. Going back to the beginning of my time in the Joint Program, I particularly remember Carolyn Ruppel's help and guidance both in the world of geophysics and of computers. The support and friendship of Jim Dolan and Dave Dubois in the OBS lab has provided a constant factor over the years.

Prior to my arrival in Woods Hole, I was introduced to the sea-going life and the world of the ocean floor by Nigel Edwards and Kristin Rohr. Henry Dick's geodynamics field trips to the Josephine and Bay of Islands ophiolites have taught me much of the geology that I know. Bob Detrick has enabled me to go on many trips, research cruises and to conferences. Karl Grünvold showed us all the most exciting sites in Iceland. John Sinton took me on his class tour of the volcanic centers of the Hawaiian island chain. I particularly remember a field trip to the ophiolite in Oman with Peter Kelemen and Greg Hirth. Juanjo Dañobeitia invited us on a short survey of the Galapagos spreading center.

A large suite of housemates - at present Ken Gartner and Margie Oleksiak, previously Sharon Moran, the Greek gang (Gretchen Grozier, Megan Jamison, Pete Kaufman, Eric Parks, and Ann Tweedie ) as well as many WHOI housing companions have made life more enjoyable through their companionship. Especially Gretchen has been a dear friend ever since we set off on our first adventure in Greece. Pete bridged the link between Greece and MIT for me and was a great hiking partner. Nic Fiszman has always been a lasting friend. Einat Aharonov, Gorka Sancho and Nic Cauchy have helped extend life beyond the realm of work.

The first people that I met in the Joint Program were Gera Panteleyev, Natalia Beliakova, Garrett Ito, Javier Escartín, Gary Jaroslow, Dan Lizarralde and Rafi Katzman. 
They have all remained good friends as we have accompanied each other through the events of the last few years. Natasha has been a warm and spontaneous friend since the moment we met each other. Garrett, thank you for the many dances and your quiet company. Cecily Wolfe eventually took pity on me and let me sleep in her tent, which I still am borrowing. Since that moment Cecily has been a mentor, an office mate and a good friend. Javier has been a close friend for a long time now and a companion on trips to many different parts of the USA.

Finally it is my parents who gave me an exciting and challenging upbringing and introduced me to the thrill of discovering the world as well as to the enchantment of the sea. Especially my mother has always encouraged me to do the best I can at whatever I attempt. She has read all my scientific papers and tried, with a large degree of success, to understand them. With my sister and brothers, as well as my old friends, I have competed and joined together in making our way through life's events. 


\section{Chapter 1}

\section{Magma Chambers, Crustal Construction, And AXIAL MORPHOLOGY}




\section{Evolution of Magma Chamber Models}

Two-thirds of the surface of the Earth is created at mid-ocean ridges where magmas generated within the mantle rise and cool to form the oceanic crust. The separation of two lithospheric plates at mid-ocean ridges results in upwelling of the underlying mantle which undergoes decompression melting as it rises. This melt is focused into a very narrow zone, on the order of a few kilometers wide, where lava is emplaced either as dikes, sills and extrusive flows, or cools more slowly forming gabbro. Through these processes new oceanic crust is formed along mid-ocean ridges.

The existence of crustal magma chambers at mid-ocean ridges has been a critical element in most models of oceanic crustal formation since the early 1970s. Until the first detailed seismic experiments were carried out on mid-ocean ridges in the 1980s, it was widely believed that most ridge crests, even those at relatively slow spreading rates, were associated with large (10-20 km wide by $3-4 \mathrm{~km}$ thick), essentially molten, well-mixed magma reservoirs [e.g., Cann, 1974; Dewey and Kidd, 1977; Casey and Karson, 1981; Pallister and Hopson, 1981; Nicolas et al., 1988]. These large magma chambers were attractive for several reasons. They offer a simple explanation for the lithostratigraphy of oceanic crust inferred from seismic studies [Raitt, 1963; Shor et al., 1970] and from ophiolites [Geotimes, 1972]. An upper layer of extrusive pillow lavas and sheeted dikes could be generated by periodic eruptions through the top of the magma chamber. A middle unit of isotropic gabbro may form by freezing of the margins of the chamber due to cooling from above. The lower layered gabbros would then form by cooling and settling of crystals on the floor of the magma chamber. A large crustal magma chamber also explains the observation that most mid-ocean ridge basalts are not in equilibrium with presumed mantle compositions [e.g., Bryan, 1976], but require some cooling and crystal 
fractionation at shallow crystal levels [e.g., Stolper and Walker, 1980; Grove and Bryan, 1983].

However, seismic studies carried out at both fast and slow spreading ridges over the past fifteen years effectively preclude the existence of the large, molten crustal magma bodies envisioned in these earlier models [Solomon and Toomey, 1992] and have led to a completely new view of the size and longevity of crustal magma bodies at ridge crests, and their role in the formation of the oceanic crust. No seismic evidence exists for crustal magma bodies of any significant dimensions along slow spreading ridges, like the MidAtlantic Ridge [Purdy and Detrick, 1986; Toomey et al., 1988; Detrick et al., 1990] and crustal magma chambers are believed to be volumetrically small, intrusive bodies that are rapidly frozen by hydrothermal cooling [Smith and Cann, 1992]. Even at fast spreading ridges, like the East Pacific Rise, seismic studies indicate that magma is largely confined to a narrow ( 1-2 km wide), thin $(<1 \mathrm{~km})$, mostly molten magma lens or sill [Detrick et al., 1987; Harding et al., 1989; Kent et al., 1990; Hussenoeder et al., 1996] overlying a broader region of the lower crust, which has low seismic velocities and contains at most a few percent partial melt [Toomey et al., 1990; Vera et al., 1990; Caress et al., 1992]. These seismic observations are supported by gravity models of the fast spreading EPR [Madsen et al., 1984; Wang and Cochran, 1993; Magde et al., 1995], which do not require a large ( $>10 \mathrm{~km}$ wide), low density crustal magma body.

These geophysical data have been interpreted in terms of a composite magma chamber at fast-spreading ridges which consists of a thin, narrow, sill-like body overlying a thicker, wider crystal mush zone [Sinton and Detrick, 1992]. The manner in which the oceanic crust is generated from such a magmatic system is quite different than for a large magma reservoir. At fast spreading ridges the entire crust is envisioned as forming in the magma sill with eruption through the top of the sill building the extrusive section, and sub- 
solidus flow down and out from the base of the sill generating the layered lower crust [Henstock et al., 1993; Quick and Denlinger, 1993; Phipps Morgan and Chen, 1993a]. However, geological observations suggest that magma sills may also exist in the lower crust that freeze to generate the layered gabbros [Kelemen et al., 1996]. Short-lived magma bodies at slow spreading ridge are consistent with geological observations that the oceanic crust is not as well layered as was previously thought [e.g., Cannat, 1993]. The existence of volumetrically small crustal magma bodies is supported by the geochemical variability observed in mid-ocean ridge basalts which is also difficult to reconcile with a well-mixed magma reservoir [e.g., Langmuir et al., 1986; Mével, 1987; Sinton et al., 1991].

Seismic observations of magma sill reflectors from the northern and southern EPR, and sparse observations from intermediate spreading ridges (Valu Fa and Juan de Fuca) indicate a spreading rate dependence for the average depth of magma chamber reflectors [Purdy et al., 1992]. These depth variations have been modeled to depend on the balance of heat advected from below and that removed by hydrothermal cooling [Henstock et al., 1993; Phipps Morgan and Chen, 1993a]. The thermal balance at mid-ocean ridges also affects the rheology of the crust [Phipps Morgan et al., 1987; Chen and Morgan, 1990a; Chen and Morgan, 1990b]. Slow spreading ridges have an axial valley, while fast spreading ridges have an axial high [Small and Sandwell, 1989]. The transition in mode of deformation of the plate boundary at mid-ocean ridges is modeled to be very sensitive to variations in crustal temperature and thickness [Phipps Morgan and Chen, 1993b].

The new ridge crest magma chamber model which has been developed over the last fifteen years raises important, and still unresolved, questions about how oceanic crust is formed. How is magma delivered from the mantle? Since the crustal magma reservoirs are volumetrically so small and short-lived at all but the fastest spreading rates, are there 
magma reservoirs in the underlying mantle? How is the lower crust formed from the composite magma chamber? Also, an important problem is the temporal variability of these processes. What are the time scales of input of magma from the mantle and output through eruption onto the seafloor? How are the properties of the crustal magma bodies related to variations in spreading rate, magma supply, hydrothermal activity or eruptive cycles? How can a thin narrow magma sill exist without being rapidly frozen by hydrothermal cooling? What controls the width of the neovolcanic zone and how does it control the architecture of the shallow crust? What is the size and quantity of lava in individual eruptions?

\section{Thesis Overview}

This Thesis discusses the importance of spreading rate, melt supply, hydrothermal cooling, eruption geometry, and the differences in timing of these processes in constructing the layered oceanic crust. The objective of this Thesis is to examine the influence of magma supply and eruptive processes on axial morphology, crustal construction, and the properties of crustal magma chambers at intermediate and fast spreading ridges. The magmatic system at mid-ocean ridges is complicated, and represents the boundary between a quasi-steady input of magma from below and the periodic intrusion of dikes and eruption of lavas onto the seafloor. The local crustal thermal structure is important in controlling magma sill properties on relatively short time scales (10s to 1,000 s of years) and this is superimposed on the longer term dependence of the properties of the magmatic system on spreading rate and magma supply. The thermal regime and composition of the lithosphere also control the rheology thereby determining the axial morphology of mid-ocean ridges.

The lithospheric structure of two ridges with contrasting axial morphologies that are spreading at the same intermediate rate is investigated in Chapter 2 using gravity data from the Juan de Fuca and northern Gorda ridges. The Cleft segment of the Juan de Fuca ridge 
has an axial high morphology while the northern segment of the Gorda ridge has a rift valley. The difference in residual gravity anomalies is used to determine the change in crustal thickness and mantle temperature between these two ridge segments. These observational results are used to test thermal predictions for the dependence of ridge morphology on magma supply and spreading rate [e.g., Phipps Morgan and Chen, 1993b].

The relationship between seismically constrained variations in crustal structure and indicators of ridge magma supply is re-examined in Chapter 3. Observations over the past decade have lead to the development of a magma supply model for fast spreading ridges. Broad, shallow ridge segments are assumed to reflect a high magma supply and are predicted to have larger, more robust magma chambers, erupt more primitive basalts, form thicker crust, and have more vigorous hydrothermal activity than sections of the ridge with a deeper, narrower rise crest. Multichannel seismic reflection data from an 800-km-long section of the southern East Pacific Rise (SEPR) allow a quantitative examination of the correlation between along-axis variations in crustal structure and other indicators of magma supply on a regional scale, and show that there are several scales of spatial and temporal variability that modify the simple correlations predicted by the magma supply model. The observed variation in magma sill depth is compared to different models proposed to explain the ponding of magma in the mid-crust.

In Chapter 4, the common assumption that magma ponds at a level of neutral buoyancy in the shallow crust [c.f. Walker, 1989; Ryan, 1993] is tested. At the level of neutral buoyancy the melt densities are equal to the bulk densities of the surrounding crust. The depth of the level of neutral buoyancy is determined from estimates of melt density based on the composition of erupted lavas and estimates of the crustal density structure from the inversion of the seismic velocity structure of the crust and in situ borehole 
measurements of crustal porosity. This estimate of the level of neutral buoyancy is compared with seismically constrained depths of ridge crest magma chambers to test the level of neutral buoyancy model for mid-ocean ridges. The results are also discussed in terms of the alternative hypothesis that the thermal structure of the rise crest controls the depth at which melt ponds in the upper crust [Phipps Morgan and Chen, 1993a].

A stochastic model for the emplacement of dikes and lava flows to generate an upper oceanic crustal structure similar to that observed in seismic data from the East Pacific Rise (EPR), in ocean drill holes, and in ophiolites is explored in Chapter 5. Wide-angle seismic reflections from the steep velocity gradient at the base of seismic layer $2 \mathrm{~A}$ are interpreted to be the extrusive/sheeted dike contact. Seismic data from the northern and southern EPR constrain the on-axis extrusive layer thickness, the distance over which the thickening of the extrusive layer occurs, and its off-axis thickness. Ophiolites and ocean drill holes (DSDP Hole 504B) provide additional estimates of the thickness of the extrusive layer and constrain the thickness of the transition region from extrusives to sheeted dikes. The predictions of this model are compared with measured seafloor lava ages [Goldstein et al., 1994] and with the shallow velocity structure determined on the northern EPR [Christeson et al., 1992].

Chapter 6 summarizes the main conclusions of Chapters 2 through 5 and discusses some questions about the volcanic processes constructing the crust and the factors controlling the crustal rheology of mid-ocean ridges that remain to be addressed or are raised by this work.

Chapter 2 was published in the Journal of Geophysical Research, 1995. Chapter 3 was submitted to the Journal of Geophysical Research, Sept. 1996. Chapter 4 has been published in Geophysical Research Letters, 1993. Chapter 5 has been published in Earth 
and Planetary Science Letters, 1996. My co-author on Chapters 2 and 4 is Robert Detrick, on Chapter 3 my co-authors are Robert Detrick and Graham Kent, and on Chapter 5, Hans Schouten and Robert Detrick. I have been supported in this work by NSF grants: OCE9296017, OCE-9402033, and OCE-80203300, and by the Joint Program Education Office.

The full citations for the papers corresponding to each of the Thesis Chapters are listed below:

Hooft, E.E.E. and R.S. Detrick, The relationship between axial morphology, crustal thickness and mantle temperatures along the Juan de Fuca and Gorda Ridges., $J$. Geophys. Res., 100, 22,499-22,508, 1995.

Hooft, E.E.E., R.S. Detrick, and G.M. Kent, Seismic structure and indicators of magma budget along the southern East Pacific Rise, J. Geophys. Res., submitted, $1996 \mathrm{a}$.

Hooft, E.E. and R.S. Detrick, The role of density in the accumulation of basaltic melts at mid-ocean ridges, Geophys. Res. Lett., 20, 423-426, 1993.

Hooft, E.E.E., H. Schouten, and R.S. Detrick, Constraining crustal emplacement processes from the variation of seismic layer 2A thickness at the East Pacific Rise, Earth Planet. Sci. Lett., 142, 289-309, 1996b.

\section{References:}

Bryan, W.B., Regional variation and petrogenesis of basalt glasses from the FAMOUS area, Mid-Atlantic Ridge, J. Petrol., 20, 293-325, 1976.

Cann, J.R., A model for oceanic crustal structure developed, Geophys. J. R. Astr. Soc., 39, 169-187, 1974.

Cannat, M., Emplacement of mantle rocks in the seafloor at mid-ocean ridges, J. Geophys. Res., 98, 4163-4172, 1993. 
Caress, D., Burnett, M. and Orcutt, J., Tomographic image of the axial low velocity zone at $12^{\circ} 50^{\prime} \mathrm{N}$ on the East Pacific Rise, submitted to, J. Geophys. Res., 97, 9243-9264, 1992.

Casey, J.F. and Karson, J.A., Magma chamber profiles from the Bay of Islands ophiolite complex, Nature, 292, 295-301, 1981.

Chen, Y.J. and Morgan, W.J., Rift valley/no rift valley transition at mid-ocean ridges, $J$. Geophys. Res., 95, 17,571-17,581, 1990a.

Chen, Y. and Morgan, W.J., A nonlinear rheology model for mid-ocean ridge axis topography, J. Geophys. Res., 95 No. B11, 17583-17604, 1990b.

Christeson, G.L., Purdy, G.M. and Fryer, G.J., Structure of young upper crust at the East Pacific Rise near 9³0'N, Geophys. Res. Lett., 19, 1045-1048, 1992.

Detrick, R.S., Buhl, P., Vera, E.E., Mutter, J.C., Orcutt, J.A., Madsen, J.A. and Brocher, T.M., Multichannel seismic imaging of a crustal magma chamber along the East Pacific Rise, Nature, 326, 35-41, 1987.

Detrick, R.S., Mutter, J.C., Buhl, P. and Kim, I.I., No evidence from multichannel reflection data for a crustal magma chamber in the MARK area on the Mid-Atlantic Ridge, Nature, 347, 61-64, 1990.

Dewey, J.F. and Kidd, W.S.F., Geometry of plate accretion, Geol. Soc. Am. Bull., 88, 960-968, 1977.

Geotimes, Penrose conference on ophiolites, 17, 24-25, 1972.

Goldstein, S.J., Perfit, M., R., Batiza, R., Fornari, D.J. and Murrell, M., Off-axis volcanism at the East Pacific Rise detected by uranium-series dating of basalts, Nature, 367, 157-159, 1994.

Grove, T.L. and Bryan, W.B., Fractionation of pyroxene-phyric MORB at low pressure: An experimental study, Contr. Mineral. and Petrol., 84, 293-309, 1983. 
Harding, A.J., Kappus, M.E., Orcutt, J.A., Vera, E.E., Buhl, P., Mutter, J.C., Detrick, R.S. and Brocher, T., The structure of young oceanic crust at $13^{\circ} \mathrm{N}$ on the East Pacific Rise from ESPs, J. Geophys. Res., 94, 12163-12196, 1989.

Henstock, T.J., Woods, A.W. and White, R.S., The accretion of oceanic crust by episodic sill instrusion, J. Geophys. Res., 98, 4143-4161, 1993.

Hussenoeder, S.A., Collins, J.A., Kent, G.M., Detrick, R.S. and Group, T., Seismic analysis of the axial magma chamber reflector along the southern East Pacific Rise from conventional reflection profiling, J. Geophys. Res., in press, 1996.

Kelemen, P.B., Koga, K. and Shimizu, N., Geochemistry of gabbro sills in the crust/mantle transition zone of the Oman ophiolite: Implications for the origin of the oceanic lower crust, submitted, 1996.

Kent, G.M., Harding, A.J. and Orcutt, J.A., Evidence for a smaller magma chamber beneath the East Pacific Rise at 9³0'N, Nature, 344, 650-653, 1990.

Langmuir, C.H., Bender, J.F. and Batiza, R., Petrologic and tectonic segmentation of the East Pacific Rise, 5³0'-14³0'N, Nature, 322, 422-429, 1986.

Madsen, J.A., Forsyth, D.W. and Detrick, R.S., A new isostatic model for the East Pacific Rise crest, J. Geophys. Res., 89, 9997-10,015, 1984.

Magde, L.S., Detrick, R.S. and Group, T., The crustal and upper mantle contribution to the axial gravity anomaly at the Southern East Pacific Rise, J. Geophys. Res., 100, 3747-3766, 1995.

Mével, C.M., Evolution of oceanic gabbros from DSDP Leg 82: Influence of the fluid phase on metamorphic crystallization, Earth Planet. Sci. Lett., 83, 67-79, 1987.

Nicolas, A., Reuber, I. and Benn, K., A new magma chamber model based on structural studies in the Oman ophiolite, Tectonophys., 151, 87-105, 1988.

Pallister, J.S. and Hopson, C.A., Semail ophiolite plutonic suite: Field relations, phase variation, cryptic variation and layering and a model of a spreading ridge magma chamber, J. Geophys. Res., 86, 2593-2644, 1981. 
Phipps Morgan, J. and Chen, Y.J., The genesis of oceanic crust: Magma injection, hydrothermal circulation, and crustal flow, J. Geophys. Res., 98, 6283-6298, 1993a.

Phipps Morgan, J. and Chen, Y.J., Dependence of ridge-axis morphology on magma supply and spreading rate, Nature, 364, 706-708, $1993 \mathrm{~b}$.

Phipps Morgan, J., Parmentier, E.M. and Lin, J., Mechanism for the origin of mid-ocean ridge axial topography: Implications for the thermal structure of accreting plate boundaries, Journal of Geophysical Researches, 92, 12,823-12,836, 1987.

Purdy, G.M., Christeson, G. and Solomon, S., Relationship between spreading rate and the seismic structure of mid-ocean ridges, Nature, 355, 815-817, 1992.

Purdy, G.M. and Detrick, R.S., Crustal structure of the Mid-Atlantic Ridge at $23^{\circ} \mathrm{N}$ from seismic refraction studies, J. Geophys. Res., 91, 3739-3762, 1986.

Quick, J.E. and Denlinger, R.P., Ductile deformation and the origin of layered gabbros in ophiolites, J. Geophys. Res., 98, 14,015-14,028, 1993.

Raitt, R.W., The crustal rock, vol. pp. 85-102, Wiley-Interscience, New York, NY, 1963.

Ryan, M.P., Neutral buoyancy and the structure of mid-ocean ridge magma reservoirs, $J$. Geophys. Res., 98, 22,321-22,338, 1993.

Shor, G.G., Jr., Menard, H.W. and Raitt, R.W., Structure of the Pacific Basin, in The Sea, vol. 4 edited by Maxwell, A.E., pp. 3-27, Wiley-Interscience, New York, NY, 1970.

Sinton, J.M. and Detrick, R.S., Mid-ocean ridge magma chambers, J. Geophys. Res., 97, 197-216, 1992.

Sinton, J.M., Smaglik, S.M., Mahoney, J.J. and Macdonald, K.C., Magmatic processes at superfast spreading mid-ocean ridges: Glass compositional variations along the East Pacific Rise $13^{\circ} \mathrm{S}-23^{\circ} \mathrm{S}$, J. Geophys. Res., 96, 6133-6155, 1991.

Small, C. and Sandwell, D.T., An abrupt change in ridge axis gravity with spreading rate, J. Geophys. Res., 94, 17,383-17,392, 1989. 
Smith, D.K. and Cann, J.R., The role of seamount volcanism in crustal construction at the

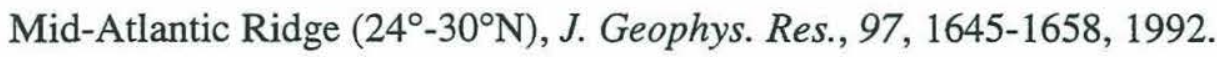

Solomon, S.C. and Toomey, D.R., The structure of mid-ocean ridges, Annual Reviews of Earth and Planetary Sciences, 20, 329-364, 1992.

Stolper, E. and Walker, D., Melt density and the average composition of basalt, Contr. Mineral. and Petrol., 74, 7-12, 1980.

Toomey, D.R., Purdy, G.M., Solomon, S.C. and Wilcock, W.S.D., The threedimensional seismic velocity structure of the East Pacific Rise near latitude $9^{\circ} 30^{\prime} \mathrm{N}$, Nature, 347, 639-645, 1990.

Toomey, D.R., Solomon, S.C. and Purdy, G.M., Microearthquakes beneath the median valley of the Mid-Atlantic Ridge near $23^{\circ} \mathrm{N}$ : Tomography and tectonics, J. Geophys. Res., 93, 9093-9112, 1988.

Vera, E.E., Buhl, P., Mutter, J.C., Harding, A.J., Orcutt, J.A. and Detrick, R.S., The structure of 0-0.2 My old oceanic crust at $9^{\circ} \mathrm{N}$ on the East Pacific Rise from expanded spread profiles, J. Geophys. Res., 95, 15,529-15,556, 1990.

Walker, G.P.L., Gravitational (density) controls on volcanism, magma chambers and intrusions, Australian J. Earth Sci., 36, 149-165, 1989.

Wang, X. and Cochran, J.R., Gravity anomalies, isostasy, and mantle flow at the East Pacific Rise crest, J. Geophys. Res., 98, 19,505-19,532, 1993. 
Chapter 2

\section{RELATIONSHIP BETWEEN AXIAL MORPHOLOGY, CRUSTAL ThICKNESS, AND MANTLE TEMPERATURE ALONG THE JUAN DE FUCA AND GORDA RIDGES}




\title{
Relationship between axial morphology, crustal thickness, and mantle temperature along the Juan de Fuca and Gorda Ridges
}

\author{
Emilie E. E. Hooft \\ Massachusetts Institute of Technology/Woods Hole Oceanographic Institution Joint Program in Oceanography \\ Woods Hole, Massachusetts \\ Robert S. Detrick \\ Department of Geology and Geophysics, Woods Hole Oceanographic Institution, Woods Hole, Massachusetts
}

\begin{abstract}
We analyze gravity data over the Juan de Fuca and northern Gorda Ridges to understand the lithospheric structure of two ridges with contrasting axial morphologies spreading at the same intermediate rate $(28 \mathrm{~mm} / \mathrm{yr}$ half rate). The Cleft Segment, at the south end of the Juan de Fuca Ridge, has an axial high morphology while the northern segment of the Gorda Ridge has a rift valley. Residual mantle Bouguer anomalies (RMBA) on the northern Gorda Ridge are elevated relative to the Cleft Segment by $10-20 \mathrm{mGal}$, indicating thinner crust and/or a colder mantle. The minimum value $(-50 \mathrm{mGal})$ of the RMBA along the Juan de Fuca Ridge is over Axial Seamount and gradually increases south toward the Blanco Transform. The observed RMBA are interpreted to result from along axis variations in crustal thickness and mantle density, both of which are controlled by temperatures in the upper mantle where decompression melting occurs. We estimate that mantle temperatures are elevated by $30^{\circ}-40^{\circ} \mathrm{C}$ beneath Axial Seamount, resulting in an excess crustal thickness of $\sim 1.7 \mathrm{~km}$. The Cleft Segment is associated with crust that is estimated to be only $300-700 \mathrm{~m}$ thicker, and mantle temperatures are only $10^{\circ}-15^{\circ} \mathrm{C}$ higher than beneath the northern Gorda Ridge. However, even these small differences in crustal thickness and mantle temperature appear to be sufficient to produce a major change in lithospheric strength and axial morphology. These results are consistent with the predicted sensitivity of recent thermo-mechanical models for rift valley formation to small changes in crustal thickness and mantle temperature at intermediate spreading rates. We attribute the systematic differences in axial morphology, crustal thickness, mantle temperature, and lithospheric strength along the Juan de Fuca/Gorda ridge system to the presence of the Cobb thermal anomaly at Axial Seamount. The hotter mantle beneath the Juan de Fuca Ridge results in greater amounts of decompression melting and the formation of a thicker crust and a thinner, weaker lithosphere than along the Gorda Ridge.
\end{abstract}

\section{Introduction}

One of the first order features of mid-ocean ridges is the difference in axial morphology observed between fast and slow spreading ridges. Spreading centers with half spreading rates of less than $15-20 \mathrm{~mm} / \mathrm{yr}$ are typically associated with a $1-2 \mathrm{~km}$ deep, $15-30 \mathrm{~km}$ wide rift valley, while ridges with half spreading rates faster than about $30-35 \mathrm{~mm} / \mathrm{yr}$ are associated with a 2-10 $\mathrm{km}$ wide, 200-300 $\mathrm{m}$ axial high [Macdonald, 1982]. The transition from rift valley to axial high appears to be relatively abrupt and occurs at half spreading rates of $20-30 \mathrm{~mm} / \mathrm{yr}$ [Small and Sandwell, 1989]. However, spreading rate does not appear to be the only controlling variable on ridge crest morphology. For example, the Reykjanes Ridge has an axial high despite a half spreading rate of only $10 \mathrm{~mm} / \mathrm{yr}$ [Searle and Laughton, 1981]. Along the Southeast Indian Ridge the axial morphology changes from a rift valley in the Australian-Antarctic Discordance to an axial high east and west of this zone even though this entire section of ridge crest has a relatively uniform half spreading rate of 30-35 mm/yr [Sempéré et al., 1991]. Along-axis changes in ridge crest morphology can even occur at the segment scale.

Copyright 1995 by the American Geophysical Union.

Paper number 95JB02502.

0148-0227/95/95JB-02502\$05.00
Along the southern Mid-Atlantic Ridge several cases have been reported where the ridge crest is absent near the midpoint of a segment while showing a clear rift valley near the ends of a segment [Kuo and Forsyth, 1988; Blackman and Forsyth, 1991; Fox et al., 1991].

The strength of the lithosphere determines how it deforms under extensional forces and thus controls whether the ridge crest forms an axial high (weak lithosphere is isostatically compensated) or a rift valley (stronger lithosphere deforms by brittle-plastic necking) [Sleep, 1969; Lauchenbruch, 1973; Tapponnier and Francheteau, 1978; Sleep and Rosendahl, 1979; Phipps Morgan et al., 1987; Chen and Morgan, 1990]. The rheological properties of the lithosphere depend on both temperature and composition (crustal rocks are weaker than mantle rocks at the same temperature [e.g., Brace and Kohlstedt, 1980; Kirby, 1983]). The thermal structure of the oceanic lithosphere is determined by the advection of heat by magma emplacement and conductive and hydrothermal cooling. An increased magma supply at a fixed spreading rate increases the heat supply and creates a greater thickness of weaker crustal rocks and a hotter, weaker lithosphere. At intermediate spreading rates, ridge crest morphology is particularly sensitive to changes in the thermal structure and magma supply [Phipps Morgan and Chen, 1993b]. 


\section{HOOFT AND DETRICK: JUAN DE FUCA AXIAL MORPHOLOGY VARIATIONS}

The Juan de Fuca and Gorda Ridges are a classic example of the difference in axial morphology that is found at intermediate spreading rates. Although both ridges are spreading at about the same rate $(\sim 28 \mathrm{~mm} / \mathrm{yr}$ half rate), the northern Gorda Ridge is characterized by an axial valley ( $400-600 \mathrm{~m}$ deep) typical of slow spreading ridges, while the southern Juan de Fuca Ridge is generally associated with an axial high (up to $300 \mathrm{~m}$ high) characteristic of fast spreading ridges. In this paper we compile gravity and bathymetry data over these two ridges and interpret the residual gravity anomaly in terms of mantle temperature anomalies and crustal thickness variations. By correlating variations in axial morphology with differences in lithospheric structure, we test current ideas on the origin of rift valleys and axial highs and show that relatively small changes in crustal thickness and mantle temperature are sufficient at intermediate spreading rates to result in large differences in the morphology of the ridge axis.

\section{Tectonic Setting}

The Juan de Fuca/Gorda spreading system has been intensely studied over the past fifteen years (see special issues on the Juan de Fuca Ridge published in the Journal of Geophysical Research in 1987, 1990, and 1993). The ridge crest has been subdivided into a number of distinct spreading segments based on detailed bathymetric and multibeam mapping [Delaney et al., 1981; Malahoff et al., 1982; Embley et al., 1983; Karsten et al., 1986). On the Juan de Fuca Ridge these segments are called (from north to the south) the West Valley, Endeavour, Northern Symmetric (or Cobb), Axial (or Coaxial), Vance (or Southern Symmetric), and Cleft Segments (Figure 1). The Gorda Ridge consists of three main segments, the northern, central, and southern Gorda Ridge (also known as the Escanaba Trough). The Juan de Fuca Ridge is bounded to the north by a triple junction formed by the ridge, the left lateral Nootka Fault, and the 140-km-long Sovanco

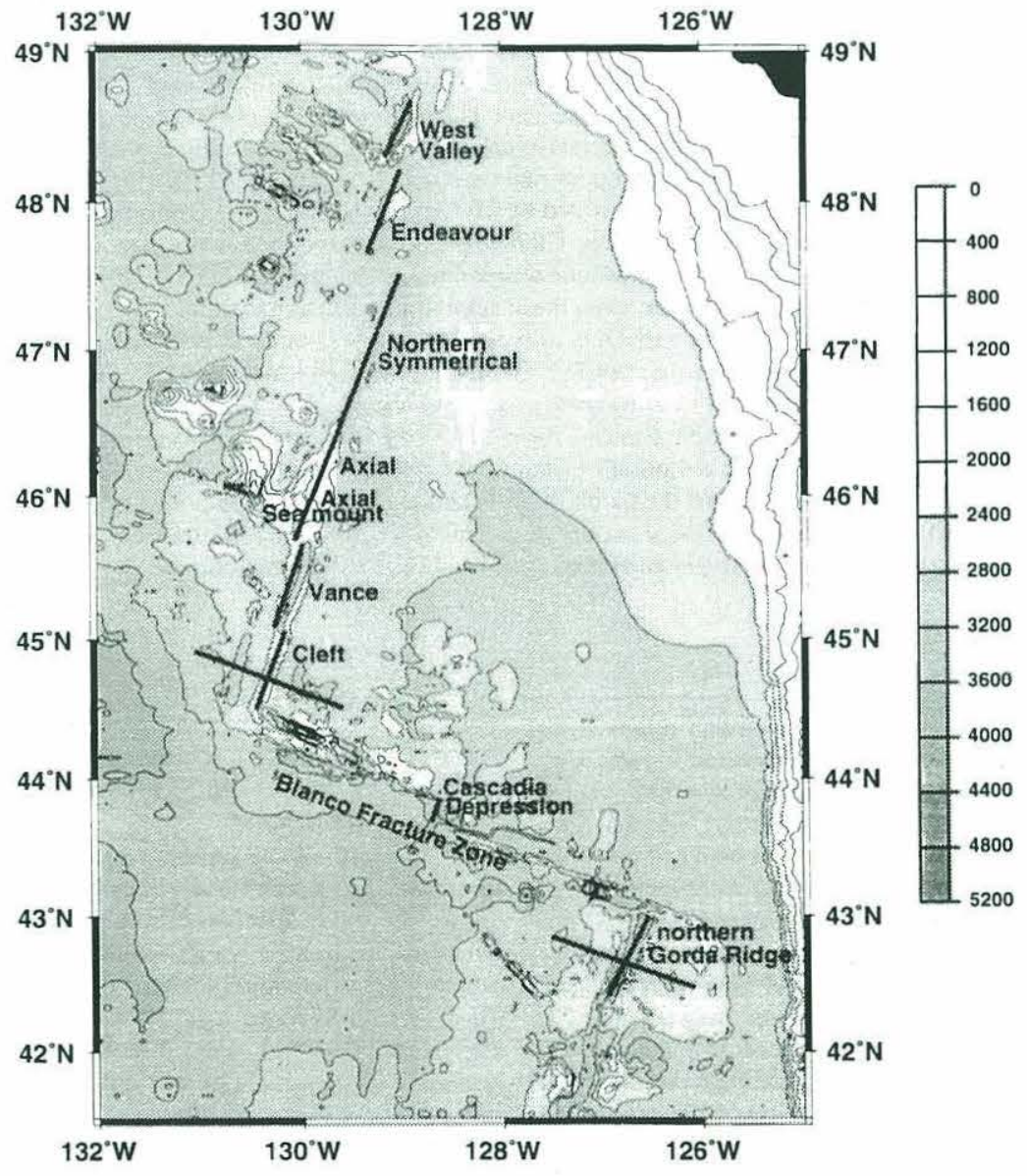

Figure 1. Bathymetry map over the Gorda Ridge, the Blanco Fracture Zone and the Juan de Fuca Ridge. Grid spacing is $1 \mathrm{~km}$; contour interval is $400 \mathrm{~m}$. Both ridges are spreading at the same intermediate spreading rate $(\sim 28$ $\mathrm{mm} / \mathrm{yr}$ ). The data included in the bathymetry compilation were shipboard bathymetry extracted from the National Geophysical Data Center (NGDC) and multibeam bathymetry from the Lamont-Doherty Earth Observatory RIDGE Multibeam Data Synthesis. Between ship tracks the bathymetry was supplemented with DBDB5 data (Digital Bathymetric Data Base 5.) Where multibeam bathymetry existed, the NGDC bathymetry was not used. The accuracy of this map varies widely, from $\sim 50 \mathrm{~m}$ over the ridge crest which is entirely mapped with multibeam data and degrading into regions that were filled using the DBDB5 data. The location of the ridge axis is shown by the black lines as are the two across-axis profiles shown in Figure 2. 


\section{HOOFT AND DETRICK: JUAN DE FUCA AXIAL MORPHOLOGY VARIATIONS}

Fracture Zone [Atwater, 1970; Hyndman et al., 1979]. To the south the Blanco Fracture Zone offsets the spreading axis $400 \mathrm{~km}$ from the Juan de Fuca to the Gorda Ridge.

The Juan de Fuca plate is being flooded by turbidites derived from the North American continental margin to the east [McCoy, 1983], and their low density affects the gravity signature. Sediment thicknesses reach $\sim 500 \mathrm{~m}, 150 \mathrm{~km}$ to the east of the ridge axis versus $\sim 250 \mathrm{~m}$ at the same distance on the western side of the ridge [Ludwig and Houtz, 1976]. The turbidites also flow, via the Cascadia channel, through a small pull-apart basin in the Blanco Fracture Zone (the Cascadia Depression) onto the Tufts Abyssal Plain to the west of the Gorda Ridge [Embley and Wilson, 1992]. Within this region, sediment thicknesses range from $\sim 400 \mathrm{~m}$ in the NW corner to $\sim 100 \mathrm{~m}$ in the SW. East of the Gorda Ridge sediments also thicken very rapidly reaching $1-2 \mathrm{~km}$ over the subduction trench at the continental margin.

The Juan de Fuca/Gorda area is part of a classic magnetic anomaly study region [Raff and Mason, 1961; Vine and Matthews, 1963], and the spreading rates and tectonic history of this area have been well characterized [Hey and Wilson, 1982; Wilson and Hey, 1984; Wilson, 1988, 1993]. The tectonic evolution of the Juan de Fuca Ridge over the past $18 \mathrm{Ma}$ has been dominated by a southward propagating rift that intersected the Blanco Fracture Zone at $1.5 \mathrm{Ma}$ [Wilson, 1988]. Within the Bruhnes the Vance Segment has been accreting at a nearly symmetric rate of $28.5 \mathrm{~mm} / \mathrm{yr}$, while the Cleft Segment is spreading faster to the west $(28.5 \mathrm{~mm} / \mathrm{yr})$ than to the east $(23.2$ $\mathrm{mm} / \mathrm{yr}$ ) [Tivey, 1994]. Early interpretation of magnetic anomalies across the Gorda Ridge revealed half spreading rates
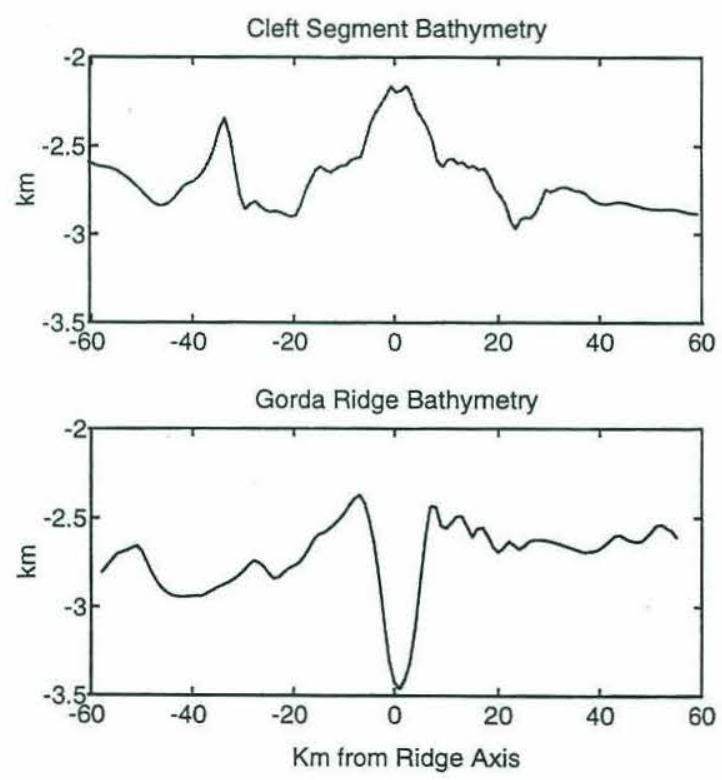

Figure 2. Bathymetry profiles across the central portion of the axis of the Cleft Segment of the Juan de Fuca Ridge and the northern segment of the Gorda ridge. The location of these profiles is shown by black lines in Figure 1. The Cleft Segment has an axial high of $\sim 300 \mathrm{~m}$ with a small graben at the summit, typical of the morphology of fast spreading ridges. In contrast, the northern segment of the Gorda Ridge exhibits a rift valley of $\sim 1 \mathrm{~km}$ depth, similar to the morphology of the slow spreading Mid-Atlantic Ridge. varying from $30 \mathrm{~mm} / \mathrm{yr}$ on the northern section of the ridge to 10 $\mathrm{mm} / \mathrm{yr}$ on the southern Gorda Ridge [Atwater and Mudie, 1973; Riddihough, 1980]. Kinematic plate modeling by Wilson [1986] indicates deformation (crustal shortening) of the southernmost section of the Gorda "plate" near the Mendocino transform. The northern Gorda Ridge appears to have escaped this tectonic complexity [Masson et al., 1988], and its spreading rate is comparable to the southern Juan de Fuca Ridge.

Despite their similar spreading rates the Juan de Fuca and Gorda spreading centers have distinctly different morphologies, with the Juan de Fuca Ridge generally characterized by a rifted, axial high while the Gorda Ridge is associated with a rift valley (Figure 2). The Endeavour, Northern Symmetrical Segment, Axial, Vance, and Cleft Segments of the Juan de Fuca Ridge exhibit a rifted axial high morphology, though the rift on the Cleft Segment is subdued. West Valley at the northern end of the Juan de Fuca Ridge has a rift valley. The along axis bathymetry of most of the central and southern Juan de Fuca Ridge is comparatively flat except for the presence of Axial Seamount. Only the Endeavour and West Valley Segments show significant along axis variations in axial depth. Recent changes in the location of the spreading axis of the northern portion of the Juan de Fuca Ridge may complicate the interpretation of the morphology of West Valley [Davis and Currie, 1993; K.M.M. Rohr and K.P. Furlong, Birth of a triple junction, death of a plate: Tectonics of the Queen Charlotte triple junction, submitted to Geology, 1995]. The character of the Endeavour segment may be affected by an increased melt supply as a result of overriding the Heckle melting anomaly [Karsten, 1988] which has created the Heckle seamount chain on the Pacific plate to the west of the ridge. In contrast, all three segments of the Gorda Ridge have rift valleys reminiscent of the slow spreading Mid-Atlantic Ridge. The variation in axial depth along the axis of the Gorda Ridge is also similar to a slow spreading ridge with a deeper rift valley near the segment ends than at the segment mid-point.

There is also a pronounced difference in seismicity between the Juan de Fuca Ridge and Gorda Ridge that parallels the differences in axial morphology. While the Juan de Fuca Ridge is remarkably aseismic, the Gorda Ridge is very seismically active with microearthquake focal depths extending to the mantle ( $7 \pm 2 \mathrm{~km}$ [Johnson and Lewis, 1984] or $15 \pm 2 \mathrm{~km}$ depth [Solano and Bibee, 1985]). The earthquake density per $55 \mathrm{~km}$ of ridge length normal to the transform direction was 15-20 times greater along the Gorda Ridge than along the Juan de Fuca Ridge during the period 1961-1969 [Environmental Science Services Administration, 1970]. Recent monitoring of the northeast Pacific using the more sensitive military Sounds Surveillance System (SOSUS) hydrophone arrays has confirmed the relative seismic quiescence of the Juan de Fuca Ridge compared to the Gorda Ridge [Fox et al., 1994].

The differences in axial morphology and seismicity are consistent with the presence of a stronger axial lithosphere beneath the Gorda Ridge than along most of the Juan de Fuca Ridge. This variation of lithospheric rheology, despite very similar spreading rates, may be due to differences in crustal thickness or thermal structure or some combination of these two effects. Few seismic constraints exist on the changes in crustal structure or thickness between the Juan de Fuca and Gorda Ridges. Most recent seismic work on the Juan de Fuca Ridge has focused on the structure of the middle and upper crust [McClain and Lewis, 1982; Morton et al., 1987; Cudrak, 1988; Rohr et al., 1988; White and Clowes, 1990; Christeson et al., 1993; Cudrak and Clowes, 1993; McDonald et al., 1994]. The thermal 
HOOFT AND DETRICK: JUAN DE FUCA AXIAL MORPHOLOGY VARIATIONS

structure of the crust can be estimated from the presence or absence of a magma body in the crust. However, evidence of crustal magma bodies similar to those found along the morphologically similar East Pacific Rise [Detrick et al., 1987; 1993] is equivocal. No seismic constraints exist on the presence of crustal magma bodies along the Gorda Ridge nor is seismic data available to determine if a systematic difference in crustal thickness exists between the Juan de Fuca and Gorda Ridges. We will use gravity data in this paper to determine the relative variations in crustal thickness and mantle thermal structure between the Juan de Fuca and Gorda Ridge.

\section{Free Air Gravity and Bathymetry}

Bathymetry and free air gravity anomaly maps for the Juan de Fuca and Gorda Ridges are shown in Figure 1 and Plate 1. The bathymetry map (Figure 1) was compiled over the region within $125^{\circ}-132^{\circ} \mathrm{W}$ and $41.5^{\circ}-49^{\circ} \mathrm{N}$. It covers the entire Juan de Fuca Ridge from the Sovanco Fracture Zone down to the Blanco Fracture Zone and the northern half of the Gorda Ridge. The trench on the western margin of the North American continent forms the eastern boundary of the mapped region. To the west of the Juan de Fuca Ridge the map covers ocean floor of ages $5 \mathrm{My}$ and younger. The compiled data include shipboard bathymetry extracted from the National Geophysical Data Center (NGDC) and multibeam bathymetry extracted from the Lamont-Doherty Earth Observatory RIDGE (Ridge InterDisciplinary Global Studies) multibeam data synthesis [Keeley et al., 1994]. Between ship tracks the bathymetry was supplemented with DBDB5 data (Digital Bathymetric Data Base 5). Where multibeam bathymetry existed the NGDC bathymetry was not used. All of the data were resampled at a grid spacing of $1 \mathrm{~km}$ and then the surface-fitting-under-tension algorithm of the Generic Mapping Tools (GMT) program [Smith and Wessel, 1990] was applied to obtain the final bathymetric map (Figure 1). The accuracy of this map varies widely, being accurate to $\sim 50 \mathrm{~m}$ over the ridge crest, which is entirely mapped with multibeam data, and degrading into regions that were filled using the DBDB5 data.

Shipboard free air gravity data from the NGDC database were compiled in two subregions which are centered on the Juan de Fuca and Gorda Ridges, $128^{\circ}-132^{\circ} \mathrm{W}, 44^{\circ}-49^{\circ} \mathrm{N}$ and $125^{\circ}$ $129^{\circ} \mathrm{W}, 41.5^{\circ}-44^{\circ} \mathrm{N}$ respectively (Plate 1 ). To improve the internal consistency of the gravity data, we use the method of Prince and Forsyth [1984] to minimize discrepancies in gravity measurements at ship track crossings. We estimate the data uncertainty to be $5 \mathrm{mGal}$ based on the rms crossover error. After applying appropriate shifts to continuous segments of ship data, we gridded the gravity data using the surface-fitting-undertension algorithm of the GMT program [Smith and Wessel, 1990] with a grid spacing of 1 arc $\min \left(=\sim 0.0167^{\circ}\right)$. The resulting gravity maps are shown in Plates la and $1 \mathrm{~b}$. These maps are accurate near the ship tracks which are shown in black dots since no gravity data exist between ship tracks.

\section{Gravity Reduction}

The calculation of mantle Bouguer anomalies (MBA) and residual mantle Bouguer anomalies (RMBA) follow the procedure developed by Prince and Forsyth [1988] and Kuo and Forsyth [1988]. Table 1 summarizes the values of the parameters assumed in these calculations. The theoretical gravity field was calculated over the entire region of the bathymetry map. Because mirroring of the grids introduces bias from the nonperiodic structure due to the trench in calculating the Fourier transforms for the theoretical gravity field, the grid was padded using a linear gradient. Along the ship tracks the theoretical gravity signature was subtracted from the free air gravity to obtain the $M B A$ and RMBA. These anomalies were then gridded within the two subregions in the same way as the gravity data ( 1 arc min grid spacing) to obtain maps of the MBA and RMBA. This procedure ensures that the long wavelength gravity signature of the topography is retained in the theoretical correction and that the MBA and RMBA over the two ridge segments are comparable having been calculated relative to the same reference levels.

Mantle Bouguer anomaly maps for the Juan de Fuca and Gorda Ridges are shown in Plates 1c and 1d. Again, these maps are accurate near the ship tracks which are shown with black dots. Calculation of the MBA removes most of the short wavelength variations caused by local topography leaving a broad, oval-shaped, negative anomaly aligned along the spreading axis of the Juan de Fuca Ridge (Plate 1c). The anomaly is most negative $(\sim-60 \mathrm{mGal})$ over Axial Seamount at $46^{\circ} \mathrm{N}$ and gradually becomes more positive south toward the Blanco Transform. The MBA on the Gorda Ridge is also most negative along the ridge axis, becoming more positive toward the Blanco Fracture Zone.

Off the axes of the Juan de Fuca and Gorda Ridges the MBA becomes more positive, especially west of the ridge crest. The increase in MBA off axis is primarily due to increases in density of the lithosphere which thickens and cools as it ages. However, part of the gradient in MBA seen to the southwest of the Juan de Fuca Ridge reflects crustal age differences due to the southward propagation of the ridge from 18-1.5 Ma [Wilson, 1988]. Neither the effects of lithospheric cooling nor ridge propagation are clearly observed on the eastern side of the ridge where the basaltic crust becomes rapidly buried with sediments that flood the plate from the continental margin [Ludwig and Houtz, 1976]. The low density of the sediments (relative to the igneous crust) lead to an artificially low MBA value. Owing to the effects of both extensive sediment coverage off axis and ridge propagation on the MBA signal, we only analyze along axis gravity profiles in this paper.

The RMBA is calculated by removing the effects of lithospheric cooling with age and heat conduction across ridge offsets from the MBA. The along axis bathymetry, free air gravity, MBA, and RMBA are shown in Figure 3 plotted versus distance north of the Blanco Fracture Zone. In an along axis profile the RMBA corrects the MBA for cooling at ridge offsets. When the effect of cooling against the Blanco Fracture Zone is removed from the MBA, the RMBA signature along the Cleft and Vance Segments is almost flat. The RMBA beneath Axial Seamount is $-50 \mathrm{mGal}$ and is localized within $100 \mathrm{~km}$ of the seamount. It increases to the north and south where the anomaly flattens. The RMBA on the Gorda Ridge is elevated by 10-20 $\mathrm{mGal}$ relative to the Cleft and Vance Segments indicating thinner crust and/or colder mantle.

\section{Modeling of Residual Mantle Bouguer Anomalies}

We interpret the gravity fields over the Juan de Fuca and Gorda Ridges according to two models for the density structure. In the first model the density variations creating the observed RMBA are attributed only to changes in the thickness of a constant density crust overlying a constant density mantle. In the second model, lateral variations in both crustal thickness and 

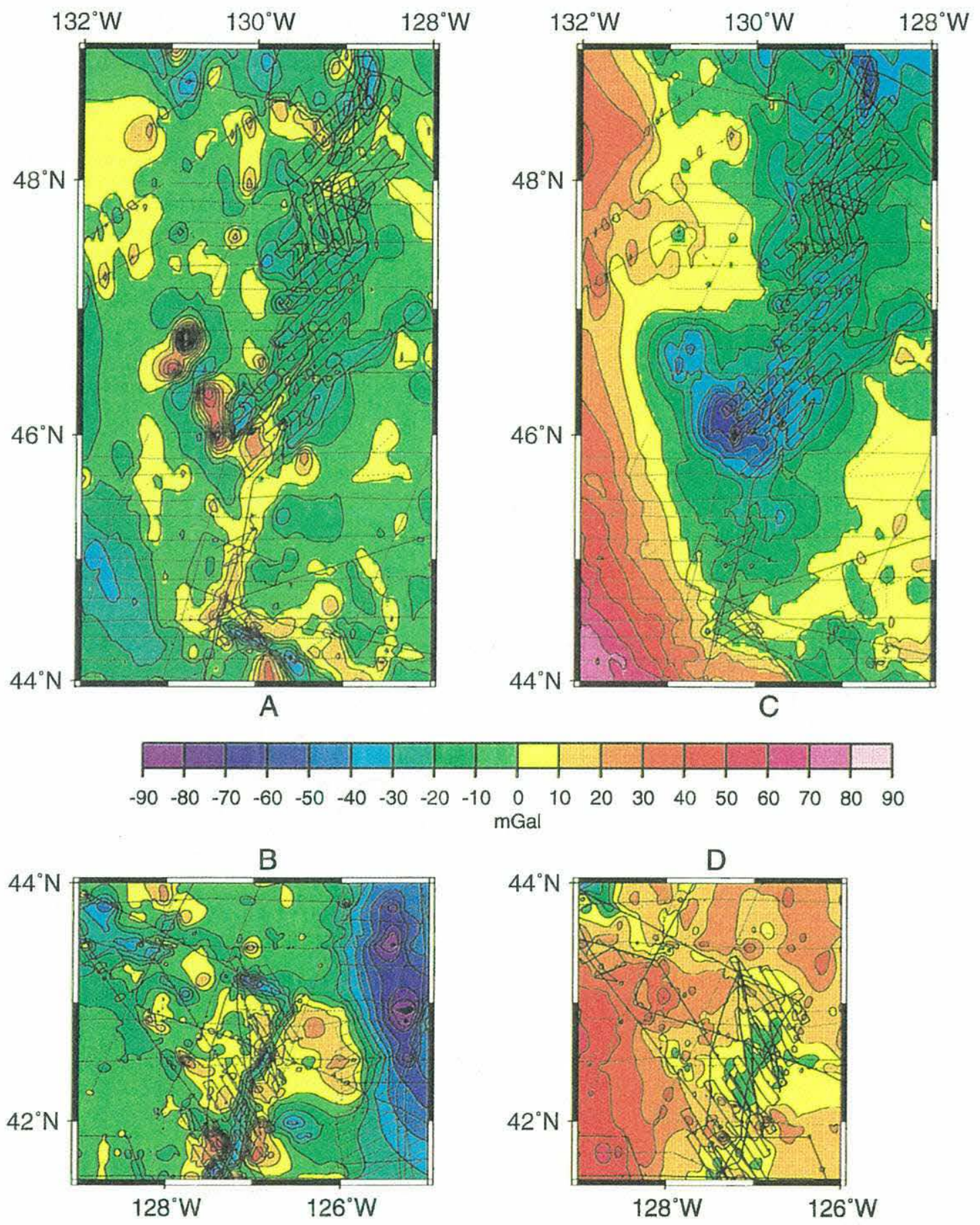

Plate 1. (a) and (b) Free air gravity and (c) and (d) mantle Bouguer anomalies (MBA) over the Juan de Fuca and Gorda Ridges. Grid spacing is 1 arc min; contour interval is $10 \mathrm{mGal}$. Shipboard free air gravity data from the NGDC data base were compiled in two subregions of the bathymetry map centered over the Juan de Fuca and the Gorda Ridges. These free air gravity maps are only accurate near the ship tracks which are shown by black dots. The free air gravity mimics the topography. The MBA is most negative over Axial Seamount, gradually becoming more positive toward the Blanco Fracture Zone. The MBA over the Gorda Ridge is also most negative along the ridge axis, becoming more positive toward the Blanco Fracture Zone. MBA over the Gorda Ridge are more positive than over the southern Juan de Fuca ridge indicating thinner crust and/or colder mantle. 
HOOFT AND DETRICK: JUAN DE FUCA AXIAL MORPHOLOGY VARIATIONS

Table 1. Values of Model Parameters

\begin{tabular}{ll}
\hline \multicolumn{1}{c}{ Parameter } & \multicolumn{1}{c}{ Value } \\
\hline Gravitational constant & $6.6673 \times 10^{-11} \mathrm{~N} \mathrm{~m}^{2} / \mathrm{kg}^{2}$ \\
Gravitational acceleration & $9.80 \mathrm{~m} / \mathrm{s}^{2}$ \\
Water/crust density contrast & $1700 \mathrm{~kg} / \mathrm{m}^{3}$ \\
Crust/mantle density contrast & $600 \mathrm{~kg} / \mathrm{m}^{3}$ \\
Mean crustal thickness & $6 \mathrm{~km}$ \\
Half spreading rate & $28 \mathrm{~mm} / \mathrm{yr}$ \\
Mantle viscosity & $10^{19} \mathrm{~Pa} \mathrm{~s}$ \\
Mean asthenospheric temperature & $1350^{\circ} \mathrm{C}$ \\
Coefficient of thermal expansion & $3.4 \times 10^{-5} /{ }^{\circ} \mathrm{C}$ \\
\hline
\end{tabular}

mantle density are controlled by temperatures in the upper mantle where decompression melting occurs. Model 1 is an example of dynamic upwelling [e.g., Sparks and Parmentier, 1993] where along axis variations in upwelling rate generate crustal thickness variations; in the extreme case there need be no changes in mantle temperature. Model 2 is representative of a passive flow model where crustal thickness changes are the result of along axis variations in mantle temperature.

\section{Model 1: Crustal Thickness Variations Only}

RMBA are traditionally downward continued to obtain the crustal thickness variations required to explain the observed gravity field [Kuo and Forsyth, 1988]. We downward continue the RMBA to $6 \mathrm{~km}$ below the seafloor after applying a low-pass filter with a cosine taper between 35 and $45 \mathrm{~km}$. The crustal thickness variations are thus referenced to a "normal" crustal thickness of $6 \mathrm{~km}$. The results are shown in Figure 4a. The crust beneath Axial Seamount is inferred to be $\sim 2 \mathrm{~km}$ thicker than the assumed mean thickness of $6 \mathrm{~km}$. The crustal root under Axial Seamount extends over $100 \mathrm{~km}$ along axis, slightly wider than its bathymetric expression $(\sim 80 \mathrm{~km})$. The crust/mantle interface is

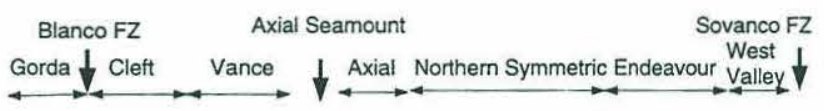

A

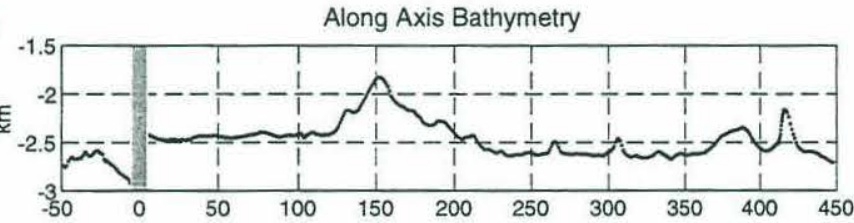

B

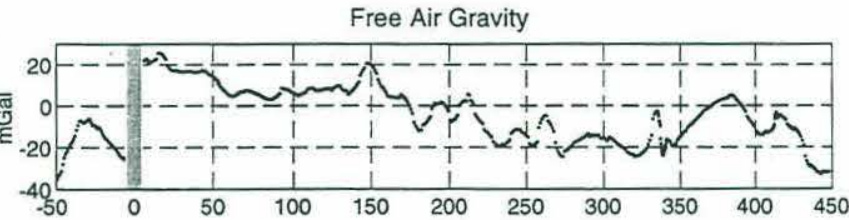

C

Mantle Bouguer Anomaly

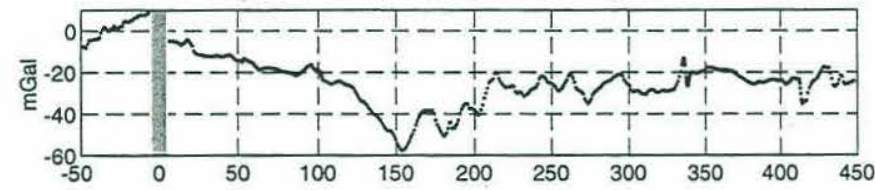

D

Residual Mantle Bouguer Anomaly

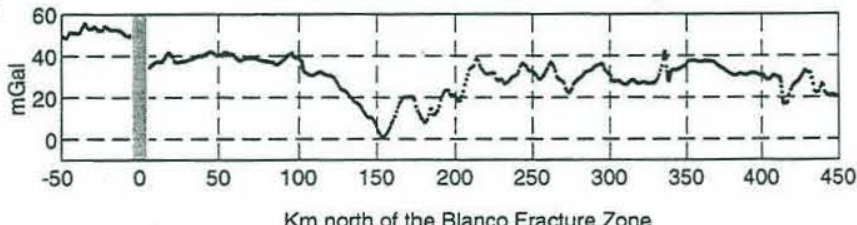

Figure 3. Along-axis profiles of bathymetry, free air gravity, MBA, and RMBA plotted versus distance north of the Blanco Fracture Zone, measured along the ridge as on Figure 1. The Blanco Fracture Zone is indicated by the gray bar. The Vance and Cleft Segments have a very flat along axis topography. In contrast, the northern Gorda Segment has a bowed along axis topography, shallower at the segment center than at its ends. The corresponding MBA is most negative ( $\sim 60 \mathrm{mGal})$ over Axial Seamount and gradually becomes more positive towards the Blanco Transform. The MBA on the Gorda Ridge also increases sharply towards the fracture zone. When the effect of cooling against the Blanco Fracture Zone is removed from the MBA, the RMBA signature is almost flat along the Cleft and Vance Segments. The RMBA on the Gorda Ridge is elevated by $10-20 \mathrm{mGal}$ relative to the Cleft and Vance Segments indicating thinner crust and/or colder mantle. 


\section{HOOFT AND DETRICK: JUAN DE FUCA AXIAL MORPHOLOGY VARIATIONS}

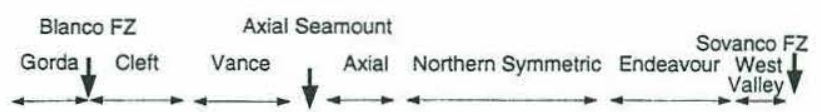

Model 1

A Crustal Thickness

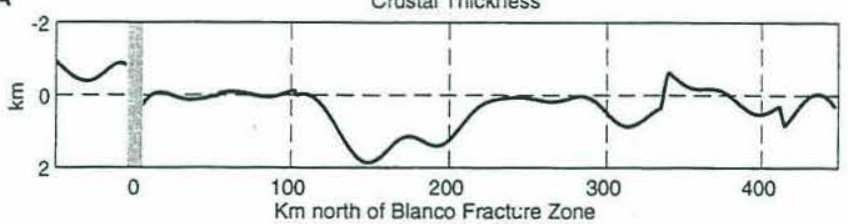

Model 2

B

Crustal Thickness

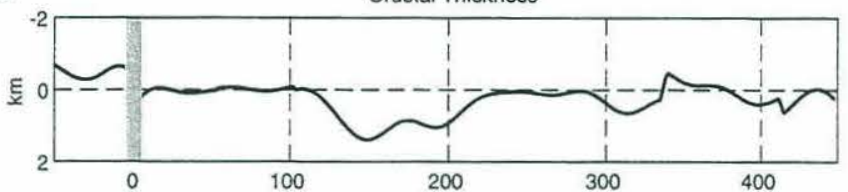

C Thermal Anomaly

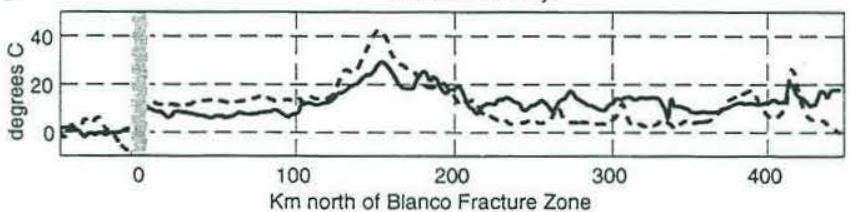

Figure 4. (a) Model 1: Predicted variations in crustal thickness assuming that the observed RMBA is due only to changes in the thickness of a constant density crust overlying a constant density mantle. Beneath Axial Seamount the crust is $-2 \mathrm{~km}$ thicker than the "normal" crustal thickness of $6 \mathrm{~km}$. The Moho is very flat along the Cleft and Vance Segments as is typical of fast spreading ridges. Along the northern Gorda Ridge, crust is thickest at the center of the segment and thinner at the ends of the segment (by $\sim 500 \mathrm{~m}$ ), as is commonly observed along slow spreading ridge segments. Crust on the Cleft Segment is thicker than that on the northern Gorda Segment by $0.5-1$ $\mathrm{km}$. (b) Model 2: The predicted variation in crustal thickness is shown assuming that both mantle density and crustal thickness variations are controlled by mantle temperature [Ito and Lin, 1995]. Crustal thickness variations account for $70 \%-75 \%$ of the RMBA signal; the remainder is due to temperature-related mantle density variations. (c) Shows the along axis mantle temperature variations required to explain the observed RMBA (solid line) and calculated by assuming that the axial topography is isostatically compensated (dashed line). Note the small differences in crustal thickness and mantle temperature between the Cleft and Vance Segments, which have an axial high, and the northern Gorda Ridge, which has a rift valley.

very flat along the Cleft and Vance Segments as is typical of fast spreading ridges. Along the northern Gorda Ridge, crust is thickest at the center of the segment and thinner at the ends of the segment (by $\sim 500 \mathrm{~m}$ ), as is commonly observed along slow spreading ridge segments [e.g., Lin et al., 1990]. Crust on the Cleft and Vance Segments is $0.5-1 \mathrm{~km}$ thicker than on the northern Gorda Segment. This difference in crustal thickness is a maximum estimate and assumes that none of the observed density variations are due to variations in crustal or mantle density. Thus at most, the large difference in axial morphology between the southern Juan de Fuca and Gorda Ridges is associated with a difference in average crustal thickness of about a kilometer.

\section{Model 2: Crustal Thickness and Mantle Temperature} Variations

Crustal thickness variations may- result from mantle thermal anomalies which affect the amount of decompression melting and also the density structure of the upper mantle. The presence of a mantle thermal anomaly is suggested by analyses of lavas along the Juan de Fuca Ridge. The composition of basalts from the Juan de Fuca Ridge and Axial Seamount are transitional between normal (N-type) and enriched (E-type) mid-ocean ridge basalt and quite variable along axis, indicating a heterogeneous mantle source [Morgan, 1985]. There is no evidence in the seamount lavas for geochemical or isotopic enrichment typical of hotspot or mantle plume activity. However, elevated values of $\mathrm{Na}_{2} \mathrm{O}, \mathrm{CaO}$ and $\mathrm{Sr}$, at a given $\mathrm{MgO}$ content, differentiate the seamount lavas from those of the adjoining ridge segments [Rhodes et al., 1990], suggesting that it is associated with a zone of anomalously warm mantle. These observations suggest that both crustal thickness variations and temperature-related mantle density variations may be responsible for the observed gravity anomalies.

Ito and Lin [1995] developed a model in which crustal thickness and mantle density variations are both controlled by mantle temperature: crustal thickness by temperature enhanced melting and mantle density by thermal expansion. The linear melting function in their model, which incorporates passive mantle flow, heat transport, and decompression melting, gives 


\section{HOOFT AND DETRICK: JUAN DE FUCA AXIAL MORPHOLOGY VARIATIONS}

rise to a linear relationship between mantle temperature, $\Delta \mathrm{T}$ at a depth of $100 \mathrm{~km}$, variations in MBA, $\triangle \mathrm{MBA}$, and bathymetry, $\Delta \mathrm{H}$ :

$$
\begin{array}{ll}
\Delta \mathrm{T}(\mathrm{MBA})=-0.576 \Delta \mathrm{MBA} & \sigma \text { misfit }<3^{\circ} \mathrm{C} \\
\Delta \mathrm{T}(\mathrm{H})=48.3 \Delta \mathrm{H} & \sigma \text { misfit }<3^{\circ} \mathrm{C}
\end{array}
$$

Using these predicted relationships we estimated the along axis variations in crustal thickness and mantle temperature required to explain the RMBA observed along the Juan de Fuca and Gorda Ridges (Figures $3 c$ and $3 \mathrm{~d}$ ). We use the RMBA instead of the MBA to account for the cooling effect at segment ends. Calculated crustal thickness variations (Figure $4 \mathrm{~b}$ ) now give rise to $70 \%-75 \%$ of the RMBA signal. The remaining $25 \%$ $30 \%$ of the topography and gravity signal is supplied by the anomalously hot and less dense mantle beneath the rise axis. The solid line in Figure $4 \mathrm{c}$ shows the along axis mantle temperature variations $(\triangle T(R M B A))$ required to explain the observed RMBA calculated from (1). An independent estimate of the along axis variations in mantle temperature $(\Delta \mathrm{T}(\mathrm{H}))$, shown by the dashed line in Figure 4c, was made from (2) which includes the assumption that the axial topography is isostatically compensated. For this calculation axial depth was averaged over a 30-km-wide across-axis zone to minimize errors that might be introduced if dynamic stresses are contributing to axial relief. The two estimates show the same long-wavelength characteristics with the highest mantle temperatures beneath Axial Seamount, progressively cooler temperatures north and south along the Juan de Fuca Ridge away from Axial Seamount, and the lowest mantle temperatures beneath the Gorda Ridge. The bathymetrically derived $\Delta \mathrm{T}$ estimate displays more along axis variation than the RMBA-derived estimate. This is because the bathymetry contains more short wavelength energy than the gravity field. The difference between the two mantle temperature estimates (e.g., along the Cleft segment) could indicate some dynamic support for the along axis depth variations.

The results presented in Figure 4 provide the best available constraints on the differences in crustal thickness and mantle temperature along the Gorda/Juan de Fuca ridge system. Mantle temperature beneath Axial Seamount may be elevated by as much as $30^{\circ}-40^{\circ} \mathrm{C}$, and the crust may be up to $30 \%$ thicker than that formed elsewhere along the Juan de Fuca Ridge. The mantle thermal and crustal thickness anomaly associated with Axial Seamount decays rapidly along the Juan de Fuca Ridge, and the Cleft and Vance Segments are associated with crust that is only $300-700 \mathrm{~m}$ thicker and with mantle temperatures that are only $10^{\circ}-15^{\circ} \mathrm{C}$ higher than that estimated beneath the northern Gorda Ridge. Model 1 represents the maximum possible crustal thickness variations, yet the difference in crustal thickness between the northern Gorda and southern Juan de Fuca Ridges is only $0.5-1 \mathrm{~km}$. Thus our results suggest that comparatively small differences in crustal thickness and/or mantle temperature can produce dramatic changes in axial morphology at these intermediate spreading rates. In the following section we compare these observations with model predictions of how changes in crustal thickness affect the rift valley/no rift valley transition. We also consider the origin of the variation in crustal thickness and mantle temperature inferred along the Gorda/Juan de Fuca ridge system.

\section{Discussion}

A number of different mechanisms have been proposed to explain why some mid-ocean ridges have rift valleys and others do not [e.g., Sleep, 1969; Lauchenbruch, 1973; Tapponnier and Francheteau, 1978; Sleep and Rosendahl, 1979; Phipps Morgan et al., 1987; Chen and Morgan, 1990]. Over the past few years a growing consensus has developed around a hypothesis originally proposed by Tapponnier and Francheteau [1978] that median valleys form as a result of stretching and thinning of the lithosphere at the ridge axis. Chen and Morgan [1990] showed that a combination of brittle-plastic and viscous rheologies undergoing extension at a slow spreading ridge can produce an axial valley of the right dimensions provided that the crust is cool enough to behave in a brittle fashion. At higher spreading rates, like those found along the East Pacific Rise, they propose that a thin, brittle surface layer is decoupled from the stronger mantle below by the presence of a crustal magma body and a hot, ductile lower crust. The reduced strength of the crust allows local isostatic forces to create an axial high. This model has recently been refined by Phipps Morgan and Chen [1993a, b] and Neumann and Forsyth [1993] and extended to explore the effect of variable crustal thickness on the thermal and rheological properties of zero-age lithosphere and axial morphology. According to these models the transition in axial morphology from rift valley to axial high depends critically on the thermal structure of the rise axis, which will be controlled by the balance between heat supplied by magmatic intrusion and solidification and heat removed by hydrothermal circulation.

Our observations on the Juan de Fuca/Gorda system, which is spreading at an intermediate half rate of $28 \mathrm{~mm} / \mathrm{yr}$, support the sharp transition in ridge morphology predicted by the Phipps Morgan and Chen [1993b] model. The gravity data show no large difference in density structure between the two ridges. Variations in crustal thickness are at most $\sim 1 \mathrm{~km}$. If a mantle thermal anomaly is postulated as the source of these crustal thickness variations and the density anomalies are partitioned in a reasonable way between mantle thermal density variations and crustal thickness variations [Ito and Lin, 1995], then the differences in average crustal thickness between the southern Juan de Fuca and the northern Gorda Ridge may be as small as $300-700 \mathrm{~m}$. Thus our results support predictions that the transition from rift valley to axial high will occur abruptly with a small change in crustal thickness and/or mantle temperature at intermediate spreading rates.

The crustal thickness and mantle temperature variations we have inferred along the Gorda/Juan de Fuca Ridge system may be related to the presence of the Cobb thermal anomaly beneath the central Juan de Fuca Ridge (Figure 5). The Cobb hotspot has been proposed as the source of the Cobb-Eickelberg seamount chain which intersects the Juan de Fuca Ridge at $46^{\circ} \mathrm{N}$ [Duncan and Clague, 1985; Smoot, 1985]. Axial Seamount lies at the intersection of the Cobb Eickelberg seamount chain and the Juan de Fuca Ridge, and it is believed to mark the present location of the Cobb hotspot. The thermal anomaly associated with the Cobb hotspot, which we estimated in this study to be about $30^{\circ}$ $40^{\circ} \mathrm{C}$, appears to influence a large portion of the Juan de Fuca Ridge, perhaps through along axis channeling of the hotter, upwelling mantle along the ridge axis as originally proposed by Vogt and Johnson [1975]. The Gorda Ridge may be isolated from the influence of the Cobb thermal anomaly by the $400-\mathrm{km}$ long Blanco Transform which blocks the southward flow of this material.

The hotter upwelling along the Juan de Fuca Ridge results in the formation of thicker crust than along the Gorda Ridge because of a greater extent of decompression melting. This effect is most pronounced beneath Axial Seamount where the crust is $\sim 30 \%$ thicker than normal. Elsewhere along the Juan de Fuca 


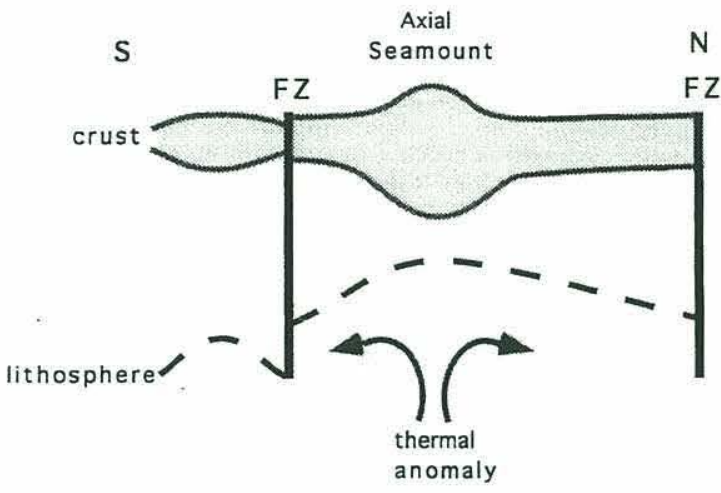

Figure 5. Cartoon illustrating the effect of the Cobb thermal anomaly located under Axial Seamount on the Juan de Fuca Ridge. Hotter upwelling mantle results in warmer, less dense mantle, a thinner lithosphere, more decompression melting, and a thicker crust beneath the Juan de Fuca Ridge. The weak lithosphere forms an axial high. The Blanco Fracture Zone isolates the Gorda Ridge from the influence of the Cobb thermal anomaly. On the northern Gorda Ridge, crust is thinner, the mantle is colder, and the lithosphere is thicker. The colder thermal regime results in a stronger lithosphere which deforms to produce a rift valley.

Ridge (except perhaps at West Valley), the crust may be up to $700 \mathrm{~m}$ thicker than that forming along the northern Gorda Ridge where the mantle is colder. The thicker crust and hotter mantle result in the formation of thinner, weaker lithosphere along the Juan de Fuca Ridge than at the Gorda Ridge. The stronger lithosphere found along the Gorda Ridge can deform by brittleplastic necking leading to the formation of a rift valley, while the weaker, thinner lithosphere along the Juan de Fuca Ridge is locally compensated forming an axial high.

\section{Conclusions}

The southern Juan de Fuca Ridge has an axial high morphology, typical of faster spreading ridges, while the northem Gorda Ridge has a rift valley morphology, as is found at slower spreading ridges, even though they are opening at the same spreading rate $(28 \mathrm{~mm} / \mathrm{yr}$ half rate). The Gorda Ridge is also characterized by much higher levels of seismicity suggesting the presence of a thicker, stronger lithosphere. Residual mantle Bouguer anomalies along the northern Gorda Ridge are elevated 10-20 mGal relative to the southern Juan de Fuca Ridge indicating the presence of a thinner crust and/or colder mantle. We attribute these systematic differences in axial morphology, gravity, and seismicity to along axis variations in crustal thickness, mantle temperature, and lithospheric strength due to the presence of the Cobb thermal anomaly at Axial Seamount along the central Juan de Fuca Ridge. We estimate that mantle temperatures beneath Axial Seamount are elevated $30^{\circ}-40^{\circ} \mathrm{C}$ and the crust is $\sim 30 \%$ thicker than that forming elsewhere along the Juan de Fuca Ridge. The mantle thermal and crustal thickness anomalies associated with the Cobb thermal anomaly decay rapidly along axis and the Vance and Cleft Segments at the southern end of the Juan de Fuca Ridge are associated with crust that is only $300-700 \mathrm{~m}$ thicker and mantle temperatures that are only $10^{\circ}-15^{\circ} \mathrm{C}$ higher than that estimated beneath the Gorda Ridge. Even when all of the along axis gravity anomaly is attributed to crustal thickness variations, the maximum difference in crustal thickness between the Gorda and southern Juan de Fuca Ridge is only $\sim 1 \mathrm{~km}$. The thicker crust and hotter mantle along the Juan de Fuca Ridge result in the formation of a thinner, weaker axial lithosphere than at the Gorda Ridge. Although the differences in crustal thickness $(\sim 0.5 \mathrm{~km})$ and/or mantle temperature $\left(10^{\circ}-15^{\circ} \mathrm{C}\right)$ that we infer between the Juan de Fuca and Gorda Ridges are not large, they are sufficient to produce a major change in lithospheric strength and axial morphology at intermediate spreading rates.

Acknowledgments. We thank Chris Fox, Garrett Ito, and Jian Lin for helpful discussions. The manuscript was improved by the thoughtful reviews of Donna Blackman and Kristin Rohr and the Associate Editor. This work was supported by National Science Foundation grant OCE9402033. WHOI contribution 9039.

\section{References}

Atwater, T., Implications of plate tectonics for the Cenozoic tectonic evolution of western North America, Geol. Soc. Am. Bull., 81, 35133536,1970

Atwater, T.M., and J. Mudie, Detailed near-bottom geophysical study of the Gorda Rise, J. Geophys. Res., 78, 8665-8686, 1973.

Blackman, D.K., and D.W. Forsyth, Isostatic compensation of tectonic features of the Mid-Atlantic Ridge: $25-27^{\circ} 30^{\prime}$ S, J. Geophys. Res., 96 , $11,741-11,758,1991$.

Brace, W.F., and D.L. Kohlstedt, Limits on lithospheric stress imposed by laboratory experiments, J. Geophys. Res., 85, 6248-6252, 1980.

Chen, Y., and W.J. Morgan, Rift valley/no rift valley transition at midocean ridges, J. Geophys. Res., 95, 17.583-17,604, 1990.

Christeson, G.L., G.M. Purdy, and K.M.M. Rohr, Structure of the Northern Symmetrical Segment of the Juan de Fuca Ridge, Mar Geophys. Res., 15, 219-240, 1993.

Cudrak, C.F., Shallow crustal structure of the Endeavour Ridge Segment, Juan de Fuca Ridge, from a detailed seismic refraction survey, $\mathrm{Ph} . \mathrm{D}$. thesis, Univ. of British Columbia, Vancouver, B.C., 1988.

Cudrak, C., and R. Clowes, Crustal structure of Endeavour Ridge Segment, Juan de Fuca Ridge, from a detailed seismic refraction survey, J. Geophys. Res., 98, 6329-6350, 1993.

Davis, E.E., and R.G. Currie, Geophysical observations of the northern Juan de Fuca Ridge system: Lessons in sea-floor spreading, Can. J. Earth Sci., 30, 278-300, 1993.

Delaney, J.R., H.P. Johnson, and J.L. Karsten, The Juan de Fuca ridgehot spot-propagating rift system: New tectonic, geochemical, and magnetic data, J. Geophys. Res., 86, 11,747-11,750, 1981.

Detrick, R.S., P. Buhl, E.E. Vera, J.C. Mutter, J.A. Orcutt, J.A. Madsen, and T.M. Brocher, Multichannel seismic imaging of a crustal magma chamber along the East Pacific Rise, Nature, 326, 35-41, 1987.

Detrick, R.S., A.J. Harding, G.M. Kent, J.A. Orcutt, J.C. Mutter, and P. Buhl, Seismic Structure of the Southern East Pacific Rise. Science, 259, 499-503, 1993.

Duncan, R.A., and D.A. Clague, Pacific plate motion recorded by linear volcanic chains, in The Ocean Basins and Margins, vol. 7A, edited by A.E. Narin et al., pp. 89-121, Plenum, New York, 1985.

Embley, R.W., and D.S. Wilson, Morphology of the Blanco Transform Fault Zone - NE Pacific: Implications for its tectonic evolution, Mar. Geophys. Res., 14, 25-45, 1992.

Embley, R.W., S.R. Hammond, A. Malahoff, W.B.F. Ryan, K. Crane, and E. Kappel, Rifts of the southern Juan de Fuca, Eos Trans. AGU, $64,853,1983$.

Environmental Science Services Administration, World Seismicity 19611969, Natl. Earthquake Inf. Cent., U.S. Dep. of Commer., Washington, D.C., 1970

Fox, P.J., N.R. Grindlay, and K.C. MacDonald, The Mid-Atlantic Ridge $\left(31^{\circ} \mathrm{S}-34^{\circ} 30^{\prime} \mathrm{S}\right)$ : Temporal and spatial variations of accretionary processes, Mar. Geophys. Res., 13, 1-20, 1991.

Fox, C.F., R.P. Dziak, H. Matsumoto, and A.E. Schreiner, Potential for monitoring low-level seismicity on the Juan de Fuca Ridge using military hydrophone arrays, Mar. Technonl. Soc. J., 27, 22-30, 1994.

Hey, R.N., and D.S. Wilson, Propagating rift explanation for the tectonic evolution of the northeast Pacific - The pseudomovie, Earth Planet. Sci. Lett., 58, 167-188, 1982. 


\section{HOOFT AND DETRICK: JUAN DE FUCA AXIAL MORPHOLOGY VARIATIONS}

Hyndman, R.D., R.P. Riddihough, and R. Herzer, The Nootka fault zone a New plate boundary off western Canada, Geophys. J. R. Astr. Soc., 58, 667-683, 1979.

Ito, G.T., and J. Lin, Mantle temperature anomalies along the present and paleo-axes of the Galapagos spreading center as inferred from gravity analyses, J. Geophys. Res., 100, 3733-3745, 1995.

Johnson, D.A.L., and B.T.R. Lewis, Micro-earthquakes in the axial valley of the northern Gorda Ridge at $43^{\circ} \mathrm{N}$, Eos Trans. AGU, 65, 1111, 1984.

Karsten, J.L., Spatial and temporal variations in the petrology, morphology, and tectonics of a migrating spreading center: The Endeavour Segment, Juan de Fuca Ridge, Ph.D. thesis, 329 pp.,Univ. of Washington, Seattle, 1988.

Karsten, J.L., S.R. Hammond, E.E. Davis, and R.G. Currie, Detailed geomorphology and neotectonics of the Endeavour Segment, Juan de Fuca Ridge: New results from Seabeam swath mapping, Geol. Soc. Am. Bull., 97, 213-221, 1986.

Keeley, C., W.B.F. Bryan, W. Haxby, D. Caress, and W. Menke, RIDGE multibeam synthesis project, RIDGE Events, 5, 5, 1994.

Kirby, S.H., Rheology of the lithosphere, Rev. Geophys., 21, 1458-1487, 1983.

Kuo, B.-Y., and D.W. Forsyth, Gravity anomalies of the ridge-transform system in the South Atlantic between 31 and $34.5^{\circ} \mathrm{S}$ : Upwelling centers and variations in crustal thickness, Mar. Geophys. Res., 10, 205-232, 1988.

Lauchenbruch, A.H., A simple mechanical model for oceanic spreading centers, J. Geophys. Res., 78, 3395-3417, 1973.

Lin, J., G.M. Purdy, H. Schouten, J.-C. Sempéré, and C. Zervas, Evidence from gravity data for focused magmatic accretion along the MidAtlantic Ridge, Nature, 344, 627-632, 1990.

Ludwig, W.J., and R.E. Houtz, Isopach map of sediments in the Pacific Ocean basin and marginal seá basins, Am. Assoc. of Pet. Geol., Tulsa, Okla., 1976.

Macdonald, K.C., Mid-ocean ridges: Fine scale tectonic, volcanic and hydrothermal processes within the plate boundary zone, Annu. Rev. Earth Planet. Sci., 10, 155-190, 1982

Malahoff, A., R. Embley, S. Hammond, W Ryan, and K. Crane, Juan de Fuca and Gorda axial morphology and tectonics from combined Sea Beam and Sea Marc data, Eos Trans. AGU, 63, 1147, 1982.

Masson, D.G., D.A. Cacchione, and D.E. Drake, Tectonic evolution of Gorda Ridge inferred from sidescan sonar images, Mar. Geophys. Res., 10, 191-204, 1988.

McClain, K.J., and B.T.R. Lewis, Geophysical evidence for the absence of a crustal magma chamber under the northern Juan de Fuca Ridge: A contrast with ROSE results, J. Geophys. Res., 87, 8477-8489, 1982

McCoy, F.W., Seafloor sediment, in Geologic Map of the Circum-Pacific Region Northeast Quadrant scale 1:10,000,000, edited by K.J. Drummond, Assoc. of Pet. Geol., Tulsa, Okla. 1983.

McDonald, M.A., S.C. Webb, J.A. Hildebrand, B.D. Comuelle, and C.G. Fox, Seismic structure and anisotropy of the Juan de Fuca Ridge at $45^{\circ} \mathrm{N}, \mathrm{J}$. Geophys. Res., 99, 4857-4874, 1994.

Morgan, C., Geochemistry of basaits from the Cobb Hotspot astride the Juan de Fuca Ridge, M.S. thesis, 138 pp., Univ. of Mass., Amherst, 1985.

Morton, J.L., N.H. Sleep, W.R. Normark, and D.H. Tompkins, Structure of the southern Juan de Fuca Ridge from seismic reflection records, $J$. Geophys. Res., 92, 11,315-11,326, 1987.

Neumann, G.A., and D.W. Forsyth, The paradox of the axial profile: Isostatic compensation along the axis of the Mid-Atlantic Ridge?, $J$. Geophys. Res., 98, 17,891-17,910, 1993.

Phipps Morgan, J., and Y.J. Chen, The genesis of oceanic crust: Magma injection, hydrothermal circulation, and crustal flow, J. Geophys. Res., 98, 6283-6298, 1993a.

Phipps Morgan, J., and Y.J. Chen, Dependence of ridge-axis morphology on magma supply and spreading rate, Nature, 364, 706-708, 1993b.

Phipps Morgan, J., E.M. Parmentier, and J. Lin, Mechanism for the origin of mid-ocean ridge axial topography: Implications for the thermal structure of accreting plate boundaries, J. Geophys. Res., 92, 12,823$12,836,1987$
Prince, R.A., and D.W. Forsyth, A simple objective method for minimizing crossover errors in marine gravity data, Geophysics, 49, 10701083, 1984.

Prince, R.A., and D.W. Forsyth, Horizontal exent of anomalously thin crust near the Vema Fracture Zone from the three-dimensional analysis of gravity anomalies, J. Geophys. Res., 93, 8051-8063, 1988.

Raff, A.D., and R.G. Mason, Magnetic survey off the west coast of North America, $40^{\circ} \mathrm{N}$ latitude to $50^{\circ} \mathrm{N}$ latitude, Geol. Soc. Am. Bull., 72 , 1267-1270, 1961

Rhodes, J.M., C. Morgan, and R.A. Liias, Geochemistry of axial seamount lavas: magmatic relationship between the Cobb hotspot and the Juan de Fuca Ridge, J. Geophys. Res., 95, 12713-12733, 1990.

Riddihough, R., Gorda plate motions from magnetic anomaly analysis, Earth Planet. Sci. Lett., S1, 163-170, 1980.

Rohr, K.M.M., B. Milkereit, and C.J. Yorath, Asymmetric deep crustal structure across the Juan de Fuca Ridge, Geology, 16, 533-537, 1988.

Searle, R.C., and A.S. Laughton, Fine-scale sonar study of tectonics and volcanism on the Reykjanes Ridge, report, pp. 5-13, Inst. of Oceanogr. Sci., Leads, U.K., 1981,

Sempéré, J.M., J. Palmer, D. Christie, J. Phipps Morgan, and A. Shor, Australian-Antarctic Discordance, Geology, 19, 429-432, 1991.

Sleep, N.H., Sensitivity of heat flow and gravity to the mechanism of seafloor spreading, J. Geophys. Res., 74, 542-560, 1969.

Sleep, N.H., and B.R. Rosendahl, Topography and tectonics of mid-ocean ridge axes, J. Geophys. Res., 84, 6831-6839, 1979.

Small, C., and D.T. Sandwell, An abrupt change in ridge axis gravity with spreading rate, J. Geophys. Res., 94, 17,383-17,392, 1989.

Smith, W.H.F., and P. Wessel, Gridding with continuous curvature splines in tension, Geophysics, 55, 293-305, 1990.

Smoot, N.C., Observations on Gulf of Alaska seamount chains by multibeam sonar, Tectonophysics, 115, 235-246, 1985.

Solano, A., and D. Bibee, Seismicity of the Gorda Ridge, Eos Trans. $A G U, 66,24,1985$.

Sparks, D.W., and E.M. Parmentier, The structure of three-dimensional convection beneath oceanic spreading centers, Geophys. J. Int., I12, 81-91, 1993.

Tapponnier, P., and J. Francheteau, Necking of the lithosphere and the mechanics of slowly accreting plate boundaries, J. Geophys. Res., 83. 3955-3970, 1978

Tivey, M.A., Fine-scale magnetic anomaly field over the southern Juan de Fuca Ridge: Axial magnetization low and implications for crustal structure, J. Geophys. Res., 99, 4833-4855, 1994.

Vine, J.F., and D.H. Matthews, Magnetic anomalies over ocean ridges, Nature, 199, 947-949, 1963.

Vogt, P.R., and L. Johnson, Transform faults and longitudinal flow below the mid-oceanic ridge, J. Geophys. Res., 80, 1399-1428, 1975.

White, D.J., and R.M., Clowes, Shallow crustal structure beneath the Juan de Fuca Ridge from 2-D seismic refraction tomography, Geophys. $J$ Int., 100, 349-367, 1990.

Wilson, D.S., A kinematic model for the Gorda plate deformation zone as a diffuse southern boundary of the Juan de Fuca Plate, J. Geophys. Res., 91, 10,259-10,269, 1986.

Wilson, D.S., Tectonic history of the Juan de Fuca Ridge over the last 40 million years, J. Geophys. Res., 93, 11863-11876, 1988.

Wilson, D.S., Confidence intervals for motion and deformation of the Juan de Fuca Plate, J. Geophys. Res., 98, 16,053-16,071, 1993.

Wilson, D.S., and R.N. Hey, Propagation as a mechanism of reorientation of the Juan de Fuca Ridge, J. Geophys. Res., 89, 9215-9225, 1984.

R.S. Detrick and E.E.E. Hooft, Department of Geology and Geophysics, Woods Hole Oceanographic Institution, Woods Hole, MA 02543-1542. (email: bobd@copper.whoi.edu; emilie@ochre.whoi.edu)

(Received January 11, 1995; revised August 4, 1995; accepted August 11, 1995. 


\section{Chapter 3}

\section{SEISMIC STRUCTURE AND INDICATORS OF MAGMA BUdGET ALONG THE SOUTHERN EAST PACIFIC RISE}




\section{$\underline{\text { Abstract }}$}

We re-examine the relationship between seismically-constrained variations in crustal structure and indicators of ridge magma supply along the southern East Pacific Rise. Over the past decade, work on the fast spreading East Pacific Rise has shown the existence of significant, segment-scale variations in depth, morphology, crustal structure, basalt geochemistry, and hydrothermal activity that have often been attributed to along-axis differences in magma supply to the ridge. Broad, shallow ridge segments have been assumed to reflect a high magma supply and are predicted to have larger, more robust magma chambers, erupt more primitive basalts, form thicker crust, and have more vigorous hydrothermal activity than sections of the East Pacific Rise with a deeper, narrower rise crest. Here we use multichannel seismic (MCS) reflection data from an 800 km-long section of the southern East Pacific Rise (SEPR) to quantitatively examine the correlation between along-axis variations in crustal structure and other indicators of magma supply on the regional scale. Good correlations exist along the SEPR between axial depth, ridge cross-sectional area, mantle Bouguer anomaly, and the $\mathrm{MgO}$ wt\% of basalts recovered from the rise axis. These correlations suggest along-axis changes in crustal thickness and temperature consistent with variations in magma supply on time scales of $\sim 100 \mathrm{Kyr}$. However, we show that the magma sill properties (depth and width of the melt lens), seismic layer $2 \mathrm{~A}$ thickness, and the intensity of hydrothermal venting are poorly correlated with regional variations in ridge depth and cross-sectional area. We suggest that the emplacement geometry (width of the intrusion zone and flow lengths), not magma supply, controls extrusive layer (seismic 2A) thickness. The depth of the magma sill is very sensitive to the local thermal structure. Magma lens properties and hydrothermal activity are closely linked to spreading events (dike intrusion, eruptions, faulting) which 
occur on much shorter time scales (ca. 10-100 yr) than the longer-term variations in magma supply reflected in along-axis changes in ridge morphology.

\section{Introduction}

"As axial width seems to reflect the magmatic budget, one might expect a correlation between axial width and the presence of hydrothermal activity. It is also intriguing to speculate that axial shape may reflect the width or depth of axial magma chambers". [Langmuir et al., 1986]

Over the past decade, work on the fast spreading East Pacific Rise (EPR) has shown the existence of significant, segment-scale variations in axial depth [Macdonald et al., 1984; Macdonald and Fox, 1988], axial volume [Scheirer and Macdonald, 1993], axial gravity anomaly [Madsen et al., 1990; Magde et al., 1995], magma chamber depth and width [Detrick et al., 1987; Detrick et al., 1993], basalt geochemistry [Langmuir et al., 1986; Sinton et al., 1991; Mahoney et al., 1994], and hydrothermal activity [Haymon et al., 1991; Baker, 1996]. This along-axis variability is largely independent of spreading rate and has often been attributed to differences in magma supply to the ridge within or between segments [Macdonald et al., 1984; Macdonald and Fox, 1988; Macdonald et al., 1992]. Broad, shallow sections of ridge are assumed to reflect a high magma supply and are predicted to have larger, more robust axial magma chambers, erupt more primitive basalts, form thicker crust, have an axial summit caldera (ASC), and have more vigorous hydrothermal circulation than sections on the EPR with a deeper, narrower rise crest (Figure 1). 
The strongest evidence for this simple magma supply model has come from the systematic, segment-scale variations in axial depth and morphology observed along the EPR [Macdonald et al., 1984; Macdonald and Fox, 1988; Lonsdale, 1989; Scheirer and Macdonald, 1993], and the apparent correlation of these variations with the presence or absence of a reflection from what has been interpreted as a magma sill at the roof of the magma chamber [Detrick et al., 1987; Harding et al., 1989; Kent et al., 1990; Detrick et al., 1993]. The axial high at the EPR is typically shallowest near the middle of segments and deepens significantly toward segment offsets [Macdonald et al., 1984; Lonsdale, 1989]. These variations in axial depth are associated with systematic changes in the shape of the axial high [Macdonald and Fox, 1988; Scheirer and Macdonald, 1993]. Where the ridge is shallowest the axial high generally has a broad, flat-topped cross-section; where the ridge axis is deeper the axial high usually has a narrow, triangular shape. Based on this morphological evidence, Macdonald et al. [1984] and Macdonald and Fox [1988] suggest that the magma supply to the crust is greater near segment centers resulting in a larger, more robust magma chamber and a shallower, more inflated ridge than near segment ends.

This interpretation is supported by the correlation, first noted by Macdonald and Fox [1988] for the $9-13^{\circ} \mathrm{N}$ EPR area, between axial morphology and the presence or absence of the AMC reflector mapped by Detrick et al. [1987]. Where the magma sill is present, such as along the ridge segment immediately south of the Clipperton transform, the axial high is broad and flat-topped, and a narrow $(<200 \mathrm{~m})$, shallow $(<50 \mathrm{~m})$ axial summit caldera (ASC) is recognized along-axis (except in the case where the ASC has been filled by recent lava flows). In contrast, where the rise axis is deep, narrow and more triangular in cross-section, such as along the ridge segment immediately north of the Clipperton transform, a magma lens reflector is not detected and an ASC is absent. Seismic reflection data from the southern EPR are generally consistent with this association 
between shallow, inflated sections of the ridge and the presence of a mid-crustal magma sill [Scheirer and Macdonald, 1993]. For example, Mutter et al. [1995] report that between $17^{\circ} \mathrm{S}$ and $17^{\circ} 30^{\prime} \mathrm{S}$, the melt lens becomes shallower and wider as the ridge axis becomes shallower and broader, and use deviations from this expected relationship to suggest very recent or ongoing magmatic activity near $17^{\circ} 26^{\prime} \mathrm{S}$. Similarly, it has been suggested that the thickness of the extrusive layer reflects the magma budget [Harding et al., 1993]. The evidence for recent volcanism [Haymon et al., 1993] and abundant hydrothermal activity [Haymon et al., 1991] along the northern EPR near $9^{\circ} 50^{\prime} \mathrm{N}$, and the general good correlation between morphological indicators of magma supply and the presence of hydrothermal plumes [Baker, 1996], are also consistent with the magma supply model summarized in Figure 1.

However, new results suggest that the relationship between morphological indicators of magma supply and axial crustal structure is more complicated than this simple model would predict. Hussenoeder et al. [1996] have shown that the thickness and inferred crystal content of the magma lens along the northern and southern EPR are uncorrelated with axial depth. Variations in magma sill depth have been reported from both the northern [Harding et al., 1993] and southern [Detrick et al., 1993] EPR that are not related to changes in the depth or cross-sectional area of the ridge. Along the northern EPR, the widest magma sill is not found at $9^{\circ} 50^{\prime} \mathrm{N}$ where the ridge is shallowest and broadest, but where the ridge is deepest just north of the $9^{\circ} 03^{\prime} \mathrm{N}$ overlapping spreading center (OSC) [Kent et al., 1993a]. Barth and Mutter [1996] report that the crust is actually thinner beneath the inflated portion of the ridge at $9^{\circ} 50^{\prime} \mathrm{N}$ than elsewhere along this ridge segment. Similarly, Begnaud and McClain [1996] and van Avendonk et al. [1997] find little difference in the thickness of crust produced on either side of the Clipperton 
transform, despite large differences in the depth and morphology of the EPR on either side of the fracture zone.

We examine the relationship between various indicators of magma supply and seismically-constrained variations in crustal structure along more than $800 \mathrm{~km}$ of the southern EPR. The variables we compare are: axial depth, cross-sectional area of the ridge, layer 2A (extrusive layer) thickness on- and off-axis, the rate at which the extrusive layer thickens off-axis, magma sill depth and width, mantle Bouguer anomaly, temperature of the erupted lavas ( $\mathrm{MgO}$ content), hydrothermal activity, and the presence of an axial summit caldera. We will show that the thickness of the extrusive section (seismic layer 2A), the properties of the magma sill (depth, width, thickness), and the intensity of hydrothermal venting are poorly correlated with morphological indicators of magma supply such as axial depth or ridge cross-sectional area. We explain these observations by proposing that the emplacement geometry (width of the dike intrusion zone and flow lengths), not magma supply, controls the extrusive (layer 2A) thickness. We also suggest that the melt lens properties and hydrothermal activity are closely linked to spreading events (dike intrusion, eruptions and faulting) which occur on much shorter time scales (ca. 10$100 \mathrm{yr}$ ) than the variations in magma supply and thermal state which are reflected in the ridge morphology.

\section{Data Processing and Analysis}

In 1991 a multichannel seismic reflection survey imaged an $\sim 800 \mathrm{~km}$ long section of the southern East Pacific Rise (Figure 2) from the northern limb of the $20.7^{\circ} \mathrm{S}$ overlapping spreading center (OSC) to the Garrett fracture zone [Detrick et al., 1993]. This extensive two ship reflection/refraction survey concentrated on three areas centered at $14^{\circ} 15^{\prime} \mathrm{S}, 17^{\circ} 20^{\prime} \mathrm{S}$, and over the $15^{\circ} 55^{\prime} \mathrm{S}$ OSC (Figure 2). Outside of these regions, 
reflection data were shot along the ridge axis and five additional across-axis seismic lines were obtained. The reflection data were acquired aboard the research vessel Maurice Ewing of the Lamont-Doherty Earth Observatory using a 4-km-long, 160-channel digital streamer with $25 \mathrm{~m}$ group separation. The source was a 20-gun, 8385-cubic-inch air gun array. For the lines north of $17^{\circ} 20^{\prime}$ S, shots were fired every $20 \mathrm{~s}$, yielding a shot spacing of $50 \mathrm{~m}$ and 40 -fold coverage for a nominal ship speed of 5 knots. South of this area, port and starboard halves of the array were alternately fired every $10 \mathrm{~s}$, yielding a shot spacing of $25 \mathrm{~m}$ and 80 -fold coverage.

The multichannel seismic data were processed using SIOSEIS (written by Paul Henkart, Scripps Institution of Oceanography, La Jolla, Ca.). Shot gathers were sorted into 12.5 -m bins producing common mid-point (CMP) gathers whose ranges extended between 263 and $4263 \mathrm{~m}$. The along-axis data were stacked using a velocity model that varied with distance along the ridge crest. The normal moveout (NMO) velocities of the seafloor, layer $2 \mathrm{~A}$, and magma sill reflections were determined from constant velocity stacks of the data constructed at locations where preliminary stacks showed a change in crustal structure. Seafloor and postcritical reflections near the base of layer 2A were muted at ranges greater than $3200 \mathrm{~m}$ to prevent excessive stretching that occurs within the steep velocity gradient at the base of layer $2 \mathrm{~A}$. Muting of the farthest offsets $(>3200 \mathrm{~m})$ of the layer $2 \mathrm{~A}$ reflection essentially includes only those rays which turn near the base of layer $2 \mathrm{~A}$ thereby minimizing any errors associated with stacking these wide-angle reflections [Harding et al., 1993]. The across-axis reflection profiles were stacked using a velocity model determined from constant velocity stacks made every $2.5 \mathrm{~km}$. Exact-log dip moveout (DMO) corrections [Liner, 1990] were applied prior to stacking. Finally, the profiles were finite difference time migrated using a $45^{\circ}$ algorithm [Brysk, 1983] to account for the 2-D velocity variations produced by seafloor and layer $2 \mathrm{~A}$ topography. On the 
resulting profiles, the magma sill widths may be slightly over-estimated due to energy diffracting off the edges of the sill [Kent et al., 1990], however, these errors are minimized by the finite difference migration.

The two-way travel time to the layer 2A and magma sill reflectors were picked from the along- and across-axis seismic profiles at $100 \mathrm{~m}$ spacing. The on-axis data picks are not significantly affected by off-axis wander of the ship or streamer during the experiment. There is a good agreement between picks of on-axis layer 2A thickness and magma sill depth made from the across-axis profiles with those made at the intersection points on the along-axis profile. The excellent navigation of this experiment is confirmed by plots of the ship track superimposed on the multibeam bathymetry of the rise crest. Even in regions where the ship deviates from the center of the axial high there is no consistent pattern of disappearance of the magma sill, or thickening of layer 2A. Two-way travel time picks were converted to depth using the composite velocity model of Harding et al. [1993] which includes a low velocity, low gradient layer ( 2.2 to $2.3 \mathrm{~km} / \mathrm{s}$ ) beneath the seafloor underlain by a layer with a high velocity gradient ( 2.3 to $5.6 \mathrm{~km} / \mathrm{s})$. The ratio of the thicknesses of these two layers is held fixed $(95: 160 \mathrm{~m})$ while their total thickness is varied to match the observed travel time. The travel time between the base of layer $2 \mathrm{~A}$ and the magma sill reflector was converted to thickness by assuming a linear gradient in velocity of $0.74 \mathrm{~km} / \mathrm{s}$ per $\mathrm{km}$ beneath the base of layer $2 \mathrm{~A}$.

On the across-axis multichannel seismic lines we measured the depth of the magma sill below the seafloor and its width, the on- and off-axis thickness of layer $2 \mathrm{~A}$ and the rate at which the thickening occurs. The water depth, cross-sectional area [Scheirer and Macdonald, 1993], latitude, and measures of seismic structure for each of the across-axis lines are given in Table 1. In this table we have also compiled the information from the across-axis seismic profiles shot in the intensive study area at $14^{\circ} 15^{\prime} \mathrm{S}$ [Kent et al., 1994], 
and at $9^{\circ} \mathrm{N}$ on the northern EPR [Harding et al., 1993; Kent et al., 1993a\&b]. All the seismic lines from the northern and southern EPR were processed and interpreted using exactly the same methods so inter-comparison of the observations is particularly meaningful. Correlation coefficients between these variables for the along- and acrossaxis lines are given in Table 2.

\section{$\underline{\text { Results }}$}

Variation in Seismic Structure along the SEPR

The SEPR has a relatively uniform depth from the Garrett transform to about $18^{\circ} \mathrm{S}$, and then deepens systematically towards the large overlapping spreading center (OSC) at $20.7^{\circ} \mathrm{S}$ (Figure 3a). The regional variation in crustal structure along this portion of the SEPR can be divided into northern, central, and southern ridge sections bounded by the Garrett transform, the $15^{\circ} 55^{\prime} \mathrm{S}$ and $17^{\circ} 55^{\prime} \mathrm{S}$ OSCs, and the large $20.7^{\circ} \mathrm{S}$ OSC, respectively. These sections of ridge are defined based on differences in the range and variability of the observed crustal structure as determined from the regional variability in seafloor depth, extrusive layer thickness and magma sill depth. The magmatic segments defined by Sinton et al. [1991] (Figure 3c) are contained within these three ridge sections; southern section = magmatic segments $\mathrm{G}, \mathrm{H}, \mathrm{I}$, and $\mathrm{J}$; central section = magmatic segments $\mathrm{L}$ and $\mathrm{K}$; northern section = magmatic segments $\mathrm{M}, \mathrm{N}$, and $\mathrm{O}$. Along the northern section of ridge the axis is broad, shallow and remarkably uniform in depth. The axis remains shallow and is very broad along the central section but shows a greater along-axis variability in seafloor depth. Between $17^{\circ} \mathrm{S}$ and $18^{\circ} \mathrm{S}$ the ridge has the most inflated morphology of the entire SEPR region. Along the southern section the ridge deepens and narrows rapidly from a shallow point in the "Hump" region at $18^{\circ} 27^{\prime} \mathrm{S}$ to the large $20.7^{\circ} \mathrm{S}$ OSC. The along-axis variability in axial depth increases from north to south. The intensive seismic studies were located at 
the $15^{\circ} 55^{\prime} \mathrm{S}$ OSC, and at latitudes $14^{\circ} 15^{\prime} \mathrm{S}$ and $17^{\circ} 20^{\prime} \mathrm{S}$ where the ridge is broad and shallow and has the morphological characteristics of a high magma budget .

Figure 4 shows four examples of across- and along-axis multichannel profiles from the SEPR. These seismic profiles illustrate the crustal structure of parts of the ridge ranging from inflated to magma-starved in morphology. Figure $4 \mathrm{a}$ is from the $17^{\circ} 20^{\prime} \mathrm{S}$ intensive study area, a portion of the ridge along the central segment with an extremely inflated morphology (cross-sectional area $=5.6 \mathrm{~km}^{2}$ ). The top panel shows an across-axis profile at $17^{\circ} 26^{\prime} \mathrm{S}$ (SEPR27) and illustrates the general features of the crustal structure of a fast-spreading ridge. The seafloor is shallowest at the axis and deepens on either side of the ridge. In cross-section the ridge has a broad, domed shape. Wide-angle reflections from the base of layer $2 \mathrm{~A}$ are imaged $\sim 0.15 \mathrm{~s}$ below the seafloor at the ridge axis. Seismic layer 2A, which we correlate with the volcanic extrusive layer [Herron, 1982; Harding et al., 1989; Christeson et al., 1992], is $230 \mathrm{~m}$ thick at the ridge axis and doubles in thickness $(570 \mathrm{~m})$ within $3 \mathrm{~km}$ on either side of the ridge. The magma sill lies at $3.85 \mathrm{~s}$, a depth of $760 \mathrm{~m}$ below the seafloor, and has a width of $850 \mathrm{~m}$.

As the ridge deepens and narrows the ridge morphology and crustal structure change. Figure $4 \mathrm{~b}$ and $\mathrm{c}$ are from the northern and southern segments (latitudes $14^{\circ} 15^{\prime} \mathrm{S}$ SEPR70 and $18^{\circ} 28^{\prime} \mathrm{S}$ - SEPR06) respectively, regions with a morphology indicative of a medium magma supply (cross-sectional areas of 4.8 and $4.9 \mathrm{~km}^{2}$ respectively). The quality of the data on lines SEPR01 through SEPR10 is not as high as for the other seismic lines because a $10 \mathrm{~s}$ shooting rate, though increasing the fold of the data, introduces noise due to reverberation of the previous shot in the water column. The ridge in these regions has a domed but narrower axial high and the axial depths are slightly greater than in Figure 4a. Note the small off-axis graben on SEPR70 and the axial graben on SEPR06, evidence for an increased role of tectonism relative to SEPR27. The on-axis thickness of layer 2A 
on SEPR70 (220 m) is about the same as in Figure 4a, while on SEPR06 it is somewhat greater $(270 \mathrm{~m})$. The off-axis thicknesses of layer 2A (510 and $520 \mathrm{~m}$ respectively) are again about twice the on-axis values. The rate of $2 \mathrm{~A}$ thickening on these two profiles is somewhat less than in the previous case, with half-widths of thickening of 3.4 and $3.2 \mathrm{~km}$ respectively. The magma sill on SEPR70 is relatively shallow (1080 m below the seafloor) and wide $(750 \mathrm{~m})$, while on SEPR06 it is deeper $(1340 \mathrm{~m})$, narrower ( 300 m), and is associated with a weaker reflection. The weak reflection on the across-axis profile may be due to the scattering of energy from seafloor topography. On the along-axis line, where topographic effects are less of a problem, the magma sill reflector appears quite bright.

Figure $4 \mathrm{~d}$ is from where the southern segment deepens towards the $20.7^{\circ} \mathrm{S}$ OSC, a region with an extremely magma-starved morphology (cross-sectional area $=0.6 \mathrm{~km}^{2}$, latitude $\left.20^{\circ} 10^{\prime} \mathrm{S}\right)$. The ridge is significantly deeper $(2846 \mathrm{~m})$ and very narrow and triangular in shape. On this profile (SEPR02) the seafloor shows abundant evidence for tectonic extension, and the resulting scattering as well as the $10 \mathrm{~s}$ shooting rate on this profile reduce the quality of the image of the crustal structure. The along-axis data reveal a magma sill at this location, but it is so weak that on the across-axis profile it can only be seen in constant velocity stacks. This magma sill has an unusually shallow depth given the magma-starved morphology. On-axis layer $2 \mathrm{~A}$ is thicker on this profile $(330 \mathrm{~m})$ and thickens more rapidly (half-width of thickening $=1.5 \mathrm{~km}$ ) than on other profiles to attain an off-axis thickness of $620 \mathrm{~m}$.

The three sections of ridge defined above show significant differences in the range and variability of the seismic crustal structure. While the extrusive layer (seismic layer $2 \mathrm{~A}$ ) has a comparatively uniform thickness over the entire region (median on-axis thickness is $235 \mathrm{~m}$; range 200-300 m; see Figure 5a), there are differences in the thickness and variability of layer $2 \mathrm{~A}$ along the ridge. The northern section has a very uniform $2 \mathrm{~A}$ 
thickness $(222 \pm 21 \mathrm{~m})$, the central section shows more variability in thickness $(233 \pm 48 \mathrm{~m})$, while the southern section of ridge has the thickest and most variable extrusive layer $(284 \pm 56 \mathrm{~m})$. It appears that some thickening of layer $2 \mathrm{~A}$ occurs towards ridge axis discontinuities (shown as vertical lines on Figure 3). This is particularly clear near the $15^{\circ} 55^{\prime} \mathrm{S}$ OSC.

In contrast to the small changes in extrusive layer thickness along-axis, the depth of the magma sill is quite variable along the study area (Figure 3a). It ranges in depth from 800 to $2000 \mathrm{~m}$ below the seafloor with a median depth of $1300 \mathrm{~m}$ (Figure 5b). The northern and central ridge sections exhibit a general along-axis doming of the magma sill (shown by a dashed line in Figure 3a). On average, the magma sill is deeper near the ends of the ridge sections and shallower near the mid-point. However, there are also local changes in magma sill depth $(\sim 500 \mathrm{~m})$ superimposed on these general trends. Along the northern ridge section the depth to the magma sill is relatively uniform $(1220 \pm 110 \mathrm{~m})$. The local variability in magma sill depth is small and mirrors the relatively uniform water depths. Along the central section of ridge, the magma sill is on average somewhat deeper and shows a much greater depth range (820 to $2000 \mathrm{~m}$ with a median depth of $1350 \mathrm{~m}$ ). The shallowest lens is observed at $17^{\circ} 25^{\prime} \mathrm{S}$ where the magma sill shoals from $1350 \mathrm{~m}$ below the seafloor to $820 \mathrm{~m}$ over a distance of only $4 \mathrm{~km}$ (Figure $4 \mathrm{a}$ ). Doming of the magma sill on a wavelength of tens of kms (e.g. between $17^{\circ}$ and $17^{\circ} 20^{\prime} \mathrm{S}$ ) may be associated with individual volcanic constructs [pers. comm., Sinton, 1995]. Along the southern section of the study area the magma sill is observed more sporadically. The depth range is similar to that of the central section $(1350 \pm 210 \mathrm{~m})$ but changes in magma sill depth are very abrupt and show no consistent pattern. An unusually shallow magma sill (896 m) is imaged at $20^{\circ} 15^{\prime} \mathrm{S}$ (Figure $4 \mathrm{~d}$ ) despite the magma-starved ridge morphology. The magma sill appears to shoal, rather than deepen, towards the large OSC at $20.7^{\circ} \mathrm{S}$. 


\section{Correlations with Indicators of Magma Supply}

We compare the variations in crustal structure along the SEPR described above with various indicators of magma supply (Figure 3). These indicators are: the depth of the seafloor at a $1 \mathrm{~km}$ spacing obtained from the URI Sea Beam data synthesis [Tighe et al., 1988]; cross-sectional area measured at $1 \mathrm{~km}$ intervals along the ridge from Scheirer and Macdonald [1993]; the along-axis mantle Bouguer anomaly calculated at $2 \mathrm{~km}$ intervals from Magde et al. [1995]; $\mathrm{MgO}$ wt\% of lavas dredged from the ridge axis from Sinton et al. [1991] and samples collected from the youngest on-axis flows by the submersible Nautile [Auzende et al., 1996]; light attenuation in the water column integrated from 100 to $300 \mathrm{~m}$ above the seafloor in bins of 1.8 minutes $(\approx 18 \mathrm{~km})$ from Baker and Urabe [1996]; and the locations along the ridge where Lonsdale [1989] detected an ASC or an axial summit graben using SeaBeam data.

\section{Morphology and Gravity}

Axial depth, ridge cross-sectional area, and along-axis mantle Bouguer anomaly are all well correlated (Figure 6). The ridge axis becomes deeper as the cross-sectional area of the ridge decreases and at the same time the mantle Bouguer anomaly increases indicating higher subsurface densities. The ridge topography is supported by a low density volume underlying the ridge crest, which is partitioned between the crust and the mantle [Wang and Cochran, 1993; Magde et al., 1995]. The along-axis variation in gravity (range $=20 \mathrm{mGal}$ ) and part of the axial depth changes (range $=400 \mathrm{~m}$ ) can be explained by a decrease in crustal thickness of $\sim 500 \mathrm{~m}$ between $18^{\circ} \mathrm{S}$ and $20^{\circ} \mathrm{S}$ [Cormier and Macdonald, 1995]. The variation in cross-sectional area (range $=6 \mathrm{~km}^{2}$ ) suggests a change in volume of the hot, low density region in the lower crust accompanied by a variation in the density 
anomaly in a narrow, deep region in the mantle [Magde et al., 1995]. Thus, as is predicted by the magma supply model, along axis variations in axial depth and ridge cross-sectional area are indicative of variations in magma supply to the ridge.

\section{Basalt Geochemistry}

The variation in basalt geochemistry along the SEPR is shown in Figure 7 [Sinton et al., 1991]. The MgO content of basalts reflects the amount of fractional crystallization that the lavas have undergone in the crust. If the parental compositions are similar, $\mathrm{MgO}$ content relates to eruption temperature. For the lavas from the SEPR, MgO contents range from 5 to 8.5 wt\% with a corresponding change in $\mathrm{Mg}$ number from 0.35 to 0.64 (Figures 7a\&b). Applying the olivine thermometer of Sisson and Grove [1993] to representative along-axis major element compositions [Sinton et al., 1991] we obtain an approximately linear relationship between $\mathrm{MgO}$ content, $\mathrm{Mg}$ number and lava temperature for this area (Figures 7a-c). Eruption temperatures range from $1100^{\circ} \mathrm{C}$ to $1210^{\circ} \mathrm{C}$. The $\mathrm{MgO}$ content (and thus the temperature) of the erupted lavas correlates well with cross-sectional area (Figures 6c, 3b\&c). The correlation between $\mathrm{MgO}$ and cross-sectional area, or alternatively the width of the axial high, which has been noted previously [Langmuir et al., 1986; Scheirer and Macdonald, 1993], suggests that along morphologically inflated sections of the ridge the erupted lavas are more primitive and reside in the crust for a shorter time.

The variation in major element basalt geochemistry ( $\mathrm{Na}_{8.0}$ and $\mathrm{Fe}_{8.0}$ - Figure $\left.7 \mathrm{~d} \& \mathrm{e}\right)$ does not indicate any systematic patterns in the extent or depth of melting along the SEPR. This is consistent with the small along-axis variations in crustal thickness inferred from gravity data in this area [Cormier and Macdonald, 1995; Magde et al., 1995]. Diapiric feeding of fast spreading ridge axes has recently been suggested by Nicolas et al. [1996] 
and Wang et al. [1996]. This melt supply model would predict higher $\mathrm{Fe}_{8.0}$ and lower $\mathrm{Na}_{8.0}$ near segment mid-points due to a greater depth and extent of melting. $\mathrm{Fe}_{8.0}$ does not vary significantly along the SEPR indicating that the depth of melting is relatively uniform. There is more variation in Na.0 along axis suggesting more variability in the extent of melting. However, the variations in $\mathrm{Na}_{8.0}$ do not correlate with variations in ridge crosssectional area or mantle Bouguer anomaly. For example, the higher $\mathrm{Na}_{8.0}$ values observed along the inflated ridge section between $14^{\circ} \mathrm{S}$ and $15^{\circ} \mathrm{S}$ are opposite of what would be expected if a mantle diapir with greater extent of melting were located beneath this section of ridge. The manner in which melt is supplied to the ridge from the mantle appears to be complicated. However, the correlation of mantle Bouguer anomaly variations with crosssectional area and axial depth suggests that on a broad scale variations in the melt supply to the SEPR result in differences in the mean thermal structure and morphology of the ridge.

\section{Magma Sill Properties}

Purdy et al. [1992] has proposed that on average, magma sill reflector depth decreases with increasing spreading rate beneath fast and intermediate spreading centers. The average depth of the magma sill is indeed greater on the northern EPR than on the southern EPR (Table 1). Spreading rate along the SEPR varies from a full rate of 146 $\mathrm{mm} / \mathrm{yr}$ at $13.8^{\circ} \mathrm{S}$ to $153 \mathrm{~mm} / \mathrm{yr}$ at $20^{\circ} \mathrm{S}$ for 0 to $0.73 \mathrm{My}$ [Naar and Hey, 1989]. Along the northern EPR spreading rates are slower, $\sim 112 \mathrm{~mm} / \mathrm{yr}$ [Carbotte and Macdonald, 1992]. The difference in mean magma sill depth is $400 \mathrm{~m}(1140 \pm 150 \mathrm{~m}$ to $1540 \pm 85 \mathrm{~m}$ below the seafloor respectively), which is greater than the standard deviation of the averages. On the other hand, there is no significant difference in the width of the magma sill between the northern and southern EPR $(680 \pm 280 \mathrm{~m}$ and $788 \pm 295 \mathrm{~m}$ respectively, Table 1.) 
The simple magma supply model predicts that for a given spreading rate, variations in magma sill depth and width depend on changes in magma supply to the ridge. However, along the SEPR, where spreading rates vary only slightly, the magma sill properties (depth and width) are not well-correlated with axial depth, cross-sectional area or $\mathrm{MgO}$ wt\% of erupted lavas (Figure 8). The magma sill shows a large range of depths along the SEPR from 800-2000 m (Figure 5b). The current magma supply model would predict a deeper and narrower magma sill where the ridge becomes deeper and narrower [Macdonald and Fox, 1988; Mutter et al., 1995]. However, we find that, on a regional scale, the correlation between magma sill depth and water depth is low (Figure 8a). This is due to the large variability in magma sill depth compared to the relatively uniform water depth in the region. A plot of magma sill depth versus cross-sectional area (Figure 8b) also shows a large amount of scatter. Similarly, lava eruption temperature ( $\mathrm{MgO}$ content) does not correlate with magma sill depth (Figure 8c). It has been suggested that magma sill width and depth are correlated and vary with ridge morphology, and that deviations from these trends indicate recent or on-going eruptions [Mutter et al., 1995]. However, we find that magma sill widths are quite variable and do not correlate with either water depth or cross-sectional area (Figure 8d\&e). The across-axis lines also show that, on the regional scale, there is a great range in magma sill width for any given magma sill depth (Figure 8f). Thus the width and depth of the magma sill are extremely variable along the SEPR, and show little relationship with morphological indicators of magma supply.

The observation that EPR lavas are not homogenized has been interpreted to mean that a continuous magma chamber can exist only if there are many separate regions of supply from below the crust, and the magma chamber is not well mixed [Langmuir et al., 1986]. This supports the rapidly varying nature of the magma sill that we have noted. A magma sill which is not fully molten [Hussenoeder et al., 1996] would probably be less 
well mixed. The magmatic system at fast spreading ridges is complicated, consisting of a mostly molten magma lens or sill [Detrick et al., 1987; Harding et al., 1989; Kent et al., 1990] overlying a broader region of the lower crust, with low seismic velocities and few percent of partial melt [Toomey et al., 1990; Vera et al., 1990; Caress et al., 1992]. There is also some evidence for a second magma sill at the Moho [Garmany, 1989; Crawford et al., 1996; Kelemen et al., 1996]. In addition, it been suggested that the lower crust at the EPR may be composed of a series of gabbroic and partially molten sills [Kelemen et al., 1996]. The correlation between $\mathrm{MgO}$ content, mantle Bouguer anomaly, and ridge crosssectional area (Figure 6) suggests that erupted melts have temperatures representative of the lower crust. This implies that the melts that erupt onto the seafloor have not resided very long within the melt lens. Magmatic events (dike intrusion and eruptions) may thus be closely tied to replenishment of the mid-crustal sill from a lower-crustal or sub-crustal reservoir [Kelemen et al., 1996; Natland and Dick, 1996].

\section{Extrusive layer (2A) thickness}

While the magma sill varies considerably in depth, the on-axis layer $2 \mathrm{~A}$ thickness is relatively constant along the ridge (Figure 9). There is no dependence on spreading rate and we find no significant difference in the thickness or rate of thickening of the extrusive layer between the northern and southern EPR (Table 1). The high correlation coefficient between on-axis layer $2 \mathrm{~A}$ thickness and water depth (Table 2) is due to the uniform value of each of these variables and is not very informative. The on-axis thickness of layer $2 \mathrm{~A}$ is constant for almost the entire range of cross-sectional areas. However, for regions with an inferred low magma budget, i.e. deep ridges with small cross-sectional areas, the on-axis layer 2A thickness appears to increase (Figure 9a). This is contrary to the magma supply model which predicts a thinner extrusive section as magma supply decreases. Off-axis layer 2A thickness does not relate to cross-sectional area (Figure 9b) and seems to be 
independent of the magma supply. Both on- and off-axis layer $2 \mathrm{~A}$ thicknesses are uncorrelated with magma sill depth (Figures $9 \mathrm{c} \& d$ ). The width of the zone of across-axis thickening of the extrusive layer shows a large range $(0.5$ to $4.5 \mathrm{~km})$ (Figure 10), but there is no correlation of the width of extrusive thickening with magma sill width (Figure 10a), and only a weak positive correlation with ridge cross-sectional area (Figure 10b). In contrast to the predictions of the magma supply model, the extrusive layer thickness shows little correlation with either morphological indicators of magma supply or magma sill depth.

\section{Hydrothermal Activity}

Hydrothermal activity along the SEPR is not strongly correlated with indicators of magma supply or magma sill depth (Figure 11). Hydrothermal activity is very variable along the SEPR and is particularly vigorous from $17^{\circ} 30^{\prime} \mathrm{S}$ to $18^{\circ} 40^{\prime} \mathrm{S}$ where the water column survey ended [Baker and Urabe, 1996]. The segment centered on $18^{\circ} 30^{\prime}$ S shows high venting activity and is unusual in that it does not have an ASC at its summit but rather a summit graben, indicating more extensive tectonic activity (across-axis seismic profile SEPR06 is located here, Figure 4c). In a study of the distribution of hydrothermal vents along the EPR, Baker [1996] concludes that a high magma supply rate and an observable magma sill are necessary but not deterministic for extensive hydrothermal venting. However, our observations suggest that there is a better correlation between hydrothermal venting and regions where an ASC or an axial graben is present [Lonsdale, 1989] than with the presence or depth of the magma lens or with indicators of variations in magma supply (Figure 3).

It is generally thought that hydrothermal fields begin, or are renewed, by dike injection events, which are associated with both heat input and cracking of the shallow

crust [Baker et al., 1987; Haymon et al., 1993; Embley and Chadwick, 1994; Embley et 
al., 1995; Wright et al., 1995] or by the cooling of extremely young lavas [Fornari and Embley, 1995]. Charlou et al. [1996] and Auzende et al. [1996] have observed hydrothermal vent chimneys predominantly located on faults at the edge of axial summit graben in the region from $18^{\circ} 22^{\prime} \mathrm{S}$ to $18^{\circ} 37^{\prime} \mathrm{S}$. In contrast, where the magma sill is observed to be unusually shallow, at $17^{\circ} 25^{\prime} \mathrm{S}$, they observed mainly diffuse venting of seawater heated by cooling lavas. Our observations over the entire region suggest that at the fast-spreading SEPR there is always a sufficient heat source within the lower crust to drive hydrothermal circulation. However, a permeability structure capable of focusing water migration through the crust is required for longer-lived hydrothermal venting. This permeability structure can be generated by cracking due to recent diking, or by tectonic fissuring. The relative importance of these two processes is still unclear.

\section{Discussion}

From the comparison of axial seismic structure with various indicators of magma supply along the SEPR we find that: (1) as expected from the magma supply model, axial depth, cross-sectional area and mantle Bouguer anomaly are well correlated with one another and with the along-axis variation in $\mathrm{MgO} w t \%$ (Figure 6); (2) contrary to predictions of the simple magma supply model, magma sill properties (depth and width) are

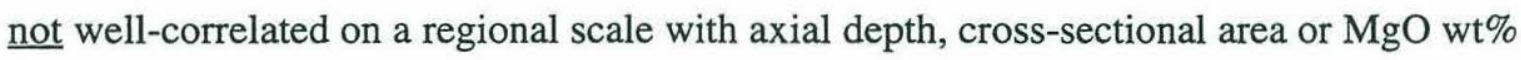
of erupted lavas; (3) on-axis layer $2 \mathrm{~A}$ thickness is relatively constant and uncorrelated with along-axis variations in cross-sectional area or magma sill depth (Figure 9); and (4) hydrothermal intensity is not strongly correlated with magma sill depth or ridge crosssectional area (Figure 11). These observations lead to three specific questions regarding the temporal and spatial processes controlling the magmatic construction of the oceanic crust: Why does extrusive thickness not seem to correlate with morphological indicators of 
magma supply? What controls the depth of the magma sill? Why doesn't magma sill depth correlate with morphological indicators of magma supply?

\section{Thickness and Construction of the Extrusive Layer}

The uniform along-axis thickness of layer 2A (Figure 5a), relative to morphologic indicators of magma supply and to the depth of the magma lens, indicates that construction of the extrusive section is controlled by eruption dynamics rather than magma supply (c.f. Kappus et al., 1995). Models of the emplacement geometry of the extrusive section show that the width of the dike intrusion zone and the length of lava flows control the thickness and thickening rate of layer 2A [e.g. Kidd, 1977; Atwater, 1979; Schouten and Denham, 1979; Pálmason, 1980; Hooft et al., 1996]. The relative uniformity of on-axis layer 2A thickness along the ridge axis thus indicates that the dike injection zone has a fairly constant width throughout this region.

Near ridge offsets, and along parts of the ridge with small cross-sectional areas, seismic layer 2A thickens (Figure 9a). Near OSCs the ridge axis is not well localized and the dike intrusion zone may be wider. This would result in a more distributed dike intrusion and thicker average extrusive section [c.f. Hooft et al., 1996]. An alternative possibility is that the magma supply decreases near these ridge offsets, and increased tectonic faulting and fissuring reduces the surficial seismic velocities of the crust. Interpretation of the two-way travel time thicknesses without accounting for these reduced velocities would result in an apparent thickening of seismic layer $2 \mathrm{~A}$, which does not correspond to an actual thickening of the extrusive section .

The off-axis thickness and thickening of seismic layer $2 \mathrm{~A}$ is more variable and may be controlled by the shape of the axial high. Emplacement models predict that, if the dikes are rooted in the magma sill, the width of the thickening region of the extrusive section is 
related to magma sill width. However, our observations show that the width of $2 \mathrm{~A}$ thickening is much greater and more variable than the width of the magma sill (Figure 10a). On the other hand, ridge crest topography does appear to control the construction of layer $2 \mathrm{~A}$ to some extent. The width of the thickening zone shows a weak positive correlation with ridge cross-sectional area (Figure 10b) - a narrower ridge has a narrower zone over which thickening occurs. These observations are consistent with the existence of a narrow dike intrusion zone and lavas that flow a considerable distance off-axis as in the layer $2 \mathrm{~A}$ construction model of Hooft et al. [1996].

\section{Controls on the Depth of the Magma Sill}

It has been suggested that magma ponds at a level of neutral buoyancy (LNB) in the crust where the melt density is equal to the bulk density of the surrounding crust [c.f. Walker, 1989; Ryan, 1993]. At mid-ocean ridges the LNB lies at an approximately constant, and very shallow depth below the seafloor ( 100-400 m) [Hooft and Detrick, 1993]. The depth of the seismically observed magma lens reflector along the SEPR is considerably deeper than this LNB. The median depth of the magma sills along the SEPR is $1300 \mathrm{~m}$ below the seafloor, and even the shallowest magma sill $(800 \mathrm{~m})$ lies well below the LNB (Figure 5b).

The Hooft and Detrick [1993] calculation of the depth of the LNB assumes that the magma sill is completely molten. However, if the magma sill contains a significant proportion of crystals, it will be neutrally buoyant at a greater depth. Detailed waveform modeling and amplitude versus offset analysis of multichannel seismic records [Hussenoeder et al., 1996] show that in some areas along the SEPR the magma sill is not fully molten and is able to propagate shear waves, though the shear wave velocity is reduced. Laboratory measurements suggest that these lowered shear wave velocities 
correspond to a melt fraction anywhere between 30\% and $80 \%$ [Murase and McBirney, 1973]. Consistent with these measurements, numerical models of the observed compressional wave velocity and anisotropy of the magma sill require a basaltic melt fraction of 50-70\% within a gabbro matrix [Mainprice, 1996]. To calculate the density of such a magma, we assume (i) that magma density is linearly related to the proportions of crystals and melt, (ii) that gabbro crystal densities range from $\sim 2.90-2.95 \mathrm{~g} / \mathrm{cm}^{3}$ [Christensen and Salisbury, 1982], and (iii) that basaltic melt density is $\sim 2.7 \mathrm{~g} / \mathrm{cm}^{3}$ [Hooft and Detrick, 1993]. Crystal contents of 30-50\% give magma densities of $2.76-2.83 \mathrm{~g} / \mathrm{cm}^{3}$ (Figure 12a). For a seismically-derived crustal density profile [Christensen and Shaw, 1970; Harding et al., 1993] (Figure 12b), such a magma sill is neutrally buoyant between 250 and $830 \mathrm{~m}$ below the seafloor. Thus, even if the magma sill has a significant crystal content it still lies well below the level of neutral buoyancy, although some more evolved (heavier) melts may lie near their LNB.

Another line of evidence indicating that the magma sills do not pond at a LNB is the large range of magma sill depths observed along the SEPR. Bulk crustal density is closely related to seismic velocity. Since the upper crustal velocity structure is relatively invariant along the ridge crest [Tolstoy et al., 1996], the upper crustal density profile remains approximately uniform. However, the depth of the seismically observed magma lens reflector varies considerably ranging from 800 to $2000 \mathrm{~m}$ below the seafloor (Figure 3 ). The large variability of magma sill depth observed along the SEPR and its location well below the LNB are inconsistent with the hypothesis that the magma lens forms by the ponding of melt at a level of neutral buoyancy within the shallow crust.

We believe that a thermally controlled permeability boundary, such as the solidus horizon, controls the depth of the magma sill at the EPR [Hooft and Detrick, 1993; Phipps Morgan and Chen, 1993a; Natland and Dick, 1996]. The thermal structure of the ridge is a 
balance between melt supplied to the ridge and heat removed by hydrothermal cooling. If magma ponds at a thermal boundary, the observed variations in magma sill depth are due to changes in axial thermal structure. This concept is consistent with the observed decrease in average depth of the magma sill with increasing spreading rate (Table 1, Purdy et al., 1992).

\section{Lack of Correlation of the Magma Sill Depth with Indicators of Magma Supply}

Models of the thermal balance at mid-ocean ridges show that the advection of heat from variations in melt supply to the ridge affects the crustal thermal structure [Phipps Morgan and Chen, 1993b]. Excess heat from an increased magma budget is predicted to result in a shallower magma lens. However, the lack of correlation between magma sill depth and cross-sectional area along the SEPR does not support such a relationship. The large variability in magma sill depth and the lack of correlation with morphologic indicators of magma supply (Figures 5 and 8 ) require temporal and/or spatial variations in the thermal structure of the ridge that are not solely dependent on spreading rate or magma supply.

We assume that the magma sill lies at the temperature of the solidus $\left(\sim 1200^{\circ} \mathrm{C}\right)$. The lower crust is assumed to be relatively isothermal since, to satisfy the geophysical observations [Toomey et al., 1990; Vera et al., 1990; Caress et al., 1992], it cannot contain more than a few percent partial melt. The uppermost crust will be rapidly cooled by the circulation of hydrothermal fluids. Temperatures increase rapidly just below the seafloor $\left(0-350^{\circ} \mathrm{C}\right.$ in the first few hundred meters), but below this the upper crust remains nearly isothermal $\left(\sim 400^{\circ} \mathrm{C}\right)$ to the maximum depth of penetration of hydrothermal fluids [Nehlig and Juteau, 1988; Sleep, 1991]. There is a conductive lid just above the magma sill with very steep thermal gradients, from $400-1200^{\circ} \mathrm{C}$ within a few hundred meters [Lister, 1983;

Nicolas, 1989]. Since the magma sill depth ranges from 800 to $2000 \mathrm{~m}$ below the 
seafloor, the steep thermal gradient and the depth of the solidus move up and down considerably within the mid to upper crust (Figure 13). Rapid variations in local thermal structure of the upper crust are probably due to an imbalance between the amount of crustal cooling relative to the heat supplied.

The heat supplied to the magma sill from below is probably relatively invariant, otherwise the thin sill would quickly be frozen by hydrothermal cooling. Based on the time required to construct the axial high area, along-axis variations in magma supply are probably maintained on order $100 \mathrm{Kyr}$ [Scheirer and Macdonald, 1993]. Crustal thickness [Barth and Mutter, 1996] and abyssal hill characteristics [Goff, 1991] also indicate that the average rate of magma supply changes little over several $100 \mathrm{Kyr}$. A record of the thermal history of axial magma chambers can be deduced from the variations in chemistry of volcanic rocks collected along flowlines on the flanks of the EPR $\left(9^{\circ} 30^{\prime} \mathrm{N}, 10^{\circ} 30^{\prime} \mathrm{N}\right.$ and $11^{\circ} 20^{\prime} \mathrm{N}$ ) [Batiza et al., 1996]. These observations show that where the ridge is magmatically robust the magma lens is steady state and there are no significant changes in eruption temperature over $\sim 800 \mathrm{Kyr}$. On the other hand, in magmatically starved areas, there are large variations in eruption temperature with time $\left(\sim 160^{\circ} \mathrm{C}\right.$ over $\left.600 \mathrm{Kyr}\right)$ suggesting that the magma lens departs from steady state. These observations are supported by a study of lower crustal rocks exposed in fracture zones and rift deeps along the fast-spreading ridge system. Gabbro samples from the ends of segments have more evolved compositions than those from more stable portions of the ridge [Constantin et al., 1996] indicating less frequent replenishment of the magma system. Relative to the more constant supply of melt from below $(\sim 100 \mathrm{Kyr})$, the variations in the amount of crustal cooling may depend on the time that has elapsed since a diking event drained the magma sill (1-10 yrs), as well as on the strength of hydrothermal cooling in the overlying crust (10s $-100 \mathrm{~s}$ of $\mathrm{yrs})$. 
The cartoon in Figure 13 summarizes two possible different states of the magma sill for two parts of the ridge that have the same magma budget, i.e. the amount of melt supplied from below is constant. Also shown are non-steady-state thermal profiles resulting from temporal variations in the amount of cooling, due to intermittent eruptive and tectonic events at the ridge crest, relative to the more constant magma supply from below. In the first case, the crustal permeability is high allowing deep penetration of hydrothermal fluids. The magma lens has also recently erupted onto the seafloor thereby draining away the melt. The amount of heat removed from the magma sill is greater than that being supplied and the sill lies fairly deep within the crust. This scenario represents across-axis seismic profile SEPR06 (Figure 4c) where the presence of an axial summit graben enhances the penetration of hydrothermal fluids and there is extensive hydrothermal activity. The resulting magma sill lies deep within the crust. On the other hand, if the crustal permeability becomes reduced and no eruption has occurred for some time, then the magma sill will slowly burn its way to shallower levels in the crust, perhaps by stoping of the overlying sheeted dike section [Nicolas and Boudier, 1991]. This scenario is representative of across-axis seismic profile SEPR70 (Figure 4b), where the magma sill lies much shallower than on SEPR06 even though both ridge segments have similar crosssectional areas, and thus their longer term magma budgets are the same. The lower panel of Figure 13 shows apparent local variations in the depth of the magma sill along the ridge axis; a shallow and almost horizontal magma sill fades over a distance of $\sim 7 \mathrm{~km}$ giving way to a bright magma sill reflector lying $\sim 1 \mathrm{~km}$ deeper.

The relationship between these local, short-term variations in crustal structure and longer-term changes in magma supply to the ridge is shown in an along-axis view in Figure 14. Over time scales of $\sim 100 \mathrm{Kyr}$ there are variations in magma supply to the different parts of this section of ridge. The resulting variations in cross-sectional area are closely 
mirrored in the along-axis patterns of the mantle Bouguer anomaly and $\mathrm{MgO}$ content of the lavas. However, the magma sill depth, extrusive thickness and locations of hydrothermal venting show little correlation with these patterns. Changes in average magma sill depth are on a scale of $\sim 200 \mathrm{~km}$. Short wavelength doming of the magma sill on the scale of $\sim 50$ $\mathrm{km}$ may be associated with individual volcanic constructs. The extrusive section thickens slightly at the ends of these constructs. The white region around the magma sill indicates a mixed zone of dikes and gabbros generated by rapid (10-100s yr), local changes in the depth of the magma sill (Figure 13). Hydrothermal venting is diffuse where there are recent eruptions, and focused where there is an ASC or axial graben.

\section{$\underline{\text { Summary }}$}

The current magma supply model predicts that broad, shallow ridge segments reflect a high magma supply and have larger, more robust magma chambers, erupt more primitive basalts, form thicker crust, and have more vigorous hydrothermal activity than sections of the East Pacific Rise with deeper, narrower axial highs. To test this paradigm we examine the correlation along $>800 \mathrm{~km}$ of the SEPR between along-axis variations in seismic crustal structure and other indicators of magma supply. Our main conclusions are:

- Good correlations exist between axial depth, ridge cross-sectional area, mantle Bouguer anomaly, and the $\mathrm{MgO} w \%$ of basalts recovered from the rise axis. These correlations suggest along-axis variations in lower crustal and upper mantle density which are consistent with variations in magma supply on time scales of $\sim 100 \mathrm{Kyr}$.

- The magma sill properties (depth and width of the melt lens), seismic layer $2 \mathrm{~A}$ thickness, and extent of hydrothermal venting are poorly correlated with regional variations in ridge depth and cross-sectional area. 
- The emplacement geometry (width of the intrusion zone, flow lengths), not magma supply, controls extrusive layer (seismic $2 \mathrm{~A}$ ) thickness.

- Hydrothermal activity is closely linked to spreading events (dike intrusion, eruptions, faulting) which occur on short time scales (ca. 10-100 yr). The presence of a permeability structure that allows water to penetrate to hot rock is key.

- Magmas accumulate at a depth in the shallow crust where their buoyant ascent is arrested by a thermally-controlled permeability boundary.

- On average magma sill depth depends on spreading rate and magma supply.

-We observe a large local variability in magma sill depth (800-2000 m below the seafloor), suggesting that on the short term the thermal structure of the crust is strongly modified. The advection of heat to the crust by the ascent of melt is relatively continuous. In contrast, the removal of heat from the crust is highly variable and depends on the variability of hydrothermal cooling, on intermittent eruptive and intrusive episodes that drain the magma sill, and on tectonic events that alter the crustal permeability structure. 


\section{Acknowledgments:}

For the acquisition of the multichannel seismic data we acknowledge the TERA Group (R. Detrick, G. Kent, A. Harding, J. Orcutt, J. Mutter and P. Buhl). We thank E. Baker, L. Magde, D. Scheirer, and J. Sinton for making their data available to construct the figure synthesizing all the along-axis indicators of magmatic budget (Figure 3). We particularly thank P. Henkart for his help in processing data on the data tape archiving system at the Scripps Institution of Oceanography and for his aid in the use of SIOSEIS. We also thank A. Harding for the use of pltsegy to plot the seimic sections. Inspiration came from discussions with J. Escartín and H. Schouten and from discussions during and after a field trip to the Oman ophiolite with P. Kelemen and G. Hirth. NSF grant \# xxx. Woods Hole Oceanographic Institution contribution \# xxxx.

\section{References:}

Atwater, T., Constraints from the FAMOUS area concerning the structure of the oceanic section, in Deep drilling results in the Atlantic Ocean: Ocean crust, vol. 2 edited by Talwani, M., Harrison, C.G. and Hayes, D.E., pp. 33-42, American Geophysical Union, Washington, DC 20009, 1979.

Auzende, J.-M., Ballu, V., Batiza, R., Bideau, D., Charlou, J.-L., Cormier, M.H., Fouquet, Y., Geistdoerfer, P., Lagabrielle, Y., Sinton, J. and Spadea, P., Recent tectonic, magmatic, and hydrothermal activity on the East Pacific Rise between $17^{\circ} \mathrm{S}$ and $19^{\circ}$ S: Submersible observations, J. Geophys. Res., 101, 17995-18010, 1996.

Baker, E.T., Geological indexes of hydrothermal venting, J. Geophys. Res., 101, 13,74113,753, 1996.

Baker, E.T., Massoth, G.J. and Feely, R.A., Cataclysmic hydrothermal venting on the Juan de Fuca Ridge, Nature, 329, 1987. 
Baker, E.T. and Urabe, T., Extensive distribution of hydrothermal plumes along the superfast spreading East Pacific Rise. $13^{\circ} 30^{\prime}-18^{\circ} 40^{\prime} \mathrm{S}$, J. Geophys. Res., 101, 8685-8697, 1996.

Barth, G.A. and Mutter, J.C., Variability in oceanic crustal thickness and structure: Multichannel seismic reflection results from the northern East Pacific Rise, $J$. Geophys. Res., 101, 17951-17975, 1996.

Batiza, R., Niu, Y., Karsten, J.L., Boger, W., Potts, E., Norby, L. and Burtler, R., Steady and non-steady state magma chambers below the East Pacific Rise, Geophys. Res. Lett., 23, 221-224, 1996.

Begnaud, M.L. and McClain, J.S., Structure of a "magma-starved" segment on a fast spreading ridge, EOS, Trans. Am. Geophys. Un., 77, 271, 1996.

Brysk, H., Numerical analysis of the $45^{\circ}$ finite-difference equation for migration, Geophys., 48, 532-542, 1983.

Carbotte, S. and Macdonald, K., East Pacific Rise $8^{\circ}-10^{\circ} 30^{\prime} \mathrm{N}$ : Evolution of ridge segments and discontinuities from SeaMARC II and three-dimensional magnetic data, J. Geophys. Res., 97, 6959-6982, 1992.

Caress, D., Burnett, M. and Orcutt, J., Tomographic image of the axial low velocity zone at $12^{\circ} 50^{\prime} \mathrm{N}$ on the East Pacific Rise, submitted to, J. Geophys. Res., 97, 9243-9264, 1992.

Charlou, J.L., Fouquet, Y., Donval, J.P., Auzende, J.M., Jean-Baptiste, P., Stievenard, M. and Michel, S., Mineral and gas chemistry of hydrothermal fluids on an ultrafast spreading ridge: East Pacific Rise, $17^{\circ}$ to $19^{\circ} \mathrm{S}$ (Naudur cruise, 1993) phase separation processes controlled by volcanic and tectonic activity, J. Geophys. Res., 101, 15, 899-15,920, 1996.

Christensen, N.I. and Salisbury, M.H., Lateral heterogeneity in the seismic structure of the oceanic crust inferred from velocity studies in the Bay of Islands ophiolites, Newfoundland, Geophys. J. R. Astr. Soc., 68, 675-688, 1982. 
Christensen, N.I. and Shaw, G.H., Elasticity of mafic rocks from the mid-Atlantic ridge, Geophys. J. R. Astr. Soc., 20, 271-284, 1970.

Christeson, G.L., Purdy, G.M. and Fryer, G.J., Structure of young upper crust at the East Pacific Rise near 9³0'N, Geophys. Res. Lett., 19, 1045-1048, 1992.

Constantin, M., Hekinian, R., Bideau, D. and Hébert, R., Construction of the oceanic lithosphere by magmatic intrusions: Petrological evidence from plutonic rocks formed along the fast-spreading East Pacific Rise, Geology, 24, 731-734, 1996.

Cormier, M.-H. and Macdonald, K.C., A three-dimensional gravity analysis of the East Pacific Rise from $18^{\circ}$ to $21^{\circ} 30^{\prime}$ S, J. Geophys. Res., 100, 8063-8082, 1995.

Crawford, W.C., Hildebrand, J.A. and Webb, S.C., Geophysical detection of a melt reservoir at the crust-mantle interface beneath the East Pacific Rise axis, Nature, submitted, 1996.

Detrick, R.S., Buhl, P., Vera, E.E., Mutter, J.C., Orcutt, J.A., Madsen, J.A. and Brocher, T.M., Multichannel seismic imaging of a crustal magma chamber along the East Pacific Rise, Nature, 326, 35-41, 1987.

Detrick, R.S., Harding, A.J., Kent, G.M., Orcutt, J.A., Mutter, J.C. and Buhl, P., Seismic structure of the southern East Pacific Rise, Science, 259, 499-503, 1993.

Embley, R.W. and Chadwick, W.W., Jr., Volcanic and hydrothermal processes associated with a recent phase of seafloor spreading at the northern Cleft segment: Juan de Fuca Ridge, J. Geophys. Res., 99, 4741-4760, 1994.

Embley, R.W., Chadwick, W.W., Jonasson, J.I.R., Butterfield, D.A. and Baker, E.T., Initial results of the rapid response to the 1993 CoAxial event: Relationships between hydrothermal and volcanic processes, Geophys. Res. Lett., 22, 143-146, 1995.

Fornari, D.J. and Embley, R.W., Tectonic and volcanic controls on hydrothermal processes at the mid-ocean ridge: An overview based on near-bottom and submersible studies, in Seafloor hydrothermal systems: Physical, chemical, biological, and geological interactions, vol. Geophysocal Monograph 91 edited by 
Humphris, S.E., Zierenberg, R.A., Mullineaux, L.S. and Thomson, R.E., pp. 146, Americal Geophysical Union, 1995.

Garmany, J., Accumulations of melt at the base of young oceanic crust, Nature, 340, 628632, 1989.

Goff, J.A., A global and regional stochastic analysis of near-ridge abyssal hill morphology, J. Geophys. Res., 96, 21,713-21,737, 1991.

Harding, A.J., Kappus, M.E., Orcutt, J.A., Vera, E.E., Buhl, P., Mutter, J.C., Detrick, R.S. and Brocher, T., The structure of young oceanic crust at $13^{\circ} \mathrm{N}$ on the East Pacific Rise from ESPs, J. Geophys. Res., 94, 12163-12196, 1989.

Harding, A.J., Kent, G.M. and Orcutt, J.A., A multichannel seismic investigation of the upper crustal structure at $9^{\circ} \mathrm{N}$ on the East Pacific Rise: Implications for crustal accretion, J. Geophys. Res., 98, 13925-13944, 1993.

Haymon, R.M., Fornari, D.J., Edwards, M.H., Carbotte, S., Wright, D. and Macdonald, K.C., Hydrothermal vent distribution along the East Pacific Rise crest $\left(9^{\circ} 09^{\prime}-54^{\prime} \mathrm{N}\right)$ and its relationship to magmatic and tectonic processes on fast-spreading mid-ocean ridges, Earth Planet. Sci. Lett., 104, 513-534, 1991.

Haymon, R.M., Fornari, D.J., Von Damm, K.L., Lilley, M.D., Perfit, M.R., Edmond, J.M., Shanks III, W.C., McLaughlin, E., Smith, M., Beedle, N. and Olson, E., Volcanic eruption of the mid-ocean ridge along the East Pacific Rise crest at $9^{\circ} 45^{\prime}-$ 52 'N: Direct submersible observations of seafloor phenomena associated with an eruption event in April, 1991, Earth Planet. Sci. Lett., 119, 85-101, 1993.

Herron, T.J., Lava flow layer-East Pacific Rise, Geophys. Res. Lett., 9, 17-20, 1982.

Hooft, E.E. and Detrick, R.S., The role of density in the accumulation of basaltic melts at mid-ocean ridges, Geophys. Res. Lett., 20, 423-426, 1993.

Hooft, E.E.E., Schouten, H. and Detrick, R.S., Constraining crustal emplacement processes from the variation of seismic layer 2A thickness at the East Pacific Rise, Earth Planet. Sci. Lett., 142, 289-309, 1996. 
Hussenoeder, S.A., Collins, J.A., Kent, G.M., Detrick, R.S. and Group, T., Seismic analysis of the axial magma chamber reflector along the southern East Pacific Rise from conventional reflection profiling, J. Geophys. Res., in press, 1996.

Kappus, M.E., Harding, A.J. and Orcutt, J.A., A baseline for upper crustal seismic velocity variations along the East Pacific Rise at $13^{\circ}$ N, J. Geophys. Res., 100, 6143$6161,1995$.

Kelemen, P.B., Koga, K. and Shimizu, N., Geochemistry of gabbro sills in the crust/mantle transition zone of the Oman ophiolite: Implications for the origin of the oceanic lower crust, submitted, 1996.

Kent, G.M., Harding, A.J. and Orcutt, J., Distribution of magma beneath the East Pacific Rise near the $9^{\circ} 03^{\prime} \mathrm{N}$ Overlapping Spreading Center from forward modeling of CDP data, J. Geophys. Res., 98, 13,971-13,996, 1993a.

Kent, G.M., Harding, A.J. and Orcutt, J.A., Evidence for a smaller magma chamber beneath the East Pacific Rise at 9³0'N, Nature, 344, 650-653, 1990.

Kent, G.M., Harding, A.J. and Orcutt, J.A., Distribution of magma beneath the East Pacific Rise between the Clipperton Transform and the $9^{\circ} 17^{\prime} \mathrm{N}$ Deval from forward modeling of CDP data, J. Geophys. Res., 98, 13,945-13,970, 1993 b.

Kent, G.M., Harding, A.J., Orcutt, J.A., Detrick, R.S., Mutter, J.C. and Buhl, P., The uniform accretion of oceanic crust south of the Garrett Transform at $14^{\circ} 15^{\prime} \mathrm{S}$ on the East Pacific Rise, J. Geophys. Res., 99, 9005-9698, 1994.

Kidd, R.G.W., A model for the process of formation of the upper oceanic crust, Geophys. J. R. Astr. Soc., 50, 149-183, 1977.

Langmuir, C.H., Bender, J.F. and Batiza, R., Petrologic and tectonic segmentation of the East Pacific Rise, $5^{\circ} 30^{\prime}-14^{\circ} 30^{\prime} \mathrm{N}$, Nature, 322, 422-429, 1986.

Liner, C.L., General theory and antaomy of dip-moveout, Geophys., 55, 595-607, 1990.

Lister, C.R.B., On the intermittency and crystallization mechanisms of sub-seafloor magma chambers, Geophys. J. R. Astr. Soc., 73, 351-365, 1983. 
Lonsdale, P., Segmentation of the Pacific-Nazca Spreading Center, $1^{\circ} \mathrm{N}-20^{\circ} \mathrm{S}, \mathrm{J}$. Geophys. Res., 94, 12,197-12,225, 1989.

Macdonald, K., Fox, P.J., Miller, S., Carbotte, S., Edwards, M., Eisen, M., Fornari, D., Perram, L., Pockalny, R., Scheirer, D., Tighe, S., Weiland, C. and Wilson, D., The East Pacific Rise and its flanks $8-18^{\circ} \mathrm{N}$ : History of segmentation, propagation and spreading direction based on SeaMARC II and Sea Beam studies, Mar. Geophys. Res., 14, 299-344, 1992.

Macdonald, K.C. and Fox, P.J., The axial summit graben and cross-sectional shape of the East Pacific Rise as indicators of axial magma chambers and recent volcanic eruptions, 88, 119-131, 1988.

Macdonald, K.C., Sempéré, J.-C. and Fox, P.J., East Pacific Rise from Siqueiros to Orozco fracture zones: Along-strike continuity of axial neovolcanic zones and structure and evolution of overlapping spreading centers, J. Geophys. Res., 89, 6049-6069, 1984.

Madsen, J.A., Detrick, R.S., Mutter, J.C., Buhl, P. and Orcutt, J.C., A two- and threedimensional analysis of gravity anomalies associated with the East Pacific Rise at $9^{\circ} \mathrm{N}$ and $13^{\circ}$ N, J. Geophys. Res., 95, 4967-4987, 1990.

Magde, L.S., Detrick, R.S. and Group, T., The crustal and upper mantle contribution to the axial gravity anomaly at the Southern East Pacific Rise, J. Geophys. Res., 100, 3747-3766, 1995.

Mahoney, J.J., Sinton, J.M., Kurz, M.D., Macdougall, J.D., Spencer, K.J. and Lugmair, G.W., Isotope and trace element characteristics of a super-fast spreading ridge: East Pacific Rise, 13-23ㅇ, Earth Planet. Sci. Lett., 121, 173-193, 1994.

Mainprice, D., Modeling the anisotropic seismic properties of partially molten rocks found at mid-ocean ridges, Tectonophys., submitted to Adolphe Nicolas Special Volume, 1996.

Murase, T. and McBirney, A., Properties of some common igneous rocks and their melts at high temperatures, Geol. Soc. Am. Bull., 84, 3563-3592, 1973. 
Mutter, J.C., Carbotte, S.M., Su, W., Xu, L., Buhl, P., Detrick, R.S., Kent, G.M., Orcutt, J.A. and Harding, A.J., Seismic images of active magma systems beneath the East Pacific Rise between $17^{\circ} 05^{\prime}$ and $17^{\circ} 35^{\prime}$ S, Science, 268, 391-395, 1995.

Naar, D.F. and Hey, R.N., Recent Pacific-Easter-Nazca plate motions, International Union of Geodesy and Geophysics and American Geophysical Union, 9-30, 1989.

Natland, J.H. and Dick, H.J.B., Melt migration through high-level gabbroic cumulates of the East Pacific Rise at Hess Deep: The origin of magma lenses and the deep crustal structure of fast-spreading ridges, Proc. ODP Sci. Results, 147, 21-58, 1996.

Nehlig, P. and Juteau, T., Flow porosities, permeabilities and preliminary data on fluid inclusions and fossil thermal gradients in the crustal sequence of the Sumail ophiolite (Oman), Tectonophys., 151, 199-221, 1988.

Nicolas, A.,Structure of ophiolites and dynamics of oceanic lithosphere, vol. 4, pp. 367, Kluwer Academic Publishers, Dordrecht, The Netherlands, 1989.

Nicolas, A. and Boudier, F., Rooting of the sheeted dike complex in the Oman ophiolite, in Ophiolite Genesis and Evolution of the Oceanic Lithosphere, vol. edited by Peters, T., Nicolas, A. and Coleman, R., pp. 39-54, Ministry of Petroleum and Minerals, Muscat, Oman, 1991.

Nicolas, A., Boudier, F. and Ildefonse, B., Variable crustal thickness in the Oman ophiolite: Implications for oceanic crust, J. Geophys. Res., 101, 17941-17950, 1996.

Pálmason, G., Continuum model of crustal generation in Iceland: Kinematic aspects, $J$. Geophys., 47, 7-18, 1980.

Phipps Morgan, J. and Chen, Y.J., The genesis of oceanic crust: Magma injection, hydrothermal circulation, and crustal flow, J. Geophys. Res., 98, 6283-6298, 1993a.

Phipps Morgan, J. and Chen, Y.J., Dependence of ridge-axis morphology on magma supply and spreading rate, Nature, 364, 706-708, $1993 \mathrm{~b}$. 
Purdy, G.M., Christeson, G. and Solomon, S., Relationship between spreading rate and the seismic structure of mid-ocean ridges, Nature, 355, 815-817, 1992.

Ryan, M.P., Neutral buoyancy and the structure of mid-ocean ridge magma reservoirs, $J$. Geophys. Res., 98, 22,321-22,338, 1993.

Scheirer, D.S. and Macdonald, K.C., Variation in cross-sectional area of the axial ridge along the East Pacific Rise: Evidence for the magmatic budget of a fast spreading center, J. Geophys. Res., 98, 7871-7886, 1993.

Schouten, H. and Denham, C.R., Modeling the oceanic magnetic source layer, in Deep Drilling Results in the Atlantic Ocean: Ocean Crust, Maurice Ewing Ser., vol. 2 edited by Talwani, M., Harrison, C.G. and Hayes, D.E., pp. 151-159, AGU, Washington, D.C., 1979.

Sinton, J.M., Smaglik, S.M., Mahoney, J.J. and Macdonald, K.C., Magmatic processes at superfast spreading mid-ocean ridges: Glass compositional variations along the East Pacific Rise $13^{\circ} \mathrm{S}-23^{\circ} \mathrm{S}$, J. Geophys. Res., 96, 6133-6155, 1991.

Sisson, T.W. and Grove, T.L., Temperatures and $\mathrm{H} 2 \mathrm{O}$ contents of low-MgO highalumina basalts, Contr. Mineral. and Petrol., 113, 167-184, 1993.

Sleep, N.H., Hydrothermal circulation, Anhydrite precipitation, and thermal structure at ridge axes, J. Geophys. Res., 96, 2375-2387, 1991.

Tighe, S.A., Detrick, R.S., Fox, P.J., Langmuir, C.H., Mutter, J.C., Ryan, W.B. and Tyce, R.C., East Pacific Rise Data Synthesis Final Report, Vol. 1, Tighe, (ed.), JOI, Inc. (publ.), Washington, DC, 1988.

Tolstoy, M., Harding, A.J., Orcutt, J.A. and Group, T., Deepening of the axial magma chamber on the southern East Pacific Rise toward the Garrett Fracture Zone, $J$. Geophys. Res., submitted, 1996.

Toomey, D.R., Purdy, G.M., Solomon, S.C. and Wilcock, W.S.D., The threedimensional seismic velocity structure of the East Pacific Rise near latitude $9^{\circ} 30^{\prime} \mathrm{N}$, Nature, 347, 639-645, 1990. 
van Avendonk, H., Harding, A.J., Orcutt, J.A. and McClain, J., A 2-D tomographic study of the Clipperton transform fault, J. Geophys. Res., submitted, 1997.

Vera, E.E., Buhl, P., Mutter, J.C., Harding, A.J., Orcutt, J.A. and Detrick, R.S., The structure of 0-0.2 My old oceanic crust at $9^{\circ} \mathrm{N}$ on the East Pacific Rise from expanded spread profiles, J. Geophys. Res., 95, 15,529-15,556, 1990.

Walker, G.P.L., Gravitational (density) controls on volcanism, magma chambers and intrusions, Australian J. Earth Sci., 36, 149-165, 1989.

Wang, X. and Cochran, J.R., Gravity anomalies, isostasy, and mantle flow at the East Pacific Rise crest, J. Geophys. Res., 98, 19,505-19,532, 1993.

Wang, X., Cochran, J.R. and Barth, G., Gravity anomalies, crustal thickness and the pattern of mantle flow at the fast spreading East Pacific Rise, $9^{\circ} \mathrm{N}-10^{\circ} \mathrm{N}$ : Evidence for three-dimensional upwelling, J. Geophys. Res., 101, 17927-17940, 1996.

Wright, D.J., Haymon, R.M. and Fornari, D.J., Crustal fissuring and its relationship to magmatic and hydrothermal processes on the East Pacific Rise crest ( $9^{\circ} 12^{\prime}$ to $\left.54^{\prime} \mathrm{N}\right)$, J. Geophys. Res., 100, 6097-6120, 1995. 
Table 1. Ridge morphology, magma sill and Layer 2A characteristics

${ }^{1}$ From the along axis data

2 Excluding CDP 33. Including CDP33: $1450 \pm 1500$

* Interpolated from Scheirer and Macdonald [1993]

¥ I picked and calculated from Kent et al. [1994]

¥ I picked and calculated from Harding et al. [1993]

a Kent et al. [1994]

b Harding et al. [1993]

c Kent et al. [1993b]

d Kent et al. [1993a] 
Table 1: Ridge morphology, magma sill and Layer 2A characteristics

\begin{tabular}{|c|c|c|c|c|c|c|c|c|}
\hline \multirow[t]{2}{*}{ Latitude } & \multirow[t]{2}{*}{ line \# } & \multirow{2}{*}{$\begin{array}{l}\text { water } \\
\text { depth } \\
\text { (m) }\end{array}$} & \multirow{2}{*}{$\begin{array}{l}\text { cross- } \\
\text { sectional } \\
\text { area* } \\
\left(\mathrm{km}^{2}\right)\end{array}$} & \multicolumn{2}{|c|}{ magma sill } & \multicolumn{3}{|c|}{ Layer 2A Thickness } \\
\hline & & & & $\begin{array}{l}\text { width } \\
\text { (m) }\end{array}$ & $\begin{array}{l}\text { depth } \\
\text { (m) }\end{array}$ & $\begin{array}{l}\text { On-axis } \\
\text { (m) }\end{array}$ & $\begin{array}{l}\text { Off-axis } \\
\text { (m) }\end{array}$ & $\begin{array}{l}\text { Half-width } \\
(\mathrm{km})\end{array}$ \\
\hline \multicolumn{9}{|c|}{ Southern East Pacific Rise } \\
\hline-20.16 & SEPR02 & 2846 & 0.6 & & $1060^{1}$ & 330 & 620 & 1.5 \\
\hline-19.44 & SEPR04 & 2782 & 2.3 & 560 & 1110 & 240 & 410 & 0.7 \\
\hline-18.46 & SEPR06 & 2619 & 4.9 & 300 & 1340 & 270 & 520 & 3.2 \\
\hline-18.21 & SEPR08 & 2673 & 5.0 & 590 & 1550 & 200 & 350 & 1.2 \\
\hline-17.54 & SEPR34 & 2611 & 5.2 & 740 & 1210 & 260 & 460 & 4.1 \\
\hline-17.46 & SEPR26 & 2590 & 5.1 & 1540 & 1000 & 230 & 390 & 2.0 \\
\hline-17.44 & SEPR33 & 2588 & 5.4 & 950 & 1190 & 247 & 530 & 2.3 \\
\hline-17.42 & SEPR27 & 2591 & 5.6 & 850 & 760 & 230 & 570 & 3.0 \\
\hline-17.38 & SEPR28 & 2611 & 5.5 & 710 & 1100 & 240 & 490 & 2.1 \\
\hline-17.33 & SEPR32 & 2621 & 5.0 & 375 & 1350 & 210 & 530 & 1.3 \\
\hline-17.29 & SEPR29 & 2621 & 5.4 & 875 & 1140 & 260 & 510 & 1.5 \\
\hline-17.24 & SEPR31 & 2610 & 6.2 & 710 & 1110 & 250 & 530 & 1.3 \\
\hline-17.20 & SEPR30 & 2605 & 5.8 & 560 & 1150 & 270 & 560 & 1.6 \\
\hline-17.16 & SEPR11 & 2601 & 5.3 & 500 & 1210 & 260 & 450 & 1.9 \\
\hline-17.07 & SEPR10 & 2628 & 5.4 & 1010 & 1260 & 240 & 480 & 2.2 \\
\hline-14.49 & SEPR57 & 2631 & 4.3 & $650^{\mathrm{a}}$ & $1100^{¥}$ & $240^{\Psi}$ & $570 \mathrm{a}$ & $1.8^{\mathrm{a}}-\mathrm{c} \mathrm{c}$ \\
\hline-14.45 & SEPR68 & 2628 & 4.2 & $400^{a}$ & $1000^{¥}$ & $270^{ \pm}$ & $540 \mathrm{a}$ & $1.5^{\mathrm{a}}$ \\
\hline-14.41 & SEPR56 & 2630 & 4.4 & $700^{\mathrm{a}}$ & $990^{\Psi}$ & $190^{¥}$ & $540 \mathrm{a}$ & $2.3^{\mathrm{a}}$ \\
\hline-14.37 & SEPR67 & 2634 & 4.5 & $1050^{\mathrm{a}}$ & $940^{*}$ & $270^{¥}$ & $540^{a}$ & $2.7^{a}$ \\
\hline-14.33 & SEPR69 & 2636 & 4.9 & $950^{\mathrm{a}}$ & $960 \%$ & $280^{¥}$ & $570^{a}$ & $2.5^{\mathrm{a}}$ \\
\hline-14.29 & SEPR66 & 2640 & 5.0 & $750^{\mathrm{a}}$ & $1040^{¥}$ & $210^{¥}$ & $530^{a}$ & $2.8^{\mathrm{a}}$ \\
\hline-14.25 & SEPR70 & 2642 & 4.8 & $750^{\mathrm{a}}$ & $1080^{¥}$ & $220 ¥$ & $510^{a}$ & $3.4^{\mathrm{a}}$ \\
\hline-14.21 & SEPR65 & 2638 & 4.4 & $700^{\mathrm{a}}$ & $1100^{¥}$ & $240 \approx$ & $530^{a}$ & $3.2^{\mathrm{a}}$ \\
\hline-14.17 & SEPR71 & 2635 & 4.6 & $750^{\mathrm{a}}$ & 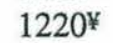 & $270^{¥}$ & $540^{a}$ & $3.4^{\mathrm{a}}$ \\
\hline-14.13 & SEPR64 & 2636 & 4.2 & $375^{a}$ & $1250^{¥}$ & $240 \approx$ & $510 \mathrm{a}$ & $2.9 \mathrm{a}$ \\
\hline-14.09 & SEPR72 & 2635 & 4.7 & $550^{a}$ & $1120^{¥}$ & $250 ¥$ & $540 \mathrm{a}$ & $2.4 \mathrm{a}$ \\
\hline-14.05 & SEPR63 & 2634 & 4.8 & $550^{\mathrm{a}}$ & $1220^{*}$ & $210^{¥}$ & $530^{a}$ & $2.8^{\mathrm{a}}$ \\
\hline-14.01 & SEPR46 & 2636 & 4.9 & $400^{a}$ & $1220^{¥}$ & $270 ¥$ & $550^{a}$ & $2.7 \mathrm{a}$ \\
\hline-13.81 & SEPR61 & 2640 & 4.5 & 690 & 1200 & 200 & 520 & 1.9 \\
\hline & mean & 2640 & 4.7 & 680 & 1140 & 245 & 515 & 2.3 \\
\hline \multicolumn{2}{|c|}{ standard deviation } & 50 & 1.1 & 260 & 150 & 30 & 57 & 0.8 \\
\hline \multicolumn{9}{|c|}{ Northern East Pacific Rise } \\
\hline+08.92 & CDP37 & 2580 & 3.5 & $750^{d}$ & $1660^{d}$ & $380 \ddagger$ & $560^{b}$ & $2.1^{\mathrm{b}}$ \\
\hline+09.31 & CDP33 & 2590 & 3.2 & $4100^{c}$ & $1500^{c}$ & $200 \ddagger$ & $510^{\mathrm{b}}$ & $1.6^{\mathrm{b}}$ \\
\hline+09.49 & CDP31 & 2580 & 3.6 & $1200^{c}$ & $1560^{c}$ & $180 \ddagger$ & $450^{b}$ & $4.1^{b}$ \\
\hline+09.66 & CDP29 & 2560 & 3.6 & $700^{c}$ & $1550 \mathrm{c}$ & $230 \div$ & $440^{b}$ & $2.3 \mathrm{~b}$ \\
\hline+09.83 & CDP27 & 2510 & 4.0 & $500^{c}$ & $1430^{c}$ & $280 \div$ & $460^{b}$ & $2.5^{b}$ \\
\hline \multirow{2}{*}{\multicolumn{2}{|c|}{$\begin{array}{r}\text { mean } \\
\text { standard deviation }\end{array}$}} & 2570 & 3.6 & $788^{2}$ & 1540 & 254 & 484 & 2.5 \\
\hline & & 40 & 0.3 & $295^{2}$ & 85 & 80 & 50 & 0.9 \\
\hline
\end{tabular}


Table 2: Correlation coefficients for across-axis and along-axis data from the southern EPR

a) Correlation coefficients for the Southern East Pacific Rise: $N=29$

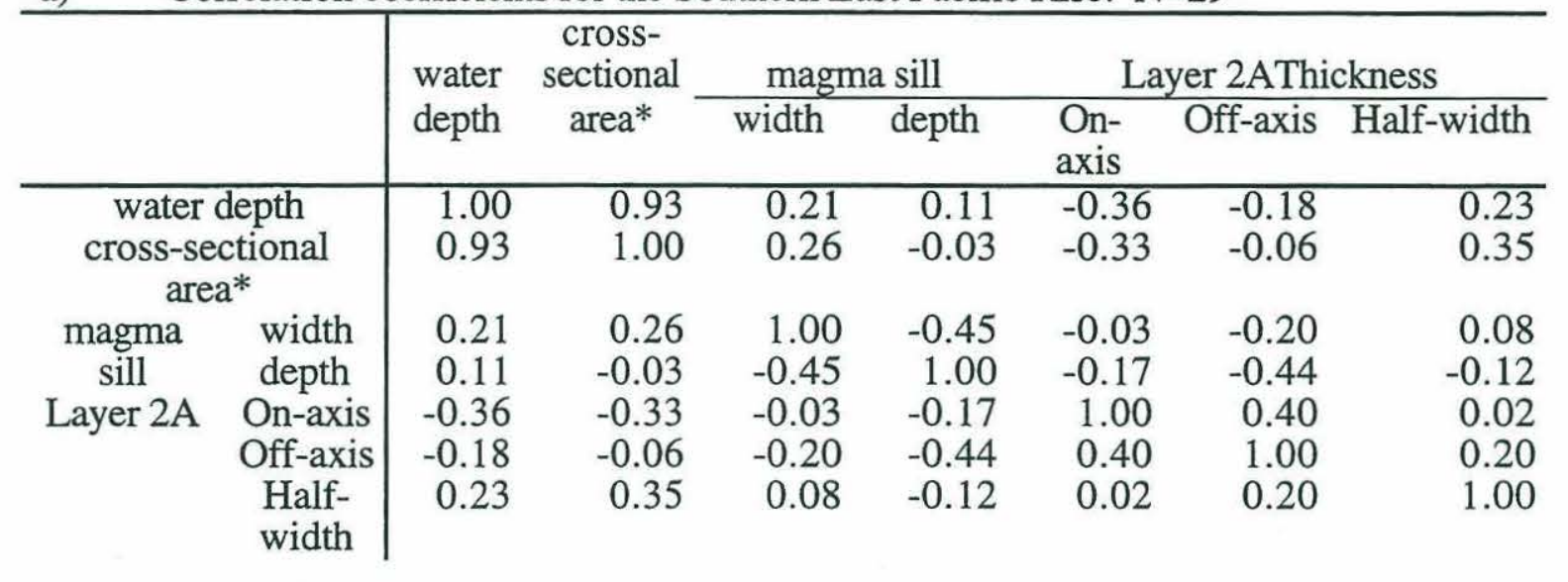

b) Correlation coefficients for the Along-Axis data: $\mathrm{N}>4071$

\begin{tabular}{|c|c|c|c|c|c|}
\hline & \multirow{2}{*}{$\begin{array}{l}\text { water } \\
\text { depth }\end{array}$} & \multirow{2}{*}{$\begin{array}{c}\text { cross- } \\
\text { sectional } \\
\text { area* }\end{array}$} & \multicolumn{2}{|c|}{ magma sill } & Layer 2A Thickness \\
\hline & & & width & depth & On-axis Off-axis Half-width \\
\hline water depth & 1.00 & 0.79 & & -0.05 & -0.96 \\
\hline $\begin{array}{l}\text { cross-sectional } \\
\text { area* }\end{array}$ & 0.79 & 1.00 & & 0.11 & -0.70 \\
\hline magma width & & & & & \\
\hline sill depth & -0.05 & 0.11 & & 1.00 & 0.34 \\
\hline $\begin{array}{cc}\text { Layer 2A } & \text { On-axis } \\
& \text { Off-axis } \\
& \text { Half- } \\
& \text { width }\end{array}$ & -0.96 & -0.70 & & 0.34 & 1.00 \\
\hline
\end{tabular}


Figure 1. The current paradigm for magmatic activity on fast spreading ridges predicts a contrast in ridge morphology and crustal structure between ridge sections with a high magma budget and those that have a low magma budget 


\section{SIMPLE MAGMA SUPPLY MODEL}

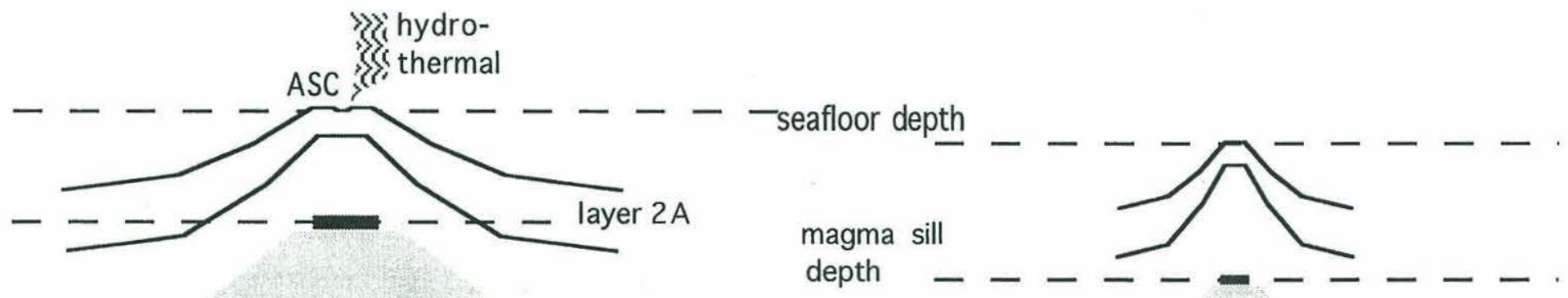

low velocity zone

A. High Magma Budget

- thicker crust

- shallow water depth

- broad cross-sectional area

- wide low velocity zone

- high MgO content

- high temperature

- low density

- shallow melt lens

- thicker layer 2A

- ASC present

- hydrothermal venting
B. Low Magma Budget

- thinner crust

- deeper water depth

- narrow cross-sectional area

- narrow low velocity zone - lower MgO content

- lower temperature

- higher density

- deeper melt lens

- thinner layer 2A

- no ASC present

- no hydrothermal venting 
Figure 2. Map of the southern East Pacific Rise (SEPR). Major segment boundaries are indicated. A multichannel seismic line was shot along the ridge crest form the northern limb of the $20.7^{\circ} \mathrm{S}$ propagator to the Garrett fracture zone. Boxes indicate the intensive multichannel seismic study areas at $14^{\circ} \mathrm{S}, 15^{\circ} 55^{\prime} \mathrm{S}$ and $17^{\circ} \mathrm{S}$. The remaining five acrossaxis seismic lines are shown by dark lines, as well as the location of SEPR27 and SEPR70 in the intensive study areas at $17^{\circ} \mathrm{S}$ and $14^{\circ} \mathrm{S}$ respectively. 


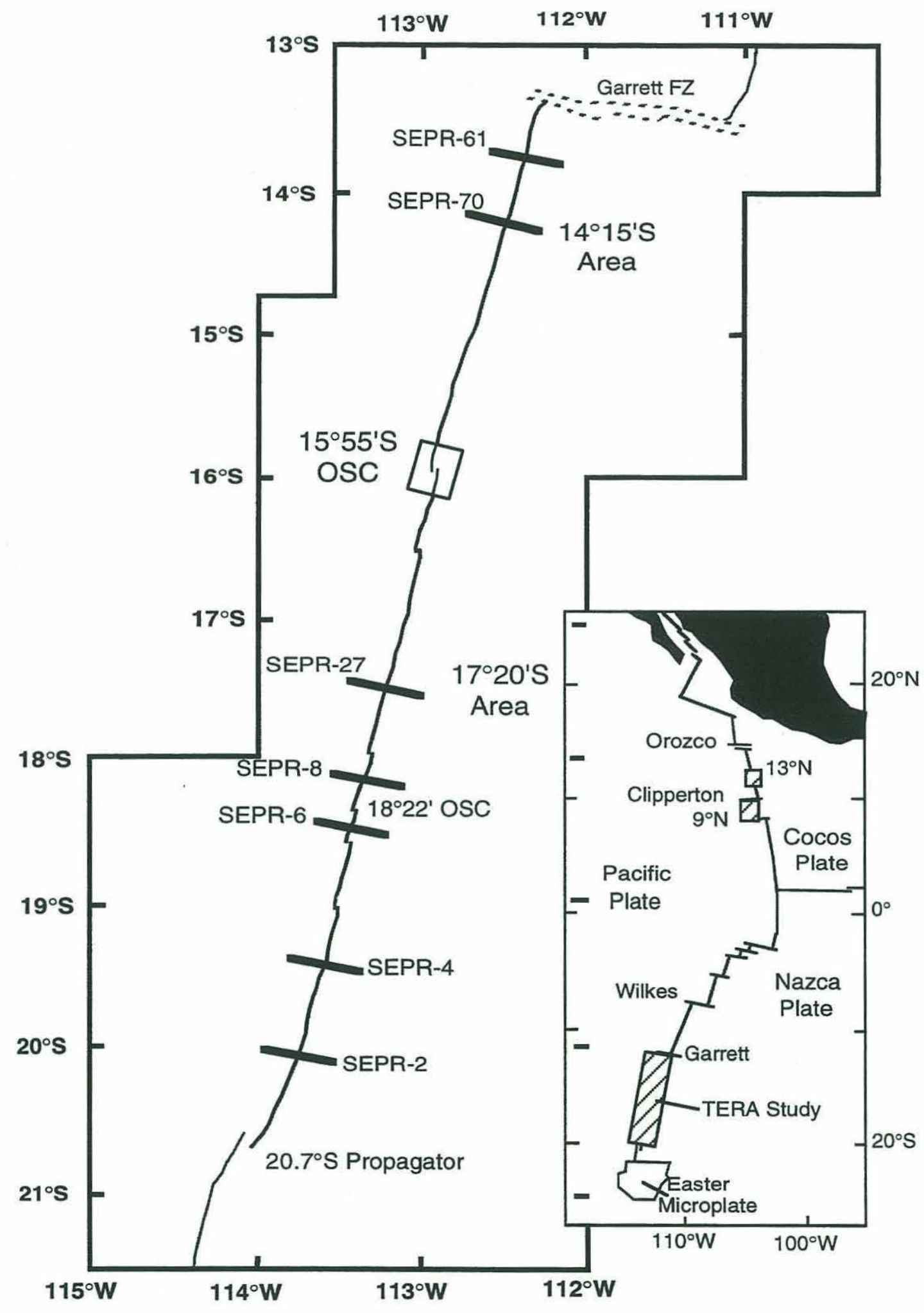


Figure 3. Along-axis summary figure of the seismic structure and other indicators of magma budget along the SEPR from the $20.7^{\circ} \mathrm{S}$ propagator to the Garrett fracture zone $\left(13.4^{\circ} \mathrm{S}\right),>800 \mathrm{~km}$. Vertical lines show overlapping spreading centers (OSCs). The northern, central and southern ridge sections are defined based on differences in the range and variability of the seafloor depth, extrusive thickness, and magma sill depth, and are bounded by the Garrett transform, the $15^{\circ} 55^{\prime} \mathrm{S}$ and $17^{\circ} 55^{\prime} \mathrm{S}$ OSCs, and the large $20.7^{\circ} \mathrm{S}$ OSC. (a) seafloor topography (light grey) [Tighe et al., 1988], depth to the base of the extrusive layer (layer 2A) (dark grey), and the magma sill reflector (black). Note the relatively uniform thickness of layer $2 \mathrm{~A}$ and the large variability in magma sill depth. The general variation of magma sill depth along three sections of the ridge is outlined (dashed line). Locations of the across-axis seismic profiles shown in Figure 4 are indicated in light grey at the bottom of the figure. (b) cross-sectional area of the ridge (dark) [Scheirer and Macdonald, 1993] and the mantle Bouguer anomaly (light grey) [Magde et al., 1995]. Note the excellent correlation between these two measures of the volume of the crustal low velocity zone. (c) $\mathrm{MgO} \mathrm{wt} \%$ for basalt samples dredged from the ridge axis (dark stars) [Sinton et al., 1991]. T-MORBs are indicated by dark circles. Samples collected from the youngest on-axis flows on Nautile submersible dives (light circles) [pers. comm. Sinton, 1995] do not deviate much from the dredge samples collected in the same area. The curve represents a running mean made through the data to show the local trend (variability is $\sim \pm 1$ wt\%). The scale on the left-hand side shows the corresponding lava temperatures. The letters indicate the nomenclature for different magmatic segments [Sinton et al., 1991]. (d) Light attenuation in the water column integrated from 100 to $300 \mathrm{~m}$ above the seafloor in bins of 0.03 degrees [Baker and Urabe, 1996]. Along the $\mathrm{x}$-axis the dark bars show the portions of the ridge along which Lonsdale [1989] located an ASC or axial graben using SeaBeam data. Note the large variability in the location of hydrothermal fields and the correlation with the presence of an ASC. 
a)

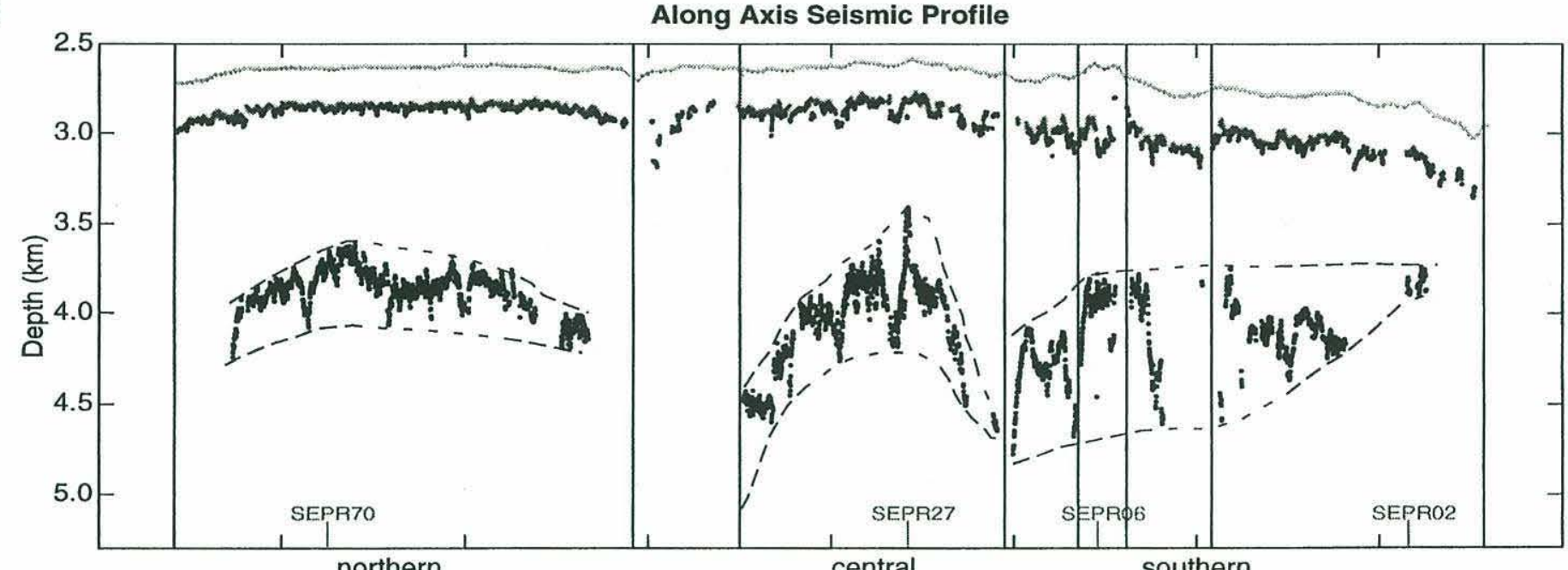

b)

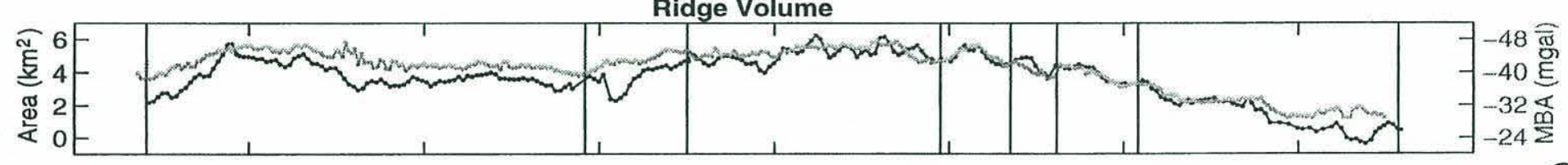

c)

d)
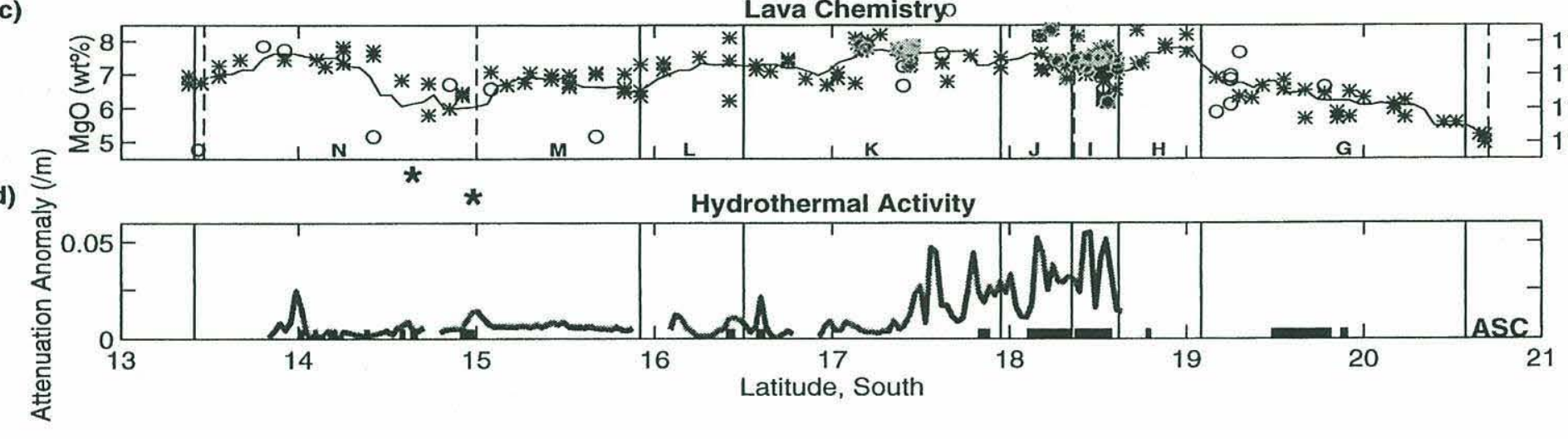
Figure 4. Along- and across-axis seismic lines from four areas of the ridge that range from inflated to magma-starved. The across-axis data have had prestack DMO applied, then were stacked and finite difference migrated to correct for seafloor and layer 2A topography. Note the range in widths of the ridge crest and amount of topography. Also the differences in the thickening profiles of layer $2 \mathrm{~A}$. The along-axis lines show the stacked multichannel seismic section. Note the uniformity in the depth and nature of the layer $2 \mathrm{~A}$ reflection everywhere along the axis. In contrast there are significant along-axis differences in the depth of the magma sill reflector. (a) Across-axis profile SEPR27 at $17^{\circ} 25^{\prime} \mathrm{S}$ and alongaxis profile SEPR 35 from $17^{\circ} 32^{\prime} \mathrm{S}$ to $17^{\circ} 15^{\prime} \mathrm{S}$. The ridge is shallow and has a wide domed morphology. At $17^{\circ} 24^{\prime} \mathrm{N}$, just north of the shallowest and broadest portion of the ridge, the melt lens shoals from an average depth of $1150 \mathrm{~m}$ to $800 \mathrm{~m}$ below the seafloor over a distance of $4 \mathrm{~km}$. (b) Across-axis profile SEPR70 at 14 $15^{\circ} \mathrm{S}$ and along-axis profile SEPR 45 from $14^{\circ} 23^{\prime} \mathrm{S}$ to $14^{\circ} 07^{\prime} \mathrm{S}$. The magma sill is shallow and relatively uniform in depth (1080 m below the seafloor). Note the graben on west side of the ridge on the across-axis profile. (c) Across-axis profile SEPR06 at $18^{\circ} 28^{\prime} \mathrm{S}$ and along-axis profiles SEPR05 and SEPR07 from $18^{\circ} 37^{\prime} \mathrm{S}$ to $18^{\circ} 21^{\prime} \mathrm{S}$. Note the axial summit graben on the across-axis profile. The magma sill lies at a deeper depth (1340 m below the seafloor) and deepens towards the OSCs at the $18^{\circ} 39^{\prime}$ S and $18^{\circ} 21^{\prime}$ S. Note that SEPR70 and SEPR06 have similar cross-sectional areas and yet there is a large difference in magma sill depth between the two. (d) Across-axis profile SEPR02 at $20^{\circ} 10^{\prime} \mathrm{S}$ and along-axis profiles SEPR01 and SEPR03 from $20^{\circ} 17^{\prime} \mathrm{S}$ to $20^{\circ} 01^{\prime} \mathrm{S}$. The ridge is deep and very narrow in this region and there is evidence for significant tectonism on the flanks. From $20^{\circ} 10-15$ 'S on the along-axis line a small, and surprisingly shallow (1060 m below the seafloor) magma lens is imaged for the magma-starved morphology. 
(A)

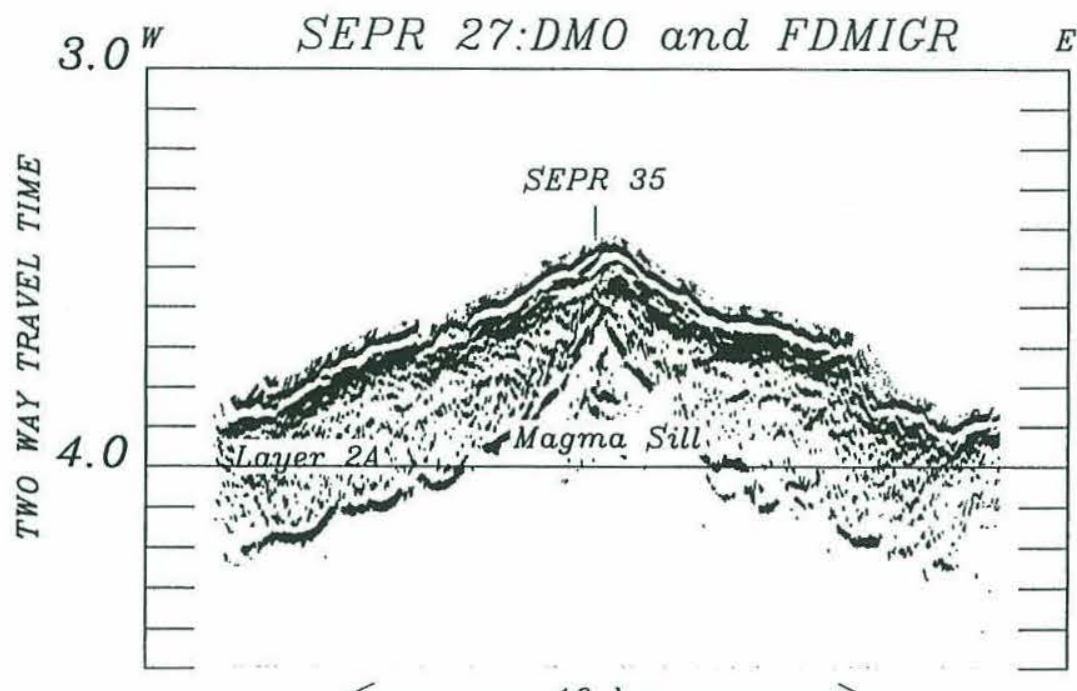

$10 \mathrm{~km} \longrightarrow$

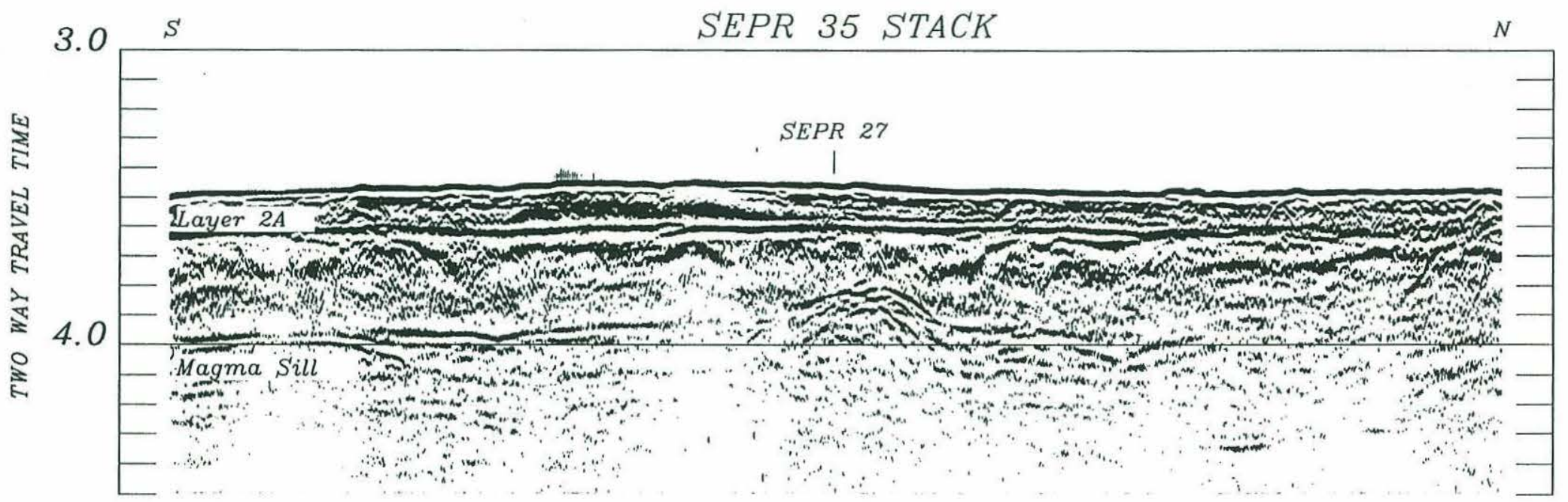


(B)
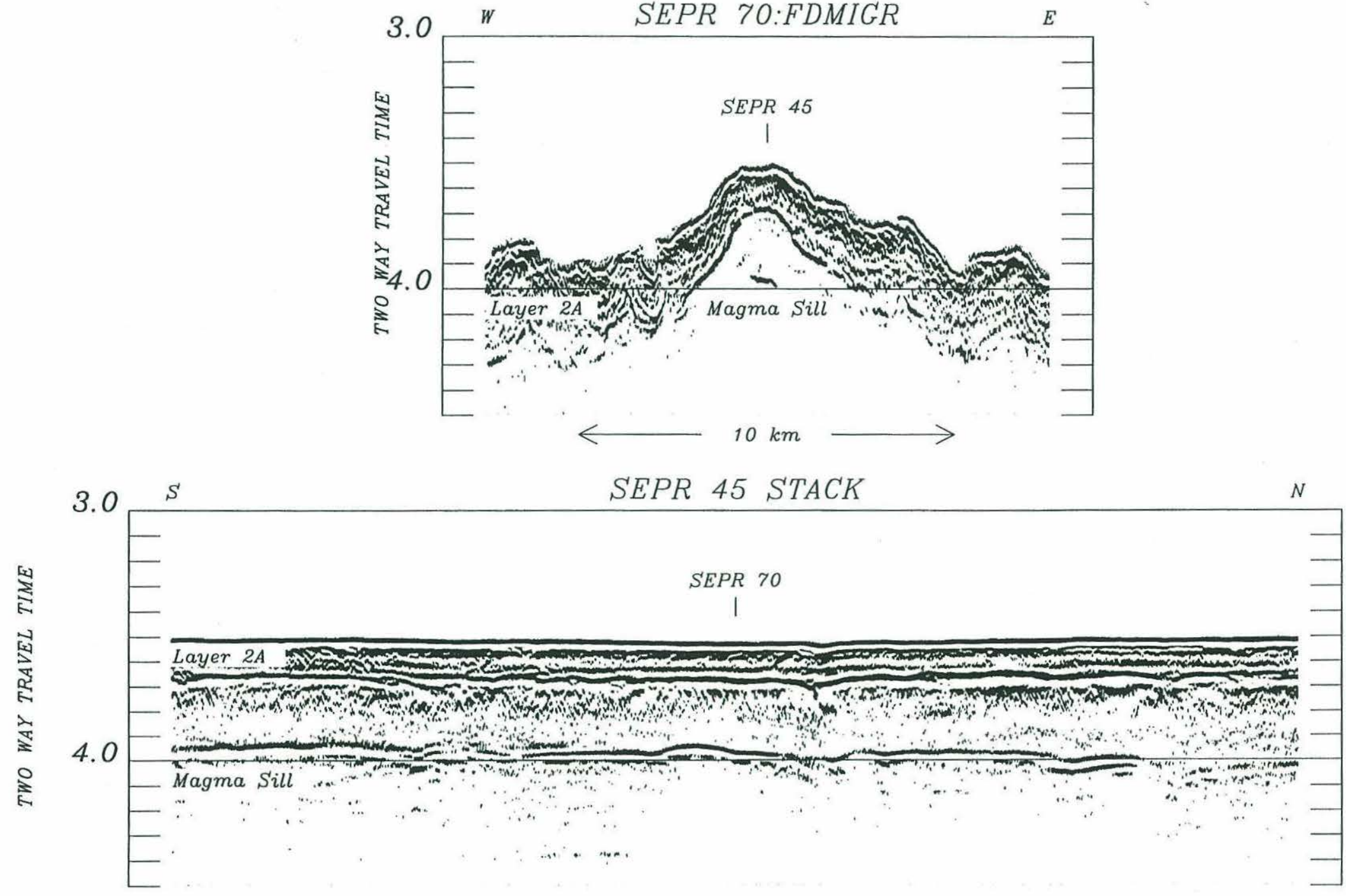
(C)
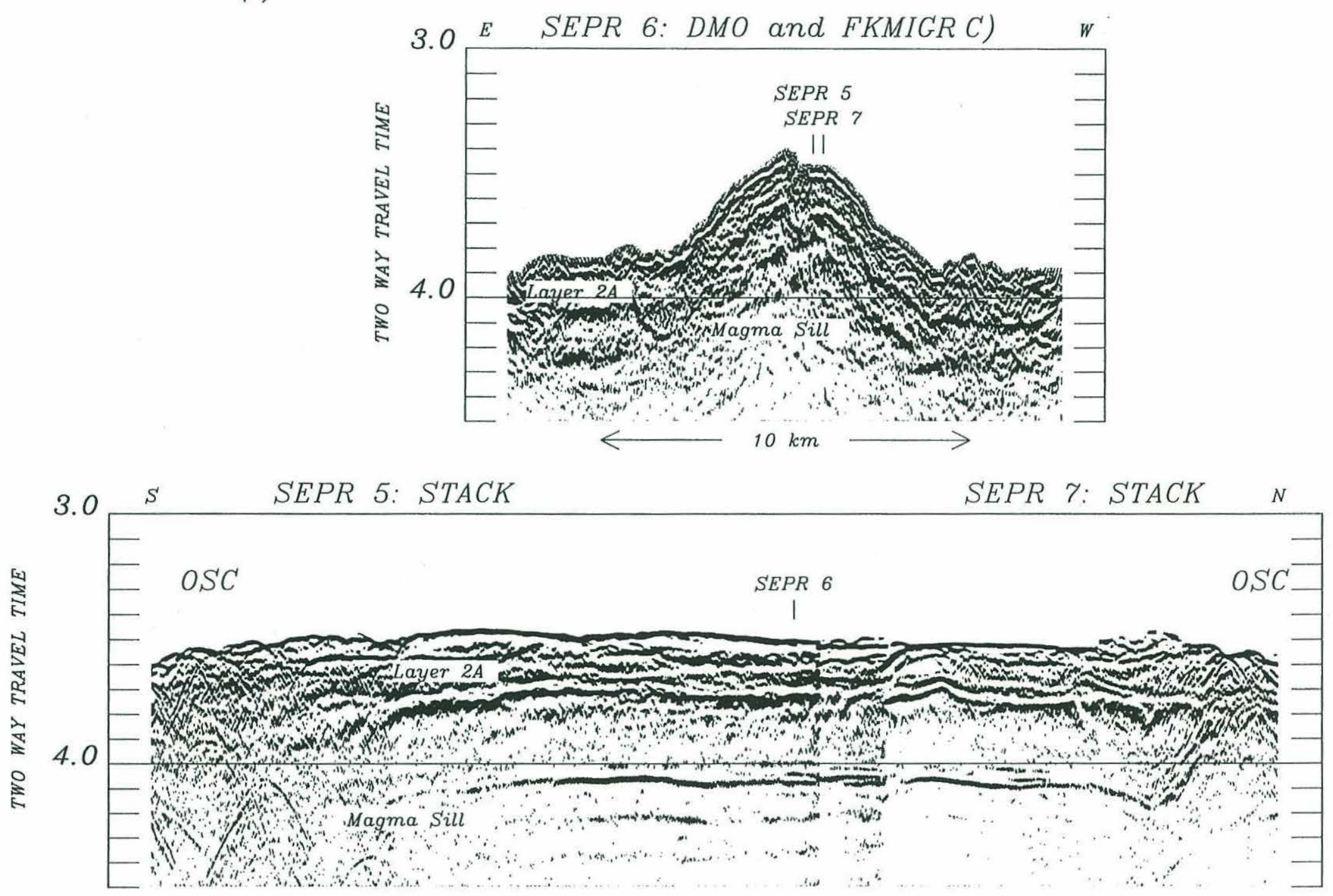
(D)
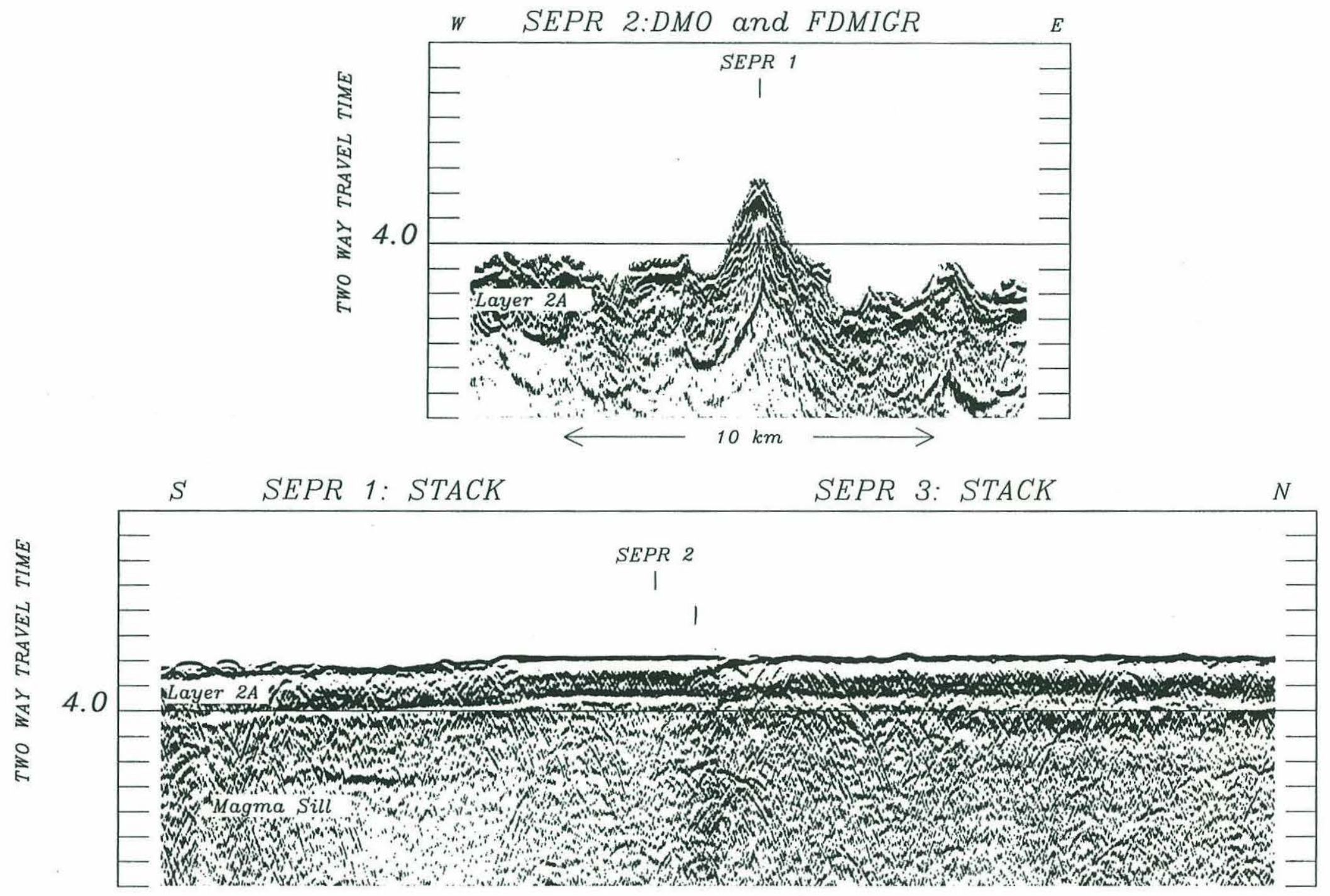
Figure 5. Histograms of 2A and magma sill depth from the SEPR. Data is binned at 100 $\mathrm{m}$. This emphasizes the uniformity of layer $2 \mathrm{~A}$ thickness on the ridge crest and the much larger variability of magma sill depth. 


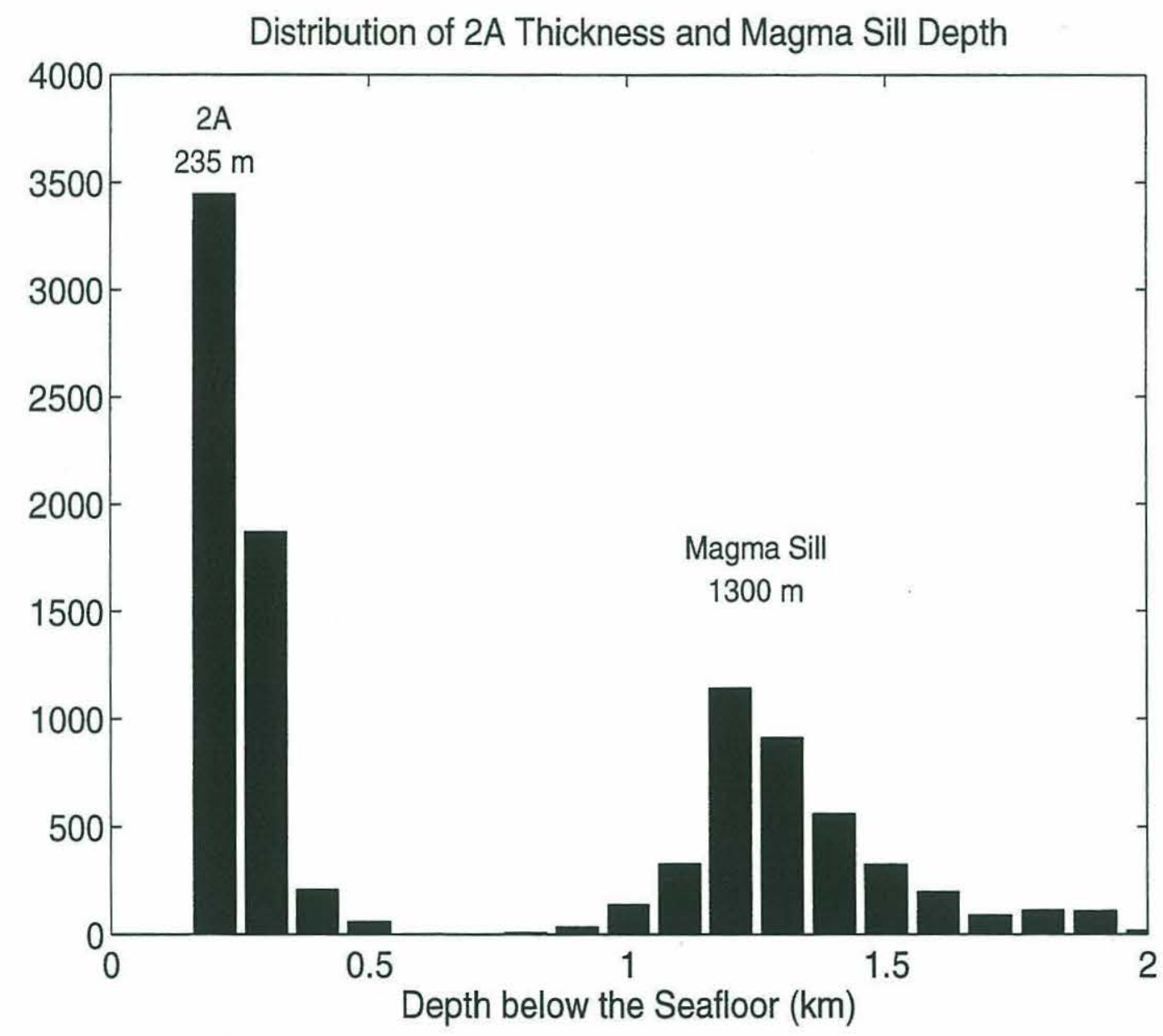


Figure 6. Plots showing water depth, mantle Bouguer anomaly, and $\mathrm{MgO}$ content of dredged lavas for the SEPR plotted as a function of cross-sectional area. Correlation coefficients for these variables are shown on the figure. Variations in magma supply are accompanied by crustal thickness changes of $\sim 500 \mathrm{~m}$ and are maintained over $\sim 100 \mathrm{Kyr}$. 
a)

b)

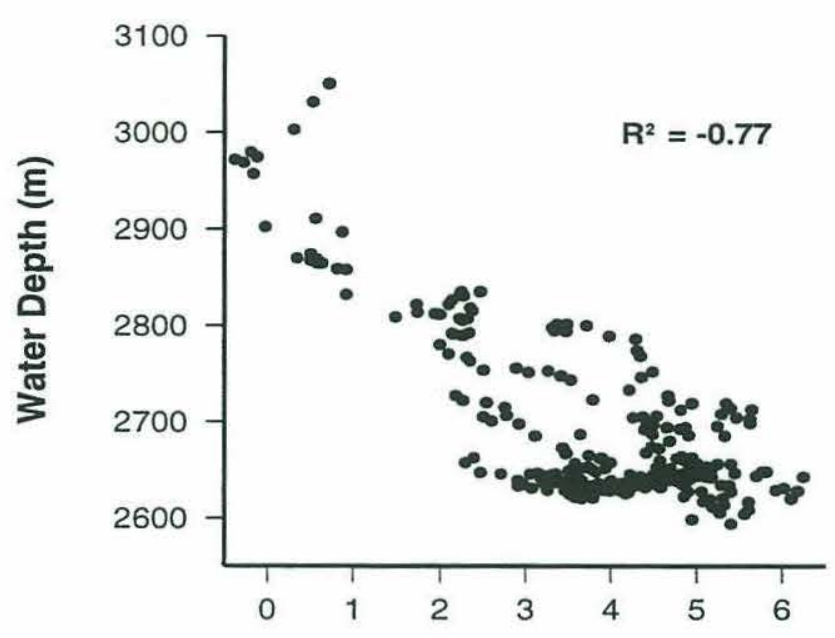

c)
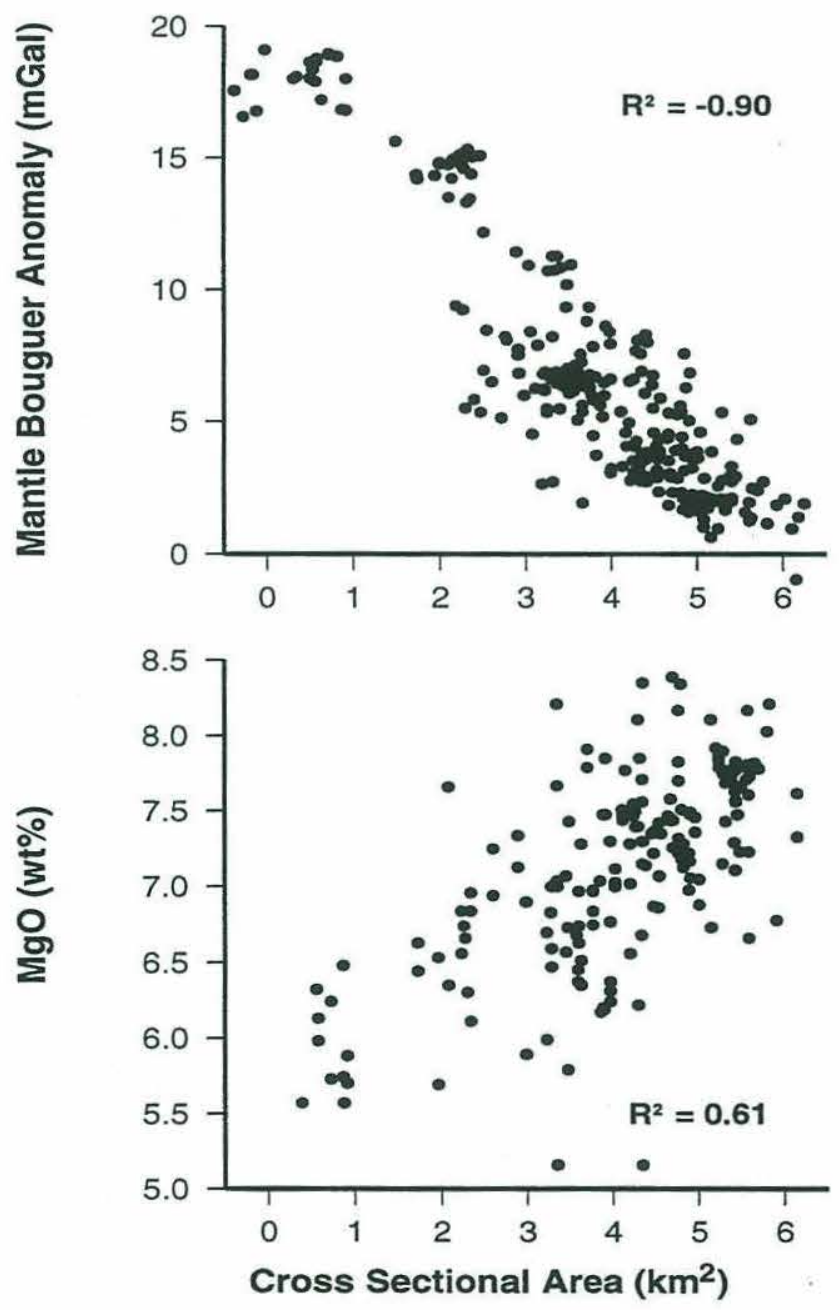
Figure 7. Major element geochemistry of lavas dredged from the ridge axis (representative glass analyses from Table 1 - Sinton et al., 1991). OSCs are shown by black lines as in Figure 3. a) $\mathrm{MgO}$ content in wt\%. b) $\mathrm{Mg}$ number $=(\mathrm{Mg} / \mathrm{Mg}+\mathrm{Fe}$ molar $)$. c) Lava temperature calculated from the major element composition using the olivine thermometer of Sisson and Grove [1993] assuming atmospheric pressure and no water content. d\&e) $\mathrm{Na}_{8.0}$ and $\mathrm{Fe}_{8.0}$ calculated using the regression of Sinton et al. [1991] (Table 2). 
a)

Along Axis Chemistry

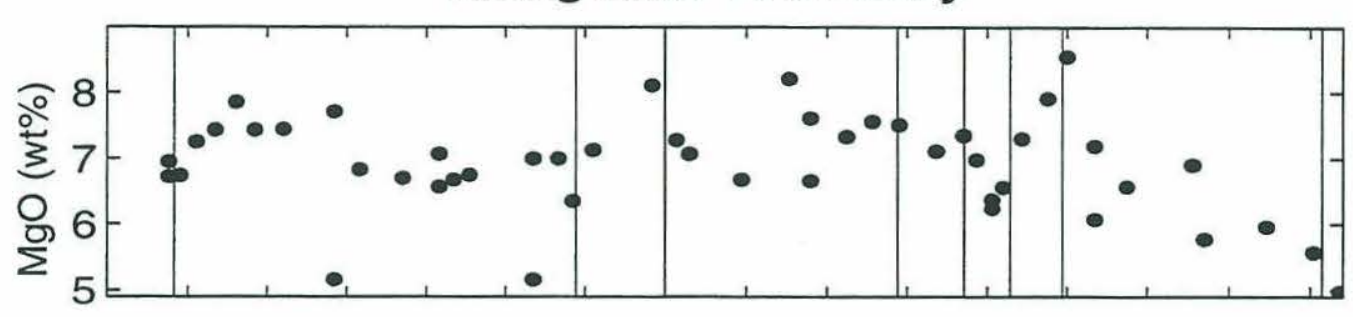

b)

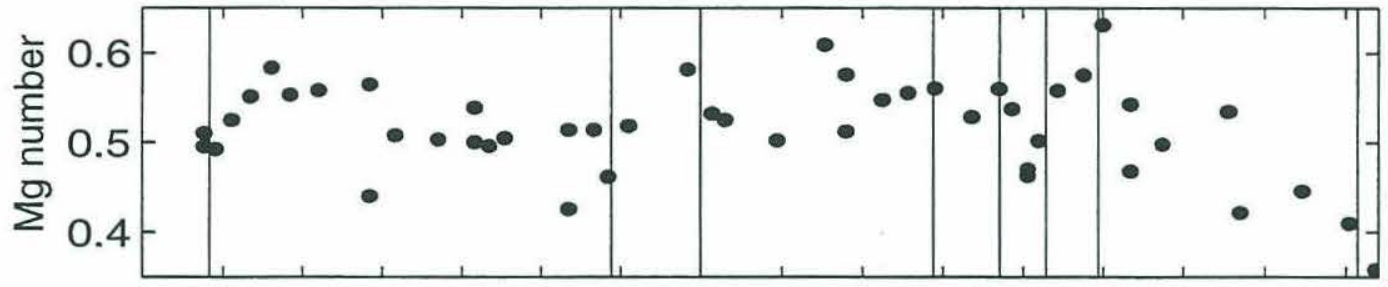

c)
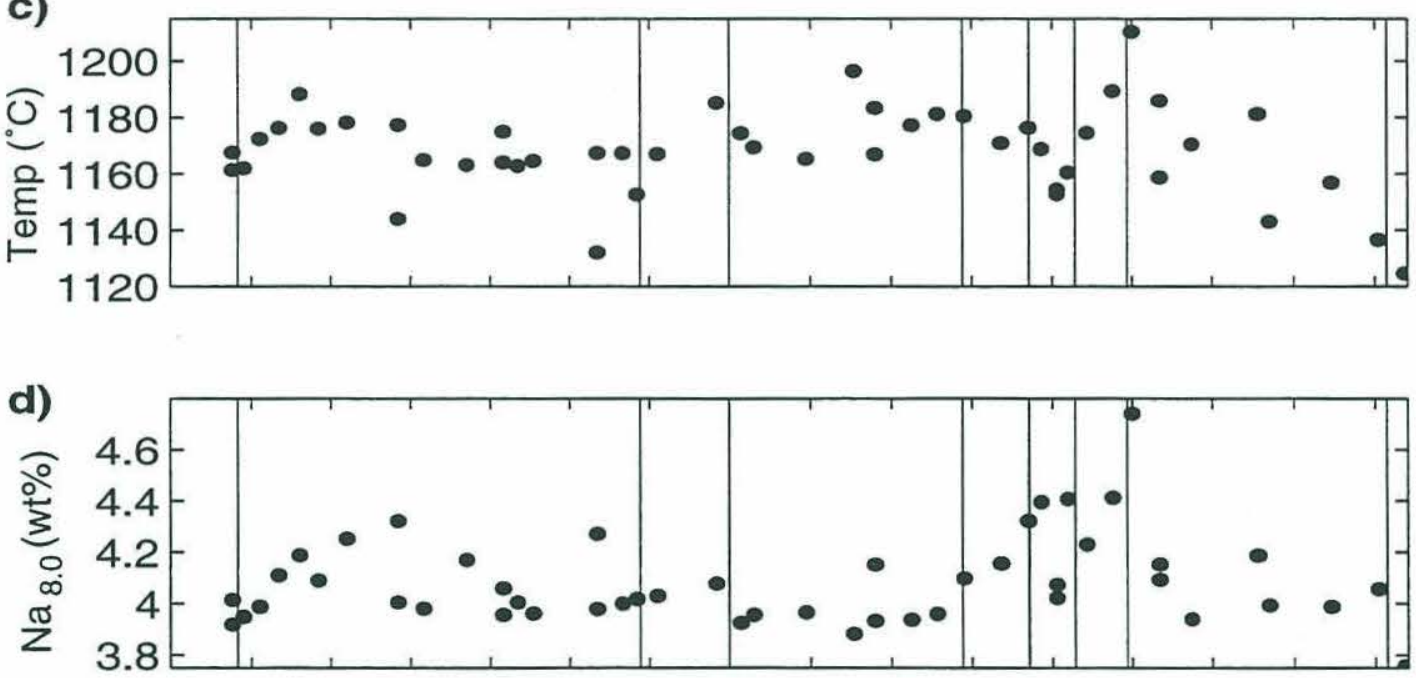

e).

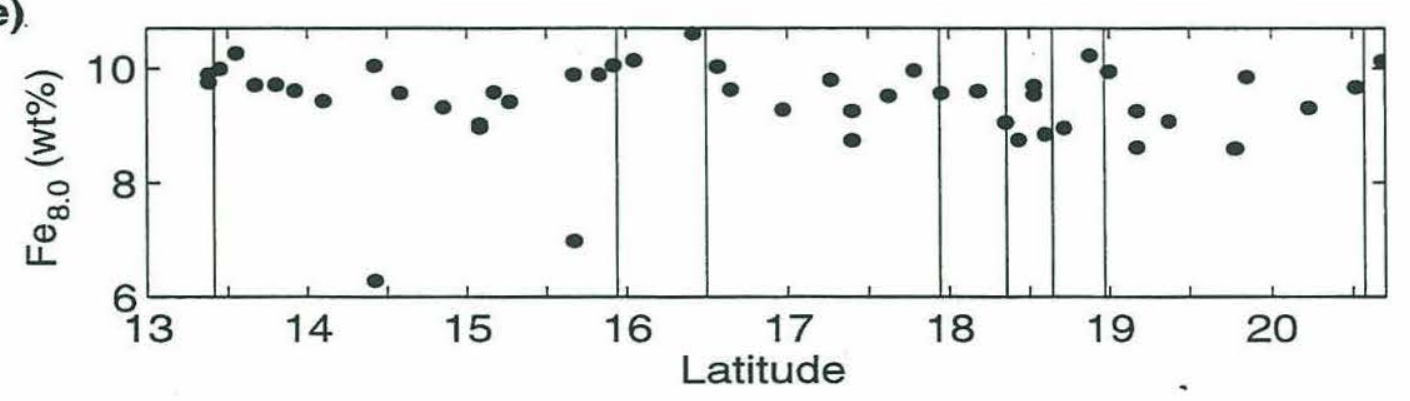


Figure 8. Relationships between indicators of magma budget and magma sill depth and width. All the along-axis data points are shown as dots, the measurements based on the across-axis lines are shown as grey diamonds. The correlation coefficients for these relationships are given in Table 2. Note the large variability in magma sill depth which does not correlate with indicators of magma budget. The lack of correlation between $\mathrm{MgO}$ of the lavas and magma sill depth indicates that the residence time of the magmas in the sill must be short. 
a)

b)
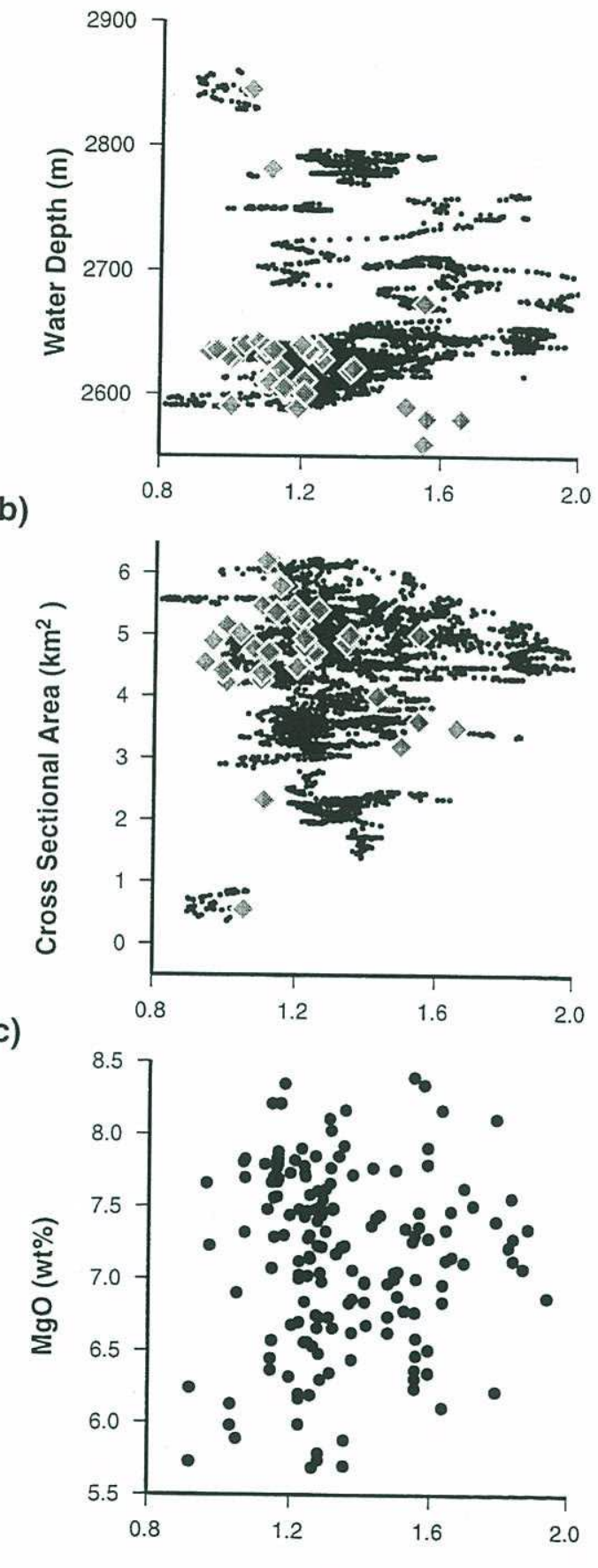

Magma Sill Depth (km) d)

e)

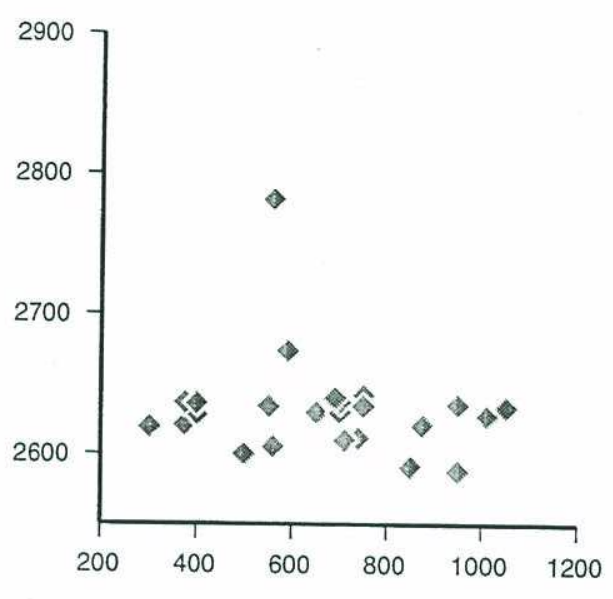

f)
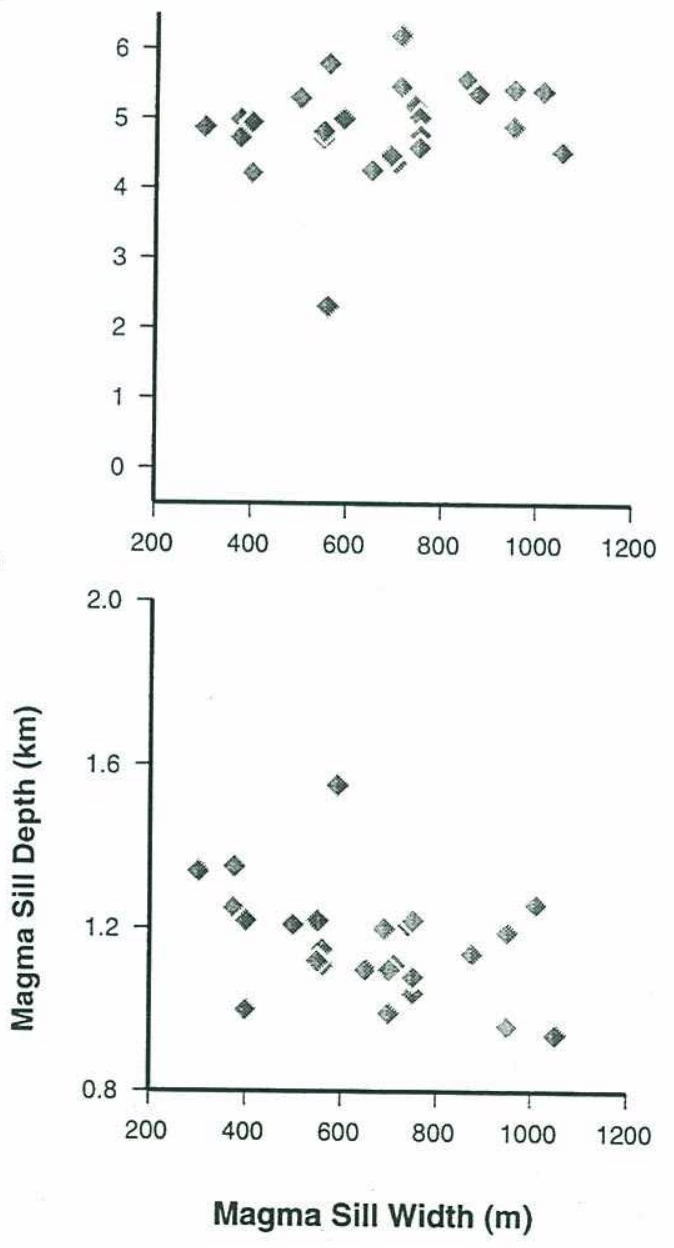
Figure 9. Relationship between indicators of magma budget and layer 2A thickness onand off-axis. The symbols and correlation coefficients are given as in Figure 8. The correlation coefficients for these relationships are given in Table 2. The on-axis layer $2 \mathrm{~A}$ thickness is uniform except for an increase in thickness where the ridge cross-sectional area is low. The off-axis thickness of layer $2 \mathrm{~A}$ is not related to morphological indicators of magma supply. 
a)

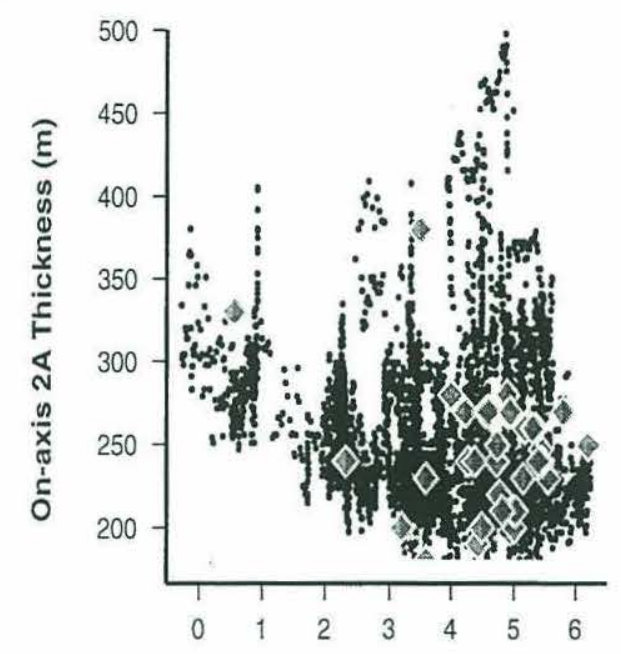

b)

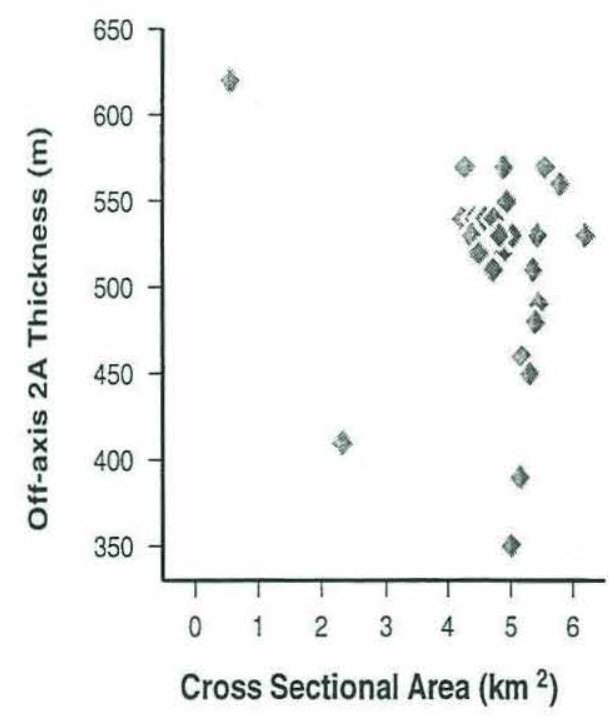

c)

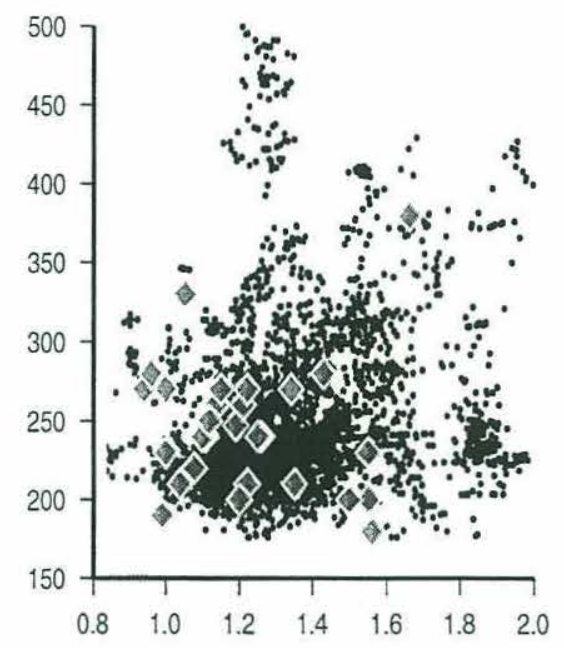

d)

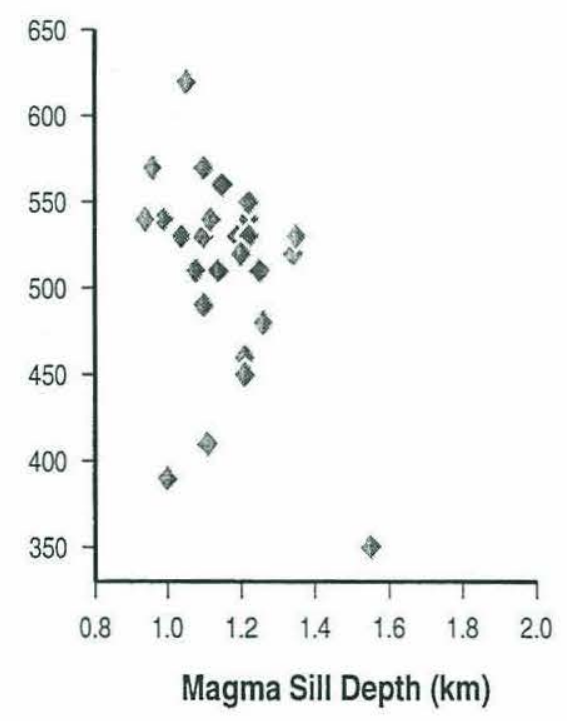


Figure 10. Relationship between on and off-axis thickness of layer $2 \mathrm{~A}$ and the width of the region of thickening, based on the across axis seismic lines, and indicators of magmatic budget. The symbols are as in Figure 8 . The correlation coefficients for these relationships are given in Table 2 . The width of layer $2 \mathrm{~A}$ thickening may increase with cross-sectional area. 
a)

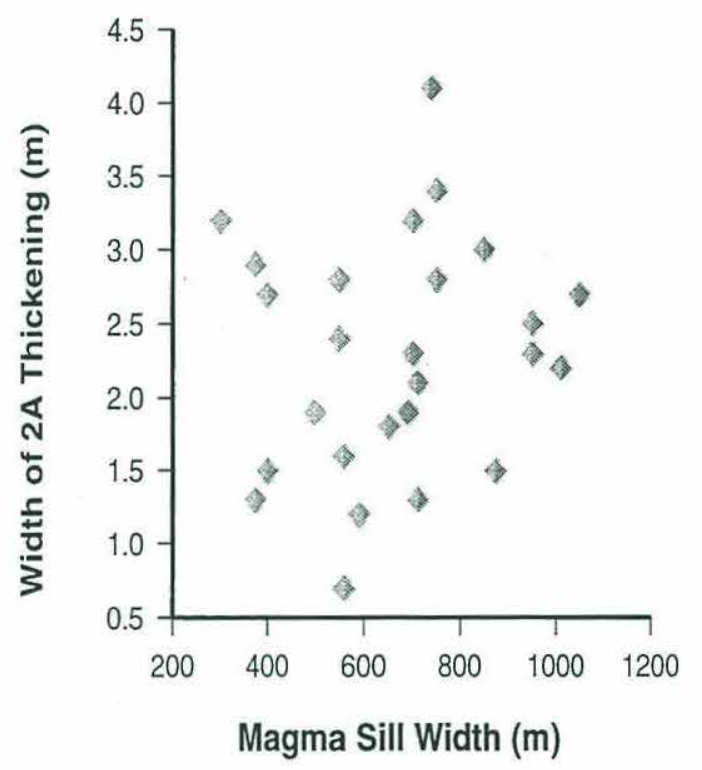

b)

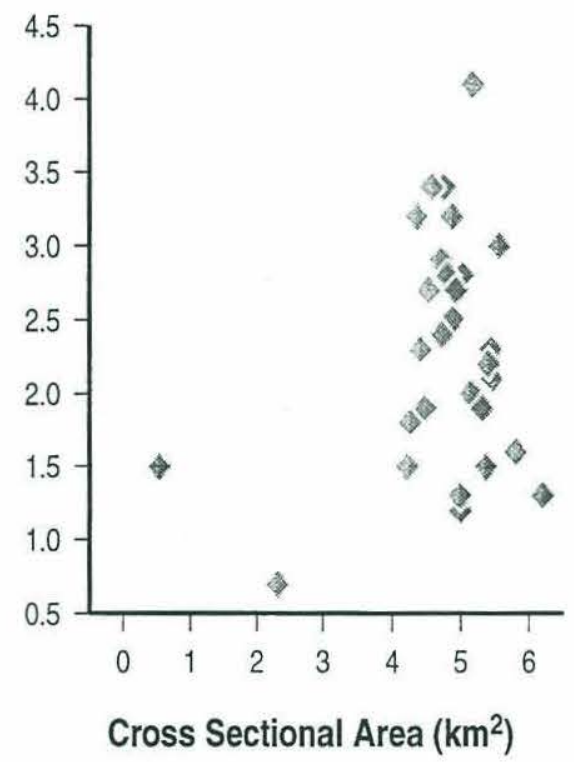


Figure 11. Relationship between light attenuation in the water column, an indicator of hydrothermal venting, ridge cross-sectional area, and magma sill depth along the ridge crest. There is little correlation between these parameters. 
a)

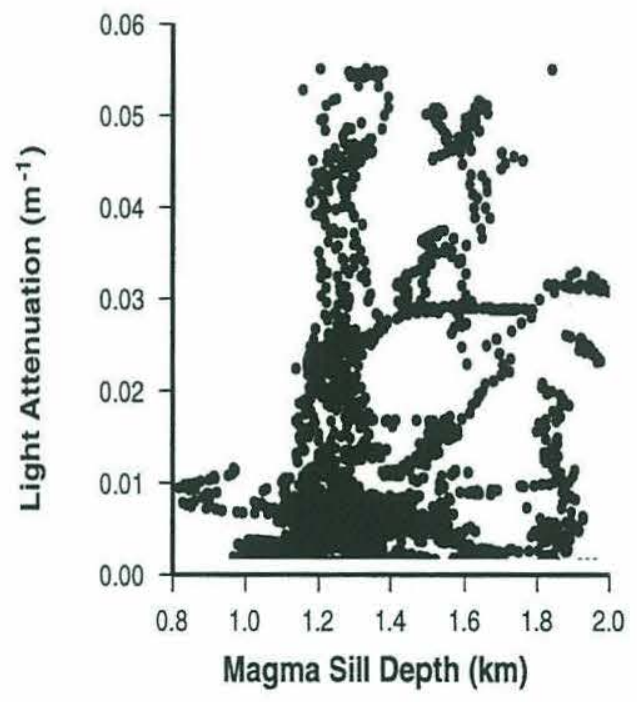

b)

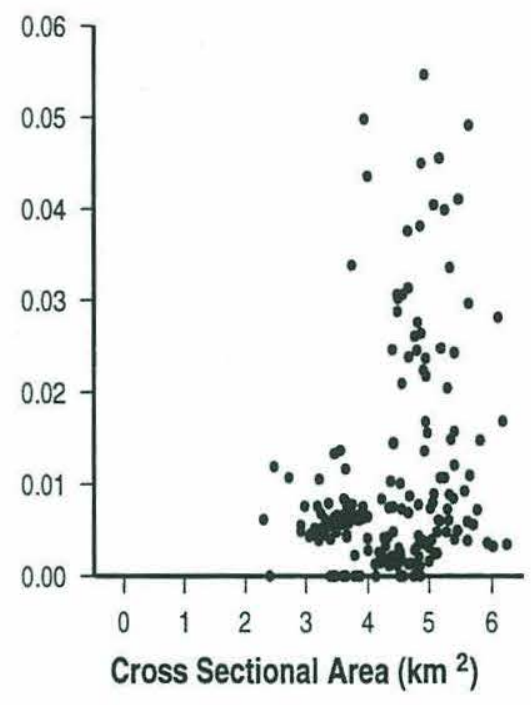


Figure 12. a) Contours of crystal content (\%) as a function of the density of the crystals and the density of the magma sill. We fix the melt density at $2.7 \mathrm{~g} / \mathrm{cm}^{3}$, though this value may lie between 2.68 and $2.73 \mathrm{~g} / \mathrm{cm}^{3}$ [Hooft and Detrick, 1993]. Crystal density ranges from $2.8-3.0 \mathrm{~g} / \mathrm{cm}^{3}$, most gabbro crystals lie between 2.90 and $2.95 \mathrm{~g} / \mathrm{cm}^{3}$ [Christensen and Salisbury, 1982]. We assume a linear relationship between the density of the magma sill, $\rho_{m s}$, and the crystal and melt densities, $\rho_{x}$ and $\rho_{m}$ respectively, as a function of percentage of crystals present, $\phi$ :

$$
\rho_{m s}=\rho_{m s}+\frac{\phi}{100} \times \rho_{x}
$$

b) Density structure for the crust, $\rho_{\text {crust }}$, determined from seismic measurements of compressional wave velocity, $V_{p}$, [Harding et al., 1993] using the empirical relationship of Christensen and Shaw [1970]

$$
\rho_{\text {crust }}=1.85+0.165 V_{p}
$$

For a fully molten magma sill the level of neutral buoyancy (LNB) is $100-400 \mathrm{~m}$ below the seafloor [Hooft and Detrick, 1993]. For a crystal content of $30-50 \%$, the LNB is $250-830$ $\mathrm{m}$ below the seafloor. The observed magma sill reflectors lie deeper $(800-2000 \mathrm{~m}$ below the seafloor) than the LNB.

c) Histogram of the distribution of magma sill densities calculated from the measured magma sill depths (Figure 5b) assuming that they lie at neutral buoyancy and the crustal density structure in (b). This requires a magma sill crystal content of $80 \%$ to completely solid which is too high for the observed seismic properties of the magma sill. 
a) Percentage of crystals in magma sill, assuming melt density $=2.7 \mathrm{~g} / \mathrm{cm}^{3}$ )

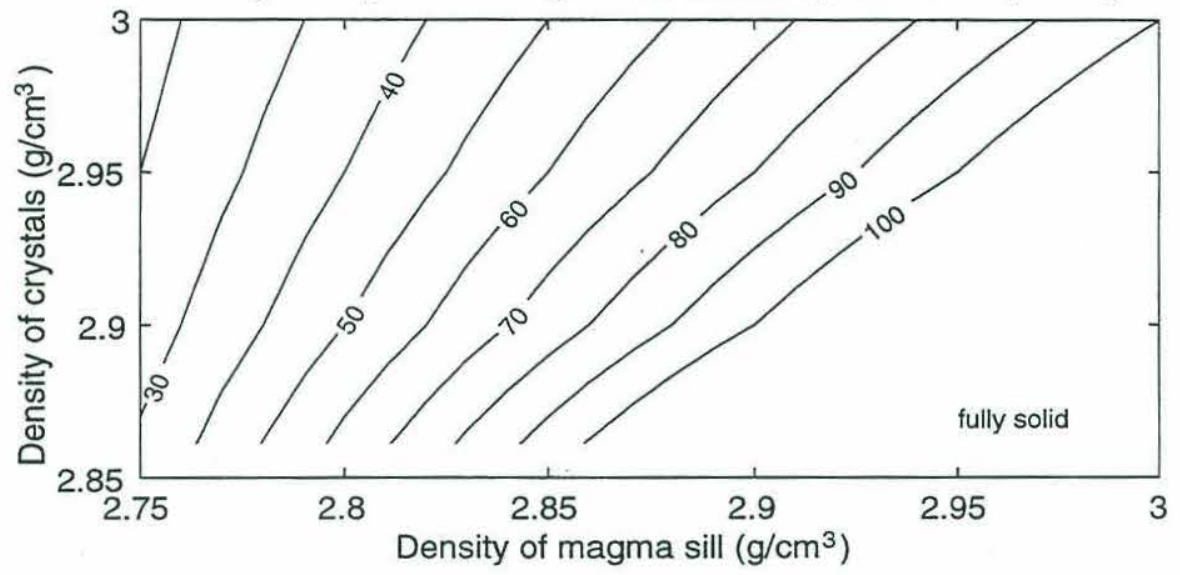

b) Seismically-derived Crustal Density Profile

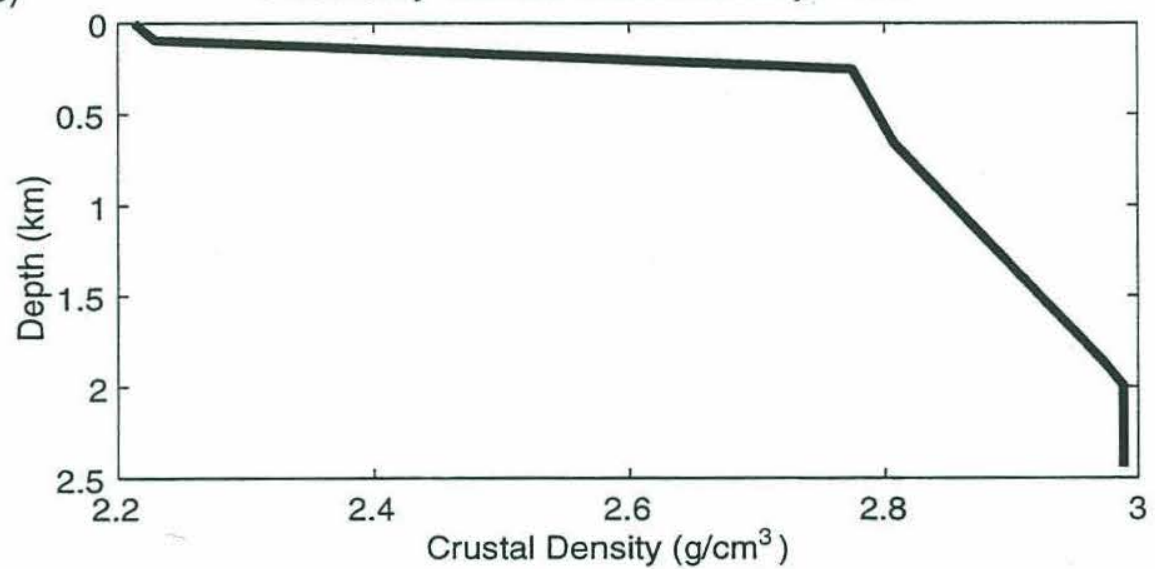

c) Histogram of magma sill density, assuming it lies at neutral buoyancy

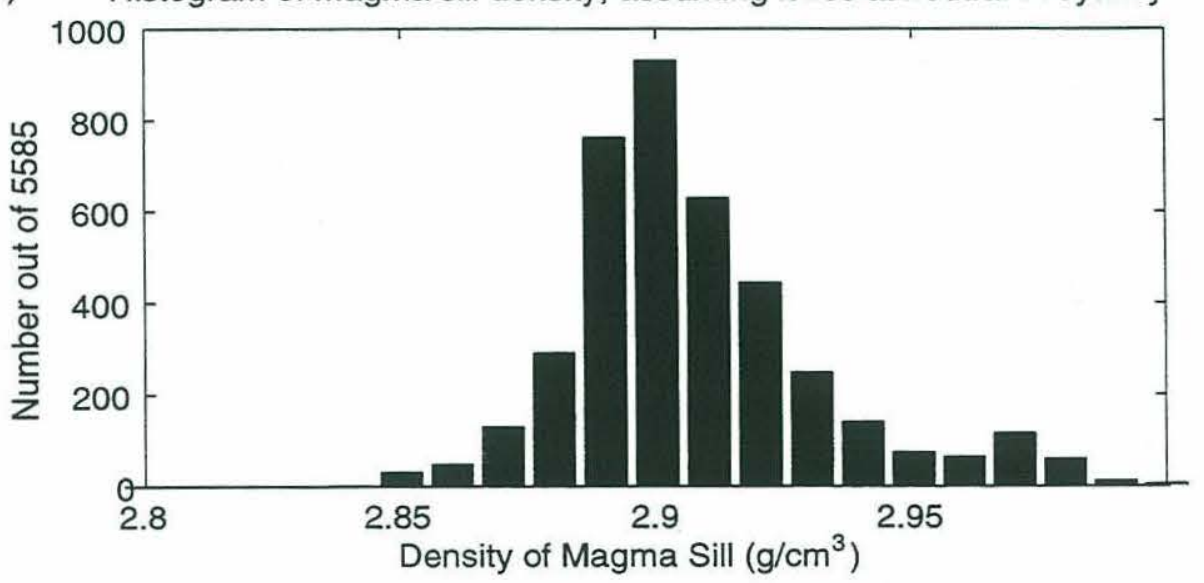


Figure 13. Upper Panel: Cartoon showing two ridge crest thermal structures, and the accompanying crustal structures; the extrusives and sheeted dikes, the depth of hydrothermal venting, and the magma sills. The depth of the magma sill is determined by a thermally controlled permeability boundary. The thermal structure of the crust depends on the balance of heat advected, by the supply of melt, and cooling, by the removal of melt, conduction, and hydrothermal convection. The two scenarios shown are for a constant magma supply. Hydrothermal cooling is very sensitive to the permeability structure of the crust and fluctuates due to intermittent eruptive and tectonic events. Hydrothermal cooling maintains the upper crust at $\sim 400^{\circ} \mathrm{C}$ down to the depth of penetration of fluids. Below this temperature increases very rapidly to reach the solidus at the magma sill. The lower crust is also relatively isothermal. On the left, heat removal by hydrothermal cooling and the recent eruption of the magma sill exceeds the heat supplied from beneath. The isotherms are moving down in the crust leading to a deeper magma sill. On the right, there have been no recent eruptions and hydrothermal cooling is weak. Heat supplied from below exceeds that removed from above and the magma sill is burning its way up to shallower levels in the crust. These scenarios simulate the observations on SEPR06 (Figure 4c) and SEPR70 (Figure 4d), both of which have similar magma budgets as indicated by their crosssectional areas. However, on SEPR06 the magma sill is deep and has a weak reflection and there is an axial summit graben with related hydrothermal venting. On the other hand, on SEPR70, the magma sill is shallow and bright and there is no evidence for recent tectonic activity. Lower Panel: Along-axis seismic section SEPR09 from $18^{\circ} 13^{\prime} \mathrm{S}$ to $18^{\circ} 02^{\prime} \mathrm{S}$ illustrating apparent local depth variations of the magma sill. Note how the magma sill is almost horizontal, however, over $\sim 7 \mathrm{~km}$ the shallower magma sill fades giving way to a bright magma sill reflector lying $\sim 1 \mathrm{~km}$ deeper. 
(2)
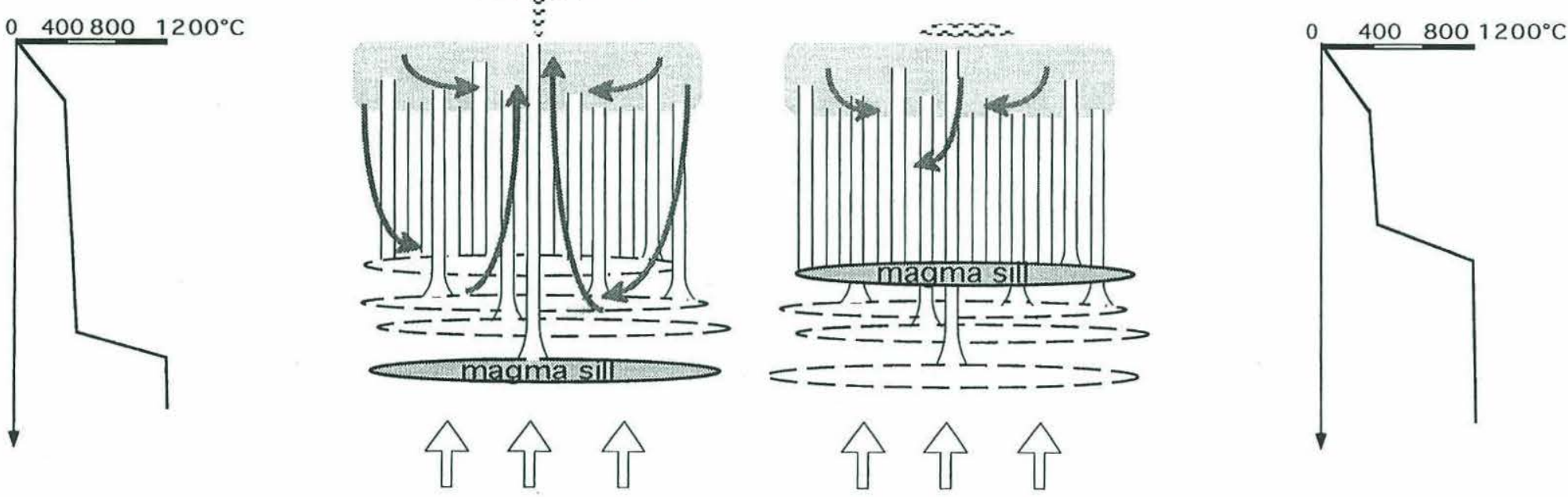

灾

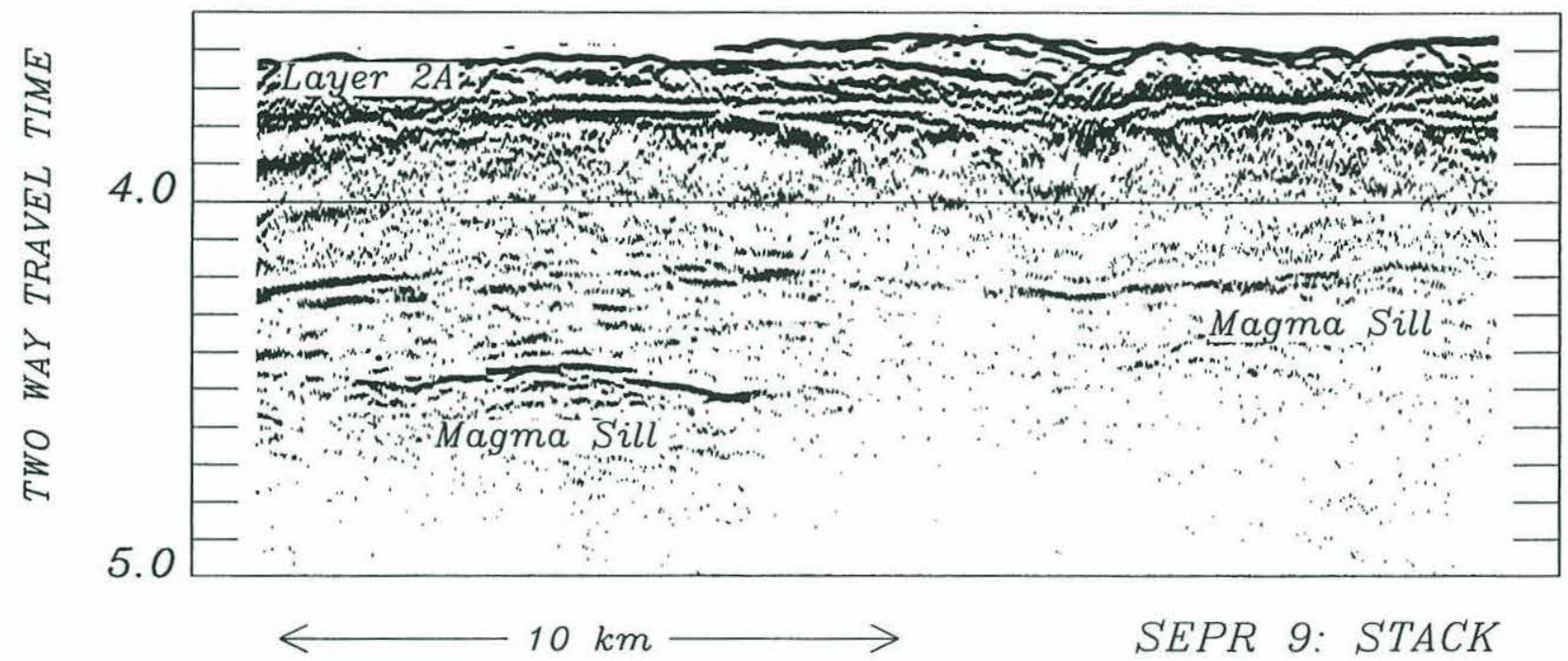


Figure 14. An along-axis view showing the relationship between the local, short-term variations in crustal structure in Figure 13 and longer-term changes in magma supply to the ridge. The upper panel shows the gabbro section (hatched pattern), magma sill (thick, double dark line), sheeted dike section (vertical lines), and extrusive section (horizontal zigzag pattern). The white region around the magma sill indicates a mixed zone of dikes and gabbros generated by short-term depth changes of the magma sill (Figure 13). Hydrothermal venting (wavy pattern) is diffuse where there are recent eruptions (1-10 yrs), and focused and longer-lived (10-100s yrs) where there is an axial summit caldera (ASC). Short wavelength doming of the magma sill on the scale of $\sim 50 \mathrm{~km}$ may be associated with individual volcanic constructs. The extrusive section thickens slightly at the ends of these units. The longer-term changes in average magma sill depth are on a larger scale $(\sim 200$ $\mathrm{km})$. The lower portion of the figure indicates the variation in cross-sectional area along this portion of the ridge axis. General shoaling of the magma sill is accompanied by a trend of increasing cross-sectional area, but in detail the patterns are different. 


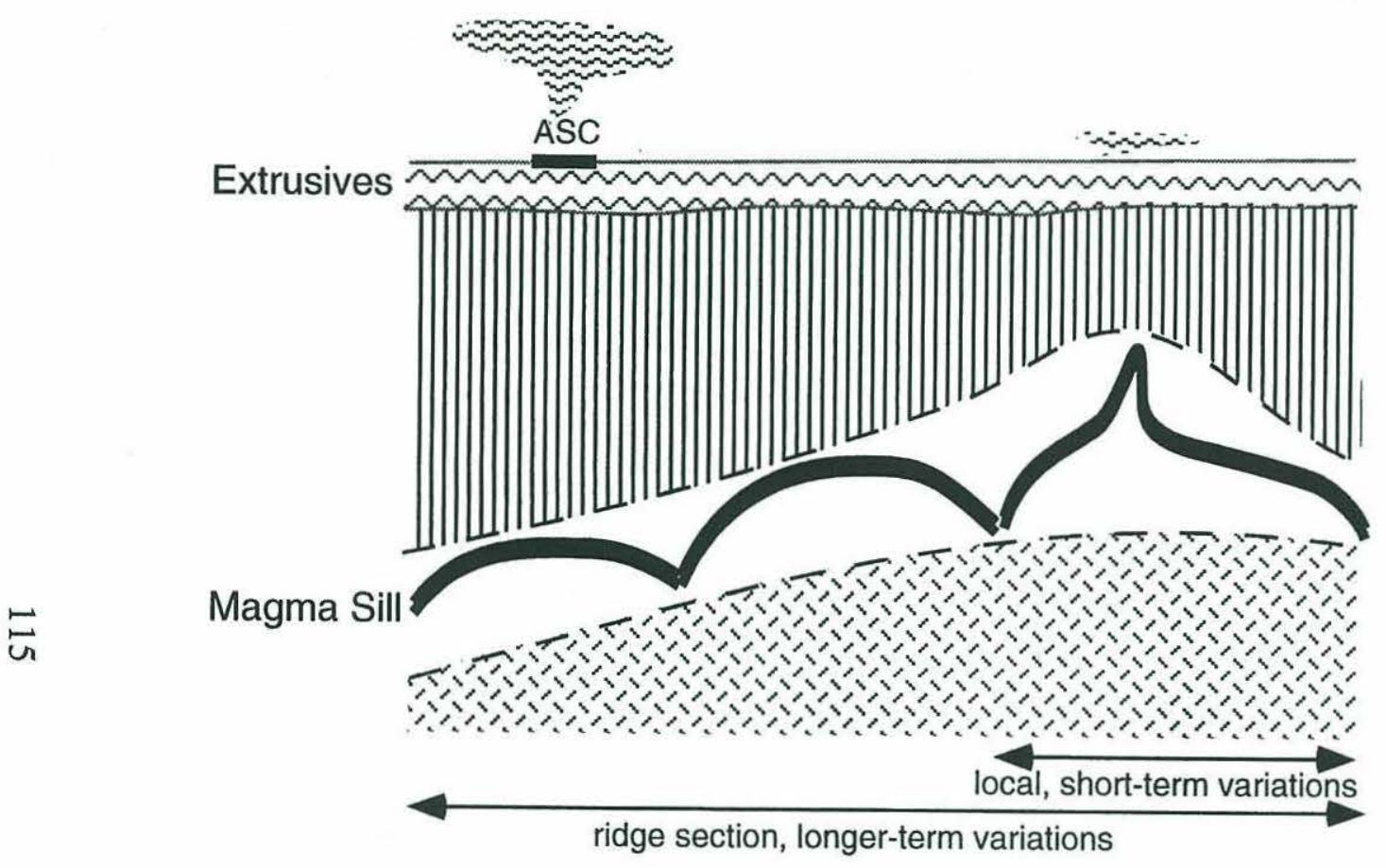

ridge section, longer-term variations

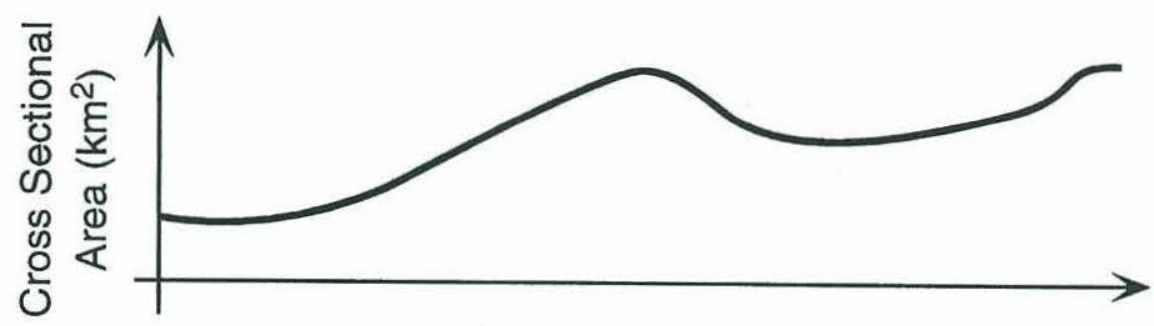

\section{Scales of Variability}

10-100 yr.

Spreading events affect permeability structure

Emplacement geometry - width of intrusion zone and flow lengths

$<100 \mathrm{Kyr} \&>10-100 \mathrm{yr}$

Large local variability in crustal thermal structure - changes in cooling relative to melt supply from below Intermittent eruptions and tectonic events.

$\sim 100 \mathrm{Kyr}$.

correlation:

Mantle Bouguer Anomaly $\mathrm{MgO} \mathrm{wt} \%$ of dredged lavas no correlation:

magma sill depth and width extrusive thickness

hydrothermal venting 
Chapter 4

\section{The Role of Density In the Accumulation of Basaltic MELTS AT Mid-OCEAN RIDGES}




\section{THE ROLE OF DENSITY IN THE ACCUMULATION OF BASALTIC MELTS AT MID-OCEAN RIDGES

\author{
E.E. Hooft and R. S. Detrick
} \\ Department of Geology and Geophysics, Woods Hole Oceanographic Institution}

\begin{abstract}
It is commonly assumed that magma ponds at a level of neutral buoyancy in the shallow crust where melt densities are equal to the bulk density of the surrounding crust. At the East Pacific Rise this neutral buoyancy level lies only $100-400 \mathrm{~m}$ below the sea floor, significantly shallower than the depths $(>1-2 \mathrm{~km})$ of the magma bodies imaged in multichannel reflection data, suggesting that other factors must control the collection of melt in these reservoirs. The apparent inverse relationship between magma chamber depth and spreading rate at intermediate and fast spreading ridges suggests that the thermal structure of the rise axis, not the buoyancy of melt, is the primary factor that controls the depth at which melt ponds in crustal magma chambers beneath midocean ridges.
\end{abstract}

Introduction

Multichannel seismic studies along the fast spreading East Pacific Rise (EPR) show the existence of a narrow $(<1-4 \mathrm{~km}$ wide), thin (10s-100s of m thick) sill-like magma body $1-2$ $\mathrm{km}$ below the sea floor (Detrick et al., 1987; Detrick et al., 1993). Despite its narrow width, reflections from the roof of this magma sill are remarkably continuous along the rise axis and relatively constant in two-way travel time below the sea floor over distances of many tens of kilometers. Along the northern EPR between $9^{\circ} \mathrm{N}$ and $13^{\circ} \mathrm{N}$ this reflector typically occurs $\geq 1.2-1.6 \mathrm{~km}$ below the sea floor (Detrick et al., 1987). Along the faster spreading southern EPR between the Garrett $\mathrm{FZ}$ and $20.7^{\circ} \mathrm{S}$ the magma sill is somewhat shallower with a median depth of $1.3 \mathrm{~km}$, and in some locations (e.g. $14^{\circ} 14^{\prime} \mathrm{S}, 17^{\circ} 25^{\prime} \mathrm{S}$ ) it rises to within $1000 \mathrm{~m}$ of the sea floor (Detrick et al., 1993). Similar axial reflectors have also been observed at intermediate-rate spreading ridges including the Juan de Fuca (Morton et al., 1987) and Valu Fa (Morton and Sleep, 1985; Collier and Sinha, 1990) ridges where they are significantly deeper $(>3 \mathrm{~km})$ than the magma bodies found along the EPR (Figure 1).

What controls the level of magma ponding beneath these spreading centers and the striking along-axis uniformity in the depth of magma sills apparent in multichannel seismic reflection data? It is commonly assumed that the ascent of magmas through the crust beneath magmatic systems is primarily driven by the buoyancy of the melt relative to the surrounding country rock (c.f. Ryan, 1987; Walker, 1989). When the density of the melt and that of the local crustal rocks are equal, the melt is neutrally buoyant and will tend to spread laterally instead of rising or sinking. The collection of melt at a level of neutral buoyancy (LNB) could explain the

\section{Copyright 1993 by the American Geophysical Union.}

Paper number 93GL00295

0094-8534/93/93GL-00295\$03.00 formation of the shallow, sill-like crustal magma bodies observed along mid-ocean ridges. However, factors other than density can affect the upward migration of melt within the crust. For example, the ascending melt may stall at a rheological boundary, like the brittle-ductile transition (Smith and Cann, 1992) or the freezing horizon (Phipps Morgan and Chen, 1993). The mechanics of dike formation and propagation and the state of stress in the shallow crust may also influence the accumulation of shallow magma reservoirs (Rubin, 1990; Gudmundsson, 1990).

In this paper we test the hypothesis that the magma bodies observed beneath mid-ocean ridges form at a LNB in the shallow crust by comparing the seismically constrained depths of ridge crest magma chambers with the depth of the LNB determined from estimates of melt and crustal density.

\section{Estimation of melt and crustal densities}

The LNB has been defined by Ryan (1987) as the depth in the crust where the magma density is equal to the local bulk density of the surrounding country rock. Below this level magma will be less dense than its surroundings and tend to rise, while above the LNB magma will be negatively buoyant and will sink. Therefore the LNB corresponds to the depth, $z_{n b}$, of the cross-over of the effective, large-scale in situ density of the crust, $\rho(z)$, with the magma density, $\rho_{m}$. To estimate the LNB at the EPR we must know both the magma density, $\rho_{\mathrm{m}}$, and the variation of density with depth in oceanic crust, $\rho(z)$.

Melt Density: The density of the liquid from which a basaltic glass formed can be computed using the empirical method of Bottinga and Weill (1970). They determined the

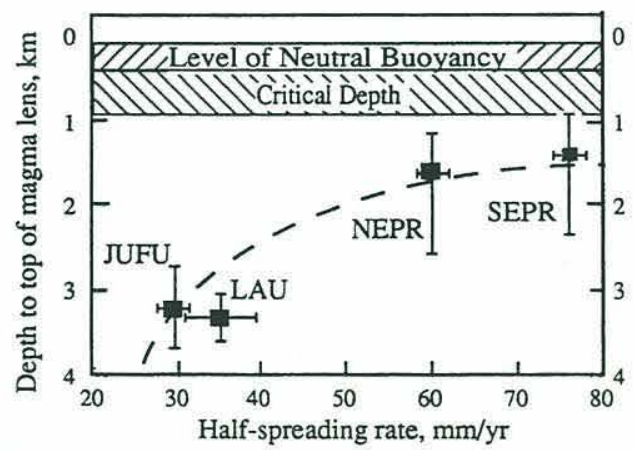

Fig 1. Depth to the top of the AMC versus spreading rate for the northern (NEPR) and southern (SEPR) East Pacific Rise, and Juan de Fuca (JUFU) and Valu Fau (LAU) ridges (replotted from Phipps Morgan and Chen, 1993). The neutral buoyancy level and critical depth calculated for the EPR are also shown. The dashed curve represents the predicted depth to the solidus (assumed to be $1200^{\circ} \mathrm{C}$ ) as a function of spreading rate from Phipps Morgan and Chen (1993). 
partial molar volume of the major oxide components in a liquid and thence the density of a silicate melt as a function of major oxide composition and temperature.

Using these equations melt densities were calculated for the entire Smithsonian Institution Glass file consisting of 2004 samples of basaltic glasses from around the world's oceans. A plot of melt density versus $\mathrm{Fe} \#(\mathrm{Fe} /(\mathrm{Fe}+\mathrm{Mg})$, shown in Figure 2, follows the theoretical curves predicted for the evolution of residual basaltic liquids (Stolper and Walker, 1980). Most oceanic basalts lie in the density minimum of this evolution curve suggesting that melt density is an important factor in determining the eruptability of magmas (Stolper and Walker, 1980). The average melt density is $2700 \mathrm{kgm}^{-3} ; 73 \%$ of the samples lie within a range of $\pm 20 \mathrm{kgm}^{-3}$ from this value.

We will adopt a value of $2700 \pm 20 \mathrm{kgm}^{-3}$ for $\rho_{\mathrm{m}}$ in this paper. Density increases due to continued crystal fractionation (for the range of eruptable basalts) are only a few percent of this average melt density and will not significantly effect our results. Volatiles can lower melt densities, especially if exsolution of these gases occurs. But, the volatile content of MORB is in general very low and the effect of volatiles on density will be small while remaining dissolved (e.g. $0.25 \%$ $\mathrm{H}_{2} \mathrm{O}$ will reduce the melt densities by only $20 \mathrm{kgm}^{-3}$ ). Thus the effects of fractional crystallization and volatiles on melt density are second order and largely offsetting.

Crustal Density Structure: Seismic studies at the EPR (e.g. Vera et al., 1990; Christeson et al., 1992) document the presence of a near-surface layer, $\sim 150 \mathrm{~m}$ thick at the rise axis, of extremely low $(<3 \mathrm{~km} / \mathrm{s}$ ) compressional wave velocities (Figure 3a). Below this layer p-wave velocities increase rapidly to $\sim 5 \mathrm{~km} / \mathrm{s}$ at $300 \mathrm{~m}$ and $\sim 6 \mathrm{~km} / \mathrm{s} 1-1.2 \mathrm{~km}$ below the sea floor. The low seismic velocities observed in the upper kilometer of the crust are due to high bulk porosities caused by the presence of fractures and voids too large to be sampled in the laboratory. An accurate estimate of the crustal density structure at a ridge crest thus requires a knowledge of the variation in bulk porosity with depth in oceanic crust.

The only in situ measurements of bulk porosity to substantial depths within young oceanic crust have been made in Hole $504 \mathrm{~B}$ on $\sim 5.9$ Ma old sea floor on the flanks of the Costa Rica Rift in the eastern equatorial Pacific. Large-scale electrical resistivities measured in this borehole (e.g. Becker 1985) have been used to calculate apparent bulk porosities using Archie's law (Figure 3b). Bulk porosities are high (10-

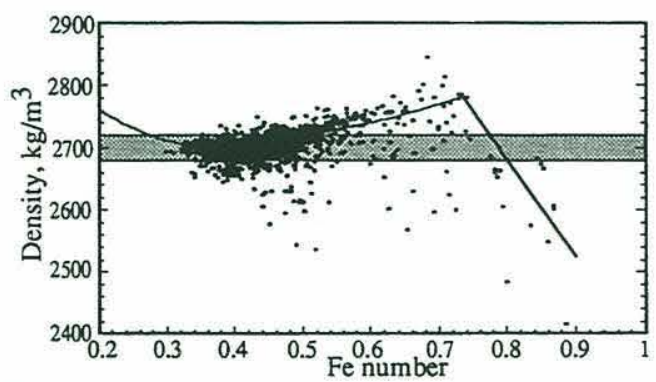

Fig 2. Plot of melt density for MOR basaltic glasses versus the degree of fractionation represented by the Fe\#= $\mathrm{Fe} /(\mathrm{Fe}+\mathrm{Mg})$. The curve shows the evolution of residual melt during fractional crystallization (Stolper and Walker, 1980). The mean melt density is $2700 \pm 20 \mathrm{kgm}^{-3}$ (shaded bar).
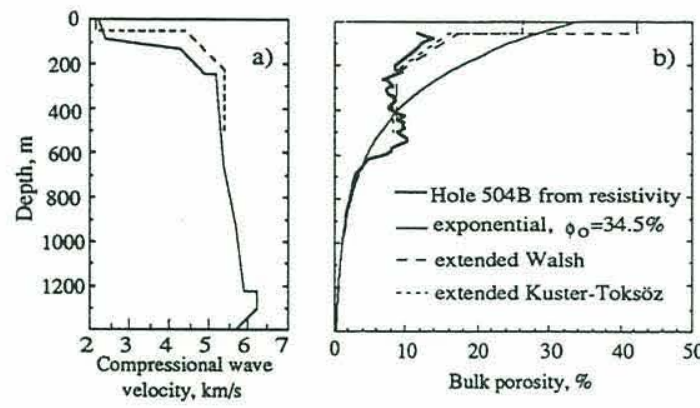

Fig 3. (Left) Seismic velocity models of the EPR crest near $9^{\circ} 30^{\prime} \mathrm{N}$ after Christeson et al. (1992) (dashed line) and Vera et al. (1990) (solid line). (Right) Variation of crustal bulk porosity with depth in young oceanic crust: based on in situ measurements in Hole 504B (from Becker et al., 1985), theoretical velocity-porosity relationships based on extended Walsh and Kuster-Toksöz theories (from Berge et al., 1992), and an exponential decrease in bulk porosity with depth $\left(\phi_{0}\right.$ $=34.5 \% ; \lambda=3.3 * 10^{-3} \mathrm{~m}^{-1}$ ).

$15 \%$ ) in the shallowmost crust, decrease to $7-10 \%$ within the lower part of the extrusive section (200-600 m sub-basement) then drop sharply to values of $<1-2 \%$ in the underlying sheeted dike section. Bulk porosities remain extremely low $(<1 \%)$ throughout the sheeted dike section to the base of present hole (1726 m sub-basement).

In situ measurements of crustal physical properties have not been made at the EPR. However, an estimate of crustal porosity and bulk density can be obtained by using observed seismic velocities at the rise axis and theoretical predictions of the variation in seismic velocity as a function of pore volume and aspect ratio. Classical Hashin-Shtrikman limits on the relationship between porosity and seismic velocity ignore void shapes and are too broad to provide useful constraints. However, Berge et al. (1992) have devised two hybrid theories, which they call the extended Walsh and extended Kuster-Toksöz theories which provide upper and lower bounds on effective medium properties for porosities of up to $30 \%$ and a distribution of pore aspect ratios representative of the upper oceanic crust (Wilkens et al., 1991). Figure 3b shows the variation in porosity with depth predicted using these theories for the Christeson et al. (1992) seismic model of the EPR shown in Figure 3a. Bulk crustal porosities are very high (26-43\%) in the upper $100 \mathrm{~m}$ then decrease to values of less than $10 \% 200 \mathrm{~m}$ into the crust. Note that below $100 \mathrm{~m}$ into basement the results are in close agreement with in situ bulk porosity measurements made at Hole 504B. Below about $700 \mathrm{~m}$ depth large-scale crustal porosity decreases exponentially with depth (Figure $3 b$ ).

Porosity and density are inversely related and the bulk density at any depth $z$ below the sea floor can be directly calculated from the bulk porosity, $\phi(\mathrm{z})$, using the expression:

$$
\rho(z)=\rho g-\phi(z)(\rho g-\rho w)
$$

where $\rho g=2950 \mathrm{kgm}^{-3}$ is the matrix grain density and the density of water, $\rho_{W}=1000 \mathrm{kgm}^{-3}$. Figure 4 a shows $\rho(z)$ for the two EPR crustal porosity models of Berge et al. (1992). Also shown is $p(z)$ calculated assuming an exponential decrease in porosity with depth: 

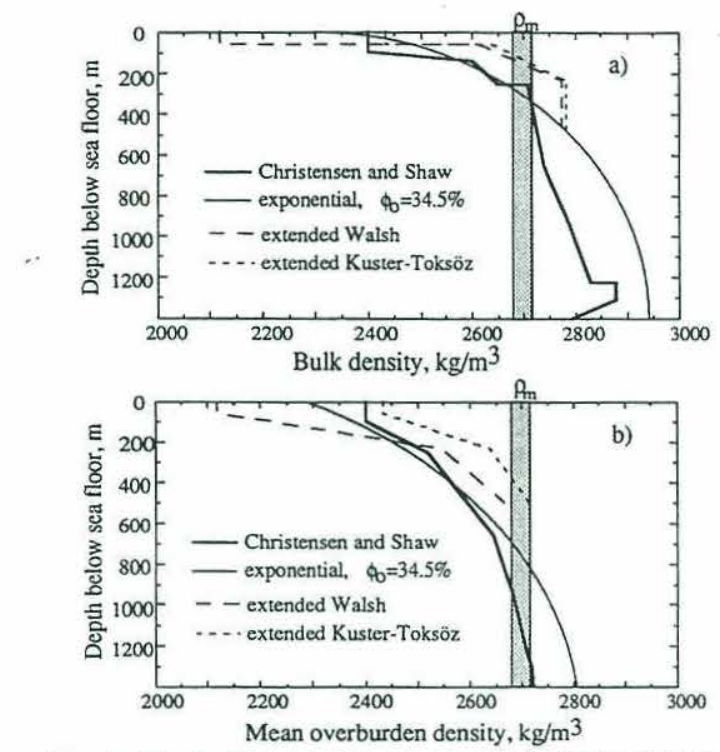

Fig 4. (Top) Crustal density versus depth in young oceanic crust based on the bulk porosity estimates shown in Fig. 3. Also shown is a density model based on the EPR seismic velocity model of Vera et al (1990) calculated using the empirical velocity-density equation of Christensen and Shaw (1970): $p=1.85+0.165 V_{p}$. The shaded bar represents the mean magma density from Fig. 2. The LNB at the EPR is lies at $100-400 \mathrm{~m}$ depth. (Bottom) Variation in mean overburden density versus depth. These curves were calculated from the four density models shown above. The critical depth, $z_{c}$, at the EPR is located at $400-900 \mathrm{~m}$ depth.

$$
\phi(z)=\phi_{0} e^{-\lambda z}
$$

with an assumed surface porosity, $\phi_{0}$, of $34.5 \%$ and $\lambda=3.3 * 10^{-3} \mathrm{~m}^{-1}$. This function is consistent with the high near-surface crustal porosities inferred seismically at the EPR and provides a good fit to the decrease in in situ porosities measured in Hole 504B below $600 \mathrm{~m}$ depth (Figure 3b).

An independent estimate of the density structure of oceanic crust at the EPR can be obtained by converting measured seismic crustal velocities to density using empirical relationships determined from laboratory measurements of compressional wave velocity and density made on oceanic dredge samples (Christensen and Shaw, 1970). Because laboratory velocity measurements don't take into account large-scale crustal porosity, this approach will be most accurate for the deeper parts of the crustal section. The seismic structure of the rise axis was taken from an expanding spread profile shot along the crest of the EPR at $9^{\circ} \mathrm{N}$ (Vera et al., 1990). The resulting $p(z)$ curve is plotted in Figure $4 \mathrm{a}$. Note that the decrease in compressional wave velocity between 1.2 and $1.6 \mathrm{~km}$ depth in the Vera et al. (1990) model marks the top of the axial magma chamber; the inferred decrease in crustal density below this depth is due to the presence of magma and is not an intrinsic feature of the density structure of oceanic crust.

The three different methods of estimating the density structure of oceanic crust at the EPR described above all provide remarkably consistent results (Figure 4a). Bulk crustal densities are expected to be very low $\left(<2500 \mathrm{kgm}^{-3}\right)$ in the upper $100 \mathrm{~m}$ of the crust. They increase rapidly to about $2700 \mathrm{kgm}^{-3} \sim 150-400 \mathrm{~m}$ into the crust, and reach values of $2800-2900 \mathrm{kgm}^{-3}$ at $1000 \mathrm{~m}$ depth.

\section{Discussion}

A LNB will exist in the shallow oceanic crust where the average melt density $\left(2700 \pm 20 \mathrm{kgm}^{-3}\right)$ intersects the crustal density curve. For the data shown in Figure $4 \mathrm{a}$ the LNB is located about $100-400 \mathrm{~m}$ below the sea floor at the EPR. The LNB cannot lie significantly deeper than this at the EPR without being in serious disagreement with the known seismic velocity structure of the EPR, theoretical and empirical relationships between seismic velocity, bulk porosity and density, and in situ measurements of the physical properties of young oceanic crust.

If density were the principal factor controlling the accumulation of melt beneath mid-ocean ridges, as some investigators have suggested (e.g. Ryan, 1987), we would expect crustal magma bodies to form at the depth of this LNB, i.e. about $100-400 \mathrm{~m}$ below the sea floor. However, the axial magma chambers documented seismically along the EPR occur 1-2 km below the sea floor, well below the calculated depth of the LNB (Figure 1). Even along the fast spreading southern EPR, where the shallowest crustal magma bodies have been documented, the top of the magma sill is typically more than $1000 \mathrm{~m}$ below the sea floor (Detrick et al., 1993). Along the Juan de Fuca (Morton et al., 1987) and Valu Fa (Morton and Sleep, 1985; Collier and Sinha, 1990) ridges magma chambers lie deeper than $3 \mathrm{~km}$. We thus conclude that magma chambers beneath intermediate and fast spreading ridges do not form at a LNB and other factors must control the accumulation of melt beneath mid-ocean ridges.

All of the mid-ocean ridge magma chambers observed to date lie at or below what we call the critical depth, $\mathrm{z}_{\mathrm{C}}$, the depth below which lithostatic pressure alone provides enough hydrostatic head to force magma from the reservoir to the surface. At the critical depth $\rho_{a v}\left(z_{c}\right)=\rho_{m}$ where $\rho_{a v}(z)$ is the mean overburden density at depth $z$.

Figure $4 \mathrm{~b}$ shows the mean overburden density versus depth, $\rho_{a v}(z)$, calculated for the four crustal density models shown in Figure 4a. Our best estimate of the critical depth at the EPR is that it lies $400-900 \mathrm{~m}$ below the sea floor. The axial magma chambers imaged seismically at the EPR occur close to, but below, the critical depth while those found along the intermediate spreading Valu Fa and Juan de Fuca Ridges lie well below the critical depth (Figure 2). Magma that ponds above the critical depth may still be eruptable since other mechanisms may increase magma reservoir pressures above this minimum value, but for magma bodies lying below the critical depth lithostatic pressure alone is sufficient to insure eruptability provided a continuous pressure connection (e.g. a dike) exists with the surface.

If magma ponds at mid-ocean ridges in crustal reservoirs well below the LNB, as the evidence presented in this paper strongly suggests, what stops the buoyancy-driven ascent of melt through the crust? The answer to this question is not entirely clear. Gudmundsson (1990) has proposed that rapid injections of dikes at a fast spreading ridge create a stress barrier in the mid-crust where the horizontal compressive stress is higher than the vertical stress causing sill formation 
that leads to the development of a mid-crustal magma chamber. Rubin (1990) showed that in regions undergoing active extension, the brittle-ductile boundary may become a depth of "effective" neutral buoyancy due to the accumulation of non-hydrostatic, tectonically-induced stress differences. Phipps Morgan and Chen (1993) have proposed that melt will be stopped in its upward ascent when it reaches the freezing horizon due to viscous stresses that favor magma ponding.

Whether it is the brittle-ductile boundary or the freezing horizon that effectiveiy stops the upward ascent of melt, the depth of both will be primarily controlled by the thermal structure of the crust at the ridge axis. The strongest evidence for a thermal control on the depth at which magma accumulates beneath mid-ocean ridges is the variation in depth of crustal magma chambers with spreading rate, first noted by Purdy et al. (1992), and illustrated in Figure 1. The hypothesis that the depth of magma bodies beneath mid-ocean ridges are primarily controlled by thermal processes has recently been tested quantitatively by Phipps Morgan and Chen (1993). They show that the depth of the $1200^{\circ} \mathrm{C}$ isotherm varies with spreading rate in a way that is consistent with the variation in the depth to axial magma bodies determined seismically along intermediate and fast spreading ridges (Figure 1). Their results, and the seismic evidence that axial magma chambers lie below the LNB, support the hypothesis that the buoyancy of melt is not the primary factor controlling the depth of magma bodies beneath ridge crests.

\section{Conclusions}

1. The crustal magma bodies observed beneath mid-ocean ridges do not form at a level of neutral buoyancy in the shallow crust. The neutral buoyancy level lies only 100 $400 \mathrm{~m}$ below the sea floor, much shallower than the depth (1$3 \mathrm{~km}$ ) of the axial magma bodies imaged in multichannel reflection data at intermediate and fast spreading ridges.

2. The magma bodies found along mid-ocean ridges are located at or below the critical depth where lithostatic pressure due to the integrated weight of the overlying crustal column alone is sufficient for magma to be erupted onto the sea floor.

3. The apparent inverse relationship between magma chamber depth and spreading rate at intermediate and fast spreading ridges suggests that the thermal structure of the rise axis is the primary factor that controls the depth at which melt ponds in crustal magma chambers beneath mid-ocean ridges.

Acknowledgments. This research was supported by NSF grant OCE-9296017. E. Hooft was supported by the WHOI Joint Program Education Office. W. Bryan stimulated the calculation of melt densities. Joe Cann, Jian Lin and Deborah Smith provided helpful discussions, as did two anonymous reviewers. WHOI contribution 8176 .

\section{References}

Becker, K., Large scale electrical resistivity and bulk porosity of the oceanic crust, DSDP Hole 504B, Costa Rica Rift, Init. Rep. Deep Sea Drill. Proj., 83, 419-427, 1985.

Berge, P., G. Fryer, G. and R. Wilkens, Velocityporosity relationships in the upper oceanic crust: Theoretical considerations, J. Geophys. Res.. 97, 15,239-15,254, 1992.
Bottinga, Y. and D.F. Weill, Densities of liquid silicate systems calculated from partial molar volumes of oxide components, Amer. J. Sci. 269, 169-182, 1970.

Christensen, N.I., and G.H. Shaw, Elasticity of mafic rocks from the mid-Atlantic ridge, Geophys. J. Roy. Astron. Soc. 20, 271-284, 1970.

Christeson, G.L., G.M. Purdy and G.J. Fryer, Structure of young upper crust at the East Pacific Rise near $9^{\circ} 30^{\prime} \mathrm{N}$, Geophys. Res. Lett., 19, 1045-1048, 1992.

Collier, J. and M. Sinha, Seismic images of a magma chamber beneath the Lau Basin back-arc spreading center, Nature, 346, 646-648, 1990.

Detrick, R.S., P. Buhl, E. Vera, J. Mutter, J. Orcutt, J. Madsen, and T. Brocher, Multi-channel seismic imaging of a crustal magma chamber along the East Pacific Rise, Nature, 326, 35-41, 1987.

Detrick, R.S., A.J. Harding, G.M. Kent, J.A. Orcutt, J.C. Mutter, P. Buhl, Seismic structure of the southern East Pacific Rise, Science, 259, 499-503, 1993.

Gudmundsson, A., Emplacement of dikes, sills and crustal magma chambers at divergent plate boundaries, Tectonophys. 176, 257-275, 1990.

Morton, J.L., and N.H. Sleep, Seismic reflections from the Lau Basin magma chamber. In: Geology and offshore resources of Pacific island arcs - Tonga region. Circum Pacific Council of Energy and Mineral Resources Earth Sciences Series, eds. D.W. Scholl and T.L. Vallier, pp.441453, 1985.

Morton, J.L., N.H. Sleep, W.R. Normark and D.H. Tomkins, Structure of the southern Juan de Fuca Ridge from seismic reflection records, J. Geophys. Res., 92, 11,31511,326, 1987.

Phipps Morgan, J., and Y.J. Chen, The genesis of oceanic crust: Magma injection, hydrothermal circulation, and crustal flow, L. Geophys. Res, in press

Purdy, G.M. L. Kong, G. Christeson and S. Solomon, Relationship between spreading rate and the seismic structure of mid-ocean ridges, Nature, 355, 815-817, 1992.

Ryan, M.P., Neutral buoyancy and the mechanical evolution of magmatic systems, Geochem. Soc. Spec. Pub. №. $1,1987$.

Rubin, A.M., A comparison of rift-zone tectonics in Iceland and Hawaii, Bull. Volcanol. 52, 302-319, 1990.

Smith, D.K. and J.R. Cann, The role of seamount volcanism in crustal construction at the mid-Atlantic ridge $\left(24^{\circ} \mathrm{N}-30^{\circ} \mathrm{N}\right), \mathrm{J}$. Geophys. Res., 97 1645-1658, 1992.

Stolper, E.and D. Walker, Melt density and the average composition of basalt, Contrib. Mineral. Pterol., 74, 7-12, 1980.

Vera, E.E., J. Mutter, P. Buhl, J. Orcutt, A. Harding, M. Kappus, R. Detrick, and T. Brocher, The structure of 0 - to $0.2-\mathrm{m}$.y.-old oceanic crust at $9^{\circ} \mathrm{N}$ on the East Pacific Rise from expanded spread profiles, J. Geophys. Res., 25 . 15,529-15,556, 1990.

Walker, G.P.L., Gravitational (density) controls on volcanism, magma chambers and intrusions, Australian J. Earth Sci. 36, 149-165, 1989.

Wilkens, R.H., G.J. Fryer, J. Karsten, Evolution of porosity and seismic structure of the upper oceanic crust: Importance of aspect ratios, J. Geophys. Res. 96, 17,98117,995, 1991.

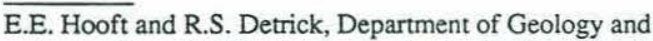
Geophysics, Woods Hole Oceanographic Institution, Woods Hole, MA 02543.

(Received September 25, 1992; revised January 12, 1993; accepted Febuary 1, 1993.) 
Chapter 5

\section{CONSTRAINING CRUSTAL EMPLACEMENT PROCESSES FROM THE VARAITION IN SEISMIC LAYER 2A THICKNESS AT THE EAST PACIFIC RISE}




\title{
EPSL
}

Earth and Planetary Science Letters 142 (1996) 289-309

\section{Constraining crustal emplacement processes from the variation in seismic layer 2A thickness at the East Pacific Rise}

\author{
Emilie E.E. Hooft ${ }^{\mathrm{a}, *}$, Hans Schouten ${ }^{\mathrm{b}}$, Robert S. Detrick ${ }^{\mathrm{b}}$ \\ ${ }^{a}$ Massachusetts Institute of Technology / Woods Hole Oceanographic Institution Joint Program in Oceanography, Woods Hole, MA \\ 02543-1542, USA \\ ${ }^{b}$ Department of Geology and Geophysics, Woods Hole Oceanographic Institution, Woods Hole, MA 02543-1542, USA
}

Received 11 December 1995; accepted 14 May 1996

\begin{abstract}
A stochastic model for the emplacement of dikes and lava flows at a fast spreading ridge can generate an upper oceanic crustal structure similar to that observed in seismic data from the East Pacific Rise (EPR), in ocean drill holes, and in ophiolites. In this model the location of successive dike intrusion events relative to the ridge axis is determined by a Gaussian probability function, and the cumulative flow lengths of the erupted lavas are chosen to build a Gaussian-shaped lava pile. We interpret wide-angle seismic reflections from the steep velocity gradient at the base of seismic layer $2 \mathrm{~A}$ to be the extrusive/sheeted dike contact. Seismic data from the northern and southern EPR place constraints on the on-axis extrusive layer thickness $(230 \pm 50 \mathrm{~m}$ ), the distance over which the thickening of the extrusive layer occurs (width of the accretion zone $=1-3 \mathrm{~km}$ ) and its off-axis thickness (300-800 m). Ophiolites and ocean drill holes (DSDP Hole 504B) provide additional estimates of the thickness of the extrusive layer and constrain the thickness of the transition region from extrusives to sheeted dikes $(\sim 100-200 \mathrm{~m}$ ). A simple stochastic emplacement model, where the lavas are described by one mean flow length, fits the thickening of the extrusive layer off-axis inferred from the deepening of seismic layer $2 \mathrm{~A}$, but the predicted transition from sheeted dikes to extrusives is too thick. In order to match the dimensions and flat-topped shape of the seismic layer 2A boundary as well as the thickness of the extrusive-sheeted dike transition, a bimodal distribution of lava flows is used. Short flows, confined within the axial summit caldera (ASC), build up approximately half the extrusive volume. Occasional voluminous flows spill out of the ASC, or erupt outside of the ASC, and pond at a considerable distance off-axis to build up the remainder of the extrusive section. The upper part of the final extrusive section will be dominated by the off-axis flows, while the lower portions will be primarily composed of short flows erupted within the ASC. Magnetic transition widths predicted from the overlap of lavas $(\sim 2 \mathrm{~km})$ in this model are similar to those measured in deep-tow studies. Assuming a smoothing function which acts over one seismic wavelength, the upper crustal velocity structure predicted by the bimodal lava emplacement model is consistent with the shallow seismic velocity structure measured on the EPR. The ages of seafloor lavas in this model are younger than the tectonic spreading model ages by $\sim 30-70 \mathrm{kyr}$, in agreement with anomalously young lava ages obtained from radioisotope dating of seafloor basalts near the EPR.
\end{abstract}

Keywords: East Pacific Rise; emplacement; dikes; oceanic crust; models

\footnotetext{
• Corresponding author. Fax: +1 508457 2150. E-mail: emilie@ochre.whoi.edu

0012-821X/96/\$12.00 Copyright () 1996 Elsevier Science B.V. All rights reserved. PII S0012-821X(96)00101-X
} 


\section{Introduction}

The upper portion of the oceanic crust is formed by dike intrusion and the eruption of lava flows. These two magmatic processes generate an upper crustal structure composed of lavas piled on top of one another, underlain by a sheeted dike complex. Constraints on the processes of upper crustal construction have come from ophiolite studies [1,2], observations in active rifts (e.g., Iceland [3]), modeling of marine magnetic anomaly shapes and transition thicknesses [4-8], mapping [9-14], dating [15], and drilling (e.g. DSDP Hole 504B [16]) of young ocean crust. Ophiolite studies, on the basis of chilled margin statistics $[1,17,18]$ and measurements of the thickness of the lava/dike transition [1] predict narrow intrusion zone widths of $10-50 \mathrm{~m}$. Modeling of marine magnetic anomaly transition widths suggests a lava emplacement zone 1-3 km wide. Geological mapping and dating of lava flows at the East Pacific Rise (EPR) suggest that volcanic activity is primarily confined within the narrow ( 50-200 m wide) axial summit caldera (ASC), but there is evidence for very young flows on the flanks of the axial high outside the ASC that suggest eruptive activity over a much wider zone or transport of lavas a considerable distance off-axis (e.g. [19]). The relative importance of off-axis eruptive activity and the processes that control the thickness of the extrusive section are still poorly understood.

Advances in seismic imaging of the shallow velocity structure at the East Pacific Rise allow the thickness of what is commonly interpreted as the extrusive layer to be directly mapped. In this paper, we use the variation in this seismically determined extrusive thickness to provide new constraints on crustal emplacement processes. We show that the dike intrusion zone must be extremely localized about the ridge axis. The extrusive section is made up of two units of about equal thickness: a lower unit, composed of short flows confined within the axial summit caldera, and an upper unit, of flows which spill out of the axial summit caldera (ASC), or are channelled across the shoulders of the rise axis in lava tubes and flow long distances down the flanks of the axial high, or erupt off-axis. We discuss the implications of this emplacement model on the seismic velocity structure of the shallow oceanic crust, subsidence rates, dip of isochrons in the extrusive section, magnetic anomaly transition widths, and the age of lavas exposed at the seafloor.

\section{Observational constraints on upper oceanic crustal structure at the EPR}

The typical seismic velocity structure of the shallow oceanic crust has been characterized from high quality expanding spread profiles (ESP) $[20,21]$, tomographic images [22], refraction data [23], wide aperture profiles (WAP) $[24,25]$ and on-bottom refraction work (NOBEL) [26]. These studies have identified a small velocity layer which is $100-200 \mathrm{~m}$ thick, has velocities $\leq 2.6 \mathrm{~km} / \mathrm{s}$ and a low vertical velocity gradient. This surficial low velocity layer is underlain by a steep gradient zone where velocities $>\sim 5 \mathrm{~km} / \mathrm{s}$ are reached in a few hundred meters. The crustal section with the surficial low velocity layer and the underlying steep velocity gradient is called layer $2 \mathrm{~A}$. The underlying crust, with velocities $>\sim 5 \mathrm{~km} / \mathrm{s}$ and a very gradual velocity gradient, corresponds to layer $2 \mathrm{~B}$ [27]. The base of the high gradient region is imaged in multichannel seismic reflection (MCS) experiments as a shallow wide angle reflection formed by refracted energy turning in the steep gradient $[24,28,29]$. No normal incidence reflection is seen, since there is no impedance contrast, rather the steep gradient generates diving rays which are observed at large offsets on the streamer. In Fig. 1b,d, the wide angle reflection from the base of layer $2 \mathrm{~A}$ is outlined with a gray line for two seismic profiles shot across the rise crest of the southern EPR (SEPR31 at $17^{\circ} 14^{\prime} \mathrm{S}$, and SEPR06 at $18^{\circ} 28^{\prime} \mathrm{S}$ ). To obtain the thickness of layer $2 \mathrm{~A}$ the two-way travel times to the base of layer $2 \mathrm{~A}$ are converted to depth using the composite velocity model of Harding et al. [28].

The shallow velocity structure of the ocean crust is controlled by the composition and porosity of the upper crust. We interpret layer $2 \mathrm{~A}$ in young $(<1$ $\mathrm{My}$ ) oceanic crust to be the extrusive section and use measurements of its thickness to map the variability in the accumulation of extrusives. The surficial lowvelocity zone is attributed to a layer of high-porosity pillows and flows (e.g. [30,31]), with porosities possibly greater than $20 \%$ [32-34]. The higher-velocity 
a)

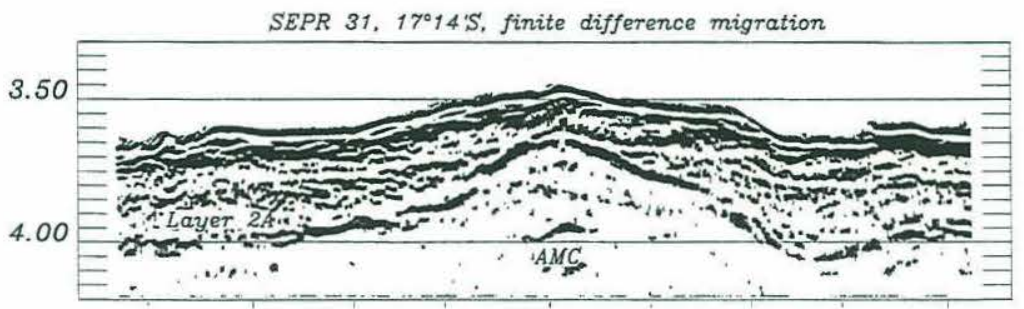

b)

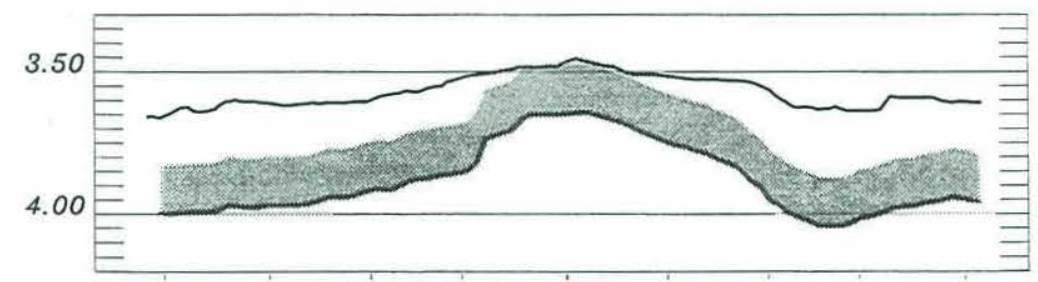

c)

SEPR 6, $18^{\circ} 28^{\prime}$ ', finite difference migration

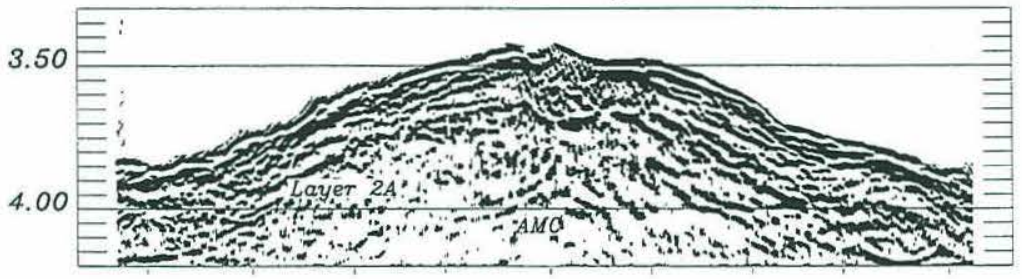

d)

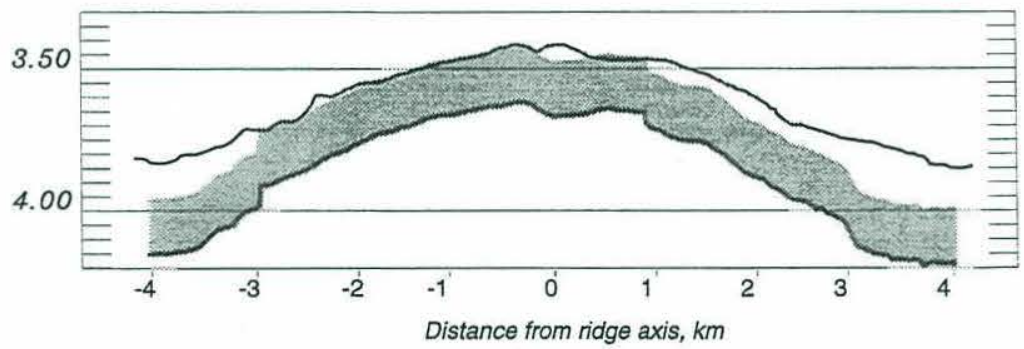

Fig. 1. (a) and (c) Across-axis multichannel seismic sections from the southern East Pacific Rise, SEPR $31\left(17^{\circ} 14^{\prime} \mathrm{S}\right)$ and SEPR06 (18 $\left.28^{\prime} \mathrm{S}\right)$ [40]. The data were stacked using a velocity-depth function that varied laterally and then finite difference migrated to account for the seafloor and layer 2A topography. The axial magma chamber (AMC) and the base of layer $2 \mathrm{~A}$ are indicated on the figures. (b) and (d) Line drawings showing picks of the seafloor and layer $2 \mathrm{~A}$ reflections in black and dark gray lines, respectively. The light gray constant thickness band corresponds to the on-axis thickness of layer $2 \mathrm{~A}$. This emphasizes that the on-axis thickness is built up very rapidly, while the off-axis accretion of layer $2 \mathrm{~A}$ occurs over a few kilometers. Both profiles show similar on-axis and off-axis layer $2 \mathrm{~A}$ thicknesses, $\sim 250 \mathrm{~m}$ and $500-550 \mathrm{~m}$, respectively. The two profiles represent end-members of the width of the region over which the accretion of layer $2 \mathrm{~A}$ takes place: on SEPR31 it is narrow while on SEPR06 it is broad and the widths of the $2 \mathrm{~A}$ accretion zone are $1.2 \mathrm{~km}$ and $3 \mathrm{~km}$, respectively. Note that the layer $2 \mathrm{~A} / 2 \mathrm{~B}$ boundary has a flat-topped, concave shape beneath the rise axis. 
Table 1

Seismic constraints on the variability of layer $2 \mathrm{~A}$ along the EPR

\begin{tabular}{llll}
\hline Experiment, latitude & On-axis 2A thickness & Off-axis 2A thickness & $\begin{array}{l}\text { Thickness of 2A } \\
\text { accretion zone }\end{array}$ \\
\hline MCS NEPR, $8^{\circ} 50^{\prime}-9^{\circ} 50^{\prime} \mathrm{N}^{\text {a }}$ & $\sim 230 \pm 50 \mathrm{~m}$ & $0.8-2 \mathrm{~km}$ \\
& $\sim 400 \mathrm{~m}$ near $99^{\circ} \mathrm{N}$ OSC & $440-560 \mathrm{~m}$ & $0.5-3 \mathrm{~km}$ \\
MCS SEPR, $13^{\circ}-20.5^{\circ} \mathrm{S}^{\mathrm{b}}$ & $235 \pm 40 \mathrm{~m}$ & $400-800 \mathrm{~m}$ & $3 \mathrm{~km}$ \\
& $300-400 \mathrm{~m}$ near OSCs & & \\
WAP, $9^{\circ} 35^{\prime} \mathrm{N}^{\mathrm{c}}$ & $\sim 150 \pm 30 \mathrm{~m}$ & $250-280 \mathrm{~m}$ & \\
ESP, $9^{\circ} 35^{\prime} \mathrm{N}^{\mathrm{d}}$ & $150 \mathrm{~m}$ & $310-350 \mathrm{~m}$ & \\
NOBEL, $9^{\circ} 30^{\prime} \mathrm{N}{ }^{\mathrm{c}}$ & $130 \mathrm{~m}$ & $\sim 300 \mathrm{~m}$ & \\
\hline
\end{tabular}

${ }^{a}$ Harding et al. [28]. ${ }^{b}$ Hooft et al. [41]. ${ }^{c}$ Vera and Diebold [24]. ${ }^{d}$ Vera et al. [20]. ${ }^{c}$ Christeson et al. [36].

layer $2 \mathrm{~B}$ material underlying the surficial low-velocity layer has been interpreted to be either the top of the sheeted dike sequence $[28,35,36]$ or low-porosity pillow lavas and flows $[20,21,23,37]$. At DSDP Hole $504 \mathrm{~B}-6 \mathrm{My}$ old, intermediate spreading crust high seismic velocities are reached within the extrusive section [38]. At Hess Deep - young, fast spreading crust - the transition from extrusives to sheeted dikes occurs at a depth corresponding to the location of the base of layer $2 \mathrm{~A}$ in velocity-depth profiles measured on fast-spreading crust [26]. We follow the reasoning of Christeson et al., 1994 [27] in considering the velocity structure measured at DSDP Hole 504B to be the result of the alteration and reduction of bulk porosity of the shallow crust.
With increasing age the base of layer $2 \mathrm{~A}$ migrates from the sheeted dike/extrusive boundary upwards to a porosity contrast within the extrusive section. By comparison with Hess Deep, we interpret layer 2A to consist of both the extrusive and mixed zones (i.e., it is a transition zone where lavas and sheeted dikes intermingle). The high velocity, low gradient material represents the top of the sheeted dike complex (layer 2B). The wide angle multichannel reflections are due to rays turning in the steep-velocity gradient in the transition zone at the base of layer $2 \mathrm{~A}$.

Large lateral variations in layer $2 \mathrm{~A}$ thickness are observed in multichannel seismic data at the fastspreading northern $[24,28]$ and southern $[29,39-41]$ EPR, in wide aperture profiles [24] in the $9^{\circ} \mathrm{N}$ area,

Table 2

Geological observations

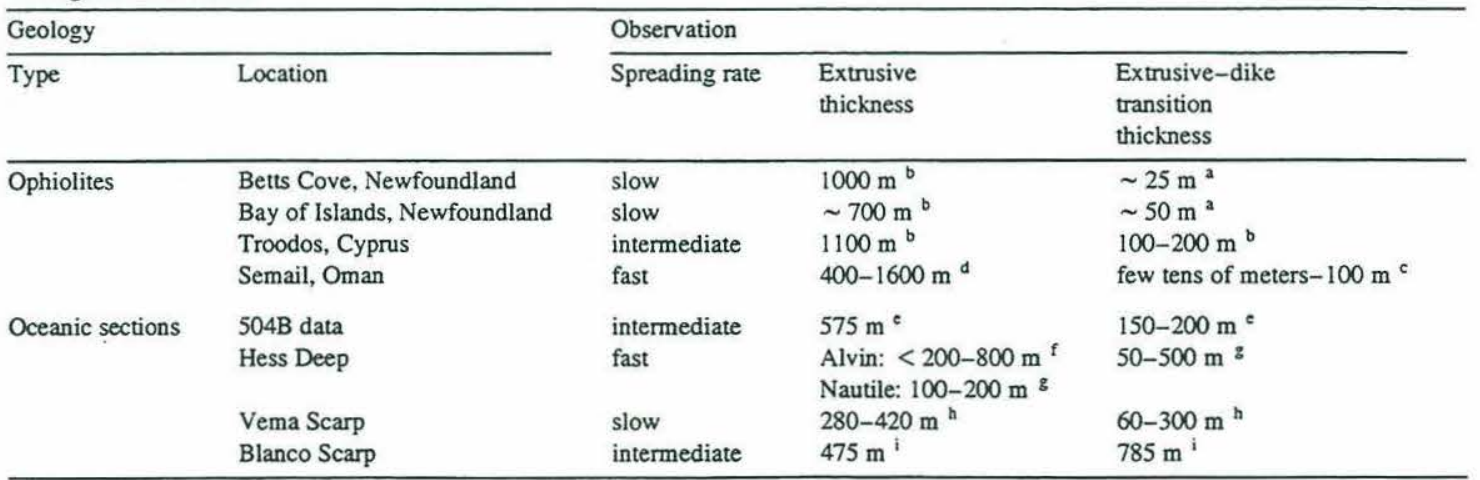

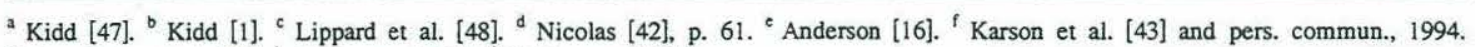

${ }^{8}$ Francheteau et al. [44]. " Cannat et al. [45]. ${ }^{i}$ Naidoo et al. [34]. 
in expanding spread profiles [20] at $9^{\circ} 35^{\prime} \mathrm{N}$, and in on-bottom refraction studies [27] at $9^{\circ} 30^{\prime} \mathrm{N}$. Table 1 shows the on-axis and off-axis thicknesses and the width of the $2 \mathrm{~A}$ accretion zone - the distance from the axis over which layer $2 \mathrm{~A}$ thickens to the mean off-axis thickness - for different seismic experiments on the northern and southern EPR. Moving off the rise crest, layer $2 \mathrm{~A}$ is observed to approximately double in thickness over a distance of a few kilometers. In general, on-axis layer $2 \mathrm{~A}$ thicknesses are remarkably uniform, $\sim 230 \pm 50 \mathrm{~m}$ except near overlapping spreading centers where the thicknesses reach $\sim 400 \mathrm{~m}[28,29,41]$. Off-axis thicknesses of $400-800 \mathrm{~m}$ are reached within $1-3 \mathrm{~km}$ of the rise axis. In spite of the differences in spreading rate, layer $2 \mathrm{~A}$ thicknesses are similar along the northern $(55 \mathrm{~mm} / \mathrm{yr}$ half-rate) and southern $(75 \mathrm{~mm} / \mathrm{yr}$ halfrate) EPR, although different seismic techniques give somewhat different results, due to the differences in inherent resolution [26]. If the velocities in the extrusives and dikes are assumed to be constant and the steep velocity gradient at the base of layer $2 \mathrm{~A}$ is due to the interfingering of these two units, then the thickness of the high velocity gradient zone corresponds to the thickness of the transition zone from extrusives to sheeted dikes. In seismic data from the northern EPR this high velocity gradient zone has a thickness of $\sim 100-300 \mathrm{~m}[20,26]$.

These seismically derived constraints on extrusive layer thickness and thickness of the extrusive-dike transition can be compared with geological observations on sections of oceanic crust exposed in Hess Deep, in ophiolites, and drilled in Hole 504B (Table 2). Extrusive layer thicknesses estimated in ophiolites range from 400 to $1600 \mathrm{~m}[1,42]$. In contrast, estimates of extrusive thicknesses from oceanic scarps are only $\sim 300-500 \mathrm{~m}[43-46]$ while at DSDP Hole 504B the extrusive section is less than $600 \mathrm{~m}$ thick [16], comparable to layer 2A thicknesses determined from off-axis seismic data (Table 1). The extrusive-dike transition zone (defined as the vertical depth from $20 \%$ to $70 \%$ sheeted dikes) is quite thin in ophiolite sections (Table 2), a few tens of meters to $100-200 \mathrm{~m}[1,47,48]$. Oceanic scarps give values also ranging from a few tens of meters up to a few hundred meters [44-46], while at DSDP Hole 504B the extrusive-dike transition is $\sim 150 \mathrm{~m}$ thick [16]. These estimates are comparable to the thickness of the layer $2 \mathrm{~A} / 2 \mathrm{~B}$ transition estimated seismically. Modeling of the extrusive-dike transition thickness in ophiolites shows that the dike intrusion zone must be very narrow, only $10-50 \mathrm{~m}$ wide [1]. Such a narrow dike intrusion width is supported by independent statistical observations of the proportion of dikes in ophiolites that exhibit one-sided cooling, due to having been split by a subsequent dike $[1,17,18]$. Studies of marine magnetic anomaly reversal widths and variability [4-8] suggest a relatively wide zone of lava emplacement, 1-3 km wide. However, these data can not resolve the relative contributions of the width of the intrusion zone and lava flow distribution to the lava emplacement process. Macdonald [6] attributes the width of the magnetic anomaly reversal to a combination of a relatively wide intrusion zone and long lava flows.

There are four observables which help constrain the dimensions of the upper crustal emplacement process: the on-axis 2A thickness, off-axis $2 \mathrm{~A}$ thickness, width of the $2 \mathrm{~A}$ accretion zone, and the extrusive-sheeted dike transition thickness. These values are obtained from seismic and geological observations. In this paper we attempt to match two endmember profiles of layer $2 \mathrm{~A}$ thickening from the southern EPR. At the same time we maintain an extrusive-dike transition thickness that is consistent with geological observations - greater than $50 \mathrm{~m}$ and no wider than 150-200 m. The two across-axis seismic sections from the Southern East Pacific Rise, SEPR31, $17^{\circ} 14^{\prime} \mathrm{S}$, and SEPR06, $18^{\circ} 28^{\prime} \mathrm{S}$, (Fig. 1a,c) were chosen because they characterize the variability in the width and shape of thickening of layer $2 \mathrm{~A}$. Although both of these profiles (Fig. 1b,d) have similar on-axis $(250 \mathrm{~m})$ and off-axis layer $2 \mathrm{~A}$ thicknesses $(550 \mathrm{~m})$, they differ in the width of the zone over which the thickening takes place; SEPR31 is narrow (width of the $2 \mathrm{~A}$ accretion zone is $1.2 \mathrm{~km}$ ) while SEPR06 thickens over a wide zone (width of the $2 \mathrm{~A}$ accretion zone is $3 \mathrm{~km}$ ). Both thickening profiles are flat-topped (i.e., the minimum on-axis thickness is maintained for some distance before the layer starts to thicken). 


\section{Emplacement models}

\subsection{Unimodal lava emplacement model}

We use a stochastic model to construct the sheeted dike and extrusive sections of the oceanic crust (c.f. $[4,5])$. At an active spreading center, steady state is only achieved statistically, since the accretion process is a series of discrete, successive events. Fig. 2 shows a schematic example of four steps in the emplacement process. Dikes are injected into the crust at a location determined randomly from a probability function. Each dike is associated with a lava flow. Lava flows out on either side of the locus of intrusion to a distance determined randomly from a second probability function. Earlier flows are covered by later flows. The lava pile subsides as it is covered so that a flat seafloor is maintained. The variables used in the emplacement models are defined in Table 3. The dikes are assumed to have a thickness, $w=1 \mathrm{~m}$. This is consistent with dike widths of $0.5-1.5 \mathrm{~m}$ observed at Hess Deep [43] and a mean of $\sim 1 \mathrm{~m}$ for the dike width distribution measured in the Troodos ophiolite, Cyprus [1]. The source region of the dikes lies below the base of our model. The probability function of the location of dike intrusion relative to the ridge axis that we use is a Gaussian, with a standard deviation of intrusion, $\sigma_{i}$. Of the dikes, $95 \%$ are intruded within a distance of $\pm 2 \sigma_{i}$ from the ridge axis. Lava flow lengths are such that cumulative flows erupted at the same location build a Gaussian-shaped extrusive pile with

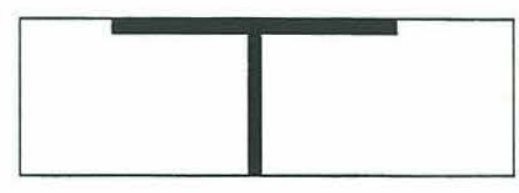

Time 1
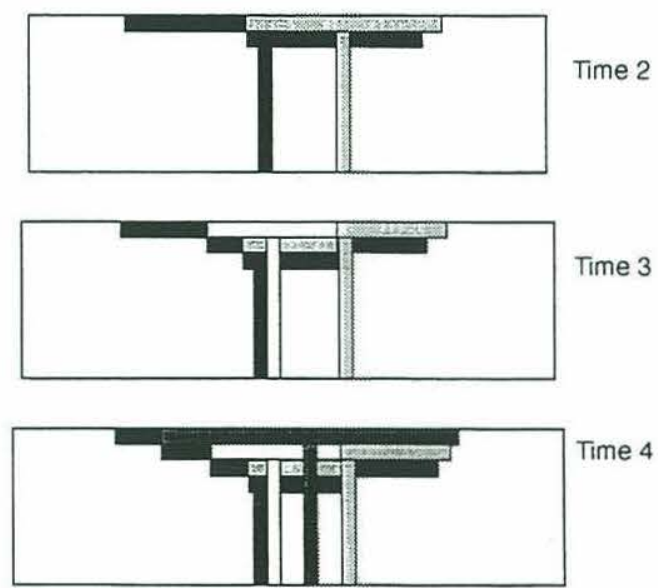

Fig. 2. Cartoon of four steps in the stochastic emplacement process that constructs the upper crust. The location of dike intrusion is determined from the probability function for the intrusion location relative to the ridge axis. Pre-existing crust spreads to the side a distance equal to half a dike width. The length of the lava flow erupted from this dike is determined from the probability function describing the flow lengths. The lava flow extends equal distances on either side of the point of intrusion. Pre-existing crust underlying the new flow subsides an amount equal to one flow thickness. The cycle then repeats itself with the selection of a new point of intrusion and the determination of the accompanying lava flow length.

Table 3

Model variables

\begin{tabular}{|c|c|}
\hline Model variable & Definition \\
\hline \multicolumn{2}{|c|}{ Unimodal Lava Emplacement Model } \\
\hline$\sigma_{i}$ & standard deviation of dike intrusion \\
\hline$\sigma_{e}$ & standard deviation of lava emplacement \\
\hline pso & probability that a dike erupts to form a lava flow \\
\hline$t$ & thickness of the lava flows \\
\hline$w$ & width of the dikes $=1 \mathrm{~m}$ \\
\hline \multicolumn{2}{|c|}{ Bimodal Lava Emplacement Model } \\
\hline$\sigma_{i}$ & standard deviation of dike intrusion for all flows $=10 \mathrm{~m}$ \\
\hline$\sigma_{e s}$ & standard deviation of lava emplacement of the short flows ( $95 \%$ of events) \\
\hline$\sigma_{e L}$ & standard deviation of lava emplacement of the long flows ( $5 \%$ of events) \\
\hline $\operatorname{minl}$ & distance over which no lava accumulates for the long flows \\
\hline$t$ & thickness of the lava flows (both short and long) \\
\hline pso & probability that a dike erupts to form a lava flow $=1$ \\
\hline$w$ & width of the dikes $=1 \mathrm{~m}$ \\
\hline
\end{tabular}


standard deviation $\sigma_{e}$. Thus, the half-flow length probability function that we chose is the derivative of a half-Gaussian, which is the Rayleigh distribution. The flows have a uniform thickness, $t$, and the median flow length is $(2 \pi)^{1 / 2} \sigma_{e}$. Observations in Hawaii and Iceland suggest that a significant proportion $(50-75 \%)$ of diking events do not form a surface eruption (Delaney, pers. commun., RIDGE The-

Unimodal Lava Emplacement Model

Isochrons: $\sigma \mathrm{i}=\mathbf{3 0 0} \mathrm{m}$

a)

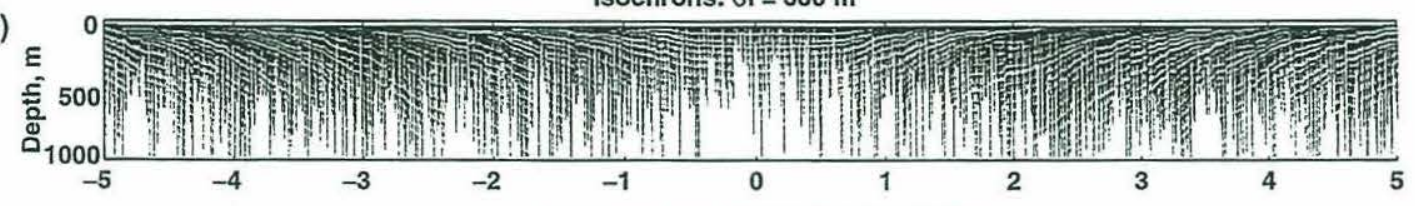

b)

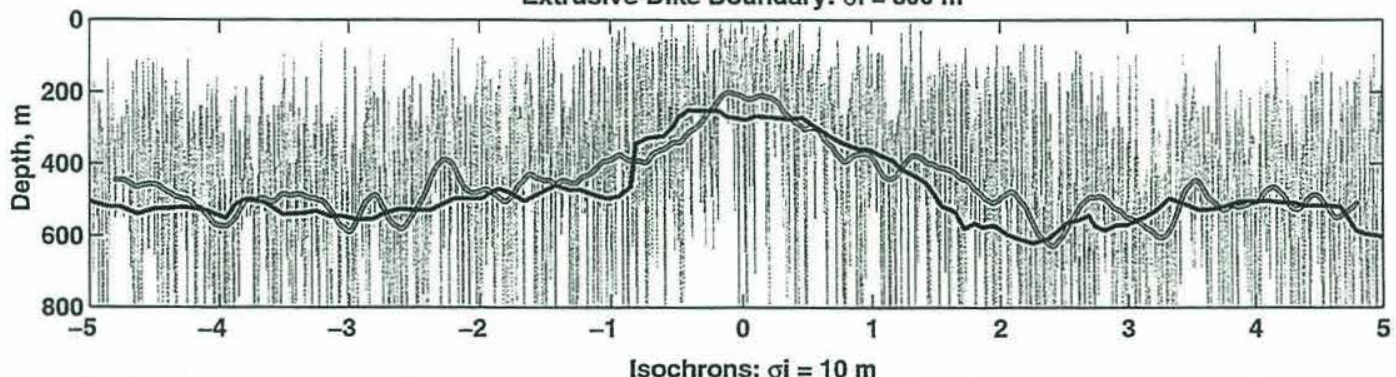

c)

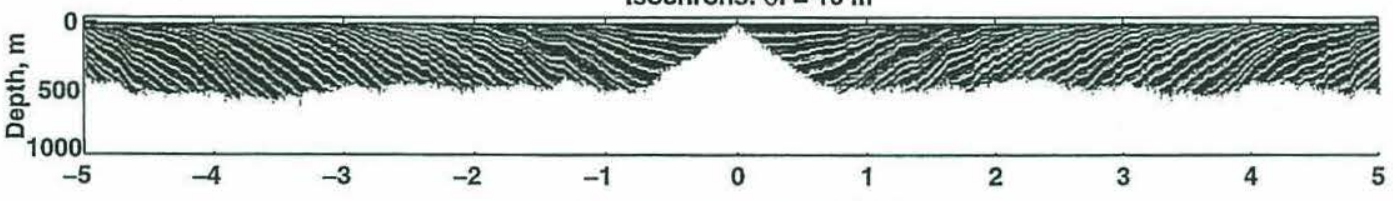

d)

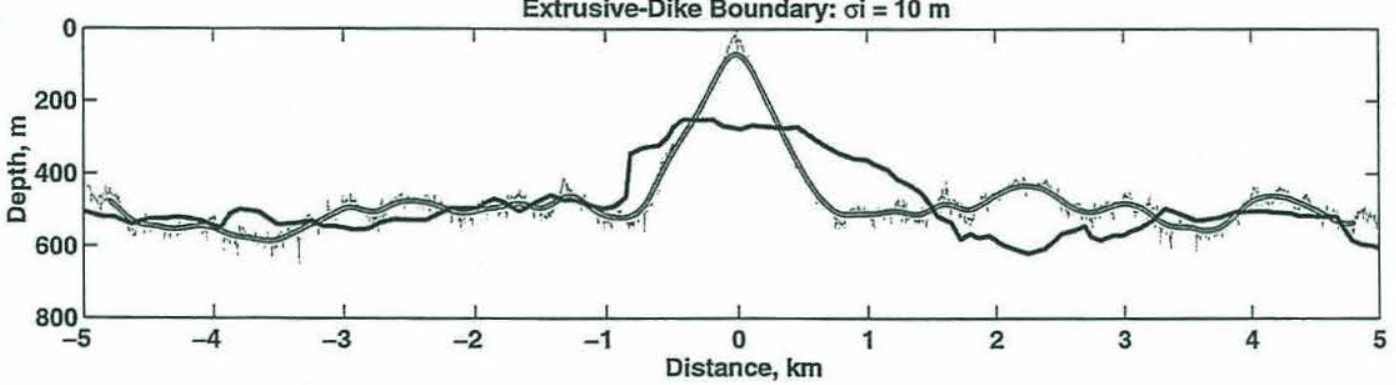

Fig. 3. Two runs of the unimodal lava emplacement model of upper crustal construction where the standard deviation of intrusion is wide, $\sigma_{i}=300 \mathrm{~m}$ (a and b) and narrow, $\sigma_{i}=10 \mathrm{~m}$ ( $\mathrm{c}$ and d), the standard deviation of extrusion, $\sigma_{e}=500 \mathrm{~m}$, the thickness of the dikes and of the lava flows is $1 \mathrm{~m}$ and $40 \%$ of the dikes erupt a lava flow. (a) and (c) The isochrons within the extrusives are shown by changing shades of gray. The dikes are shown in white. No vertical exaggeration. (b) and (d) The gray line is the boundary between the sheeted dikes and extrusives. The hollow line is the result of spatially filtering the extrusive-dike boundary with a triangular filter of wavelength $200 \mathrm{~m}$ to simulate a seismic observation of this contact. The solid black line is the across-axis layer 2A thickness from line SEPR31. For the model with $\sigma_{i}=300 \mathrm{~m}$ the character as well as the on-axis $(200 \mathrm{~m})$, off-axis thicknesses $(510 \mathrm{~m})$, and width of the $2 \mathrm{~A}$ accretion zone $(2300 \mathrm{~m})$ match the seismic profile well. However, the transition zone from extrusives to sheeted dikes is $310 \mathrm{~m}$, thicker than that observed in ophiolite sections and oceanic scarps. When $\sigma_{i}=10 \mathrm{~m}$, the transition zone from extrusives to sheeted dikes is $50 \mathrm{~m}$, comparable to ophiolite and oceanic scarp observations. However, the shape of the layer $2 \mathrm{~A}$ boundary is pointed rather than flat-topped, with a very small on-axis thickness $(70 \mathrm{~m})$ and does not resemble the seismic profile. 
oretical Institute, June, 1995). This results in additional extension during lava emplacement or, alternatively, represents a change in the effective ratio of the thickness of the dikes to that of the lava flows. We incorporate this effect by introducing the variable $p s 0$, which represents the probability that a dike will actually erupt to form a lava flow on the seafloor. Any extension of the crust due to tectonics is considered negligible in this model. At fast spreading ridges faulting accounts for only $3-10 \%$ of the total spreading rate $[49,50]$. To match a full spreading rate of $150 \mathrm{~mm} / \mathrm{yr}$ (southern EPR) a $1 \mathrm{~m}$ thick dike must be intruded on average every 7 years, assuming that all the extension is accommodated by construction of the sheeted dike section. At a full spreading rate of $110 \mathrm{~mm} / \mathrm{yr}$ (northern EPR) a diking event occurs on average every 9 years. Note, however, that diking events are likely to be clustered in time at any particular location with intervening quiescent periods.
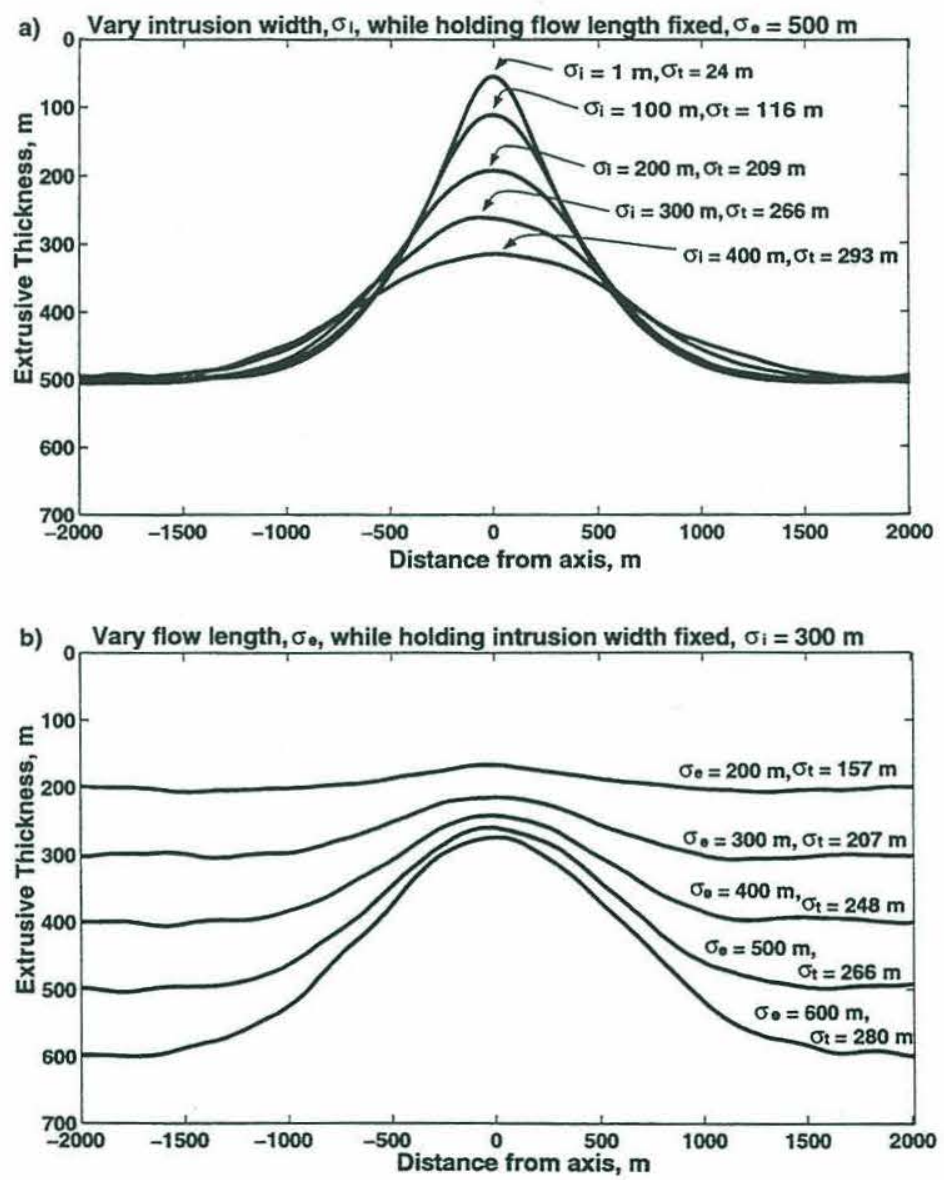

Fig. 4. The change in shape of the $2 \mathrm{~A} / 2 \mathrm{~B}$ boundary when varying the standard deviation of dike intrusion $\sigma_{i}$, and the standard deviation of lava emplacement, $\sigma_{e}$, for the unimodal lava emplacement model. The curves shown are for averages of 50 model runs which are subsequently filtered with a triangular filter of $200 \mathrm{~m}$ wavelength. For these runs, $p s 0=0.4, t=1 \mathrm{~m}$, and $w=1 \mathrm{~m}$. (a) The intrusion width is varied, $\sigma_{i}=1-400 \mathrm{~m}$ in $100 \mathrm{~m}$ increments, while the flow length is held fixed, $\sigma_{e}=500 \mathrm{~m}$. (b) The flow length is varied, $\sigma_{e}=200-600$ in $100 \mathrm{~m}$ increments, while the intrusion width remains fixed, $\sigma_{i}=300 \mathrm{~m}$. The standard deviation of the mean of the 50 model runs, $\sigma_{t}$, is indicated as a measure of the variability in the profiles, which reflects the thickness of the transition zone from $20 \%$ to $70 \%$ sheeted dikes. 
The crustal structure generated by our model generates a highly variable contact between the extrusives and sheeted dikes and predicts that isochrons within the extrusive section dip towards the ridge axis (Fig. 3a). Fig. 3a shows the result of over 10,000 intrusion and emplacement events to form an upper crustal section $10 \mathrm{~km}$ wide. To match seismic profile SEPR31, the model was run using $\sigma_{i}=300$ $\mathrm{m}$, and $\sigma_{e}=500 \mathrm{~m}$, with $40 \%$ of the dikes erupting. On average, as they are rafted away from the axis, the tips of the earlier flows are not covered by subsequent flows, resulting in isochrons within the upper crustal section which dip towards the ridge axis. The contact between sheeted dikes and extrusives in this model is extremely variable. To simulate a seismic observation of the extrusive-sheeted dike contact that is generated by this model, we have smoothed the contact using a triangular filter with a width of one seismic wavelength (Fig. 3b). At a dominant frequency of $20 \mathrm{~Hz}$ and crustal velocity of $\sim 4 \mathrm{~km} / \mathrm{s}$, the seismic wavelength is $200 \mathrm{~m}$. One seismic wavelength is an approximation of the distance required for the energy to turn within layer $2 \mathrm{~A}$ and generate a wide-angle 'reflection'/refraction. The variation in extrusive layer thickness predicted by the model compares well with seismic observations of layer $2 \mathrm{~A}$ thickness variations at the EPR in terms of the on-axis $(200 \mathrm{~m})$ and off-axis $(510 \mathrm{~m})$ thicknesses and the distance over which this thickening occurs ( $2300 \mathrm{~m}$ half-width). However, the extrusive-dike transition thickness calculated from the model is $310 \mathrm{~m}$, wider than most geological estimates (Table 2). If the model is run with the same $\sigma_{e}$ but $\sigma_{i}=10 \mathrm{~m}$ (Fig. 3c,d), the transition zone from extrusives to sheeted dikes is $50 \mathrm{~m}$, which is comparable to ophiolite and oceanic scarp observations. However, now the shape of the layer $2 \mathrm{~A}$ boundary is pointed rather than flat-topped with a very small on-axis thickness $(70 \mathrm{~m})$, which does not resemble the seismic profile. When the extrusive-dike transition thickness is included as a constraint, there is no longer a solution of the unimodal lava emplacement model which satisfies the four seismic and geological observables.

\subsection{Sensitivity of the model}

We examine the effect of changing the character- istic dimensions of dike intrusion and lava emplacement on the four observables that we can measure: the on-axis extrusive layer thickness, the off-axis extrusive layer thickness, the width of $2 A$ accretion and the transition thickness from $20 \%$ to $70 \%$ sheeted dikes. The unimodal lava emplacement model is characterized by five parameters (Table 3 ): the standard deviation of dike intrusion, $\sigma_{i}$, the standard deviation of the extrusive pile, $\sigma_{e}$, the probability that a dike will erupt a lava flow, $p s 0$, the thickness of the lava flows, $t$, and the width of the dikes, $w$. Fig. 4 shows the effect of varying the two parameters, $\sigma_{i}$ and $\sigma_{e}$, on the shape of the $2 \mathrm{~A} / 2 \mathrm{~B}$ boundary for an average of 50 model runs which are subsequently filtered with a $200 \mathrm{~m}$ wavelength triangular filter. For these runs, $p s O=0.4, t=1 \mathrm{~m}$, and $w=1$ $\mathrm{m}$. The parameter $\sigma_{t}$ is the standard deviation of the mean of the 50 model runs and reflects the thickness of the transition zone from $20-70 \%$ sheeted dikes. In Fig. $4 \mathrm{a}, \sigma_{e}$ is held fixed. If $\sigma_{i}$ is extremely narrow, then the $2 \mathrm{~A} / 2 \mathrm{~B}$ boundary will have a pointed shape with a very thin layer $2 \mathrm{~A}$ at the rise axis and a very narrow transition thickness, $\sigma_{t}$ (Fig. 3c,d). If $\sigma_{i}$ is wider, then the on-axis thickness of layer $2 \mathrm{~A}$ and the thickness of the transition zone increase, and the 2A/2B boundary has a broader, flat-topped shape. The off-axis thickness remains constant, since $\sigma_{e}$ is constant, and thus, when the statistical variability of the model is smoothed out, the total volume of extrusives remains the same. In Fig. $4 \mathrm{~b}, \sigma_{i}$ is held constant and $\sigma_{e}$ is increased. This results in an increase in the off-axis thickness of the extrusive layer, which is accompanied by an increase in on-axis thickness. Longer flows also result in layer 2A thickening over a greater distance off-axis and lead to a small increase in the thickness of the transition zone, $\sigma_{t}$.

The off-axis thickness of the lava pile can be determined from mass conservation and is independent of $\sigma_{i}$. The off-axis extrusive thickness is:

$(2 \pi)^{1 / 2} \sigma_{e}\left(\frac{t \cdot p s 0)}{w}\right)$

The off-axis extrusive thickness depends on the mean lava flow length, scales linearly with the flow thickness and with the percentage of dikes that erupt, and scales inversely with dike width. Fig. 5a shows 
a)

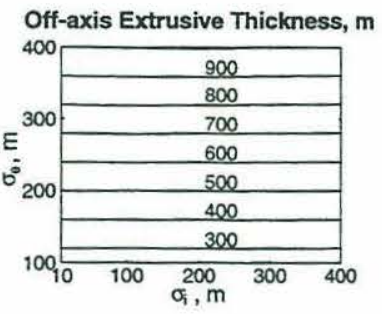

b)

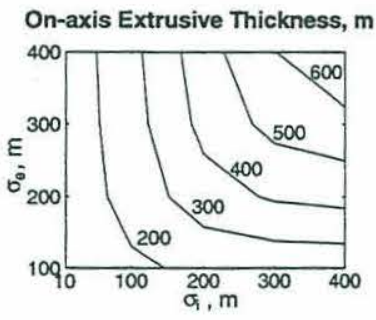

c)

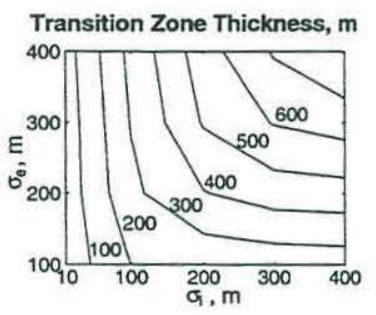

Fig. 5. Contour plots of the values of the on-axis extrusive thickness, off-axis extrusive thickness, and transition thickness as a function of $\sigma_{i}$ and $\sigma_{e}$ for the unimodal lava emplacement model. Values are determined from the mean of five runs of the emplacement model with $\sigma_{i}$ ranging from 10 to $400 \mathrm{~m}$ and $\sigma_{c}$ ranging from 100 to $400 \mathrm{~m}$. For these iterations the scaling variables are held fixed; $t=1 \mathrm{~m}, w=1 \mathrm{~m}$, and $p s 0=1$. The on-axis thickness of the extrusive layer and the extrusive-dike transition thickness are sensitive to both $\sigma_{i}$ and $\sigma_{e}$, while the off-axis extrusive layer thickness depends only on $\sigma_{e}$.

the off-axis extrusive thickness as a function of the two stochastic variables, $\sigma_{i}$ and $\sigma_{e}$, determined from the mean of five runs of the emplacement model, with $\sigma_{i}$ ranging from 10 to $400 \mathrm{~m}$ and $\sigma_{e}$ ranging from 100 to $400 \mathrm{~m}$. The on-axis extrusive thickness depends on the ratio of the two standard deviations and scales in the same way as the off-axis extrusive thickness:
$(2 \pi)^{1 / 2} \sigma_{e}\left[1-\exp \left(\frac{-\sigma_{i}}{\sigma_{e}}\right)\right]\left(\frac{t \cdot p s 0}{w}\right)$

The on-axis extrusive thickness is contoured as a function of $\sigma_{i}$ and $\sigma_{e}$ in Fig. 5b. As the intrusive width and the flow length tend to zero, the on-axis thickness goes to zero. For an infinitely wide intrusion zone, the extrusive thickness on axis is equal to that off axis. The thickness of the transition zone from extrusives to sheeted dikes is shown in Fig. 5c and has a similar dependence on $\sigma_{i}, \sigma_{e}, t, p s 0$ and $w$ as the on-axis extrusive thickness. Note that, for the definition that we have chosen $(20-70 \%$ sheeted dikes), the transition width is always greater than or equal to the on-axis extrusive thickness. The width of the $2 \mathrm{~A}$ accretion zone is a less stable measurement and much more sensitive to the statistical variability in the model. As can be seen from Fig. 4, the width of the $2 \mathrm{~A}$ accretion zone is positively related to $\sigma_{e}$ but also varies with $\sigma_{i}$. The width of the $2 \mathrm{~A}$ accretion zone is independent of $t$, but depends on psO and $w$.

This stochastic emplacement model with a unimodal distribution of flows matches the variation in layer $2 \mathrm{~A}$ thickness observed seismically at the EPR (Fig. 3) and provides some intuitive insight into the processes that control extrusive thickness at fast spreading ridges. For example, this model shows that the distance off-axis at which layer $2 \mathrm{~A}$ reaches its final thickness is primarily affected by the distance flows extend off-axis. For a unimodal distribution of flows, the shape of the layer $2 \mathrm{~A} / 2 \mathrm{~B}$ boundary (flattopped rather than triangular) requires a zone of intrusion on the order of a few hundred meters. However, this unimodal lava emplacement model cannot explain both the broad, flat-topped shape of the layer $2 \mathrm{~A} / 2 \mathrm{~B}$ boundary and at the same time the sharpness of the extrusive-dike transition measured in outcrop and drill holes. The wider intrusion zone required to match the seismic observations will result in a broad transition zone, due to the variability in location of dike intrusion. Indeed, for this unimodal lava emplacement model the transition thickness is greater than or equal to the on-axis layer $2 \mathrm{~A}$ thickness, which at the EPR is about $250 \mathrm{~m}$ (Fig. 5). The transition thickness predicted for the model shown in Fig. 3, which fits the observed layer 2A thickness, is over $300 \mathrm{~m}$. This is larger than transition thicknesses 
of a few tens of meters to $100-200 \mathrm{~m}$ measured in ophiolites [1,42] and 150-200 $\mathrm{m}$ drilled at Hole 504B [16] (Table 2). To match the observed sharpness of the extrusive-dike transition thickness, the standard deviation of intrusion must be narrower than the mean flow length by about an order of magnitude [1]. Solutions to the unimodal lava emplacement model which match the shape of the seismic $2 \mathrm{~A} / 2 \mathrm{~B}$ boundary have $\sigma_{i}$ and $\sigma_{e}$ of the same order of magnitude. In order to match the sharpness of the extrusive-dike transition zone observed in ophiolites, $\sigma_{i}$ must be of the order of 10-50 m. However, this will result in a very small on-axis $2 \mathrm{~A}$ thickness and a boundary which is peaked rather than flat-topped (Fig. 3c,d), contrary to what is observed in the seismic data.

\subsection{Bimodal lava emplacement model}

We propose a stochastic emplacement model with a bimodal distribution of flows in order to match both the dimensions and shape of the seismic boundary and the geologically observed extrusive-dike transition thickness. The idea underlying the bimodal lava emplacement model is to rapidly build up the on-axis thickness of extrusives by accumulating a sequence of short flows erupted at the ridge crest (standard deviation of emplacement, $\sigma_{e s}$ ). The more progressive thickening of the extrusive layer over $1-3 \mathrm{~km}$ observed in the seismic sections is accomplished by a series of flows that are about as long as the width of the region of thickening (standard deviation of emplacement, $\sigma_{e L}$ ). Geologically, the short flows remain confined within the axial summit caldera (ASC). The long flows flow down the flanks of the rise crest, are channelled across the shoulders of the rise in lava tubes, or erupt outside the ASC (Fig. 6). The upper part of the resulting extrusive section is composed of flows deposited away from the axis while the lower portion consists of flows deposited on-axis. Since the on-axis thickness of layer $2 \mathrm{~A}$ is approximately half of the off-axis thickness, the on-axis and off-axis flows must contribute equal volumes to the extrusive section. To accomplish this, if the flows all have the same thickness, the short flows must be erupted much more frequently than the long flows ( $95 \%$ of the time). In this case, the mean volume of the long flows is $\sim 20$ times that of the short flows. On the other hand, the relative number of events decreases if the short flows are much thicker than the long flows, possibly due to the ponding of these flows against the walls of the ASC. A flow thickness $t=2 \mathrm{~m}$ implies flows with a cross-sectional area of $2,000 \mathrm{~m}^{2}$ for the long flows. To compare this 2-D flow volume with that of the mid-crustal melt sill, we assume a melt sill thickness of $50 \mathrm{~m}$ and a sill width of $800 \mathrm{~m}$ [51]. The melt sill has a volume of $4,000 \mathrm{~m}^{2}$, twice that needed to form the rare, voluminous, long flow length eruptions.

A model to build the extrusive section of the ocean crust that combines an initially narrow and subsequently wide zone of accretion was suggested

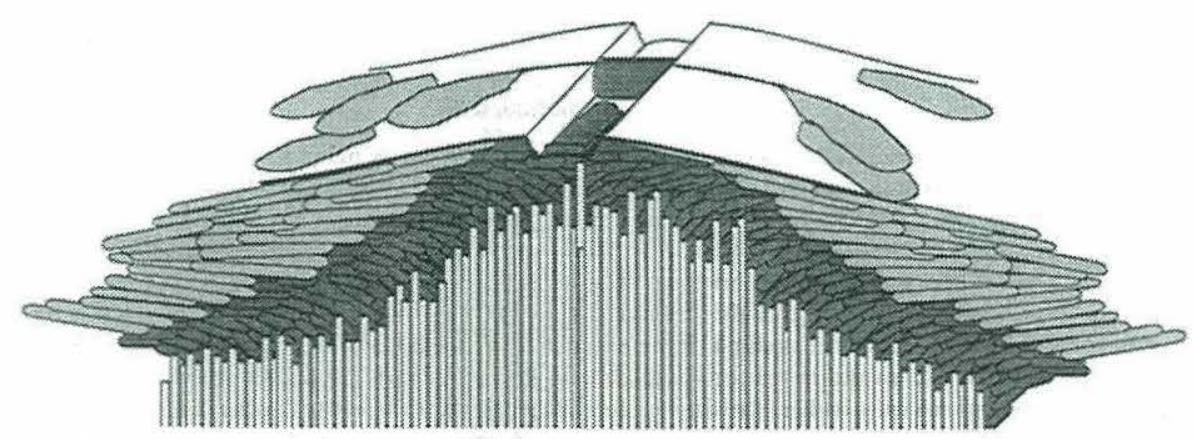

Fig. 6. Diagram showing the bimodal flow length emplacement model. Short flows, shown in dark gray, remain confined within the axial summit caldera (ASC) and build up half the volume of the extrusive section. Occasional long flows, shown in light gray, are envisioned to flow down the flanks of the rise crest, be channeled across the shoulders of the rise in lava tubes, or erupt outside the ASC. They flow far off-axis and build up the remainder of the extrusive section. The accompanying dikes are shown in white. 


\section{Bimodal Lava Emplacement Model}

Isochrons matching SEPRO

a)

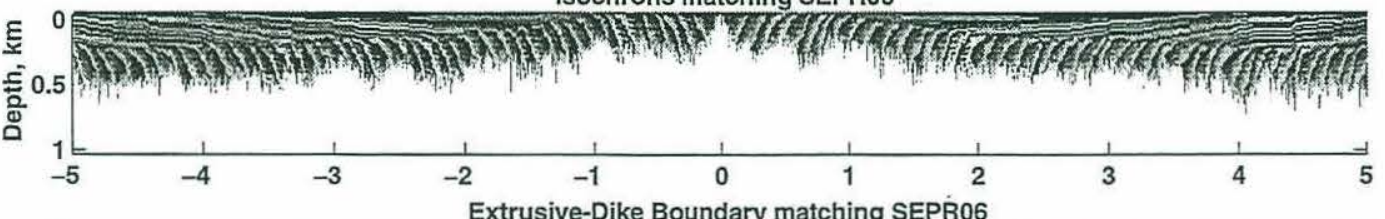

b)

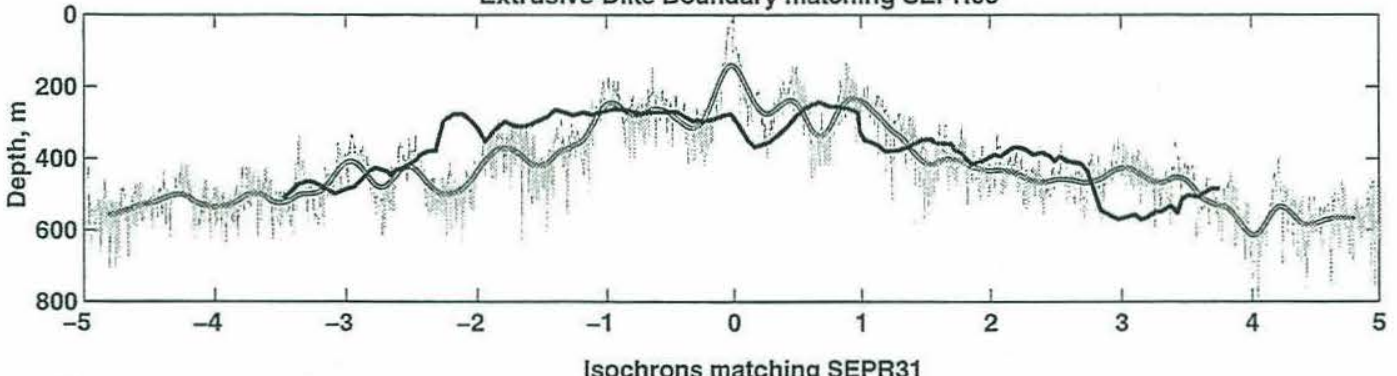

c)

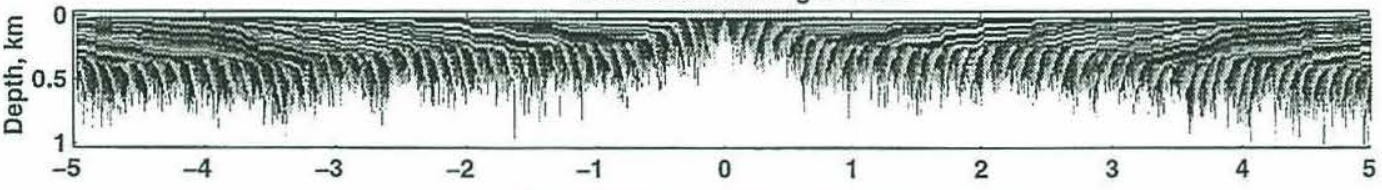

d)

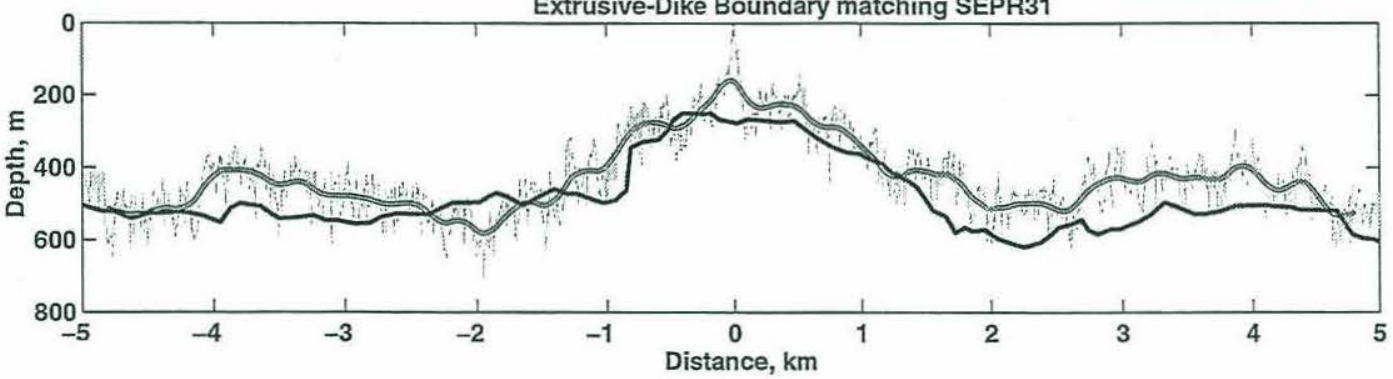

Fig. 7. Two examples of runs of the bimodal lava emplacement model of upper crustal construction that match the layer $2 \mathrm{~A}$ thicknesses for the across-axis seismic lines SEPR06 (wide region of 2A accretion) and SEPR31 (narrow region of 2A accretion) shown in Fig. 1. (a) Run of the bimodal lava emplacement model that matches SEPR06; standard deviation of intrusion, $\sigma_{i}=10 \mathrm{~m}$, lava flow distribution, $95 \%$ of the flows have $\sigma_{e S}=75 \mathrm{~m}, 5 \%$ of the flows have $\sigma_{e L}=1500 \mathrm{~m}, t=1.5 \mathrm{~m}$. For the long flows the distance over which no lava accumulates is $1000 \mathrm{~m}$. (c) Run of the bimodal lava emplacement model that matches SEPR31; standard deviation of intrusion, $\sigma_{i}=10 \mathrm{~m}$, lava flow distribution, $95 \%$ of the flows have $\sigma_{e s}=50 \mathrm{~m}, 5 \%$ of the flows have $\sigma_{e L}=1000 \mathrm{~m}, t=2.2 \mathrm{~m}$. For the long flows the distance over which no lava accumulates is $400 \mathrm{~m}$. In both figures the isochrons in the extrusive section are shown with a gray scale, sheeted dikes are in white. No vertical exaggeration. Note the shallow dip of the upper extrusive section $\left(0-10^{\circ}\right.$ and $\left.15^{\circ}\right)$ and the steep dips in the lower extrusives, $50-70^{\circ}$. The boundary between the two units is sharp and dips are zero at the contact. (b) and (d) The gray line is the boundary between the sheeted dikes and extrusives for the two model runs. The hollow line shows the model extrusive-sheeted dike contact averaged using a 200 $\mathrm{m}$ wavelength triangular filter. The black line is the layer $2 \mathrm{~A}$ thicknesses determined from (b) line SEPR06 and (d) line SEPR 31 . The on-axis, off-axis thicknesses and the widths of the $2 \mathrm{~A}$ accretion zone match well. The transition zone thickness for these models is $90 \mathrm{~m}$ and $70 \mathrm{~m}$, respectively, compatible with measurements made on ophiolites and oceanic crustal scarps. Note that these fits are not unique, but provide a characterization of the differences and types of length scales required to fit the observables available to constrain crustal accretion. 
by Atwater [52] to reconcile: (a) the observation of a wide emplacement zone suggested by the presence of intact volcanoes on the surface of the off-axis seafloor in the FAMOUS area; and (b) ophiolite observations of a very localized transition from extrusives to sheeted dikes. Our attempt to constrain the accretion process using the geometry and dimensions of the seismic layer 2A boundary and, at the same time, match the transition thickness observed in ophiolites has also led us to require a bimodal lava emplacement model for the fast spreading EPR. Our ability to image seismically layer $2 \mathrm{~A}$ thickness variations enables us to constrain the relative volumes contributed by these two modes of extrusion and the length scales involved.

In the bimodal lava emplacement model, the narrow intrusion zone and short flows generate the on-axis extrusive pile and result in a narrow transition zone from extrusives to sheeted dikes. The off-axis flows thicken the crust to the final thickness over the distance of a few kilometers. However, the shape of the extrusive-sheeted dike boundary obtained remains pointed rather than flat-topped. To obtain a flat-topped $2 \mathrm{~A} / 2 \mathrm{~B}$ boundary, as is observed in the across-axis seismic lines (Fig. 1), zero eruptive volume from the long flows must be accumulated over the flat region. A distribution of long flows that have zero thickness until some distance, minl, from the axis (Fig. 2c) gives an inflection point in the cumulative lava volume. This simulates eruptions that flow over the shoulders of the ASC, leaving a negligible thickness of lava until they pond in deeper areas off-axis. Alternatively, this represents flows that are channelled, perhaps in subseafloor lava tubes, from the axis across the rift shoulders to an eruption site off-axis [14], or voluminous flows that are erupted off-axis from a small number of dikes (Fig. 6). Once a flow leaves the summit region there is little to impede its flow until it reaches the base of the axial high $3-4 \mathrm{~km}$ off-axis. The variables used in the bimodal lava emplacement model are listed in Table 3. To keep the number of variables to a minimum, we have kept $\sigma_{i}$ the same for both the long and the short lava flows $\left(\sigma_{i}=10 \mathrm{~m}\right)$ and we fixed $p s O=1$ and $w=1 \mathrm{~m}$. As in the unimodal lava emplacement model, the effect of decreasing the thickness of the lava flows or decreasing the amount of dikes that erupt a lava flow is to decrease the thickness of the extrusive pile and of the transition zone. Decreasing the amount of dikes that erupt a lava flow also broadens the width of the $2 \mathrm{~A}$ accretion zone.

Fig. 7 shows two examples of the bimodal lava emplacement model that match the two across-axis seismic lines which represent extremes of the distance over which the off-axis thickness is attained, SEPR06 (broad 2A accretion zone) and SEPR31 (narrow 2A accretion zone), shown in Fig. 1. Solutions to both the unimodal and the bimodal lava emplacement models are non-unique, but the crustal accretion models that we present provide a characterization of the differences and types of length scales required to match the available observations. To fit layer 2A thicknesses for line SEPR06 (Fig. 7a,b), the model had a standard deviation of intrusion, $\sigma_{i}=10$ $\mathrm{m}$; lava flow length distribution, $95 \%$ of the flows have $\sigma_{e S}=75 \mathrm{~m}, 5 \%$ of the flows have $\sigma_{e L}=1500$ $\mathrm{m}$; and the thickness of the lava flows, $t=1.5 \mathrm{~m}$. As a simplification, we assume that all dikes erupt a lava flow, since there is a trade-off between lava flow thickness and percentage of dikes erupting flows. For the long flows, the distance from the axis over which no off-axis lava accumulates, $\min l=$ $1000 \mathrm{~m}$. This is the distance from the axis over which layer $2 \mathrm{~A}$ is not accreting new material beyond what was built up on the axis (Fig. 1b). Averaging the geological contact obtained from this model with a $200 \mathrm{~m}$ wavelength triangular filter gave model values of on-axis thickness $=140 \mathrm{~m}$, off-axis thickness $=460 \mathrm{~m}$, width of $2 \mathrm{~A}$ accretion zone $=2170 \mathrm{~m}$, and transition zone thickness $=90 \mathrm{~m}$. A good match was also obtained for line SEPR31 (Fig. 7c,d). The model parameters used in this case were: standard deviation of intrusion, $\sigma_{i}=10 \mathrm{~m}$; lava flow length distribution, $95 \%$ of the flows have $\sigma_{e s}=50 \mathrm{~m}, 5 \%$ of the flows have $\sigma_{e L}=1000 \mathrm{~m}$; and the thickness of the lava flows, $t=2.2 \mathrm{~m}$. For the long flows the distance over which no off-axis lava accumulates, $\min l=400 \mathrm{~m}-$ layer $2 \mathrm{~A}$ does not thicken beyond the on-axis thickness over this distance from the ridge axis (Fig. 1d). The filtered sheeted dike-extrusive boundary had an on-axis thickness $=160 \mathrm{~m}$, off-axis thickness $=500 \mathrm{~m}$, width of $2 \mathrm{~A}$ accretion zone $=1700 \mathrm{~m}$ and a transition thickness $=70 \mathrm{~m}$. For these two model runs the filtered extrusive-dike contact matches the seismic layer $2 \mathrm{~A}$ thickness pro- 

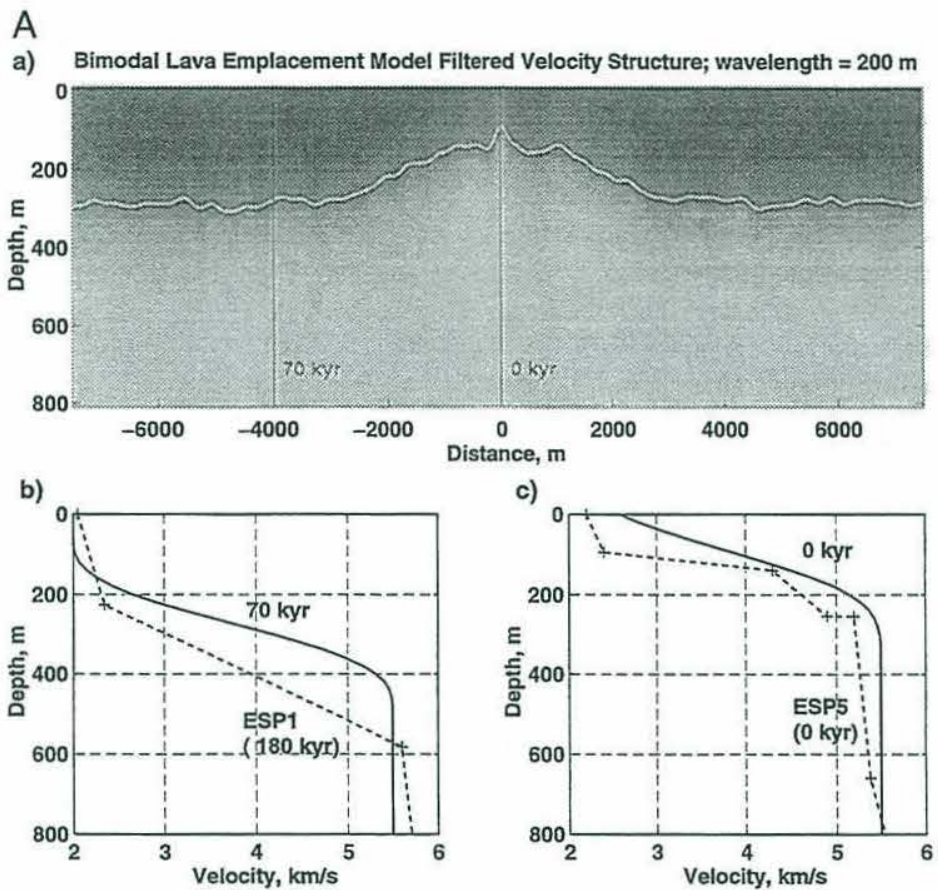

B
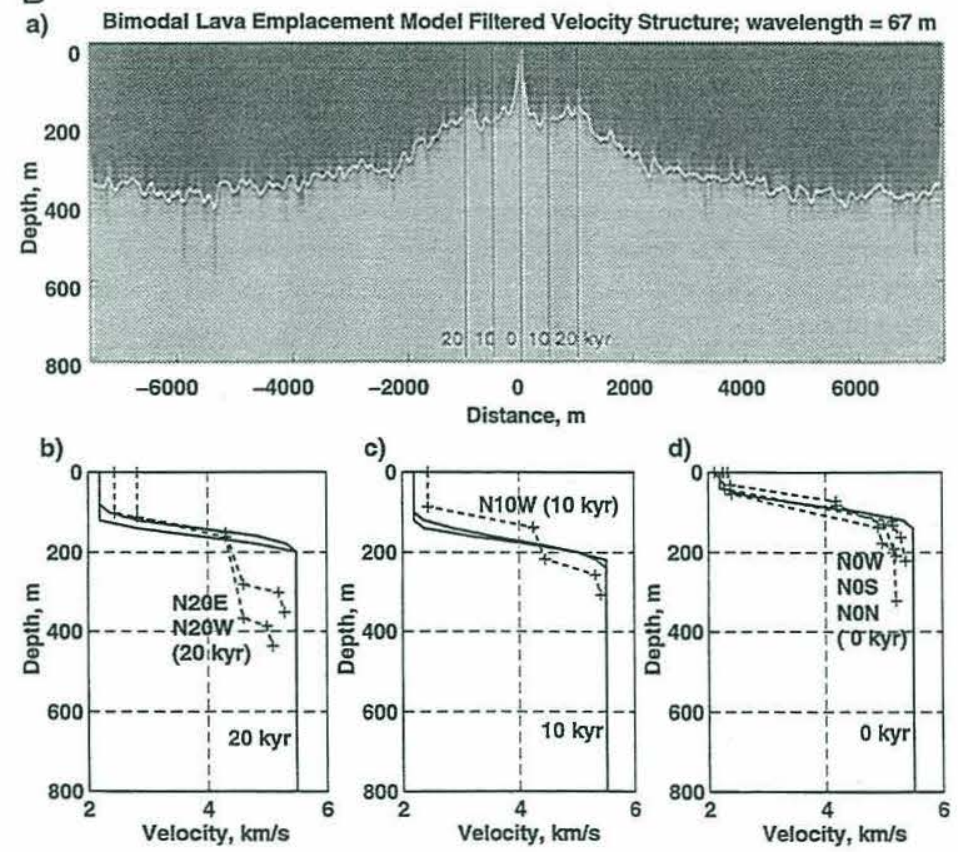
files well, both in terms of its shape, variability, and extrusive thickness values. In addition, the transition thicknesses calculated from the bimodal lava emplacement model are comparable to those measured in ophiolites and oceanic crustal sections. The differences in the width of the zone of $2 \mathrm{~A}$ accretion for the two models is consistent with the observed variation in across-axis topography for the two seismic profiles (Fig. 1a,c). SEPR06 has a broad axial high and thus off-axis lava flows do not pond till further from the ridge axis, resulting in a broader zone of thickening. On the other hand, SEPR31 shows a subdued narrow axial high and thus long lava flows rapidly reach relatively flat seafloor and pond closer to the rise axis, causing earlier thickening of the lava pile and a narrow $2 \mathrm{~A}$ accretion zone.

\section{Implications of the model}

In this section we explore the implications of the stochastic emplacement model for measured seismic velocities in the upper crust, magnetic anomaly transition widths, and seafloor lava ages. From the model we determined the velocity structure of the upper crust, the dip of isochrons with depth, the age of seafloor lavas relative to the underlying crust, and magnetic transition widths. The thickness of the shallow, steep velocity gradient reflects the thickness of the transition region from extrusives to sheeted dikes and the inherent resolution of the seismic technique used. The length of the lava flows and their subsidence rates affect the dip of isochrons in the extrusive section, the width of the transition region observed in magnetic anomalies, as well as the age of lavas on the seafloor.

\section{I. Velocity-depth profiles of the upper crust}

In order to see if the emplacement model that we propose is consistent with the shallow velocity structure observed at the EPR, we have calculated a synthetic velocity structure based on the distribution of extrusives and dikes predicted from the emplacement model. The shallow velocity structure of the crust is primarily determined by bulk porosity. Fractured porous lavas have a higher porosity than massive sheeted dikes so the relative abundance of lavas and dikes in a vertical section will have a major effect on the velocity structure. We assume that the velocities in the extrusive and sheeted dike sections are constant and equal to $2.2 \mathrm{~km} / \mathrm{s}$ and $5.5 \mathrm{~km} / \mathrm{s}$, respectively. The constant low velocity extrusive section results in a surficial low velocity zone. The underlying high gradient region is due to the mixed zone where dikes and extrusives interfinger. This is an approximation which does not take into account the probable variation of velocity with depth within the extrusive pile that results as this layer gets buried and porosity, decreases due to the closing of cracks and voids. Differences due to any morphological or chemical differences between the on-axis and the off-axis flows (i.e. the upper and lower extrusives) are also ignored.

The first area where we compare the measured with the predicted seismic velocity structure is $9^{\circ} 35^{\prime} \mathrm{N}$

Fig. 8. A(a) Velocity structure for a bimodal lava emplacement model run that fits the layer $2 \mathrm{~A}$ thicknesses measured on the wide aperture profile at $9^{\circ} 35^{\prime} \mathrm{N}$ EPR [24]. $\sigma_{i}=10 \mathrm{~m}, \sigma_{e s}=60 \mathrm{~m}, \sigma_{e l}=1200 \mathrm{~m}, t=1 \mathrm{~m}, \operatorname{minl}=1000 \mathrm{~m}$. Velocities of $2.2 \mathrm{~km} / \mathrm{s}$ (dark gray) and 5.5 $\mathrm{km} / \mathrm{s}$ (light gray) are assigned to the extrusive and sheeted-dike sections respectively. A velocity filter (a cone of radius one wavelength, $200 \mathrm{~m}$ ) was applied. The base of the steep velocity gradient is similar to that obtained by the linear triangular filter of the geological boundary (white line). (b) and (c) Depth sections of the velocity model on- and off-axis ( $70 \mathrm{kyr}$ ) (solid line), their locations are shown in (a) as dark vertical lines. These are compared to the velocity-depth profiles determined at this latitude, ESP5 (off-axis, $180 \mathrm{kyr}$ ) and ESP1 (on-axis) (dashed line) [20]. Note the similarity in the thickness of the surficial low-velocity zone and the depth over which the steep velocity gradient extends. $\mathrm{B}$ (a) Velocity structure for a bimodal lava emplacement model run that fits the layer $2 \mathrm{~A}$ thicknesses measured on the CDP31 at $9^{\circ} 30^{\prime} \mathrm{N}$ EPR [28], $\sigma_{i}=10 \mathrm{~m}, \sigma_{e s}=75 \mathrm{~m}, \sigma_{e l}=1500 \mathrm{~m}, t=1 \mathrm{~m}, \operatorname{minl}=1000 \mathrm{~m}$. Velocities of $2.2 \mathrm{~km} / \mathrm{s}$ (dark gray) and 5.5 $\mathrm{km} / \mathrm{s}$ (light gray) are assigned to the extrusive and sheeted dike sections, respectively. A velocity filter (a cone of radius one seismic wavelength, $67 \mathrm{~m}$ ) was applied. The base of the steep velocity gradient is similar to that obtained by the linear triangular filter of the geological boundary (white line). (b)-(d) Depth sections of the velocity model on-axis and at 10 and $20 \mathrm{kyr}$ (solid line), their locations are shown in (a) as dark vertical lines. These are compared to the velocity-depth profiles determined at this latitude from the on-bottom refraction (NOBEL) experiment [36]. Note the similarity in the thickness of the surficial low-velocity zone and the depth over which the steep velocity gradient extends. 
on the EPR. The seismic velocity structure at this location is constrained by several expanding spread profiles (ESP) [20]. The geometry of the layer $2 \mathrm{~A}$ boundary is constrained from a two-ship wide aperture profile (WAP) shot here [24]. We generate a model using the bimodal distribution of flows that fits the layer $2 \mathrm{~A}$ geometry in this area and assign velocities of $2.2 \mathrm{~km} / \mathrm{s}$ and $5.5 \mathrm{~km} / \mathrm{s}$ to the extrusives and sheeted dikes, respectively. The source used for the ESPs had a dominant frequency of 20 $\mathrm{Hz}$ corresponding to a wavelength of $200 \mathrm{~m}$ at 4 $\mathrm{km} / \mathrm{s}$. We therefore averaged our velocity structure using a cone-shaped filter with radius $200 \mathrm{~m}$ (Fig. $8 \mathrm{Aa})$ in order to compare it with the seismically derived velocity structure. The base of the resulting high gradient region closely resembles the result of running a one-dimensional triangular filter over the extrusive-dike contact. Velocity-depth profiles were constructed at ages of $0 \mathrm{kyr}$ and $70 \mathrm{kyr}$ (solid lines in Fig. 8A). They compare very well with the velocity-depth profiles obtained from the ESPS (dashed lines). There is no surficial low-velocity zone in the model for $0 \mathrm{kyr}$, while one is observed in ESP5. ESP5 may be located slightly off-axis, which would account for this discrepancy. ESP1 actually lies on $180 \mathrm{kyr}$ old crust but velocity profiles at 180 $\mathrm{kyr}$ and $70 \mathrm{kyr}$ are assumed to represent off-axis sections where crustal construction has been completed. The thickness, shape, and slope of the high gradient region is very similar to those measured with the ESPs.

The same procedure was applied to a second area at $9^{\circ} 30^{\prime} \mathrm{N}$ on the EPR, where the upper crustal velocity structure is constrained by a high-resolution on-bottom refraction experiment [36]. The geometry of layer $2 \mathrm{~A}$ is determined from MCS line CDP31 [28]. The on-bottom refraction experiment used a source with a dominant frequency of $60 \mathrm{~Hz}$. A model was constructed to matched the line CDP31 and was filtered at a wavelength of $67 \mathrm{~m}$ (Fig. 8Ba). Again, depth sections through the resulting velocity model show a high velocity gradient very similar in thickness, shape, and slope to those measured in the on-bottom refraction experiment on crust 0,10 and 20 kyr (Fig. 8Bb-d).

The fact that the boundary between the sheeted dikes and extrusives is not seismically sharp is consistent with the multichannel data. The base of layer
$2 \mathrm{~A}$ is not imaged as a normal incidence reflection in the multichannel seismic data but. rather, is a diving ray which turns in a steep velocity gradient and is observed at larger offsets on the streamer as a wideangle 'reflection'/refraction. These observations support the idea that the boundary between the extrusives and sheeted dikes is not sharp on the scale of a quarter-wavelength $(\sim 50 \mathrm{~m})$. However, on the scale of a full wavelength a coherent steep velocity gradient is sensed, causing the rays to turn back to the surface and resulting in a wide-angle reflection. Therefore, in this case, one seismic wavelength is an estimate of the distance required for energy to refract in a steep velocity gradient and produce a turning ray.

The thickness of the seismic high velocity gradient predicted from the bimodal lava emplacement model depends on the thickness of the transition zone from extrusives to sheeted dikes and on the dominant wavelength of the experiment that is measuring the velocity structure. For a model with a wide transition region, as would be obtained for the unimodal lava emplacement model, a shorter seismic wavelength will give a sharp boundary but, laterally. it will be highly variable. A long seismic wavelength will average out the variability and give a thicker high velocity gradient than has been seismically observed. For a narrow transition region, the long wavelength energy will simply see a somewhat broader transition region than the shorter wavelength. Under the simple assumptions that we make here the velocity structure predicted from the bimodal lava emplacement model is consistent with the shallow crustal velocity structure measured at the EPR. At the same time, the higher resolution on-bottom refraction experiment resolved a thinner on-axis thickness of layer $2 \mathrm{~A}$ than the MCS experiment (Fig. $8 \mathrm{Be}$ and $\mathrm{Ad}$, respectively), consistent with the bimodal lava emplacement model.

\subsection{Isochron dips and magnetic anomaly transition widths}

Lavas erupted on the seafloor are rapidly buried by subsequent flows and subside. In the unimodal lava emplacement model subsidence rates are 20 $\mathrm{mm} / \mathrm{yr}$, assuming full spreading rates of $150 \mathrm{~mm} / \mathrm{yr}$ for the southern EPR. For the bimodal lava emplace- 
ment model, the rates of subsidence are initially very high, $\sim 200 \mathrm{~mm} / \mathrm{yr}$ for the first $1.5 \mathrm{kyr}$, and then drop to $40-10 \mathrm{~mm} / \mathrm{yr}$ during the following $8-27$ kyr. The dips of isochrons are sensitive to the length of the lava flows and the amount of subsidence that occurs. In the unimodal lava emplacement model, dips are relatively steep throughout the extrusive section and vary from $\sim 0^{\circ}$, near the surface, to $\sim 30^{\circ}$ at depth (Fig. 3). For the bimodal lava emplacement models that we propose in this paper (Fig. $7 \mathrm{a}, \mathrm{c})$, the upper lavas, composed of the long flows, have very shallow dips, $0^{\circ}$ to $\sim 10-15^{\circ}$. At the boundary between the two lava types dips are $0^{\circ}$. In the lower extrusive section flow lengths are short and subsidence rates are high and the dips are extremely steep, $50-70^{\circ}$. In Iceland, lava flow dips are zero near the surface and increase with depth reaching $6^{\circ} 1500 \mathrm{~m}$ below the original top of the lava pile [43]. Considering the differences in extrusive thickness between Iceland and the EPR, these observations cannot differentiate between both modes of lava emplacement. The two models are distinguishable because, in the bimodal lava emplacement model, the dips are reduced to zero at the boundary between the upper and lower lavas. H. Schouten and E.E.E. Hooft (Two-layered structure of the pillow lavas in oceanic crust and ophiolites, manuscript in prep., 1996) find evidence of a bimodal dip structure in the paleomagnetic inclinations of several DSDP/ODP drill cores, suggesting that a bimodal emplacement of the upper oceanic crust also occurs at intermediate and slow spreading centers.

Work on the transition width of marine magnetic anomalies from deep-tow measurements on the Gorda Rise [4] suggest that the portion of the transition width due to constructional processes is $1.7 \mathrm{~km}$. Near-bottom magnetic profiles from ridges in the Pacific covering intermediate to fast spreading rates give an average half-width of crustal formation of 2-3 km [8]. Measurements made by Macdonald et al., [7] on the EPR $21^{\circ} \mathrm{N}$ give transition widths of $1-1.4 \mathrm{~km}$. For our bimodal lava emplacement model the dips of the isochrons vary with depth in the extrusive section. We have calculated the magnetic anomaly from the geometry of the bimodal lava emplacement model and compared it with the anomaly that would be obtained assuming the simple geometries of earlier models. The transition widths obtained, $\sim 2-3 \mathrm{~km}$, are similar to those observed. However, as mentioned before, these magnetic anomaly reversal data cannot resolve the relative contributions of the width of the intrusion zone and lava flow distribution to the lava emplacement process.

\subsection{Age of seafloor lavas}

Goldstein et al. [15] dated seafloor lavas on a transect across the EPR at $9^{\circ} 31^{\prime} \mathrm{N}$ and showed that these lavas were at least 20-70 kyr younger than the predicted age of the crust based on spreading rate (Fig. 9). They suggested that off-axis eruptions are probably the cause of these anomalously young ages, implying the existence of a comparatively broad (several kilometers half-width) zone of intrusion. However, if a significant proportion of the dikes are intruded over a wide zone, the extrusive-dike transition becomes much broader than is consistent with geological observations (Table 2).

In the emplacement model that we propose, the intrusion zone is very narrow (on the order of a few tens of meters) but the upper part of the extrusive section forms by flows that have been transported a long distance (up to several kilometers) off-axis from their point of eruption. These flows will have ages that are younger than the predicted age of the crust based on the spreading rate. From runs of the bimodal lava emplacement model that match the range of the seismically observed variation in layer $2 \mathrm{~A}$ thickness in the $9^{\circ} \mathrm{N}$ area on the EPR $[24,28]$, we predict seafloor ages will average about $\sim 30-70$ kyr younger than the crustal spreading age (Fig. 9). This is in agreement with the anomalously young lavas dated by Goldstein et al. [15] (Fig. 9), however, the predicted ages are in general younger than those observed. The discrepancy between the model and the dating can be explained if a significant amount of the off-axis thickening occurs below the surface, by the intrusion of sills. Another possibility is that, if the time from melt segregation in the mantle to eruption on the surface is substantial, then the time since eruption is significantly overestimated by the uranium-series disequilibrium dating [15].

Due to the narrowness of the extrusive-dike transition and its minimal effect on the seismic layer $2 \mathrm{~A}$ thickening profile, we infer that the number of dikes 


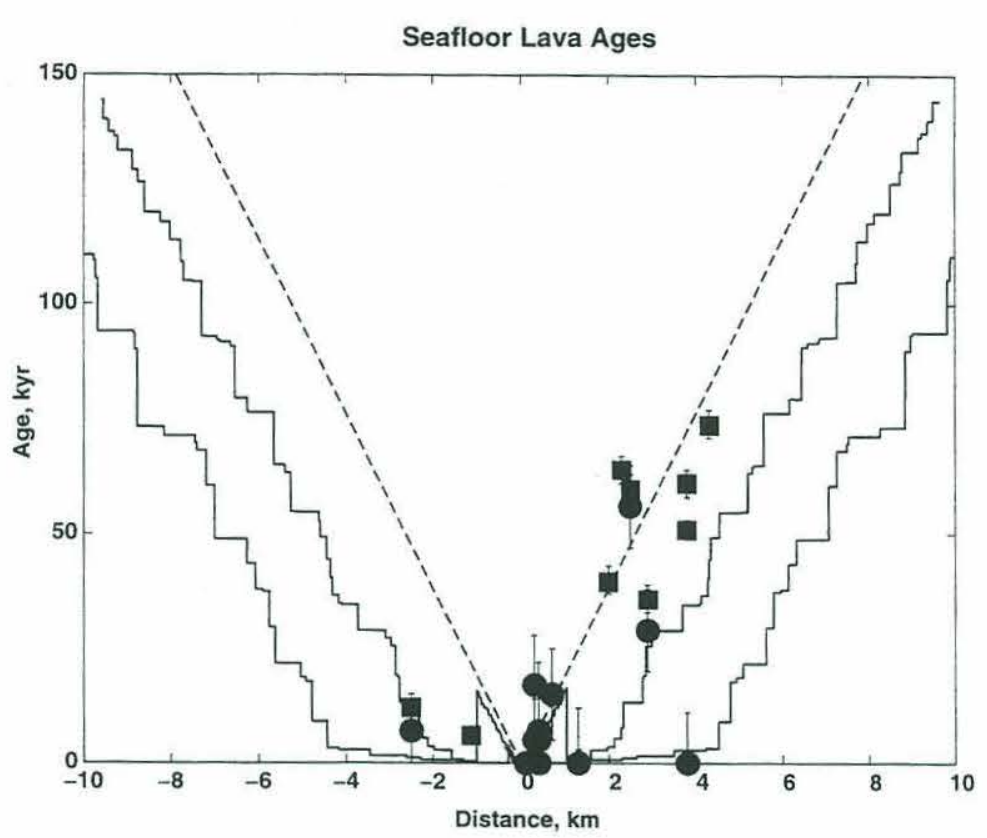

Fig. 9. Age offsets predicted by this model. The solid lines shows the ages of seafloor lavas determined from two bimodal lava emplacement models that match the range of layer $2 \mathrm{~A}$ thickening profiles measured in the $9^{\circ} \mathrm{N}$ area $[24,28](\mathrm{Fig}$. $8 \mathrm{Aa}$ and $8 \mathrm{Ba}$ ). The dashed line is the predicted age of the seafloor based on the assumed half-spreading rate of $55 \mathrm{~mm} / \mathrm{yr}$. The seafloor ages are younger than predicted because young lavas flow out over older crust. Age offsets are $\sim 30-70 \mathrm{kyr}$. The age offsets of 20-70 kyr were observed at $9^{\circ} 31^{\prime} \mathrm{N}$ by Goldstein et al. [15] (circles $={ }^{230} \mathrm{Th}$ ages, squares $={ }^{231} \mathrm{~Pa}$ ages). Note that the bimodal lava emplacement model assumed a very narrow $(\sim 40 \mathrm{~m})$ intrusion zone. The anomalously young lava ages reported by Goldstein et al. [15] do not necessarily require a significant volume of eruptive activity outside the ASC, if lavas erupted in the ASC periodically spill out of the ASC and flow for considerable distances down the flanks of the axial high.

feeding any off-axis eruptions is minimal. The source region and crustal residence time of any off-axis eruptions may well be different from the on-axis eruptions, and so even small volumes of lavas erupted off-axis can explain the diverse compositions measured in off-axis sampling of seafloor basalts [10]. It is important to bear in mind that rare, and volumetrically insignificant, lavas erupting outside of the zone of lava emplacement will form a thin cover on the seafloor and have a high probability of being sampled. Thus, while it is possible that some lavas erupt off-axis, extensive off-axis eruptions are not necessarily required to explain the anomalously young age of seafloor lavas observed near the EPR.

The existence of a narrow dike intrusion zone is consistent with the observation that most hydrothermal activity along the northern and southern EPR is located within the ASC $[9,14]$. Hydrothermal activity is driven by a heat source, on short time scales by a dike, over long times by an underlying magma body. The predominance of hydrothermal activity within the ASC supports the assertion that the majority of dikes are intruded very close to the ridge axis. Lava flows in the bimodal lava emplacement model extend up to a few kilometers off-axis and are also consistent with the observation that sediment cover in the $9^{\circ} 30^{\prime} \mathrm{N}$ EPR area is anomalously low up to 3-4 km from the ridge axis, beyond which the sediment thickness increases dramatically [15]. The off-axis seafloor is covered by the lavas that have flooded out of the ASC. The ASC is filled by the more common events - short flows. This could explain the observation that most off-axis seafloor is covered by lobate lava flows, while the morphology within the ASC is more varied, consisting of pillows and sheet flows with extensive collapse features 
[9,53]. Extensive collapse within the ASC also supports the high subsidence rates predicted by the bimodal lava emplacement model near the rise crest.

\section{Conclusions}

A stochastic model of the emplacement of dikes and lava flows generates an upper oceanic crustal structure similar to that observed in ophiolites, in ocean drill holes and in seismic data from the East Pacific Rise. An emplacement model with a narrow intrusion zone $(95 \%$ of the dikes are intruded within a zone $40 \mathrm{~m}$ wide, centered on the ridge axis) and a bimodal emplacement of lavas can explain the variation in thickness of layer $2 \mathrm{~A}$ observed seismically at the EPR and the sharpness of the extrusive-dike transition region observed in outcrop in ophiolites and on the seafloor. A thin, on-axis extrusive section is rapidly built up by accumulating a sequence of short flows erupted, and probably confined, within the ASC. The progressive thickening of the extrusive layer inferred from the deepening of the seismic $2 \mathrm{~A} / 2 \mathrm{~B}$ boundary over $1-3 \mathrm{~km}$ from the ridge axis is caused by longer flows that spill out of the ASC and down the flanks of the axial high or erupt off-axis (Fig. 6). In the resulting lava pile the upper part of the extrusive section is composed of flows deposited off the rise crest while the lower portion is flows deposited on-axis. This stochastic model for the construction of the upper crustal section is consistent with the velocity structure of the upper crust (producing a near-surface low velocity layer underlain by a steep velocity gradient), paleomagnetic inclinations in drill cores (a bimodal dip structure), magnetic transition widths $(\sim 2 \mathrm{~km})$, and age offsets of seafloor lavas relative to the underlying crust $(\sim 30$ $70 \mathrm{kyr}$ ). Extensive off-axis eruptions are not necessarily required to explain these age discrepancies. The similarity in seismic structure between the northern and southern EPR (full spreading rates of 110 and $150 \mathrm{~mm} / \mathrm{yr}$, respectively) indicate that the bimodal lava emplacement model is applicable to fast spreading ridges over a range of spreading rates.

\section{Acknowledgements}

Thanks to P. Buhl, R.S. Detrick, A.J. Harding, G.M. Kent, J.C. Mutter, and J.A. Orcutt for collect- ing the southern EPR multichannel seismic data set. We would like to thank Joe Cann for his help, especially with identifying the importance of the extrusive-dike transition thickness. Thanks to G.M. Kent and J. Escartín for helpful discussions. This manuscript was improved by thoughtful reviews by G. Christeson and A. Harding. This work was supported by NSF grant OCE-8020330. WHOI contribution number 9220. [CL]

\section{References}

[1] R.G.W. Kidd, A model for the process of formation of the upper oceanic crust, Geophys. J.R. Astron. Soc. 50, 149-183. 1977.

[2] J.R. Cann, A model for oceanic crustal structure developed, Geophys. J.R. Astron. Soc. 39, 169-187. 1974.

[3] G. Palmason, Kinematics and heat flow in a volcanic rift zone with application to Iceland, Geophys. J.R. Astron. Soc. 33, $451-481,1973$.

[4] T. Atwater and J.D. Mudie, Detailed near-bottom geophysical study of the Gorda Rise, J. Geophys. Res. 78, 8665-8686. 1973.

[5] H. Schouten and C.R. Denham. Modeling the oceanic magnetic source layer, in: Deep Drilling Results in the Atlantic Ocean: Ocean Crust, M. Talwani, C.G. Harrison and D.E. Hayes, eds., pp. 151-159, AGU Maurice Ewing Ser., Washington, DC, 1979.

[6] K. Macdonald, Near-bottom magnetic anomalies, asymmetric spreading, oblique spreading, and tectonics of the MidAtlantic Ridge near lat $37^{\circ} \mathrm{N}$, Geol. Soc. Am. Bull. 88 , 541-555, 1977.

[7] K.C. Macdonald, S.P. Miller, S.P. Huestis and F.N. Spiess, Three-dimensional modeling of a magnetic reversal boundary from inversion of deep-tow measurements, J. Geophys. Res. $85,3670-3680,1980$

[8] K.D. Klitgord, S.P. Huestis, J.D. Mudie and R.L. Parker, An analysis of near-bottom magnetic anomalies: Sea-floor spreading and the magnetized layer, Geophys. J.R. Astron. Soc. 43, 387-424, 1975.

[9] R.M. Haymon. D.J. Fornari, K.L. Von Damm, et al., Volcanic eruption of the mid-ocean ridge along the East Pacific Rise crest at $9^{\circ} 45^{\prime}-52^{\prime} \mathrm{N}$ : Direct submersible observations of seafloor phenomena associated with an eruption event in April, 1991, Earth Planet. Sci. Lett. 119. 85-101, 1993.

[10] M.R. Perfit, D.J. Fornari, M.C. Smith et al., Small-scale spatial and temporal variations in mid-ocean ridge crest magmatic processes, Geology 22, 375-379, 1994.

[11] P. Lonsdale, Segmentation of the Pacific-Nazca Spreading Center, $1^{\circ} \mathrm{N}-20^{\circ} \mathrm{S}$, J. Geophys. Res. 94, 12,197-12,225. 1989.

[12] K. Macdonald, P.J. Fox, S. Miller, et al., The East Pacific Rise and its flanks $8-18^{\circ} \mathrm{N}$ : History of segmentation, propagation and spreading direction based on SeaMARC II and Sea Beam studies, Mar. Geophys. Res. 14, 299-344, 1992. 
[13] K.C. Macdonald and P.J. Fox, The axial summit graben and cross-sectional shape of the East Pacific Rise as indicators of axial magma chambers and recent volcanic eruptions, Earth Planet. Sci. Lett. 88, 119-131, 1988.

[14] D.J. Fornari and R.W. Embley, Tectonic and volcanic controls on hydrothermal processes at the mid-ocean ridge: An overview based on near-bottom and submersible studies, in: Seafloor Hydrothermal Systems: Physical, Chemical, Biological, and Geological Interactions, S.E. Humphris, R.A. Zierenberg, L.S. Mullineaux and R.E. Thomson, eds., pp. 1-46, Am. Geophys. Union, Washington, DC, 1995.

[15] S.J. Goldstein. M. Perfit, R. Batiza, et al., Off-axis volcanism at the East Pacific Rise detected by uranium-series dating of basalts, Nature 367, 157-159, 1994.

[16] R.N. Anderson, et al., The first reference section over $1 \mathrm{~km}$ through layer $2 \mathrm{~A}$ of the oceanic crust. Nature $300,589-594$. 1982.

[17] J.S. Pallister, Structure of the sheeted dike complex of the Samail ophiolite near Idra. Oman. J. Geophys. Res. 86. 2661-2672, 1981.

[18] E. Rosencrantz. The structure of sheeted dikes and associated rocks in North Arm massif. Bay of Islands ophiolite complex, and the intrusive process at oceanic spreading centers. Can. J. Earth Sci. 20, 787-801, 1983.

[19] K.C. Macdonald, P.J. Fox, R.T. Alexander, et al., Volcanic growth faults and the origin of Pacific abyssal hills. Nature 380, 125-129, 1996.

[20] E.E. Vera, P. Buhl, J.C. Mutter, et al., The structure of $0-0.2$ My old oceanic crust at $9^{\circ} \mathrm{N}$ on the East Pacific Rise from expanded spread profiles, J. Geophys. Res. 95, 15,52915.556. 1990.

[21] A.J. Harding, M.E. Kappus, J.A. Orcutt, et al., The structure of young oceanic crust at $13^{\circ} \mathrm{N}$ on the East Pacific Rise from ESPs, J. Geophys. Res. 94. 12163-12196, 1989.

[22] D.R. Toomey, G.M. Purdy, S.C. Solomon and W.S.D. Wilcock, The three-dimensional seismic velocity structure of the East Pacific Rise near latitude $9^{\circ} 30^{\prime} \mathrm{N}$, Nature 347. 639-645, 1990.

[23] J.S. McClain, J.A. Orcutt and M. Burnett, The East Pacific Rise in cross section: A seismic model, J. Geophys. Res. 90. $8627-8640,1985$.

[24] E.E. Vera and J.B. Diebold, Seismic imaging of oceanic layer $2 \mathrm{~A}$ between $9^{\circ} 30^{\prime} \mathrm{N}$ and $10^{\circ} \mathrm{N}$ on the East Pacific Rise from two-ship wide-aperture profiles, J. Geophys. Res. 99. 3031-3042, 1994.

[25] M.E. Kappus, A.J. Harding and J.A. Orcutt, a baseline for upper crustal seismic velocity variations along the East $\mathrm{Pa}$ cific Rise at $13^{\circ} \mathrm{N}$, J. Geophys. Res. 100, 6143-6161, 1995.

[26] G.L. Christeson, G.M. Kent, G.M. Purdy and R.S. Detrick, Extrusive thickness variability at the East Pacific Rise 9$10^{\circ} \mathrm{N}$ : Constraints from seismic techniques, J. Geophys. Res., submitted.

[27] G.L. Christeson, G.M. Purdy and G.J. Fryer, Seismic constraints on shallow crustal emplacement processes at the fast spreading East Pacific Rise, J. Geophys. Res. 99, 17,95717,974, 1994.

[28] A.J. Harding, G.M. Kent and J.A. Orcutt, A multichannel seismic investigation of the upper crustal structure at $9^{\circ} \mathrm{N}$ on the East Pacific Rise: Implications for crustal accretion, J. Geophys. Res. 98, 13.925-13,944, 1993.

[29] G.M. Kent, A.J. Harding, J.A. Orcutt, et al., The uniform accretion of oceanic crust south of the Garrett Transform at $14^{\circ} 15^{\prime} \mathrm{S}$ on the East Pacific Rise, J. Geophys. Res. 99. 9005-9698, 1994.

[30] R.E. Houtz, Seismic properties of layer $2 \mathrm{~A}$ in the Pacific, J. Geophys. Res. 81, 6321-6340, 1976.

[31] G.M. Purdy. New observations of the shallow seismic structure of young oceanic crust. J. Geophys. Res. 92. 9351-9362. 1987.

[32] R.D. Hyndman and M.J. Drury, The physical properties of oceanic basement rocks from deep drilling on the MidAtlantic Ridge, J. Geophys. Res. 95, 17417-17429, 1976.

[33] R.H. Wilkens, G.J. Fryer and J. Karsten, Evolution of porosity and seismic structure of the upper oceanic crust: Importance of aspect ratios, J. Geophys. Res. 96, 17,981-17,995. 1991.

[34] P. Berge, G. Fryer and R. Wilkens, Velocity-porosity relationships in the upper oceanic cnust: Theoretical considerations. J. Geophys. Res. 97. 15,239-15,254. 1992.

[35] T.J. Herron, Lava flow layer - East Pacific Rise, Geophys. Res. Lett. 9, 17-20, 1982.

[36] G.L. Christeson, G.M. Purdy and G.J. Fryer, Structure of young upper crust at the East Pacific Rise near $9^{\circ} 30^{\prime} \mathrm{N}$, Geophys. Res. Lett. 19, 1045-1048, 1992.

[37] K.M.M. Rohr. B. Milkereit and C.J. Yorath, Asymmetric deep crustal structure across the Juan de Fuca Ridge, Geology, 16, 533-537, 1988.

[38] K. Becker and H. Sakai, et al., Proc. ODP Init. Rep. 111. Part A, 1988.

[39] J.C. Mutter, S.M. Carbotte, W. Su, et al.. Seismic images of active magma systems beneath the East Pacific Rise between $17^{\circ} 05^{\prime}$ and $17^{\circ} 35^{\prime} \mathrm{S}$. Science 268, 391-395. 1995.

[40] R.S. Detrick, A.J. Harding, G.M. Kent, et al., Seismic structure of the southern East Pacific Rise, Science 259, 499-503. 1993.

[41] E.E. Hooft, G.M. Kent and R.S. Detrick, Magmatic variability along the southern EPR, J. Geophys. Res., submitted.

[42] A. Nicolas, Structure of Ophiolites and Dynamics of Oceanic Lithosphere, 367 pp., Kluwer, Dordrecht, 1989.

[43] J.A. Karson, S.D. Hurst and P. Lonsdale, Tectonic rotations of dikes in fast-spreading oceanic crust exposed near Hess Deep, Geology 20, 685-688, 1992.

[44] J. Francheteau, R. Armijo, J.L. Cheminee, et al., 1 Ma East Pacific Rise oceanic crust and uppermost mantle exposed by rifting in Hess Deep (equatorial Pacific Ocean), Earth Planet. Sci. Lett. 101, 281-295, 1990.

[45] M. Cannat, V. Mamaloukas-Fangoulis, J.-M. Auzende et al., A geological cross-section of the Vema fracture zone transverse ridge, Atlantic ocean, J. Geodyn. 13, 97-118, 1991.

[46] D.D. Naidoo, J.R. Delaney and T. Juteau, A scarp-map profile of upper oceanic crust at the West Blanco Transform (WBT): insights into magmatic accretion, EOS, Trans. Am. Geophys. Union 73, 502, 1992. 
[47] R.G.W. Kidd. Modelling of processes at plate spreading boundaries, Ph.D. Thesis, Univ. East Anglia, 1976

[48] S.J. Lippard, A.W. Shelton and I.G. Gass, The ophiolite of Northern Oman, Geol. Soc. London Mem. 11, 178, 1986.

[49] P.A. Cowie, C.H. Scholz, M. Edwards and A. Malinverno. Fault strain and seismic coupling at Mid-Ocean ridges, J. Geophys. Res. 98, 17.911-17,920, 1993.

[50] S.M. Carbotte and K.C. Macdonald, Comparison of seafloor tectonic fabric at intermediate, fast, and super fast spreading ridges: Influence of spreading rate, plate motions, and ridge segmentation on fault patterns. J. Geophys. Res. 99, 13,609$13,632,1994$.
[51] G.M. Kent, A.J. Harding and J.A. Orcutt, Evidence for a smaller magma chamber beneath the East Pacific Rise at $9^{\circ} 30^{\prime} \mathrm{N}$, Nature 344, 650-653, 1990.

[52] T. Atwater, Constraints from the FAMOUS area concerning the structure of the oceanic section, in: Deep Drilling Results in the Atlantic Ocean: Ocean Crust, M. Tawani, C.G. Harrison and D.E. Hayes, eds., pp. 33-42, Am. Geophys. Union, Washington, DC, 1979.

[53] T.M. Shank, D.J. Fornari, R.A. Lutz, et al., Establishment of a long-term observatory at nascent hydrothermal vents on the East Pacific Rise at $9^{\circ} 49^{\prime}-50^{\prime} \mathrm{N}$ : Baseline observations, J. Geophys. Res., submitted, 1995. 
Chapter 6

\section{Conclusions}




\section{$\underline{\text { Review of Results }}$}

As melt rises from the mantle at mid-ocean ridges, it freezes and erupts to build the oceanic crust. The thermal regime is important for determining the depth at which magma freezes within the crust but, through its control on the rheology of the crust, also determines the morphology of the axis of the mid-ocean ridge. This Thesis underlines the importance of the crustal thermal structure in controlling local variations in magma sill depth and ridge morphology, and of eruption dynamics in the emplacement of the uppermost volcanic layer of the crust.

Analysis of gravity over the Juan de Fuca and Gorda ridges in Chapter 2 shows that even small differences in crustal thickness $(300-700 \mathrm{~m})$ and mantle temperature $\left(10-15^{\circ} \mathrm{C}\right)$ are sufficient to produce major changes in lithospheric strength and axial morphology. The presence of the Cobb thermal anomaly beneath Axial Seamount may cause the systematic differences in axial morphology, crustal thickness, mantle temperature, and lithospheric strength observed between the Juan de Fuca and Gorda ridges. The hotter mantle under the Juan de Fuca Ridge results in a greater amount of decompression melting and the formation of a thicker crust and a thinner, weaker lithospheric than along the Gorda Ridge. These results are consistent with the predicted sensitivity of recent thermo-mechanical models for rift valley formation to small changes in crustal thickness and mantle temperature at intermediate spreading rates [Phipps Morgan and Chen, 1993b].

However, recent results from other intermediate spreading ridges show that the transition from axial valley to axial high is more complicated than these observations suggest. Canales et al. [1996] show that along the Galápagos ridge (spreading rate somewhat faster than along the Juan de Fuca ridge: 31 vs. $28 \mathrm{~mm} / \mathrm{yr}$ half-rate) the transition occurs over a distance of $200-300 \mathrm{~km}$ and is accompanied by a change in mantle 
temperature of $\sim 20^{\circ} \mathrm{C}$ and $>1-2 \mathrm{~km}$ in crustal thickness [Ito and Lin, 1995]. On the other hand, Ma and Cochran [1996] show that along the intermediate spreading southeast Indian Ridge there are three distinct ridge morphologies not two; a rift valley, transitional morphology, and axial high. The transitions between these different morphological types occur over short lengths of the ridge axis. Thus, though intermediate spreading ridges display morphologies ranging form axial valley to axial high, the processes controlling axial topography may be more complicated than accounted for by recent thermo-mechanical models for rift valley formation.

Chapter 3 presents a quantitative examination of the correlation between along-axis variations in crustal structure and other indicators of magma supply on a regional scale. There are several scales of spatial and temporal variability that modify the simple correlations predicted by the current magma supply model for fast spreading ridges. Good correlations exist along the SEPR between axial depth, ridge cross-sectional area, mantle Bouguer anomaly, and the $\mathrm{MgO} w t \%$ of basalts recovered from the rise axis. These correlations suggest along-axis changes in crustal thickness and temperature consistent with variations in magma supply on time scales of $\sim 100 \mathrm{Kyr}$. However, we show that the magma sill properties (depth and width of the melt lens), seismic layer 2A thickness, and the intensity of hydrothermal venting are poorly correlated with regional variations in ridge depth and cross-sectional area. We suggest that the emplacement geometry (width of the intrusion zone and flow lengths), not magma supply, controls extrusive layer (seismic 2A) thickness. The depth of the magma sill is very sensitive to the local thermal structure. Magma lens properties and hydrothermal activity are closely linked to spreading events (dike intrusion, eruptions, faulting) which occur on much shorter time scales (ca. 10-100 yr) than the longer-term variations in magma supply reflected in along-axis changes in ridge morphology. 
The observed variation in magma sill depth is compared to different models proposed for the accumulation of magma in the mid-crust. In Chapter 4, it is shown that the seismically constrained depths of ridge crest magma chambers $(>1-2 \mathrm{~km})$ are considerably deeper than the level of neutral buoyancy $(100-400 \mathrm{~m})$, suggesting that other factors must control the collection of melt in these reservoirs. The apparent inverse relationship between magma sill depth and spreading rate [Purdy et al., 1992] suggests that a thermally controlled permeability boundary, such as the solidus horizon, controls the depth at which magma ponds in crustal magma chambers beneath mid-ocean ridges [c.f. Phipps Morgan and Chen, 1993a; Natland and Dick, 1996]. In Chapter 3, a more refined approach, which takes into account new evidence that the magma sill is not fully molten [Hussenoeder et al., 1996], reaches the same conclusion. Observation of large local variations in magma sill depth ( $800-2000 \mathrm{~m}$ below the seafloor) suggest that on shorter time scales the local thermal structure of the crust is strongly modified. The advection of heat by the ascent of melt from the mantle is relatively continuous. However, the removal of heat from the crust is highly variable and depends on the variability in hydrothermal cooling, on intermittent eruptive and intrusive episodes that drain the magma sill, and on tectonic events that alter the crustal permeability structure.

A stochastic model for the emplacement of dikes and lava flows is presented in Chapter 5. This model generates an upper oceanic crustal structure similar to that observed in seismic data from the East Pacific Rise (EPR), in ocean drill holes, and in ophiolites. In order to satisfy these geological and geophysical constraints, a bimodal distribution of lava flows is required. Short flows, confined within the axial summit caldera, build up approximately half the extrusive volume. Occasional flows spill out of the ASC, or erupt outside the ASC, and pond at a considerable distance off-axis (up to $2 \mathrm{~km}$ ) to build up the remainder of the extrusive section. Most dikes are intruded within a narrow zone at the 
ridge axis. The upper part of the final extrusive section will be dominated by the off-axis flows, while the lower portions will be primarily composed of short flows erupted within the ASC. Predicted magnetic transition widths are similar to those measured in deep-tow studies [Macdonald et al., 1980]. The ages of seafloor lavas in this model are younger than the tectonic spreading model ages by $30-70 \mathrm{Kyr}$, in agreement with anomalously young lava ages obtained from radioisotope disequilibrium dating of seafloor basalts from the EPR [Goldstein et al., 1994].

\section{Further Work}

Numerous questions about the volcanic processes of crustal construction and the rheology controlling axial morphology and magma migration remain to be addressed. The crustal magmatic system may represent the transition between semi-continuous melt percolation through the mantle and lower crust to intermittent dike emplacement in the crust and eruptions. How does the composite magma chamber work exactly? What is the relationship between the more steady-state low-velocity zone and the overlying, rapidly varying melt sill? Since there are not significant amounts of melt within the crust, are there magma reservoirs within the mantle? How is the melt delivered to the crust from the mantle? Detailed seismic and electromagnetic studies would improve our understanding of the structure of the lower crust and upper mantle at the ridge crest. Also, there is still no definitive explanation for how the composite volcanic system constructs the oceanic crust, in particular, the layered gabbro sequence.

The spatial and temporal relationships of the processes controlling the magmatic system are still not well understood. Repeating a seismic survey in a well studied area (e.g. $9^{\circ} \mathrm{N} \mathrm{EPR}$ ) would give great insight into the time dependence of the magmatic system, particularly the temporal and spatial variations in the properties (depth, width, crystal 
content and thickness) of the magma sill. Greater insight into the relationship of hydrothermal venting to magma injection events, faulting, and recent eruptions, will better constrain the importance of hydrothermal cooling versus intermittent eruptions in controlling the local thermal structure of the upper crust. A detailed study of the temporal variability of hydrothermal vents and their longevity will improve our understanding of the processes controlling their formation and the time scales over which they are active.

How does the thermal structure of the axial lithosphere control its strength and how closely is the morphology of the ridge related to the presence or absence of a melt sill. Further work using more realistic rheological models of the axial lithosphere are necessary for an improved understanding of the controls on axial morphology.

For an improved understanding of the construction of the extrusive section of the oceanic crust more constraints on the size and composition of lava flows and the location of their eruption and temporal frequency is required. A detailed study of the ridge crest to date and sample lava flows in order to determine the typical frequency and location of eruptions, the evolution of lava composition during an eruption, and the lateral extent and volume of lava flows. Mapping of the extrusive section in ophiolites is another way of testing the model for the emplacement of the volcanic section proposed in Chapter 5 .

\section{$\underline{\text { References }}$}

Canales, J.P., Dañobeitia, J.J., Detrick, R.S., Hooft, E.E.E. and Naar, D., Variations in axial morphology along the Galápagos spreading center and the influence of the Galápagos hotspot, J. Geophys. Res., in prep., 1996.

Goldstein, S.J., Perfit, M., R., Batiza, R., Fornari, D.J. and Murrell, M., Off-axis volcanism at the East Pacific Rise detected by uranium-series dating of basalts, Nature, 367, 157-159, 1994. 
Hussenoeder, S.A., Collins, J.A., Kent, G.M., Detrick, R.S. and Group, T., Seismic analysis of the axial magma chamber reflector along the southern East Pacific Rise from conventional reflection profiling, J. Geophys. Res., in press, 1996.

Ito, G.T. and Lin, J., Mantle temperature anomalies along the present and paleo-axes of the Galapagos spreading center as inferred from gravity analyses, J. Geophys. Res., 100, 3733-3745, 1995.

Ma, Y. and Cochran, J.R., Transitions in axial morphology along the Southeast Indian Ridge, J. Geophys. Res., 101, 15849-15866, 1996.

Macdonald, K.C., Miller, S.P., Huestis, S.P. and Spiess, F.N., Three-dimensional modeling of a magnetic reversal boundary from inversion of deep-tow measurements, J. Geophys. Res., 85, 3670-3680, 1980.

Natland, J.H. and Dick, H.J.B., Melt migration through high-level gabbroic cumulates of the East Pacific Rise at Hess Deep: The origin of magma lenses and the deep crustal structure of fast-spreading ridges, Proc. ODP Sci. Results, 147, 21-58, 1996.

Phipps Morgan, J. and Chen, Y.J., The genesis of oceanic crust: Magma injection, hydrothermal circulation, and crustal flow, J. Geophys. Res., 98, 6283-6298, 1993a.

Phipps Morgan, J. and Chen, Y.J., Dependence of ridge-axis morphology on magma supply and spreading rate, Nature, 364, 706-708, 1993b.

Purdy, G.M., Christeson, G. and Solomon, S., Relationship between spreading rate and the seismic structure of mid-ocean ridges, Nature, 355, 815-817, 1992. 